\title{
A Bio-Economic Model of Long-Run Striga Control with an Application to Subsistence Farming in Mali
}

\author{
Jeffrey D. Mullen
}

Dissertation submitted to the Faculty of the

Virginia Polytechnic Institute and State University

in partial fulfillment of the requirements for the degree of

\author{
Doctor of Philosophy \\ in \\ Agricultural and Applied Economics
}

Daniel B. Taylor, Chair

George W. Norton

Jeffrey Alwang

Bradford Mills

John Caldwell

February 18, 1999

Blacksburg, Virginia

Keywords: Striga, Integrated Pest Management, Mali,

Subsistence Farming, Dynamic Programming

Copyright 1999, Jeffrey D. Mullen 


\title{
A Bio-Economic Model of Long-Run Striga Control with an Application to Subsistence Farming in Mali
}

\author{
Jeffrey D. Mullen
}

\section{(ABSTRACT)}

The parasitic weeds belonging to the genus Striga are among the world's most tenacious, prolific and destructive agricultural pests. Crop loss estimates due to Striga infestations can reach 100 percent. Furthermore, the weeds' affinity for low-fertility soils and low rainfall means that those farming the most marginal lands are most severely affected. Nonetheless, subsistence farmer have yet to adopt seemingly beneficial control practices to any appreciable degree. This paper develops a bio-economic model capable of identifying: (1) affordable, effective Striga control practices consistent with the resource constraints of subsistence farmers; and (2) barriers to the adoption of those practices. The model is comprised of two components: a biological component modeling Striga population dynamics, and an economic component representing the production opportunity set, resource constraints, and price parameters farmers face.

The model is applied to two zones in Northwestern Mali, Sirakorola and Mourdiah, and solved using non-linear, dynamic programming. Data collected by the USAID IPMCRSP/Mali project are used to specify the economic parameters of the model. A new technique for estimating the lower bound of a farmer's production planning horizon is also developed and employed in the application of the model to Sirakorola and Mourdiah.

The results of several model scenarios indicate that the availability of information regarding the efficacy of Striga control practices is a primary barrier to their adoption by subsistence farmers. The movement of Striga seed between fields, however, is of limited importance. 
The "optimal control practices" identified by the model depend on the size and demographic composition of the production unit (UP), the zone in which the UP is located, and the cash budget available to the UP. At low budget levels, the model suggests planting millet without fertilizer at a high density in Sirakorola and a low density in Mourdiah. At high budget levels, the model suggests planting millet at a high density in both zones while applying urea.

The benefits of adopting the optimal set of practices are presented in both nutritional and financial terms, and can reach as much as a ten-fold increase in the nutritional content of and financial returns to a harvest. 


\section{Acknowledgements}

I would like to thank the United States Agency for International Development (USAID) for its generous support of this project through the Integrated Pest Management Collaborative Research Support Program (IPM-CRSP). I would also like to thank Mali's Institute d'Economie Rurale for its logistical support in collecting primary data, as well as the considerable intellectual contributions of its staff, including Amadou Diarra, Madame Gambi, Bourema Dembele, Makan Fofana, and countless others. In addition, my thanks go to the Office of International Research and Development at Virginia Tech and its Director, S. K. DeDada, for the valuable administrative support offered during the course of this study.

I would also like to recognize the contributions of my advisory committee. Drs. George Norton, Jeffrey Alwang, and Bradford Mills kept me focused on the larger economic issues related to the project. Dr. John Caldwell provided invaluable insight into agricultural production systems in Mali. He also served as my primary technical advisor for the biological component of the model.

Most importantly, however, I would like to thank my committee chair, Dr. Daniel Taylor. Dan provided both guidance and encouragement while allowing me the intellectual freedom to identify and pursue my own interests, for which I am grateful. In addition to his many professional contributions, Dan has served as a model dignity and courage for my personal life. His strength and commitment to family in the face of truly adverse conditions will be, without doubt, the most enduring lesson of my tenure at Virginia Tech.

And, finally, my deepest thanks go to my wife, Susan, and my two children, Madeleine Jane and Joseph Justis, for their countless personal sacrifices. Without the emotional support they provided throughout, this study would not have been completed. Their names belong on my diploma as well. 


\section{Table of Contents}

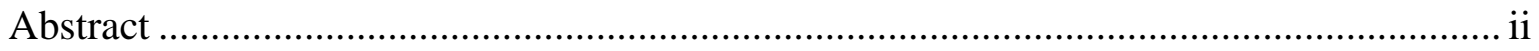

Acknowledgements ................................................................................................ iv

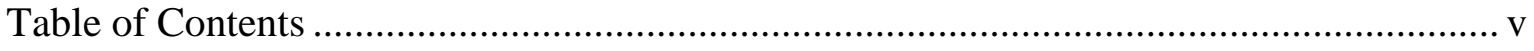

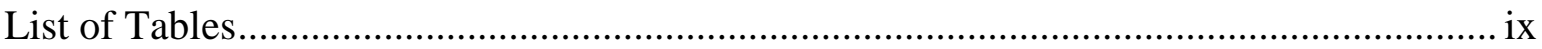

List of Figures .......................................................................................................

\section{Chapter 1: Introduction}

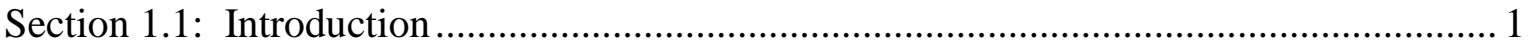

Section 1.2: Basic Biological Characteristics of Striga ............................................... 2

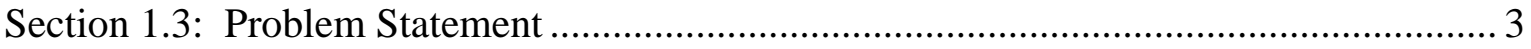

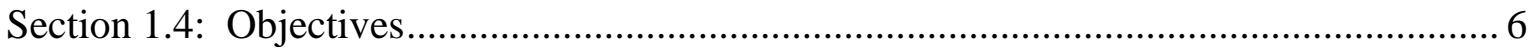

Section 1.5: Organization of the Dissertation ..................................................... 7

\section{Chapter 2: Literature Review}

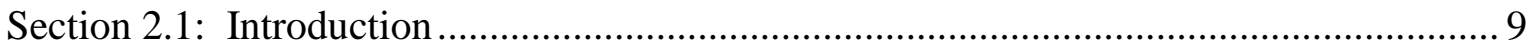

Section 2.2: Striga Population Models......................................................................... 9

Section 2.3: Effects of Nitrogen Fertilizers on the Biological Parameters ........................ 18

Section 2.4: Effects of Hand-Pulling on the Biological Parameters ............................... 28

Section 2.5: Effects of Chemical Controls on the Biological Parameters......................... 29

\section{Chapter 3: Methodology}

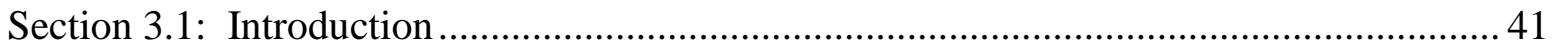

Section 3.2: Modeling Striga Population Dynamics .................................................. 41 


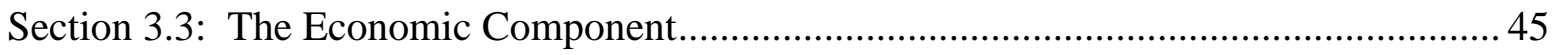

Section 3.4: Estimating the Value of Striga Eradication ................................................... 46

Section 3.5: Identifying Barriers to Adoption ................................................................... 48

Section 3.6: Concluding Remarks on the Methodology ......................................................5 53

\section{Chapter 4: The Economic Component}

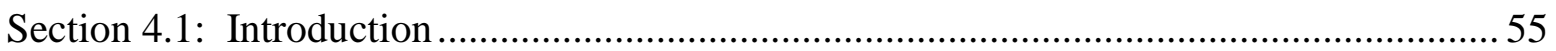

Section 4.2: Defining the Representative Agricultural Production Unit............................... 55

Section 4.3: Defining the Land Constraint .......................................................................5 59

Section 4.4: Crop Associations Available in the Model ....................................................... 61

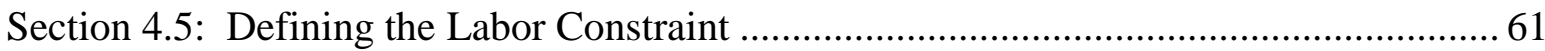

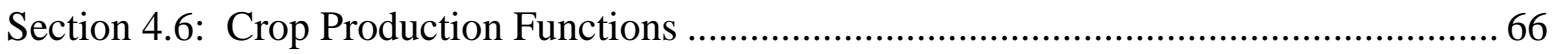

Section 4.7: Defining the Cash Constraint ............................................................................. 73

Section 4.8: Defining the Nutritional Constraint ……….............................................. 74

Section 4.9: Input and Output Prices and the Discount Rate ……...................................... 74

Section 4.10: Estimating the UP's "Planning Horizon"......................................................... 76

Section 4.11: Concluding Remarks on the Economic Component ....................................... 78 


\section{Chapter 5: The Biological Component}

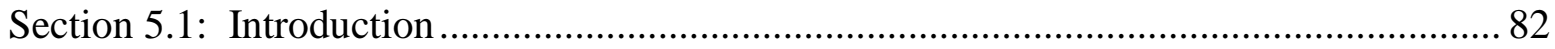

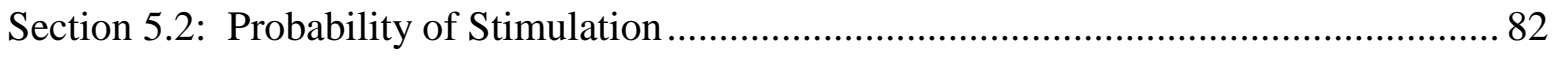

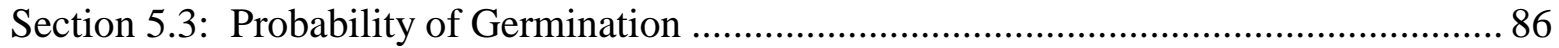

Section 5.4: Probability of Attachment ................................................................... 86

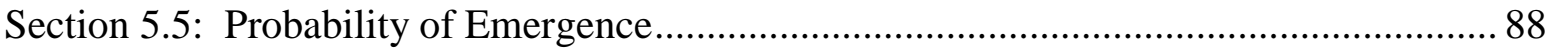

Section 5.6: Probability of Reproduction ............................................................. 91

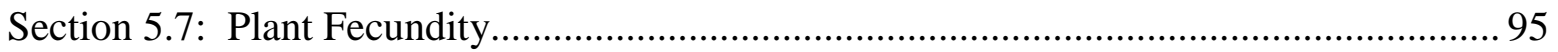

Section 5.8: Probability of Survival of New and Old Seeds ......................................... 95

Section 5.9: Modeling the Seed Externality............................................................. 98

Section 5.10: Concluding Remarks on the Biological Component...................................99

\section{Chapter 6: Results}

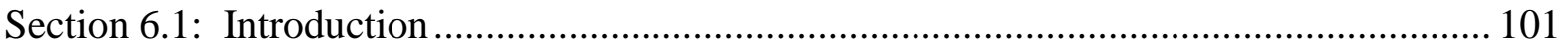

Section 6.2: Returns to Status Quo Production with Average Striga Infestation ............... 103b

Section 6.3: Returns to Status Quo Production in the Absence of Striga .......................... 109

Section 6.4: Optimal Production in the Absence of Striga ............................................. 110

Section 6.5: Optimal Production with Average Striga Infestation................................... 122

Section 6.6: Optimal Production with Average Striga Infestation

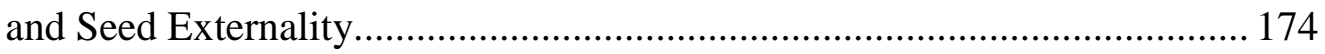

Section 6.7: Concluding Remarks on the Results ...................................................... 186 


\section{Chapter 7: Conclusions}

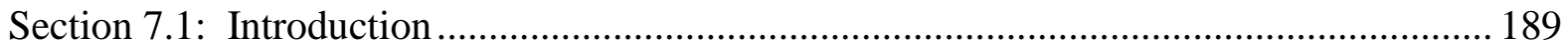

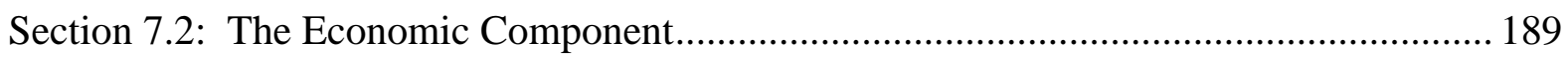

Section 7.3: The Biological Component …........................................................... 190

Section 7.4: Implications for Future Research ......................................................... 191

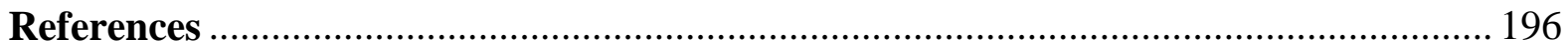

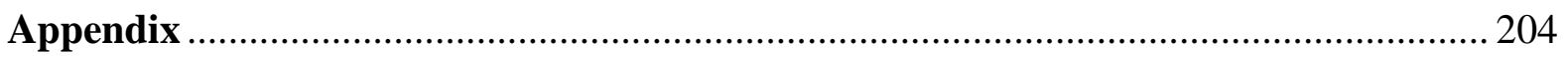




\section{List of Tables}

Table 2.1: Parameter Values Used in the Kunisch et al., Smith, Holt and Webb, and Smith and Webb Striga Population Models

Table 2.2: Effect of Nitrogen on Stimulation Activity of Sorghum Root Exudate as

Reflected by Striga Germination Rates.

Table 2.3: Influence of Urea $\mathrm{N}$ on Stimulant Activity of Sorghum

Table 2.4: Studies on the Relationship between Nitrogen and the Emergence of Striga ..... 26

Table 2.5: Summary of Studies Examining Effect of Chemical Control on Stages of Striga Development 36

Table 3.1: Possible States when Comparing Scenarios I, IV, and V, Nash Equilibrium Production Associated with each State, and Barriers Preventing Adoption of Nash Equilibrium Production

Table 4.1: Distribution of Age/Gender/Labor Categories for Each UP $\mathrm{XS}_{\text {, Sirakorola, }}$

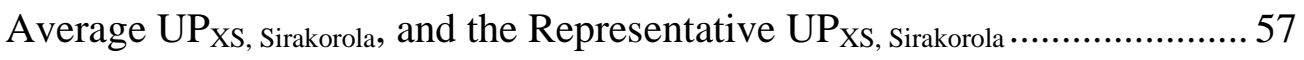

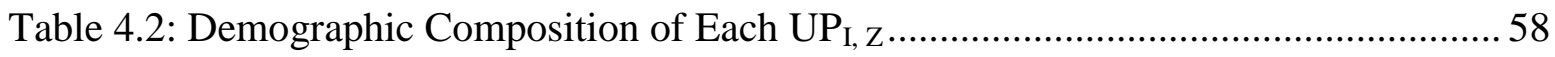

Table 4.3: Hectares Available and Cultivated, Averaged over Plot Type,

UP Size, and Zone.

Table 4.4: Hectares Planted and Percentage of Respondents Growing Crops

on Communal Fields in Sirakorola.

Table 4.5: Person-Days of Communal Labor Endowed per Week by Age,

Gender, and UP Size

Table 4.6: Duration of Time (Days) Within Which Each Agricultural Task

must be Performed, and Number of Person-Days per Hectare

Required to Perform Each Task 
Table 4.7: Estimated Parameter Values of Equation 4.5................................................... 70

Table 4.8: Input and Output Prices and Discount Rate ……………………………........ 75

Table 4.9: Testing Equality of Average Duration of Cultivation Between

Fallow Periods in Mourdiah and Sirakorola .................................................. 80

Table 5.1: Effect of Millet-Cowpea Association on Striga Infestation, 1995-1997 ............. 96

Table 5.2: Effect of Millet-Groundnut Association on Striga Infestation ............................97

Table 6.1: Roadmap of Results Presented in Chapter 6...................................................... 102

Table 6.2: Conventional Input Levels for Millet Production in Mourdiah and Sirakorola... 104

Table 6.3: Results of Scenario I (Status Quo Millet Production with Starting

Seedbank $=40,000 / \mathrm{m}^{2}$ ) for Each UP Size in Mourdiah.

Table 6.4: Results of Scenario I (Status Quo Millet Production with Starting

Seedbank $=40,000 / \mathrm{m}^{2}$ ) for Each UP Size in Sirakorola............................. 108

Table 6.5: Results of Scenario II (Status Quo Millet Production with Starting

Seedbank $=0 / \mathrm{m}^{2}$ ) for Each UP Size in Mourdiah........................................ 111

Table 6.6: Results of Scenario II (Status Quo Millet Production with Starting

Seedbank $=0 / \mathrm{m}^{2}$ ) for Each UP Size in Sirakorola.

Table 6.7: Estimates of the Net Present Value (1,000 CFA) of Striga Eradication

Under Status Quo Millet Production for Each $\mathrm{UP}_{\mathrm{I}, \mathrm{Z}}$

Table 6.8: Increases in Net Revenue (1,000 CFA) Due to Shift from Status Quo to

Optimal Millet Production in the Absence of Striga in Mourdiah.

Table 6.9: Increases in Net Revenue (1,000 CFA) Due to Shift from Status Quo to

Optimal Millet Production in the Absence of Striga in Sirakorola.

Table 6.10: Optimal Practices in Mourdiah with Average Striga Infestation and a

Very Low Budget (Starting Seedbank $=40,000 / \mathrm{m}^{2}$,

Expenditures $\leq 2,000 \mathrm{CFA} /$ Year). 
Table 6.11: Optimal Practices in Sirakorola with Average Striga Infestation and a

Very Low Budget (Starting Seedbank $=40,000 / \mathrm{m}^{2}$,

Expenditures $\leq 2,000 \mathrm{CFA} /$ Year)

Table 6.12: Estimated Financial and Nutritional Returns, Millet Production,

Seedbank Growth, and Expenditures in Mourdiah under Optimal

Practices with a Very Low Budget and Average Striga Infestation

Table 6.13: Estimated Financial and Nutritional Returns, Millet Production,

Seedbank Growth, and Expenditures in Sirakorola under Optimal

Practices with a Very Low Budget and Average Striga Infestation

Table 6.14: Estimated Changes in Expenditures, Labor Use, Nutritional and Financial

Returns from Adopting the Optimal Practices in Mourdiah with a

Very Low Budget and Average Striga Infestation.....

Table 6.15: Estimated Changes in Expenditures, Labor Use, Nutritional and Financial

Returns from Adopting the Optimal Practices in Sirakorola with a

Very Low Budget and Average Striga Infestation.....

Tabel 6.16: Optimal Practices for Medium and Large UPs in Sirakorola with

Average Striga Infestation and a Low Budget (Starting

Seedbank $=40,000 / \mathrm{m}^{2}$, Expenditures $\leq 10,000 \mathrm{CFA} /$ Year)

Table 6.17: Estimated Financial and Nutritional Returns, Millet Production, Seedbank

Growth, and Expenditures for Medium and Large UPs in Sirakorola under

Optimal Practices with a Low Budget and Average Striga Infestation 138

Table 6.18: Estimated Changes in Expenditures, Labor Use, Nutritional and Financial

Returns for Medium and Large UPs in Sirakorola from

Adopting the Optimal Practices with a Very Low Budget and

Average Striga Infestation

Table 6.19: Optimal Practices in Mourdiah with Average Striga Infestation and a

Moderate Budget (Starting Seedbank $=40,000 / \mathrm{m}^{2}$,

Expenditures $\leq 25,000 \mathrm{CFA} /$ Year). 141 
Table 6.20: Optimal Practices in Sirakorola with Average Striga Infestation and a

Moderate Budget (Starting Seedbank $=40,000 / \mathrm{m}^{2}$,

Expenditures $\leq 25,000 \mathrm{CFA} /$ Year).

Table 6.21: Estimated Financial and Nutritional Returns, Millet Production,

Seedbank Growth, and Expenditures in Mourdiah under Optimal

Practices with a Moderate Budget and Average Striga Infestation

Table 6.22: Estimated Financial and Nutritional Returns, Millet Production,

Seedbank Growth, and Expenditures in Sirakorola under Optimal

Practices with a Moderate Budget and Average Striga Infestation

Table 6.23: Estimated Changes in Expenditures, Labor Use, Nutritional and Financial

Returns from Adopting the Optimal Practices in Mourdiah with a

Moderate Budget and Average Striga Infestation.

Table 6.24: Estimated Changes in Expenditures, Labor Use, Nutritional and Financial

Returns from Adopting the Optimal Practices in Sirakorola with a

Moderate Budget and Average Striga Infestation.....

Table 6.25: Optimal Practices in Mourdiah with Average Striga Infestation and a

High Budget (Starting Seedbank $=40,000 / \mathrm{m}^{2}$,

Expenditures $\leq 50,000 \mathrm{CFA} /$ Year).

Table 6.26: Optimal Practices in Sirakorola with Average Striga Infestation and a

High Budget (Starting Seedbank $=40,000 / \mathrm{m}^{2}$,

Expenditures $\leq 50,000 \mathrm{CFA} /$ Year).

Table 6.27: Estimated Financial and Nutritional Returns, Millet Production,

Seedbank Growth, and Expenditures in Mourdiah under Optimal

Practices with a High Budget and Average Striga Infestation.

Table 6.28: Estimated Financial and Nutritional Returns, Millet Production,

Seedbank Growth, and Expenditures in Sirakorola under Optimal

Practices with a High Budget and Average Striga Infestation. 
Table 6.29: Estimated Changes in Expenditures, Labor Use, Nutritional and Financial

Returns from Adopting the Optimal Practices in Mourdiah with a

High Budget and Average Striga Infestation

Table 6.30: Estimated Changes in Expenditures, Labor Use, Nutritional and Financial

Returns from Adopting the Optimal Practices in Sirakorola with a

High Budget and Average Striga Infestation

Table 6.31: Optimal Practices in Mourdiah with Average Striga Infestation and a

Very High Budget (Starting Seedbank $=40,000 / \mathrm{m}^{2}$,

Expenditures $\leq 100,000 \mathrm{CFA} /$ Year).

Table 6.32: Optimal Practices in Sirakorola with Average Striga Infestation and a

Very High Budget (Starting Seedbank $=40,000 / \mathrm{m}^{2}$,

Expenditures $\leq 100,000 \mathrm{CFA} /$ Year).

Table 6.33: Estimated Financial and Nutritional Returns, Millet Production,

Seedbank Growth, and Expenditures in Mourdiah under Optimal

Practices with a Very High Budget and Average Striga Infestation 166

Table 6.34: Estimated Financial and Nutritional Returns, Millet Production,

Seedbank Growth, and Expenditures in Sirakorola under Optimal

Practices with a Very High Budget and Average Striga Infestation

Table 6.35: Estimated Changes in Expenditures, Labor Use, Nutritional and Financial

Returns from Adopting the Optimal Practices in Mourdiah with a

Very High Budget and Average Striga Infestation

Table 6.36: Estimated Changes in Expenditures, Labor Use, Nutritional and Financial

Returns from Adopting the Optimal Practices in Sirakorola with a

Very High Budget and Average Striga Infestation

Table 6.37: Estimated Financial and Nutritional Returns, Millet Production,

Seedbank Growth, and Expenditures in Mourdiah under Optimal

Practices with a Very Low Budget Average Striga Infestation, and

Seed Externality 176 
Table 7.1: Treatments for Striga Field Trials Suggested by the Model..... 194

Table A4.1: Results of Statistical Test of Equal Distribution of Individual Land

Between Men and Women 205

Table A4.2: Daily Nutritional Requirements by Age and Gender 206

Table A4.3: Daily Nutritional Requirements of $\mathrm{UP}_{\mathrm{I}, \mathrm{Z}}$ 207

Table A4.4: Nutritional Content of Crops (100 g Edible) Grown on Communal Plots In Mourdiah and Sirakorola 208

Table A5.1: Data Used to Estimate Equation 5.1 209

Table A5.2: Estimation of Equation (5.1), Proportion of Germinated Striga versus $\mathrm{Kg}$. Urea/Ha ..... 210

Table A5.3: Data Used to Estimate Equation 5.7 211

Table A5.4: Estimation of Equation (5.7),

Proportion of Emerged Striga without Nitrogen versus Kg. N/Ha

Table A6.1: Estimates of Nutritional and Financial Gains from Striga Eradication Under Status Quo Millet Production in Mourdiah

Table A6.2: Estimates of Nutritional and Financial Gains from Striga Eradication Under Status Quo Millet Production in Sirakorola.....

Table A6.3: Optimal Input Levels and Net Returns for $\mathrm{UP}_{\mathrm{XS}}$, Sirakorola in the Absence of Striga

Table A6.4: Optimal Input Levels and Net Returns for $\mathrm{UP}_{\mathrm{S} \text {, Sirakorola }}$ in the Absence of Striga 216

Table A6.5: Optimal Input Levels and Net Returns for $\mathrm{UP}_{\mathrm{M} \text {, Sirakorola }}$ in the Absence of Striga 217 
Table A6.6: Optimal Input Levels and Net Returns for $\mathrm{UP}_{\mathrm{L}}$, Sirakorola in the Absence of Striga

Table A6.7: Optimal Input Levels and Net Returns for $\mathrm{UP}_{\mathrm{XS}}$, Mourdiah in the Absence of Striga

Table A6.8: Optimal Input Levels and Net Returns for $\mathrm{UP}_{\mathrm{S}}$, Mourdiah in the Absence of Striga

Table A6.9: Optimal Input Levels and Net Returns for $\mathrm{UP}_{\mathrm{M} \text {, Mourdiah }}$ in the Absence of Striga

Table A6.10: Optimal Input Levels and Net Returns for $\mathrm{UP}_{\mathrm{L} \text {, Mourdiah }}$ in the Absence of Striga

Table A6.11: Optimal Input Levels and Net Returns for UP $\mathrm{XL}_{\text {, Mourdiah }}$ in the Absence of Striga

Table A6.12: Optimal Input Levels and Net Returns for $\mathrm{UP}_{\mathrm{XXL}}$, Mourdiah in the Absence of Striga

Table A6.13: Estimated Financial and Nutritional Returns, Millet Yield, Seedbank Growth, and Expenditures in Mourdiah Under Optimal Practices with a Very High Budget, Average Striga Infestation and Seed Externality. 225

Table A6.14: Estimated Financial and Nutritional Returns, Millet Yield, Seedbank Growth, and Expenditures in Sirakorola Under Optimal Practices with a Very High Budget, Average Striga Infestation and Seed Externality. 226 


\section{List of Figures}

Figure 4.1: Frequency Distribution of Length of Cultivation, by Zone

Figure 5.1: Probability of Stimulation vs. Urea

$\left(\right.$ Host Plant Density $\left.=1 / \mathrm{m}^{2}\right)$

Figure 6.1: Seedbank Growth vs. Time Under Status Quo Millet Production 105

Figure 6.2: Increase in Status Quo Production of Energy Due to Striga Eradication

As a Percentage of Total UP Needs

Figure 6.3: Increase in Status Quo Production of Protein Due to Striga Eradication

As a Percentage of Total UP Needs

Figure 6.4: Increase in Status Quo Production of Iron Due to Striga Eradication

As a Percentage of Total UP Needs

Figure 6.5: Evolution of Optimal Practices in Absence of Striga for XS UP in Mourdiah.. 117

Figure 6.6: Evolution of Optimal Practices in Absence of Striga for XS UP in Sirakorola. 118

Figure 6.7: Change in Net Returns from Adopting Optimal Practices with Average Striga

And a Very Low Budget

Figure 6.8: Change in \% UP KCal Requirement Met from Adopting Optimal Practices with Average Striga and a Very Low Budget.

Figure 6.9: Change in \% UP Protein Requirement Met from Adopting Optimal Practices with Average Striga and a Very Low Budget

Figure 6.10: Change in \% UP Iron Requirement Met from Adopting Optimal Practices with Average Striga and a Very Low Budget

Figure 6.11: Change in Net Returns from Adopting Optimal Practices with Average Striga and a Moderate Budget

Figure 6.12: Change in \% UP KCal Requirement Met from Adopting Optimal Practices with Average Striga and a Moderate Budget 148 
Figure 6.13: Change in \% UP Protein Requirement Met from Adopting Optimal Practices with Average Striga and a Moderate Budget

Figure 6.14: Change in \% UP Iron Requirement Met from Adopting Optimal Practices with Average Striga and a Moderate Budget

Figure 6.15: Change in Net Returns from Adopting Optimal Practices with Average Striga

And a High Budget. 158

Figure 6.16: Change in \% UP KCal Requirement Met from Adopting Optimal Practices with Average Striga and a High Budget

Figure 6.17: Change in \% UP Protein Requirement Met from Adopting Optimal Practices with Average Striga and a High Budget

Figure 6.18: Change in \% UP Iron Requirement Met from Adopting Optimal Practices with Average Striga and a High Budget

Figure 6.19: Change in Net Returns from Adopting Optimal Practices with Average Striga And a Very High Budget. 170

Figure 6.20: Change in \% UP KCal Requirement Met from Adopting Optimal Practices with Average Striga and a Very High Budget 171

Figure 6.21: Change in \% UP Protein Requirement Met from Adopting Optimal Practices with Average Striga and a Very High Budget

Figure 6.22: Change in \% UP Iron Requirement Met from Adopting Optimal Practices with Average Striga and a Very High Budget

Figure 6.23: Change in Percentage of Energy Needs Met Due to Seed Externality With a Very Low Budget

Figure 6.24: Change in Percentage of Protein Needs Met Due to Seed Externality With a Very Low Budget 178 
Figure 6.25: Change in Percentage of Iron Needs Met Due to Seed Externality

With a Very Low Budget

Figure 6.26: Change in Net Revenue Due to Seed Externality with a Very Low Budget .... 180

Figure 6.27: Change in Percentage of Energy Needs Met Due to Seed Externality

With a Very High Budget.

Figure 6.28: Change in Percentage of Protein Needs Met Due to Seed Externality

With a Very High Budget.

Figure 6.29: Change in Percentage of Iron Needs Met Due to Seed Externality

With a Very High Budget.

Figure 6.30: Change in Net Revenue Due to Seed Externality with a Very High Budget ... 185 


\section{Chapter 1: Introduction}

\section{Section 1.1 Introduction}

Each season agricultural pests cause substantial crop losses throughout the world. These losses have contributed to the stagnation of agricultural land and labor productivity in the world's poorest countries, and, ultimately, to the growing food deficiencies those countries have been facing. Effective pest control is fundamental to reversing this trend.

Among the most tenacious and prolific of agricultural pests are the parasitic weeds belonging to the genus Striga. Striga species have taken root throughout the continents of Africa and Asia, imparting extensive damage to staple cereal crops. Mboob (1988) estimates that annual cereal yields in Africa are reduced by $40 \%$ due to Striga. The losses, however, are not distributed evenly across the continent. The weeds' affinity for low-fertility soils and low rainfall means that those farming the most marginal lands are most severely affected. Lagoke et al. (1991) put the matter more dramatically in stating, "parasitic weeds threaten the lives of more than 100 million people in Africa" (p. 3).

The Striga problem is not new, nor are efforts to control it. For more than 60 years private and public institutions around the world have dedicated substantial resources to the development of Striga control practices. A few successful programs have been designed, namely in the United States and South Africa. These two programs differ significantly in their execution. The U.S. program has involved coordination of federal and state agricultural institutions in funding research, subsidizing the adoption of certain control measures, disseminating information, and regulating cropping patterns (including quarantines). In contrast, the South African program has been pursued primarily by individual large-scale farmers (Ayensu et al., 1984).

Unfortunately, for less developed countries the U.S. program is prohibitively expensive in terms of both money and information, and generally beyond the present organizational capacity of their public agricultural institutions. On the other hand, subsistence farmers do not have the financial resources to adopt the practices pursued by large-scale farmers 
in South Africa. To date, the development of effective Striga control programs that are affordable to poor, small-scale farmers has eluded the scientific community. Striga's elusiveness is directly related to its biology.

\section{Section 1.2 Basic Biological Characteristics of Striga}

Striga species are obligate parasites that attack the roots of their host, draining the host of nutrients and causing a variety of debilitating symptoms. These symptoms include increases in the host's root : shoot ratio (Patterson, 1990), and reduction in photosynthetic efficiency (Press and Graves, 1991). The parasitization occurs subterraneanly, prior to the weed's emergence. In fact, the host crop may be severely damaged, or even killed, before any Striga emerge from the soil (Parker and Riches, 1993). This ability to damage crops before revealing itself to farmers has earned Striga its more common name, "witchweed."

While the damage Striga imparts on the host crop is the impetus for seeking control measures, the tenacity of the weed stems from four reproductive characteristics: (1) seed production; (2) seed germination requirements; (3) the length of time seeds are viable; and (4) seed dispersion. Each of these characteristics are discussed briefly below.

Seed Production. Depending on the species, Striga may produce between 25,000 ( $S$. forbesii) and 200,000 (S. hermonthica) seeds per plant (Parker and Riches, 1993). With such high fecundity, a few plants can erupt into a severe infestation in just a few seasons.

Germination Requirements. Striga seeds require a period of pre-conditioning before they germinate. One to five weeks after being imbibed with water, under the proper climatic conditions, the seed will germinate only after contact with certain chemical stimulants (Doggett, 1984). Most, but not all, of the plants that exude these stimulants from their roots serve as hosts to the parasite. By requiring this chemical trigger for germination, Striga species ensure that their seeds rarely germinate in the absence of a suitable host. 
Seed Longevity. Striga seeds are extremely durable, remaining viable in the soil for more than a decade. While 20 years is often stated as an upper bound of the seeds' longevity (Ramaiah, 1987), this number has yet to be confirmed. There is, however, strong evidence that the seeds of some species remain viable up to 14 years (Saunders, 1933; Bebawi et al., 1984).

Seed Dispersion. Weighing between 0.3 and 12.4 micro-grams, and no longer than 0.5 mm in length (Parker and Riches, 1993), Striga seeds are very mobile. Wind, water, farm equipment, people, animals, and harvested seed can all serve as vectors for their transport within and between fields.

These four features of Striga's population dynamics place special demands on programs aimed at controlling the pest. There is no "quick fix" to the Striga problem. The seeds' longevity and germination requirements suggest any control program must be pursued, and therefore affordable, over a long period of time. The high fecundity requires diligence in the pursuit of the program - failure to provide adequate control one year can negate the value of previous years' investments in Striga control by returning the infestation to pre-program levels. The ease in which Striga seeds are transported reinforces the need for a long-run program that is diligently pursued.

\section{Section 1.3 Problem Statement}

On the southern fringe of the Sahara Desert, with unimodal, average annual rainfall between 400 and $800 \mathrm{~mm}$, the agroclimatology of Mali's Sahelian region is particularly suited to Striga. In 1986, Konate found Malian fields of millet and sorghum that suffered yield losses of up to $100 \%$ due to Striga infestations. In 1996, farmers in Mali's Mourdiah and Sirakorola zones ranked Striga as their number one pest problem (Erbaugh et al., 1996). The implications of Striga's presence in Mali are reflected in the decline of per capita food production (-0.9\% from 1979 to 1992), the increase in cereal imports (up 10,000 tons from 1980-1992), and the increase in cereal food aid (up 14,000 tons from 1979/1980-1991/1992) (World Bank, 1994). And yet, despite the proliferation of the pest 
and the damage it causes, Malian farmers have not adopted Striga control practices to any appreciable degree (Debrah, 1994).

There are a number of factors that may serve as barriers to the adoption of Striga control practices. First, subsistence farmers face acute labor and budget constraints. As such, the labor and financial demands of many practices may preclude their adoption.

Second, farmers often lack information regarding new Striga control measures. This “information gap" may take several forms: (1) farmers may not know how to apply a control measure properly; (2) expected returns to practices may not be known, so farmers cannot make appropriate adoption decisions; or (3) farmers simply may not know the practice exists.

A third factor that may impede the adoption of Striga control practices is the inherent discount rate of subsistence farmers. The fact that Striga causes damage before it emerges, i.e., before most practices can be applied, means that much of the return to investment in Striga control this season will not be realized until some season in the future. Poor farmers may not be willing to dedicate scarce resources to investments that do not offer immediate returns.

The fourth issue has to do with the dispersion of Striga seeds. The mobility of Striga seeds poses a very real threat of re-infestation. The marginal value product of a practice must, therefore, be discounted not only by the producer's rate of time preference, but also by the probability of re-infestation. To be attractive to farmers, practices must be productive enough to overcome both of these sources of discounting.

Seed dispersion also introduces a social element into the individual producer's adoption decision. Because seeds can be transported across fields, the threat of re-infestation comes not only from one's own fields, but from the fields of one's neighbors as well. In other words, there is a "seed externality" associated with failure to control Striga. As a result, an individual's long-run expected return to Striga control practices is contingent 
on the degree to which their neighbors manage to control the pest. One's adoption decision, then, may be influenced by their expectations regarding their neighbors' control efforts.

The challenge to the agricultural research community is not to develop practices that are simply effective in controlling the pests, but to develop effective controls that farmers will adopt. The Integrated Pest Management Collaborative Research Support Program in Mali (IPM-CRSP/Mali), funded by the United States Agency for International Development (USAID), is currently seeking solutions to the pest problems facing subsistence farmers in Mali. A participatory approach has been employed in which the potential beneficiaries of the project have assisted in identifying their most urgent pest problems, as well as possible means for controlling those pests. Researchers have used this information in conjunction with their own expertise to design field experiments testing the efficacy of control measures. By focusing on solutions identified by farmers, the IPM-CRSP/Mali project is, in effect, circumventing one of the potential barriers to adoption - farmer's lack of knowledge about the existence of the control measure.

The IPM-CRSP/Mali project is also attempting to avoid the other two, informationoriented barriers to adoption. The majority of the IPM-CRPS/Mali experiments are conducted within the study villages. Farmers are encouraged to observe the experiment throughout the season, and at the end of each season are asked to evaluate the performance of each treatment with respect to a variety of criteria. As a result, farmers have a greater understanding of how to apply each treatment, and the expected returns to their adoption. The farmer evaluations also provide valuable feedback to help researchers fine-tune the treatments for the following season.

The minimum length of time required to complete the cycle of experimental design, implementation, evaluation, and redesign coincides with the number of seasons over which the treatment lasts. For example, a single-season treatment requires at least one season to design and implement, evaluate, and redesign. A treatment that lasts three seasons would take at least three seasons before the full evaluation could be conducted, 
and the treatment redesigned. The fewer design-implementation-evaluation-redesign cycles needed before a recommendation can be made, the sooner returns to agricultural research can be realized.

For a Striga control treatment lasting three seasons, the minimum lag between research and returns is three years. While single-season treatments are attractive, in that they allow for three evaluations and two opportunities for redesign in the same three seasons, Striga's biology seems to demand a multiple-season control strategy. The IPMCRSP/Mali project, in particular, and Striga research, in general, would benefit from an analytical framework in which to conduct ex ante evaluations of long-run Striga control measures. Such a framework could help identify the most promising treatments for the initial long-run field trials, as well as the relevance of each of the potential barriers to adoption. This would, in turn, provide the best opportunity to minimize the lag before the benefits of long-run Striga control research are realized.

\section{Section 1.4 Objectives}

The overriding objective of this study is to develop a dynamic programming model for conducting ex ante evaluations of multiple-season Striga control measures, and to apply this model to Mali's Mourdiah and Sirakorola zones. The model's solution could then be used to guide the design of field experiments.

The model is comprised of two components:

- A biological component that simulates Striga population dynamics.

- An economic component that represents the producer's economic decisions.

These two components are coupled together to reflect the impact of Striga infestation on the production decisions of farmers, and vice-versa. The general form of the biological and economic components may be specified for any production scenario. 
Application of the model to Mali's Sirakorola and Mourdiah zones involves the following specific objectives:

- Establishment of parameters for the biological model that reflect the agroclimatic environment of each zone.

- Identification of relevant production constraints.

- Estimation of the length of farmers' planning horizon in each zone.

- Establishment of input and output price parameters for the economic model.

Parameters within the model are adjusted to specify different production scenarios. By comparing the results of the scenarios, the model is able to:

- Estimate the expected financial and nutritional benefits of eradicating Striga.

- Estimate the expected financial and nutritional benefits of adopting the model's solution, hereafter referred to as the optimal set of practices.

- Examine the relevance of each potential barrier to the adoption of the optimal set of practices.

These results will not only facilitate the design of field experiments, but will also allow policy makers to focus on policies aimed at alleviating the relevant barriers to adoption. The model may also be used to provide estimates of the value of achieving a variety of Striga-related policy objectives, from eradication to adoption of the optimal set of practices. Such information would facilitate budgeting decisions regarding the socially desirable level of investment in public policies for controlling Striga.

\section{Section 1.5 Organization of the Dissertation}

The dissertation is organized into seven chapters, including the introductory chapter. In Chapter 2, a review of literature relevant to the biological component of the model is presented. In Chapter 3, the methodology employed in the study is developed and the model's ability to examine the hypotheses of Section 1.4 is discussed. In Chapter 4, the economic component is specified with respect to the production constraints and price parameters faced by farmers in Mourdiah and Sirakorola. Chapter 5 details the 
specification of the biological component of the model to the agroclimatic conditions in Mourdiah and Sirakorola. Chapter 6 presents the results of the model, and the final chapter examines the policy implications of the results and provides recommendations for further research. 


\section{Chapter 2: Literature Review}

\section{Section 2.1 Introduction}

The literature review for this study focuses on Striga population models and studies examining the effects of Striga control practices on the development and reproductive capacity of the weed. Prior to this study, three models of Striga population dynamics have been reported in the literature. Each of these models is reviewed in Section 2.2. The remaining sections are dedicated to the effect of Striga control practices on the parameters of the population models. Section 2.3 reviews studies concerning nitrogenous fertilizers. Section 2.4 examines studies of hand-pulling emerged Striga. Section 2.5 reviews the extensive literature related to chemical control of Striga.

\section{Section 2.2 Striga Population Models}

Kunisch et al. (1991) were the first to publish a mathematical representation of Striga population dynamics. The objective of their paper was to design a model that provides an holistic framework in which to quantify the influence each stage of the Striga reproductive cycle has on population growth rates and equilibrium levels. The model is developed in the context of infestations of the species $S$. hermonthica in sorghum fields in the Sahel. The model parameters are specified, with varying degrees of confidence, based on information available in 1991.

There are eight reproductive stages in the Kunisch model: (1) the existence of viable Striga seeds in a field; (2) the stimulation of seeds by the host root exudate; (3) the germination of stimulated seeds; (4) the attachment of germinated seeds to host roots; (5) the emergence of attached seedlings; (6) the development of emerged seedlings to reproductive capacity; (7) the generation of new seeds; and (8) the survival of new and old seeds into the next season. Transition probabilities govern the ability of a seed to reach each successive stage. The most general form of the model, represented by equation $(2.1, \mathrm{~K})$, relates the number of viable Striga seeds in season $\mathrm{t}+1$ to the size of the 
Striga seedbank in season t, stimulation of Striga seed in season t, production of new Striga seeds in season t, and Striga seed survival between seasons ${ }^{1}$.

$$
\mathrm{X}_{\mathrm{I}, \mathrm{t}+1}=\left(\mathrm{X}_{\mathrm{I}, \mathrm{t}}-\mathrm{X}_{\mathrm{S}, \mathrm{t}}\right) * \mathrm{P}_{\mathrm{T}}+\mathrm{X}_{\mathrm{F}, \mathrm{t}} * \mathrm{P}_{\mathrm{V}}
$$

Where $\mathrm{X}_{\mathrm{I}, \mathrm{t}}=$ the number of viable Striga seeds $\mathrm{m}^{-2}$ at the beginning of season $\mathrm{t}$ $\mathrm{X}_{\mathrm{S}, \mathrm{t}}=$ number of seeds stimulated $\mathrm{m}^{-2}$ at the start of season $\mathrm{t}$ $\mathrm{P}_{\mathrm{T}}=$ probability a seed not stimulated at the beginning of season $\mathrm{t}$ will be viable at the start of season $\mathrm{t}+1$ $\mathrm{X}_{\mathrm{F}, \mathrm{t}}=$ number of new seeds $\mathrm{m}^{-2}$ introduced at the end of season $\mathrm{t}$ $\mathrm{P}_{\mathrm{V}}=$ probability a seed produced at the end of season $\mathrm{t}$ will be viable at the start of season $\mathrm{t}+1$

The probabilities that old and new seeds survive into the next season $\left(\mathrm{P}_{\mathrm{T}}\right.$ and $\mathrm{P}_{\mathrm{V}}$, respectively) both enter the model as fixed values. Three studies, Kust (1963), Mussa (1987), and Saunders (1933), are cited to justify setting $P_{V}$ to a fixed value, and to establish an estimate of what that value should be. The value of $\mathrm{P}_{\mathrm{T}}$ is generated by assuming "an equilibrium between decline and production of Striga seeds is reached after 12 years of absence of any host crop cultivation" (p. 50).

Kunisch et al. model the probability of stimulation $\left(\mathrm{P}_{\mathrm{S}}\right)$ as an increasing function of host plant density (W). The number of stimulated seeds, then, is a function of the size of the seed bank at the start of the season and host plant density. Equation $(2.2, \mathrm{~K})$ represents this relationship.

$$
\mathrm{X}_{\mathrm{S}, \mathrm{t}}=\mathrm{X}_{\mathrm{I}, \mathrm{t}} * \mathrm{P}_{\mathrm{S}}=\mathrm{X}_{\mathrm{I}, \mathrm{t}} *(1-\exp \{-\mathrm{aW}\})
$$

\footnotetext{
${ }^{1}$ Letters used in the names of all equations in Chapter 2 refer to the author(s): K=Kunisch et al.; $\mathrm{SH} \& \mathrm{~W}=$ Smith, Holt, and Webb; S\&W=Smith and Webb. Letters within the equations refer to variables or coefficients, not to authors.
} 
The exponential coefficient a measures the intensity of the effect host plant density has on the probability of stimulation. Kunisch et al., based on a study of corn root density by Mengel and Barber (1974), approximate $\mathrm{a}=0.1$ for sorghum.

The probabilities that a stimulated seed will germinate $\left(\mathrm{P}_{\mathrm{K}}\right)$ and will subsequently attach to a host root $\left(\mathrm{P}_{\mathrm{B}}\right)$ are both set as fixed values. $\mathrm{P}_{\mathrm{K}}$ is fixed because "reports in the literature on this aspect vary widely" (Kunisch et al., 1991, p. 48). The authors cite two unpublished studies to justify fixing the value of $\mathrm{P}_{\mathrm{B}}$. They do, however, also mention that a study by Kroschel (1989) indicates that $\mathrm{P}_{\mathrm{B}}$ is dependent on nitrogen supply.

Using these two variables, the probability of germination and the level of nitrogen supply, the number of attached parasites $\left(X_{B}\right)$ may be represented by equation $(2.3, K)$.

$$
\mathrm{X}_{\mathrm{B}, \mathrm{t}}=\mathrm{X}_{\mathrm{I}, \mathrm{t}} *(1-\exp \{-0.1 \mathrm{~W}\}) * \mathrm{P}_{\mathrm{K}} * \mathrm{P}_{\mathrm{B}}
$$

There is an asymptotic maximum number of parasites that a host plant can support. In the absence of reliable studies related to conditions of the host's rhizosphere, Kunisch et al. set the maximum parasite carrying capacity of a host plant equal to 50 . This translates into a maximum density of parasites $\mathrm{m}^{-2}(\mathrm{~K})$ equal to $50^{*} \mathrm{~W}$. As such, the probability that an attached parasite will emerge from the soil as a viable seedling $\left(\mathrm{P}_{\mathrm{E}}\right)$ is a function of $\mathrm{X}_{\mathrm{B}}$ and W. The Kunisch model uses equation $(2.4, \mathrm{~K})$ to represent the probability of emergence.

$$
\mathrm{P}_{\mathrm{E}}=\mathrm{K} /\left(\mathrm{K}+\mathrm{X}_{\mathrm{B}, \mathrm{t}}\right)=50 * \mathrm{~W} /\left(50 * \mathrm{~W}+\mathrm{X}_{\mathrm{I}, \mathrm{t}} *(1-\exp \{-0.1 \mathrm{~W}\}) * \mathrm{P}_{\mathrm{K}} * \mathrm{P}_{\mathrm{B}}\right)
$$

Equation $(2.4, \mathrm{~K})$ illustrates that $\mathrm{P}_{\mathrm{E}}$ is directly dependent on, and positively related to host plant density. The number of emerged parasites $\mathrm{m}^{-2}\left(\mathrm{X}_{\mathrm{E}}\right)$ is also positively related to host density, as shown in equation $(2.5, \mathrm{~K})$.

$$
\begin{gathered}
\mathrm{X}_{\mathrm{E}, \mathrm{t}}=\mathrm{P}_{\mathrm{E}} * \mathrm{X}_{\mathrm{B}, \mathrm{t}}=\left[50 * \mathrm{~W} /\left(50 * \mathrm{~W}+\mathrm{X}_{\mathrm{I}, \mathrm{t}} *(1-\exp \{-0.1 \mathrm{~W}\}) * \mathrm{P}_{\mathrm{K}} * \mathrm{P}_{\mathrm{B}}\right)\right] \\
*\left[\mathrm{X}_{\mathrm{I}, \mathrm{t}} *(1-\exp \{-0.1 \mathrm{~W}\}) * \mathrm{P}_{\mathrm{K}} * \mathrm{P}_{\mathrm{B}}\right] \leq 50 * \mathrm{~W}
\end{gathered}
$$


The probability of an emerged parasite reaching reproductive maturity $\left(\mathrm{P}_{\mathrm{R}}\right)$ is set to a fixed value. The product of $\mathrm{P}_{\mathrm{R}}$ and $\mathrm{X}_{\mathrm{E}}$ gives the number of parasites $\mathrm{m}^{-2}$ that reach reproductive maturity $\left(X_{R}\right)$. The number of new seeds $m^{-2}\left(X_{F}\right)$ is simply the product of the number of Striga plants that have reached reproductive maturity and average seed production per plant. Seed production per Striga plant (A) is modeled as a function of the density of reproducing Striga plants. Equation $(2.6, \mathrm{~K})$ represents seed production $\mathrm{m}^{-2}$.

$$
\mathrm{X}_{\mathrm{F}, \mathrm{t}}=\mathrm{X}_{\mathrm{R}, \mathrm{t}} * \mathrm{~A}=\mathrm{X}_{\mathrm{R}, \mathrm{t}} * \mathrm{~A}_{\max } * \exp \left\{-\left(\mathrm{X}_{\mathrm{R}, \mathrm{t}} / \mathrm{X}_{\mathrm{pW}}\right)^{\mathrm{c}}\right\}
$$

Where $\mathrm{A}_{\max }=$ maximum reproductive capacity per mature plant ${ }^{2}$

Equation $(2.7, \mathrm{~K})$ represents the operational form of equation $(2.1, \mathrm{~K})$.

$$
\begin{aligned}
\mathrm{X}_{\mathrm{I}, \mathrm{t}+1} & =\left(\mathrm{X}_{\mathrm{I}, \mathrm{t}}-\mathrm{X}_{\mathrm{I}, \mathrm{t}} * \mathrm{P}_{\mathrm{S}}\right) * \mathrm{P}_{\mathrm{T}}+\mathrm{X}_{\mathrm{I}, \mathrm{t}} * \mathrm{P}_{\mathrm{S}} * \mathrm{P}_{\mathrm{K}} * \mathrm{P}_{\mathrm{B}} * \mathrm{P}_{\mathrm{E}} * \mathrm{P}_{\mathrm{R}} * \mathrm{~A} * \mathrm{P}_{\mathrm{V}} \\
& =\left[\mathrm{X}_{\mathrm{I}, \mathrm{t}}-\mathrm{X}_{\mathrm{I}, \mathrm{t}} *(1-\exp \{-0.1 \mathrm{~W}\})\right] * \mathrm{P}_{\mathrm{T}} \\
& +\mathrm{X}_{\mathrm{I}, \mathrm{t}} *(1-\exp \{-0.1 \mathrm{~W}\}) * \mathrm{P}_{\mathrm{K}} * \mathrm{P}_{\mathrm{B}} *\left[50 * \mathrm{~W} /\left(50 * \mathrm{~W}+\mathrm{X}_{\mathrm{I}, \mathrm{t}} *(1-\exp \{-0.1 \mathrm{~W}\})\right.\right. \\
& \left.\left.* \mathrm{P}_{\mathrm{K}} * \mathrm{P}_{\mathrm{B}}\right)\right] * \mathrm{P}_{\mathrm{R}} * \mathrm{~A}_{\max } * \exp \left\{-\left(\mathrm{X}_{\mathrm{R}, \mathrm{t}} / \mathrm{X}_{\mathrm{pW}}\right)^{\mathrm{c}}\right\} * \mathrm{P}_{\mathrm{V}}
\end{aligned}
$$

While any of the parameters of the Kunisch model may be changed to reflect the adoption of control practices during a given developmental stage, the only practice that is endogenous to the model is the selection of host plant density.

Smith, Holt, and Webb (1993) modiied the Kunisch model to examine the feasibility of controlling $S$. hermonthica with a biological agent (Smicronyx umbrinus) in millet fields in Mali. There are, however, some important differences between the two models. Equation $(2.1, \mathrm{SH} \& \mathrm{~W})$ represents the most general form of the Smith, Holt, and Webb (SH\&W) model ${ }^{3}$.

\footnotetext{
${ }^{2}$ Based on Liang (1984), $A_{\max }=30,000$. Neither $X_{\mathrm{pw}}$ nor $\mathrm{c}$ are defined in the paper.
} 
$(2.1, \mathrm{SH} \& \mathrm{~W}) \quad \mathrm{X}_{\mathrm{I}, \mathrm{t}+1}=\left(\mathrm{X}_{\mathrm{I}, \mathrm{t}}-\mathrm{X}_{\mathrm{S}, \mathrm{t}}\right) * \mathrm{P}_{4}+\mathrm{X}_{\mathrm{F}, \mathrm{t}} * \mathrm{P}_{4}$

Where $\mathrm{X}_{\mathrm{I}, \mathrm{t}}=$ the number of viable Striga seeds $\mathrm{m}^{-2}$ at the beginning of season $\mathrm{t}$

$\mathrm{X}_{\mathrm{S}, \mathrm{t}}=$ number of seeds stimulated at the start of season $\mathrm{t}$

$\mathrm{P}_{4}=$ probability a seed (either old or new) will be viable at the start of season $\mathrm{t}+1$

$\mathrm{X}_{\mathrm{F}, \mathrm{t}}=$ number of new seeds $\mathrm{m}^{-2}$ introduced at the end of season $\mathrm{t}$

Equation $(2.1, \mathrm{SH} \& \mathrm{~W})$ is the same as equation $(2.1, \mathrm{~K})$ with one exception: SH\&W make no distinction between the probability of a new seed surviving into the next season $\left(\mathrm{P}_{\mathrm{V}}\right.$ in the Kunisch model) and the probability of a old seed surviving into the next season $\left(\mathrm{P}_{\mathrm{T}}\right)$. The authors do not state why they do not make this distinction.

The probability of stimulation $\left(\mathrm{P}_{\mathrm{S}}\right)$ is set to a fixed value in the SH\&W model. SH\&W claim that "[n]o information is available" regarding the relation between the proportion of seeds stimulated, the surface area of the host seedling root, and the proportion of soil penetrated by the host roots. Therefore, SH\&W feel the probability of stimulation is best set to a fixed value. This is in sharp contrast to the Kunisch model that draws on studies of corn root systems to represent $\mathrm{P}_{\mathrm{S}}$ as a function of host plant density. Equation (2.2, $\mathrm{SH} \& \mathrm{~W}$ ) represents the number of stimulated seeds $\mathrm{m}^{-2}$ in the $\mathrm{SH} \& \mathrm{~W}$ model.

\section{$(2.2, \mathrm{SH} \& \mathrm{~W}) \quad \mathrm{X}_{\mathrm{S}, \mathrm{t}}=\mathrm{X}_{\mathrm{I}, \mathrm{t}} * \mathrm{P}_{\mathrm{S}}=\mathrm{X}_{\mathrm{I}, \mathrm{t}} * 0.1$}

One possible explanation for the discrepancy between the probability of stimulation in the Kunisch and SH\&W models is that they are focused on different host crops - the former on sorghum, the latter on millet. SH\&W state that millet in Mali is grown in hills approximately one meter apart, with one millet plant per hill. If $\mathrm{W}=1$ in the Kunisch model, $\mathrm{P}_{\mathrm{S}}=0.095$, which is very close to 0.1 , the fixed value in the $\mathrm{SH} \& \mathrm{~W}$ model.

\footnotetext{
${ }^{3}$ Whenever possible notation follows that used by Kunisch et al. Otherwise the notation is that found in Smith, Holt, and Webb.
} 
$\mathrm{SH} \& \mathrm{~W}$ combine the probability of germination $\left(\mathrm{P}_{\mathrm{K}}\right.$ in the Kunisch model) and the probability of attachment $\left(\mathrm{P}_{\mathrm{B}}\right.$ in the Kunisch model) into a single parameter $\left(\mathrm{k}_{1}\right) . \mathrm{k}_{1}$ is set to a fixed value by $\mathrm{SH} \& \mathrm{~W}$, and that value is equal to the product of $\mathrm{P}_{\mathrm{K}}$ and $\mathrm{P}_{\mathrm{B}}$. As such, there is no difference between the two models with respect to the specification of the proportion of stimulated seeds that attach to a host root.

The number of attached parasites $\mathrm{m}^{-2}$ in the SH\&W model is represented by equation $(2.3, \mathrm{SH} \& \mathrm{~W})$. All of the parameters in $(2.3, \mathrm{SH} \& \mathrm{~W})$ are independent of Striga control practices.

$$
(2.3, \mathrm{SH} \& \mathrm{~W}) \quad \mathrm{X}_{\mathrm{B}, \mathrm{t}}=\mathrm{X}_{\mathrm{I}, \mathrm{t}} * \mathrm{P}_{\mathrm{S}} * \mathrm{P}_{\mathrm{K}} * \mathrm{P}_{\mathrm{B}}
$$

Based on unpublished data from millet field surveys in Mali, SH\&W set the asymptotic maximum number of Striga per host to 60. Because millet plants in Mali are grown approximately one meter apart, this translates to an asymptotic maximum of 60 Striga m $\mathrm{m}^{-2}$ $\left(\mathrm{k}_{2}\right.$ in the $\mathrm{SH} \& \mathrm{~W}$ model $)$. Equations $(2.4, \mathrm{SH} \& \mathrm{~W})$ and $(2.5, \mathrm{SH} \& \mathrm{~W})$ represent the probability of emergence and the number of emerged Striga $\mathrm{m}^{-2}$, respectively.

$(2.4, \mathrm{SH} \& \mathrm{~W}) \quad \mathrm{P}_{\mathrm{E}}=\mathrm{k}_{2} /\left(\mathrm{k}_{2}+\mathrm{X}_{\mathrm{B}, \mathrm{t}}\right)=60 /\left(60+\mathrm{X}_{\mathrm{I}, \mathrm{t}} * \mathrm{P}_{\mathrm{S}} * \mathrm{P}_{\mathrm{K}} * \mathrm{P}_{\mathrm{B}}\right)$

$(2.5, \mathrm{SH} \& \mathrm{~W}) \quad \mathrm{X}_{\mathrm{E}, \mathrm{t}}=\mathrm{P}_{\mathrm{E}} * \mathrm{X}_{\mathrm{B}, \mathrm{t}}=\left[60 /\left(60+\mathrm{X}_{\mathrm{I}, \mathrm{t}} * \mathrm{P}_{\mathrm{S}} * \mathrm{P}_{\mathrm{K}} * \mathrm{P}_{\mathrm{B}}\right)\right] * \mathrm{X}_{\mathrm{I}, \mathrm{t}} * \mathrm{P}_{\mathrm{S}} * \mathrm{P}_{\mathrm{K}} * \mathrm{P}_{\mathrm{B}}$

As in the Kunisch model, the probability of a Striga plant reaching reproductive maturity $\left(\mathrm{P}_{\mathrm{R}}\right)$ is set to a fixed value; the value of $\mathrm{P}_{\mathrm{R}}$, however, differs in the two studies (see Table 2.1). SH\&W cite unpublished data to justify the value at which they set $P_{R}$, whereas Kunisch et al. do not cite any reference for the value to which they set $P_{R}$.

SH\&W model seed production per Striga plant (A) three different ways: (1) as a fixed value; (2) as dependent on the density of reproducing $S$. hermonthica, as in equation (2.6.2,SH\&W); and (3) as dependent on the density of reproducing S. hermonthica, as in 
equation $(2.6 .3, \mathrm{SH} \& \mathrm{~W})$. The number of seeds that actually enter the field, however, is affected by the presence of the biological agent Sm. umbrinus.

Sm. umbrinus is assumed to destroy a constant proportion of $S$. hermonthica seeds (s). Equations (2.6.1,SH\&W), (2.6.2,SH\&W), and (2.6.3,SH\&W) represent the three ways in which SH\&W model the number of new seeds $\mathrm{m}^{-2}$ that enter a field at the end of the season.

(2.6.1,SH\&W)

$$
\mathrm{X}_{\mathrm{F}, \mathrm{t}}=(1-\mathrm{s}) * \mathrm{~A} * \mathrm{X}_{\mathrm{R}, \mathrm{t}}
$$

$(2.6 .2, \mathrm{SH} \& \mathrm{~W})$

$$
\mathrm{X}_{\mathrm{F}, \mathrm{t}}=(1-\mathrm{s}) *\left(\mathrm{~A}_{\max } * \mathrm{M}_{\max } / \mathrm{M}_{\max }+\mathrm{R} * \mathrm{~A}_{\max }\right) * \mathrm{X}_{\mathrm{R}, \mathrm{t}}
$$

$$
\mathrm{X}_{\mathrm{F}, \mathrm{t}}=(1-\mathrm{s}) * \mathrm{~A}_{\max } \exp \left\{-(\mathrm{R} * \mathrm{a})^{\mathrm{b}}\right\} * \mathrm{X}_{\mathrm{R}, \mathrm{t}}
$$

Where $\mathrm{A}_{\max }=$ maximum reproductive capacity per mature plant at low Striga density $\mathbf{M}_{\max }=$ maximum reproductive capacity per mature plant at high Striga density ${ }^{4}$

The likelihood that a seed, either new or old, in the field at the end of season $\mathrm{t}$ will be viable at the beginning of season $\mathrm{t}+1$ is set to a fixed value $\left(\mathrm{P}_{4}\right)$ in the $\mathrm{SH} \& \mathrm{~W}$ model. The operational form of the $\mathrm{SH} \& \mathrm{~W}$ model is represented by equation $(2.7, \mathrm{SH} \& \mathrm{~W})$.

$(2.7, \mathrm{SH} \& W) \quad \mathrm{X}_{\mathrm{I}, \mathrm{t}+1}=\mathrm{P}_{4}\left[\mathrm{X}_{\mathrm{I}, \mathrm{t}}\left(1-\mathrm{P}_{\mathrm{S}}+\mathrm{P}_{\mathrm{S}} * \mathrm{P}_{\mathrm{K}} * \mathrm{P}_{\mathrm{B}} * \mathrm{P}_{\mathrm{E}} * \mathrm{P}_{\mathrm{R}} * \mathrm{~A}\right)\right]$

$$
\begin{aligned}
& =\mathrm{P}_{4}\left[\mathrm { X } _ { \mathrm { I } , \mathrm { t } } \left(1-\mathrm{P}_{\mathrm{S}}+\mathrm{P}_{\mathrm{S}} * \mathrm{P}_{\mathrm{K}} * \mathrm{P}_{\mathrm{B}} *\left(60 /\left(60+\mathrm{X}_{\mathrm{I}, \mathrm{t}} * \mathrm{P}_{\mathrm{S}} * \mathrm{P}_{\mathrm{K}} * \mathrm{P}_{\mathrm{B}}\right)\right)\right.\right. \\
& \left.* \mathrm{P}_{\mathrm{R}} *(1-\mathrm{s}) * \mathrm{~A}\right]
\end{aligned}
$$

Comparing $(2.7, \mathrm{~K})$ with $(2.7, \mathrm{SH} \& \mathrm{~W})$, one can see that the essential difference between the Kunish and SH\&W models is in the Striga control practices that are explicitly

\footnotetext{
${ }^{4} \mathrm{R}$ is not defined.
} 
incorporated into the model. The only practice that is specified in the Kunish model is host plant density; the only control specified in the SH\&W model is use of Sm. umbrinus.

The other difference in the two models is the specification of the asymptotic maximum number of emerged Striga plants per host plant. Kunisch et al. set the Striga carrying capacity of a host equal to 50, while SH\&W set it equal to 60. In 1996, Smith and Webb ( $\mathrm{S} \& \mathrm{~W})$, based on a study of millet production in Mourdiah, estimated the maximum Striga carrying capacity to be 20 emerged parasites per host. The results of their study caused $\mathrm{S} \& \mathrm{~W}$ to reassess one other parameter of the SH\&W model.

S\&W estimated the combined probability of germination and attachment to be much lower than the parameter assumed in the SH\&W model. Based on a study by Bebawi et al. (1984) of Striga seed germination and results of an unpublished study of the probability of attachment reported in Kunisch et al. (1991), SH\&W initially set $\mathrm{k}_{1}$ equal to 0.2 . The $\mathrm{S} \& \mathrm{~W}$ study, however, estimated $\mathrm{k}_{1}$ to be 0.012 . Table 2.1 presents the parameters used in each of the three Striga population models discussed above.

The purpose of the Kunisch, SH\&W and S\&W models is to examine how the Striga seedbank is affected by the use of a single, exogenous control measure. In contrast, the objective of the model developed for this study is to determine endogenously the level of control(s) that should be employed to satisfy the producer's long-run objectives; the seedbank dynamics reflect the long-run efficacy of the control practices. Literature reporting the effects of Striga control practices on the parameters in the Kunisch, SH\&W, $\mathrm{S} \& \mathrm{~W}$ and, ultimately, the biological model developed in Chapter 3, and specified in Chapter 5, are discussed in Sections 2.3 through 2.10. 
Table 2.1: Parameter Values Used in the Kunisch et al., Smith, Holt and Webb, and Smith and Webb Striga Population Models

\begin{tabular}{|l|c|c|c|}
\hline \multicolumn{1}{|c|}{ Parameter } & Kunisch $^{5}$ & SH\&W & S\&W \\
\hline $\operatorname{Pr}($ Stimulation $)$ & $1-\exp (-0.1 \mathrm{~W})$ & 0.1 & 0.1 \\
\hline $\operatorname{Pr}($ Germination$)$ & 0.5 & 0.45 & 1 \\
\hline $\operatorname{Pr}($ Attachment $)$ & 0.4 & 0.455 & 0.012 \\
\hline $\operatorname{Pr}($ Emergence $)$ & $50 \mathrm{~W} /\left(50 \mathrm{~W}+\mathrm{X}_{\mathrm{B}}\right)$ & $60 * /\left(60+\mathrm{X}_{\mathrm{B}}\right)$ & $20 * /\left(20+\mathrm{X}_{\mathrm{B}}\right)$ \\
\hline $\operatorname{Pr}($ Reproduction) & 0.6 & 0.25 & 0.25 \\
\hline \# of Seeds Produced & $\mathrm{A}_{\max }{ }^{*} \exp \left(-\left(\mathrm{X}_{\mathrm{R}} / \mathrm{X}_{\mathrm{pW}}\right)^{\mathrm{c}}\right)$ & 7500 & 7500 \\
\hline $\operatorname{Pr}($ Survival of Old Seeds $)$ & 0.545 & 0.5 & 0.5 \\
\hline $\operatorname{Pr}($ Survival of New Seeds $)$ & 0.9 & 0.5 & 0.5 \\
\hline
\end{tabular}

\footnotetext{
${ }^{5} \mathrm{~W}=$ density of host plant $\mathrm{m}^{-2} ; \mathrm{a}=0.1 ; \mathrm{K}=$ maximum number of parasites per host plant $=50$; $\mathrm{X}_{\mathrm{B}}=$ number of attached parasites $=\mathrm{X}_{\mathrm{I}, \mathrm{t}} * \mathrm{P}_{\mathrm{S}} * \mathrm{P}_{\mathrm{K}} * \mathrm{P}_{\mathrm{B}} ; \mathrm{A}_{\max }=$ maximum reproductive capacity per Striga plant; $\mathrm{X}_{\mathrm{R}}=$ number of reproducing Striga plants $=\mathrm{X}_{\mathrm{I}, \mathrm{t}} * \mathrm{P}_{\mathrm{S}} * \mathrm{P}_{\mathrm{K}} * \mathrm{P}_{\mathrm{B}} * \mathrm{P}_{\mathrm{R}} ; \mathrm{X}_{\mathrm{pW}}$ is not defined in the paper; $c$ is not defined in the paper.

${ }^{6} \mathrm{~S} \& \mathrm{~W}$ estimate $\operatorname{Pr}($ Germination $) * \operatorname{Pr}($ Attachment $)=0.012$. They do not distinguish between the two probabilities.
} 


\section{Section 2.3 Effects of Nitrogenous Fertilizers on the Biological Parameters}

The literature examining the effects of nitrogenous fertilizers on Striga development is extensive, covering more than 60 years. Needless to say, the papers reviewed below do not constitute an exhaustive list. Prominent papers are discussed according to information they provide that is relevant to the biological parameters identified in the Kunisch, SH\&W, and S\&W Striga population models. As these models serve as the foundation for the biological model developed in Chapters III and V, this literature will provide justification and guidance in establishing the biological parameters of that model. $^{7}$

Probability of Stimulation. After a seed has been preconditioned, the next stage in the Striga life cycle is the stimulation of the seed by host or non-host root exudate. Impeding the stimulation of seeds is the first opportunity farmers have to reduce infestation levels, crop damage, and the introduction of new seeds into a field. The probability of stimulation reflects the likelihood that a Striga seed will be exposed to an active stimulant. While this literature review was unable to locate any studies examining the effect of nitrogen on the probability that a Striga seed is exposed to a stimulant, several experiments have shown that the application of nitrogen has a significant effect on the stimulatory activity of sorghum root exudate.

Raju et al. (1990) exposed sorghum seeds in vitro to ammonium nitrate at rates of 0,30, and $150 \mathrm{mg} \mathrm{N} / \mathrm{l}$. They then extracted root exudate from the sorghum seedlings and applied it to preconditioned S. asiatica seeds. They found that as nitrogen levels increased, the activity of the root exudate decreased across all sorghum genotypes tested. Table 2.2 presents the results of their experiments.

In 1990, Bebawi, Khalid and Musselman (1991) conducted a series of experiments in Sudan to see how urea $\mathrm{N}$ affects the stimulation of $S$. hermonthica seeds by the sorghum variety Dibaikri. Sorghum seeds were treated with varying concentrations of urea $\mathrm{N}$ and

\footnotetext{
${ }^{7}$ In the interest of space, all experimental details are not discussed below; readers should refer to the cited article.
} 
allowed to germinate. The root exudate was extracted, bioassayed, and applied to preconditioned S. hermonthica seeds. Striga germination rates were then observed. The authors concluded "stimulant activity from the root exudate of sorghum was significantly ( $\mathrm{p}=0.05$ ) influenced by urea N in April and May 1990" (p. 459). Results of their root exudate experiment are presented in Table 2.3.

Cechin and Press (1993) also examined the effect of nitrogen (applied as ammonium nitrate) on the stimulant activity of sorghum root exudate with respect to $S$. hermonthica. The results of their experiments concur with those of Raju et al. (1990) and Bebawi et al. (1991) - nitrogen significantly reduced the stimulant activity of sorghum root exudate.

Probability of Germination. Bebawi et al. (1991) also examined the influence of urea N on the germination of $S$. hermonthica stimulated by sorghum seeds. They found that low concentrations facilitated germination, while higher concentrations inhibited germination. Pesch and Pieterse (1982) report urea applied at 100, 200, and $400 \mathrm{mg} / \mathrm{l}$ decreased the number of $S$. hermonthica seeds that germinated in vitro when exposed to the stimulant GR-24. Cechin and Press (1993) found that the number of $S$. hermonthica seeds that germinated when exposed to sorghum root exudate in $3 \mathrm{mM}$ ammonium nitrate solution was significantly lower than the number that germinated in $1 \mathrm{mM}$ ammonium nitrate solution, indicating a negative relationship between nitrogen and the probability of germination.

Probability of Attachment. After germinating, Striga attack the host root through a haustorium. Boukar, Hess, and Payne (1996) examined how the incidence of haustoria on pearl millet roots varied between two levels of urea application ( 0 and $60 \mathrm{~kg} \mathrm{~N} / \mathrm{ha}$ ), two water regimes, and two levels of S. hermonthica infestation. They found that the 60 $\mathrm{kg} \mathrm{N} / \mathrm{ha}$ urea treatments had a greater number of haustoria per pot than the treatments without $\mathrm{N}$ across all water regimes and Striga infestation levels. 
Table 2.2 Effect of Nitrogen on Stimulation Activity of Sorghum Root Exudate as Reflected by Striga Germination Rates

\begin{tabular}{|l|c|ccc|}
\hline \multirow{2}{*}{ Genotype } & & \multicolumn{3}{|c|}{$\begin{array}{c}\text { mg N/l; } \\
\text { germination (\%) }\end{array}$} \\
\hline Swarna & Reaction to Striga & 0 & 30 & 150 \\
CSH 1 & Susceptible & 50.0 & 25.5 & 0 \\
N 13 & Susceptible & 32.2 & 19.5 & 0 \\
SRN 4841 & Resistant & 24.5 & 9.8 & 0 \\
S. e. d. (3 df) & Resistant & 16.4 & 5.7 & 0 \\
\hline
\end{tabular}

Source: Raju, P.S., M. A. Osman, P. Soman, and J. M. Peacock, "Effects of N, P, and K on Striga asiatica (L.) Kuntze Seed Germination and Infestation in Sorghum," Weed Research, vol. 30, pp. 139-144, 1990. 
Table 2.3 Influence of Urea N on Stimulant Activity of Sorghum

\begin{tabular}{|l|c|c|}
\hline \multirow{2}{*}{$\begin{array}{l}\text { Urea N } \\
(\mathrm{mg} / \mathrm{l})\end{array}$} & \multicolumn{2}{|c|}{ \# of germinated Striga seeds } \\
\hline 0 & April & May \\
\hline 5 & 22.3 & 31.0 \\
\hline 10 & 18.2 & 20.0 \\
\hline 20 & 6.4 & 10.5 \\
\hline 40 & 4.8 & 8.5 \\
\hline 80 & 2.6 & 2.3 \\
\hline 160 & 0.8 & 1.0 \\
\hline 320 & 0 & 0 \\
\hline 640 & 0 & 0 \\
\hline 1000 & 0 & 0 \\
\hline LSD $(0.05)$ & 0 & 0 \\
\hline
\end{tabular}

Source: Bebawi, F. F., S. A. Khalid and L. J. Musselman, "Effects of Urea Nitrogen on Stimulant Activity of Sorghum and Germination Capacity of Striga," in J. K. Ransom, A. D. Worsham, and C. Parker (eds), Proceedings of the $5^{\text {th }}$ International Symposium of Parasitic Weeds, Nairobi: CIMMYT, pp. 458-461, 1991. 
In contrast, Awad, et al. (1991) found that nitrogen applied at 168 and $224 \mathrm{~kg} \mathrm{~N} / \mathrm{ha}$ reduced S. asiatica attachments in sorghum by 22 and 51\%, respectively, compared to a rate of $112 \mathrm{~kg} \mathrm{~N} / \mathrm{ha} .{ }^{8}$ Cechin and Press (1993) also report experiments showing that higher concentrations of nitrogen reduced the number $S$. hermonthica attached in vitro to sorghum plants, while Pesch and Pieterse (1982) found that radicle length of $S$. hermonthica is reduced by the application of urea, implying a reduction in the probability of germinated seeds to reach and ultimately attach to host roots.

Probability of Emergence. In 1960, Last reported the results of experiments showing application of N significantly reduced the "incidence" of S. hermonthica in Sudanese sorghum fields. The statistic he reported, however, is the percentage of sorghum plants infected with Striga rather than the number of emerged Striga. As a result, it is unclear what effect N application had on the probability of a Striga seed emerging - the higher percentage of infected sorghum plants may have represented an increase or a decrease in the total number of emerged Striga.

In 1965, Agabawi and Younis examined how different N-rates affected the number of emerged Striga in sorghum fields in the Sudan. In two of the three years they conducted the experiment, $\mathrm{N}$-rates of $80 \mathrm{lb} / \mathrm{feddan}$ and higher significantly reduced the number of emerged S. hermonthica per square meter. ${ }^{9}$

Since that time, many other studies have examined the relationship between nitrogen application rates and the number of emerged Striga, with mixed results (see Table 2.4). Ogborn (1987) found that $\mathrm{N}$ applied at $23.6 \mathrm{~kg} / \mathrm{ha}$ significantly reduced the number of emerged S. hermonthica in millet fields in the Northern Zone of Nigeria. Hess and Ejeta (1987) found $100 \mathrm{~kg}$ urea/ha significantly reduced (compared to no urea) the number of emerged S. hermonthica in fields planted with two sorghum varieties in Niger, 'Framida' and 'Dabar.' Awad et al. (1991) found that $224 \mathrm{~kg} \mathrm{~N} / \mathrm{ha}$ reduced the number of emerged S. asiatica in sorghum fields by $38 \%$ compared to $112 \mathrm{~kg} \mathrm{~N} / \mathrm{ha}-$ a $0 \mathrm{~N}$ treatment was not

\footnotetext{
${ }^{8}$ The authors do not state the formulation with which $\mathrm{N}$ was applied.

${ }^{9}$ One feddan $=1.038$ acres .
} 
included as part of their experiments. Agbobli (1991) reported significant reductions of emerged S. asiatica in Togolese maize fields due to application of urea, while Kabambe (1991) found sulphate of ammonium applied at $112 \mathrm{~kg} \mathrm{~N} / \mathrm{ha}$ reduced the number of emerged S. asiatica in maize fields in Malawi.

Singh, Ndikawa, and Rao (1991) conducted experiments in sorghum fields in northern Cameroon during three consecutive years, 1987-1989. When averaged over the three host-density treatments, urea rates of 40 and $80 \mathrm{~kg}$ N/ha significantly reduced $S$. hermonthica emergence in 1989 compared to the $0 \mathrm{~N}$ treatment; in 1987 there was no statistically significant difference among the 0,40 and $80 \mathrm{~kg} \mathrm{~N} / \mathrm{ha}$ treatments. Results from the 1988 experiments are not reported.

Bebawi and Farah (1981) reported reductions in emerged Striga from application of nitrophoska in Sudanese sorghum fields. ${ }^{10}$ Rates of 43, 86, and $129 \mathrm{~kg} \mathrm{~N} / \mathrm{ha}$ reduced Striga counts compared to $0 \mathrm{~kg} \mathrm{~N} / \mathrm{ha}$ by $64 \%, 53 \%$, and $11 \%$, respectively, at eight weeks after sowing; 78\%, 74\%, and 47\%, respectively, at twelve weeks after sowing; and 80\%, $78 \%$, and $60 \%$, respectively, at sixteen weeks after sowing - all rates of $\mathrm{N}$ were statistically different from the control and from each other at $\mathrm{P}=0.05$.

Raju et al. (1990) conducted in vitro experiments with sorghum seeds, applying the equivalent of 0,25 , and $100 \mathrm{~kg} \mathrm{~N} / \mathrm{ha}$ to each pot. Application of $\mathrm{N}$ significantly reduced counts of $S$. asiatica above the soil surface compared to the $0 \mathrm{~N}$ control, although there was no statistical difference between the number of Striga in the 25 and $100 \mathrm{~kg} \mathrm{~N} / \mathrm{ha}$ treatments. The $25 \mathrm{~kg} \mathrm{~N} / \mathrm{ha}$ treatment also significantly reduced the number of Striga seedlings below the soil surface compared to the $0 \mathrm{~N}$ treatment, with the $100 \mathrm{~kg} \mathrm{~N} / \mathrm{ha}$ application further reducing the count of Striga.

The results of experiments conducted by Gworgwor and Weber (1991a) show that application of nitrophoska to sorghum grown in pots significantly reduced the number of

\footnotetext{
${ }^{10}$ The nitrophoska formulations consisted of $\mathrm{x}$ : 6.6: 15.5 NPK mixtures, where $\mathrm{x}$, referring to $\mathrm{kg}$ $\mathrm{N} / \mathrm{ha}$, varies by treatment.
} 
emerged S. hermonthica. ${ }^{11}$ Their treatments consisted of $0,0.5,1.0,1.5$, and $2.0 \mathrm{~g} \mathrm{~N} / \mathrm{kg}$ soil. The number of emerged Striga per sorghum plant was $80 \%$ lower when $0.5 \mathrm{~g} \mathrm{~N} / \mathrm{kg}$ soil was applied compared to no nitrogen application. The higher application rates did not further reduce the number of emerged Striga per plant.

On the other hand, Ogborn's experiments on sorghum in Nigeria's Northern Guinea Zone showed increases in the number of emerged S. hermonthica at application rates of 26.4, 51.7 , and $103.3 \mathrm{~kg} \mathrm{~N} / \mathrm{ha}$. It was not until the rate reached $155 \mathrm{~kg} \mathrm{~N} / \mathrm{ha}$ that the incidence of emerged Striga was significantly reduced. Similarly, Boukar, Hess and Payne (1996), in addition to their work on urea's effect on the incidence of haustoria, found urea treatments of $60 \mathrm{~kg} \mathrm{~N} / \mathrm{ha}$ on pearl millet resulted in a greater number of emerged $S$. hermonthica per plot compared to treatments without urea. Gworgwor and Weber (1991b) reported application of nitrophoska to pots sown with sorghum increased the number of emerged S. hermonthica compared to the $0 \mathrm{~N}$ control pots.

At first glance, the results of the experiments discussed above seem to contradict each other - some suggest a negative, some a positive, and some an ambiguous relationship between the application of $\mathrm{N}$ and the probability of Striga emerging. There is, however, a pattern to the results: low rates of $\mathrm{N}$ generate either no change or an increase in the number of emerged Striga, while high rates of $\mathrm{N}$ reduce the number. This pattern is consistent with the reported effects of $\mathrm{N}$ on the probability of germination, and suggests that changes in the number of germinated seeds may be driving the results of the emergence experiments.

Probability of Reproduction. Reports of the effect of nitrogenous fertilizers on the probability of a Striga plant reaching reproductive maturity are rare. Agabawi and Younis (1965), during experiments in 1961-1963, counted the number of flowering $S$. hermonthica in Sudanese sorghum fields treated with varying rates of $\mathrm{N}$ from sulphate of ammonia. In 1961, they found no statistically significant difference $(\mathrm{p}=0.05)$ between

\footnotetext{
${ }^{11}$ The formulation of nitrophoska used in the Gworgwor and Weber experiment consisted of 12: 12: 17: 2 of N, P, K, B.
} 
fields with and without $\mathrm{N}$ until the application rate reached $140 \mathrm{lb}$. N/feddan, at which point the number of flowering Striga plants declined. In 1962, rates of $40 \mathrm{lb}$. N/feddan and higher produced significant reductions in the number of flowering Striga compared to the $0 \mathrm{~N}$ treatment; in 1963, reductions were realized at $20 \mathrm{lb}$. N/feddan and higher. These results seem to suggest a cumulative, inter-seasonal effect from nitrogen application. Ogborn (1987), however, realized reductions in the number of flowering $S$. hermonthica in just one season.

The number of flowering $S$. hermonthica in Ogborn's millet experiment are consistent with the counts of emerged Striga: the application of $23.6 \mathrm{~kg} \mathrm{~N} / \mathrm{ha}$ significantly reduced the incidence of flowering Striga. The pattern of results from the sorghum experiments, however, is somewhat curious. Application of $26.4 \mathrm{~kg} \mathrm{~N} / \mathrm{ha}$ increased the number of flowering Striga, as it had the number of emerged Striga. But the number of flowering plants was significantly lower at application rates of 51.7 and $103.3 \mathrm{~kg} \mathrm{~N} / \mathrm{ha}$, contrary to the increase in emerged Striga resulting from those application rates. The application of $155 \mathrm{~kg}$ N/ha also reduced the number of flowering Striga, which is consistent with the number of emerged plants. Ogborn offers no hypothesis to explain the counter-intuitive data for the mid-level application rates.

Number of Seeds and Probability of Survival. A search of the literature was unable to locate any studies regarding how nitrogenous fertilizers affect the number of seeds set by a flowering Striga plant; nor were any published studies examining the relationship between nitrogenous fertilizers and the probability of a seed surviving between or within seasons found. 
Table 2.4 Studies on the Relationship between Nitrogen and the Emergence of Striga

\begin{tabular}{|c|c|c|c|c|c|c|}
\hline Authors & Striga species & $\begin{array}{l}\text { Type of N } \\
\text { Fertilizer }\end{array}$ & Fertilizer Rates & Host Crop & Location & General Results \\
\hline $\begin{array}{l}\text { Agabawi and Younis } \\
(1965)\end{array}$ & Hermonthica & $\begin{array}{l}\text { Sulphate of } \\
\text { Ammonia }\end{array}$ & $\begin{array}{l}0,20,40,60 \\
80,100,120 \\
\text { and } 140 \\
\text { (lb N/feddan) }\end{array}$ & Sorghum & Sudan & $\begin{array}{l}\text { Application rates }>80 \text { reduced } \\
\text { number of emerged Striga }\end{array}$ \\
\hline Ogborn (1987) & Hermonthica & $\begin{array}{l}21-14-0 \\
\text { compound }\end{array}$ & $\begin{array}{c}0,26.4,51.7 \\
103.3,155 \\
(\mathrm{~kg} \mathrm{~N} / \mathrm{ha} \\
\end{array}$ & Sorghum & Nigeria & $\begin{array}{l}\text { Rate of } 155 \text { reduced while lower rates } \\
\text { increased number of emerged Striga }\end{array}$ \\
\hline Ogborn (1987) & Hermonthica & $\mathrm{N}$ as $26: 0: 0$ & $\begin{array}{c}0,23.6 \\
(\mathrm{~kg} \mathrm{~N} / \mathrm{ha})\end{array}$ & Millet & Nigeria & $\begin{array}{c}\text { Application of N reduced number of } \\
\text { emerged Striga }\end{array}$ \\
\hline $\begin{array}{l}\text { Boukar, Hess and } \\
\text { Payne (1996) }\end{array}$ & Hermonthica & Urea & $\begin{array}{c}0 \text { and } 60 \\
(\mathrm{~kg} \mathrm{~N} / \mathrm{ha}) \\
\end{array}$ & Pearl Millet & Niger & $\begin{array}{c}\text { Urea application reduced number of } \\
\text { emerged Striga }\end{array}$ \\
\hline Agbobli (1991) & Asiatica & Urea & $\begin{array}{c}0,60,120,180 \\
\text { and } 240 \\
(\mathrm{~kg} \mathrm{~N} / \mathrm{ha}) \\
\end{array}$ & Maize & Togo & $\begin{array}{l}\text { Application rates }>60 \text { reduced } \\
\text { number of emerged Striga }\end{array}$ \\
\hline Hess and Ejeta (1987) & Hermonthica & Urea & $\begin{array}{c}0 \text { and } 100 \\
\text { (kg urea/ha) } \\
\end{array}$ & Sorghum & Niger & $\begin{array}{c}\text { Urea application reduced number of } \\
\text { emerged Striga }\end{array}$ \\
\hline $\begin{array}{l}\text { Singh, Ndikawa, and } \\
\text { Rao (1991) }\end{array}$ & Hermonthica & Urea & $\begin{array}{c}0,40, \text { and } 80 \\
(\mathrm{~kg} \mathrm{~N} / \mathrm{ha})\end{array}$ & Sorghum & Cameroon & $\begin{array}{l}\text { Results vary across years and density } \\
\text { of host plant }\end{array}$ \\
\hline Kabambe (1991) & Asiatica & $\begin{array}{l}\text { Sulphate of } \\
\text { Ammonia }\end{array}$ & $\begin{array}{l}0 \text { and } 112 \\
(\mathrm{~kg} \mathrm{~N} / \mathrm{ha})\end{array}$ & Maize & Malawi & $\begin{array}{c}\text { N application reduced number of } \\
\text { emerged Striga }\end{array}$ \\
\hline $\begin{array}{l}\text { Raju, Osman, Soman, } \\
\text { and Peacock (1990) }\end{array}$ & Asiatica & $\begin{array}{l}\text { Ammonium } \\
\text { Nitrate } \\
\left(\mathrm{NH}_{4} \mathrm{NO}_{3}\right)\end{array}$ & $\begin{array}{l}0,25,100(\mathrm{~kg} \\
\mathrm{N} / \mathrm{ha})\end{array}$ & Sorghum & India & $\begin{array}{l}\mathrm{N} \text { application reduced number of } \\
\text { Striga seedlings both above and below } \\
\text { soil surface }\end{array}$ \\
\hline
\end{tabular}


Table 2.4 Continued

\begin{tabular}{|c|c|c|c|c|c|c|}
\hline Authors & Striga species & $\begin{array}{l}\text { Type of N } \\
\text { Fertilizer }\end{array}$ & Fertilizer Rates & Host Crop & Location & General Results \\
\hline $\begin{array}{l}\text { Gworgwor and Weber } \\
\text { (1991a) }\end{array}$ & Hermonthica & $\begin{array}{l}\text { Nitrophoska } \\
(12: 12: 17: 2)\end{array}$ & $\begin{array}{c}0,0.5,1.0,1.5 \\
\text { and } 2.0(\mathrm{~g} \mathrm{~N} / \mathrm{kg} \\
\text { soil })\end{array}$ & Sorghum & $\begin{array}{l}\text { Germany/ } \\
\text { Sudan }\end{array}$ & $\begin{array}{c}\mathrm{N} \text { application reduced the number of } \\
\text { emerged Striga }\end{array}$ \\
\hline $\begin{array}{l}\text { Gworgwor and Weber } \\
\text { (1991b) }\end{array}$ & hermonthica & $\begin{array}{l}\text { Nitrophoska } \\
(12: 12: 17: 2)\end{array}$ & $\begin{array}{l}0,0.1, \text { and } 1.6 \\
(\mathrm{~g} \mathrm{~N} / \mathrm{kg} \text { soil })\end{array}$ & Sorghum & $\begin{array}{c}\text { Germany/ } \\
\text { Nigeria }\end{array}$ & $\begin{array}{l}\text { N application increased number of } \\
\text { emerged Striga }\end{array}$ \\
\hline $\begin{array}{l}\text { Bebawi and Farah } \\
\text { (1981) }\end{array}$ & hermonthica & $\begin{array}{l}\text { Nitrophoska } \\
(\mathrm{N}: 6.6: 15.5) \\
\end{array}$ & $\begin{array}{l}0,43,86, \text { and } \\
129(\mathrm{~kg} \mathrm{~N} / \mathrm{ha})\end{array}$ & Sorghum & Sudan & $\begin{array}{c}\text { N application reduced number of } \\
\text { emerged Striga }\end{array}$ \\
\hline $\begin{array}{l}\text { Awad, Worsham, } \\
\text { Eplee, and Norris } \\
\text { (1991) }\end{array}$ & asiatica & $\begin{array}{c}\text { Not } \\
\text { Reported }\end{array}$ & $\begin{array}{c}112,168, \text { and } \\
224 \\
(\mathrm{~kg} \mathrm{~N} / \mathrm{ha})\end{array}$ & Sorghum & Nigeria? & $\begin{array}{c}\text { Highest N rate reduced number of } \\
\text { emerged Striga }\end{array}$ \\
\hline
\end{tabular}




\section{Section 2.4 Effect of Hand-pulling on the Biological Parameters}

While one's ability to hire labor to pull weeds from a field is contingent on access to wage resources and the structure of the labor market, hand-pulling is a control practice that is available to all farmers. The effect of hand-pulling on the parameters of the Striga population model, however, is limited by the fact that one must wait for the weed to emerge from the soil before it can be pulled. As a result, hand-pulling does not affect the probability a Striga seed will be stimulated, germinate, attach, or emerge. Nor does hand-pulling effect the ability of a seed to survive within or between seasons. The probability of reproduction is the only parameter affected by hand-pulling.

Probability of Reproduction. Several researchers have suggested that hand-pulling Striga at high densities is an exercise in futility (Doggett, 1983; Ramaiah, 1987). However, the efficacy of hand-pulling with respect to its ability to prevent a plant from reaching reproductive maturity depends not only on the intensity of the infestation, but also on the amount of labor one is willing to invest - there is no reason why one with enough capital and access to a functioning labor market could not hire enough labor to rid a field of all emerged Striga.

The timing of weeding during the Striga life cycle also appears to affect the probability that a given plant will set seed. Hand-pulling of Striga at early stages often increases the number of emerged plants by reducing competition for nutrients (Bebawi, 1987), while a single weeding later in the Striga life cycle may have no effect at all. Babiker and Reda (1991) tested three single-weeding treatments (at 45, 60, and 75 days after sowing) in experiments in Ethiopian sorghum fields. They conclude, "handpulling had no drastic effects on [S. hermonthica] population density. The parasite showed complete recovery within a short period" (p. 182). Nonetheless, there is evidence that repeated weedings can reduce the incidence of mature Striga.

Setty and Hosmani (1987) found that hand-pulling and hoeing S. asiatica infested sorghum fields 25 and 40 days after sowing (DAS) significantly reduced Striga counts at 
60, 75, and 90 DAS, and at harvest as well. ${ }^{12}$ Carson (1988) also reports reductions in $S$. hermonthica counts due to hand-pulling in a series of experiments in millet and sorghum fields in the Gambia, although statistical analyses are not reported. The weeding treatment in the 1985 millet experiments consisted of hand-pulling of Striga shoots at flowering and maturity of the crop. The weeding treatment in the 1985 sorghum experiments consisted of hand-pulling Striga shoots 70 days after planting and at flowering of the crop. In 1986, the weeding treatment for both the sorghum and millet experiments consisted of hand-pulling at flowering of the crop. In each experiment handpulling reduced Striga counts, sometimes by as much as $90 \%$.

\section{Section 2.5 Effects of Chemical Controls on the Biological Parameters}

The literature related to chemical control of Striga is voluminous. Both pre- and postemergence vegetative herbicides have been tested extensively, as have soil fumigants to destroy Striga seeds and synthetic compounds aimed at stimulating suicidal germination. The efficacy of the chemicals depends not only on their toxicity and potential activity, but also on the application methodology (Eplee 1984).

Probability of Stimulation and Germination. The application of synthetic compounds to stimulate suicidal germination has been called the most promising method of ridding the soil of Striga seeds (Eplee, 1984). ${ }^{13}$ To date, however, that promise has not come to fruition.

The ability of synthetic compounds to stimulate Striga seeds is directly related to the dispersion of the compound in the soil. Ethylene, a highly active germination stimulant, was shown to readily disperse through soils and has been used in the United States as part of the program to eradicate S. asiatica (Eplee, 1975). A single application of ethylene could rid the soil of up to $90 \%$ of viable, preconditioned S. asiatica seeds (Eplee and Norris, 1987). Unfortunately, the application and handling of ethylene requires

\footnotetext{
${ }^{12}$ The authors do not provide the location of where their experiments were conducted.

${ }^{13}$ Suicidal germination refers to inducing Striga seeds to germinate in the absence of a suitable host. Unable to attach to a host, the germinated Striga die.
} 
expensive, technically sophisticated equipment, limiting its applicability to peasant farming systems.

Ethephon (active ingredient: (2-chloroethyl) phosphoric acid) has also shown stimulation activity when it breaks down and releases ethylene gas (Egley and Dale, 1970; Chancellor et al., 1971). ${ }^{14}$ Ethephon, however, is stable under acid conditions, failing to breakdown and release ethylene. As most infested soils are acidic, Ethephon's practical significance is greatly diminished (Parker and Riches, 1992).

In 1966, Cook and co-workers isolated the root exudate of cotton and named it strigol (Cook et al., 1966). This set off a series of efforts to develop active analogues of strigol for application in the field. Unfortunately, strigol and its analogues have shown diminished activity when applied to soil, due to both adsorption to soil particles and instability of the chemical compounds (Vail et al., 1990; Babiker and Hamdoun, 1982; Ibrahim et al., 1985). Furthermore, studies suggest that the instability of strigol analogues may be an intrinsic characteristic of structures with stimulant activity (Mangnus and Zwanenburg, 1992).

Babiker et al. (1991) tested the germination activity of thidiazuron (active ingredient: $\mathrm{N}$ phenyl-N'-1,2,3-thiadiazol-5-ylurea) on S. hermonthica in pot experiments using soil from Gezira, Sudan. Concentrations of $0.1,1$, and $5 \mathrm{mg} / \mathrm{l}$ induced germination of $34 \%$, $74 \%$, and $79 \%$ of exposed seeds, respectively. The efficacy of thidiazuron in the field has yet to be tested.

Kasasian and Parker (1971) approached the relationship between synthetic compounds and Striga germination from a different perspective. In a series of in vitro experiments they tested the ability of 237 herbicides to impede the germination of $S$. hermonthica seeds exposed to sorghum root exudate. In general, they concluded that 2,4-D, MCPA and a range of other phenoxy compounds demonstrated the greatest pre-emergence

\footnotetext{
${ }^{14}$ Source of all pesticide active ingredients listed in this chapter is $\underline{\text { Crop Protection Chemicals }}$ $\underline{\text { Reference, }}$ Chemical and Pharmaceutical Press (eds.), John Wiley and Sons, New York, 1990.
} 
activity. ${ }^{15}$ The results of statistical analyses of the compounds' performance were not presented, however.

Probability of Attachment. Thidiazuron has also been shown to affect the development of haustorium (Babiker et al., 1991). A series of in vitro experiments revealed that $S$. hermonthica exposed to thidiazuron developed a significant number of terminal haustoria, i.e., haustoria with no further root growth. ${ }^{16}$ Terminal haustoria would be less likely to attach to a host root than non-terminal haustoria. No published reports of the effects of thidiazuron on haustorium development in situ were found during the search of literature for this review.

Awad et al. (1991) report large reductions in the number of attached $S$. asiatica per sorghum plant from the application of dicamba (active ingredient: 3, 6-dichloro-0-anisic acid) at rates of $0.19,0.37$, and $0.56 \mathrm{~kg}$ a.i./ha. "Dicamba (across all rates) reduced attachment by 76, 75, 86\% [when applied with] 112, 168, and $224 \mathrm{~kg} \mathrm{~N} / \mathrm{ha}$, respectively, compared to $112 \mathrm{~kg} \mathrm{~N} /$ ha without dicamba treatment," (p. 537).

Kasasian and Parker (1971) noted several compounds inhibited Striga radicle growth in a series of in vitro experiments. However, statistical analyses of the observed inhibitory effect were not reported.

Probability of Emergence. Attached Striga emerge from the soil throughout the season. As a result, both pre- and post-emergence herbicides may affect the probability of emergence, with pre-emergence herbicides affecting the probability of all Striga seedlings and post-emergence herbicides affecting the probability of Striga seedlings that have yet to emerge as of the time of application.

A number of studies have examined the effects of pre-emergence herbicides on counts of emerged Striga. Yaduraju and Hosmani (1979) conducted trials recording the effects of

\footnotetext{
${ }^{15}$ Because broad-leaf crops such as cowpea are susceptible, phenoxy materials should not be applied in mixed cropping situations (Eplee and Norris, 1987a).
} 
Atrazine (active ingredient: 2-chloro-4-ethylamino-6-isopropylamino-5-triazine) and 2,4-D on S. asiatica emergence in Indian sorghum fields. Six pre-emergence treatments were conducted: ${ }^{17}$ (T1) Atrazine applied 1 day after sowing (d.a.s.) at $1.0 \mathrm{~kg}$ a.i./ha; (T2) Atrazine applied 1 d.a.s. at $1.0 \mathrm{~kg}$ a.i./ha and 2,4-D applied 70 d.a.s. at $0.5 \mathrm{~kg}$ a.i./ha; (T3) Atrazine applied 30 d.a.s. at $0.5 \mathrm{~kg}$ a.i./ha; (T4) 2,4-D applied 1 d.a.s. at $0.5 \mathrm{~kg}$ a.i./ha; (T5) 2,4-D applied 30 d.a.s. at $1.0 \mathrm{~kg}$ a.i./ha; and (T6) 2,4-D applied 30 d.a.s. at $1.0 \mathrm{~kg}$ a.i./ha and 2,4-D applied 70 d.a.s. at $0.5 \mathrm{~kg}$ a.i./ha. At 50 days after sowing, only T4, T5, and T6 had significantly $(\mathrm{p}=0.05)$ reduced the number of emerged Striga compared to the no-herbicide control. By 70 days after sowing, the difference in the number of emerged Striga between T4 and the control was no longer statistically significant. The difference between T5 and T6 and the control, however, increased over the course of the season.

Settty and Hosmani (1987) also looked at the ability of Atrazine to impede emergence of S. asiatica in Indian sorghum fields. In their paper they present data showing a significant reduction in the number of emerged Striga due to a "pre-emergence" application of $1 \mathrm{~kg}$ Atrazine/ha. ${ }^{18}$ Striga counts were lower than the no-Atrazine control treatment at 60,75, and 90 days after sowing, and at harvest.

Bebawi and Farah (1981) examined the effect of Atrazine on S. hermonthica emergence in Sudanese sorghum fields. Atrazine was applied 4 weeks after emergence of the sorghum plants. ${ }^{19}$ Compared to the no-Atrazine control, each of the three Atrazine treatments $(0.75,1.25$, and $1.75 \mathrm{~kg} / \mathrm{ha})$ significantly reduced Striga counts at 8 weeks after sowing. The reductions were sustained throughout the season. Other herbicides have showed promising results as well.

\footnotetext{
${ }^{16}$ In addition to thidiazuron, the Striga seeds were exposed to the germination stimulant GR24.

${ }^{17}$ Striga did not emerge until about 40 days after sowing, therefore the treatments with applications made 30 days after sowing are considered pre-emergence treatments in this discussion.

${ }^{18}$ The authors do not state when the pre-emergence herbicide was applied.

${ }^{19}$ The authors do not indicate whether Striga had emerged at this time. Within the context of this discussion it is assumed they had not.
} 
Eplee and Norris (1987b) report that after the systemic herbicide Dicamba was applied 40 days after sowing to sorghum grown in a greenhouse, all attached S. asiatica died without further growth. Awad et al. (1991) also report significant reductions in emerged $S$. asiatica due to application of Dicamba to sorghum fields.

Friesen and Korwar (1991) conducted a series of experiments in Indian sorghum fields over two years, 1980 and 1981. In 1980, a treatment of Ethephon, three different treatments of 2,4-D, and a treatment of Atrazine all significantly reduced the number of S. asiatica per $\mathrm{m}^{2}$ at the flowering stage of sorghum. In 1981, the Ethephon treatment and the Atrazine treatment significantly increased the number of Striga, while one of the 2,4-D treatments had no effect and the other two reduced the incidence of Striga at the flowering stage of sorghum.

Babiker and Reda (1991) found Dicamba reduced the incidence of S. hermonthica in Ethiopian sorghum fields, irrespective of the variety of sorghum planted. They also found that oxyfluorfen and chlorsulfuron suppressed Striga emergence.

The effects of sulfonylurea herbicides on the emergence of S. hermonthica and S. asiatica were examined by Adu-Tutu and Drennan (1991) in a series of pot experiments with maize and sorghum cultivars. One experiment consisted of five chlorsulfuron (active ingredient: 2-chloro-N-[(4-methoxy-6-methyl-1,3,5-triazin-2-yl) aminocarbonyl] benzenesulfonamide) treatments $(0,1.0,2.0,4.0$, and $6.0 \mathrm{~g}$ a.i./ha) applied at planting to two sorghum varieties. Another experiment included the same five chlorsulfuron treatments applied 2-4 weeks after the sorghum was planted. In both experiments and for both varieties, all of the chlorsulfuron application rates significantly reduced the number of emerged S. hermonthica per sorghum plant compared to the no-chlorsulfuron control. ${ }^{20}$ Metsulfuron methyl (active ingredient: Methyl-2-[[[[4-methoxy-6-methyl1,3,5-triazin-2-yl)-amino] carbonyl]-amino] sulfonyl] benzoate) also significantly

\footnotetext{
${ }^{20}$ The authors do not indicate exactly when the herbicide application was made, nor do they indicate when the Striga was counted.
} 
reduced emerged $S$. hermonthica per plant for both sorghum varieties when applied 2-4 weeks after planting.

The maize experiments showed all nicosulfuron treatments (10, 25, 50, and $100 \mathrm{~g}$ a.i./ha) applied at planting significantly reduced $S$. asiatica emergence. When applied 2-4 weeks after planting, Striga emergence was suppressed at rates of $25 \mathrm{~g}$ a.i./ha and higher. DPXE9636 also reduced emerged S. asiatica in maize when applied at planting or at 2-4 weeks after planting.

Singh et al. (1991) examined the effect of 2,4-D, triclopyr (active ingredient: 3,5,6trichloro-2-pyridoyloxy acetic acid), buctril, and ametryn (active ingredient: 2ethylamino-4-isopropylamino-6-methylthio-5-triazine)/paraquat (active ingredient: 1,1'dimethyl-4,4'-bypridinium dichloride) on the emergence of $S$. hermonthica at two different stages of sorghum development in field experiments in Cameroon. The experiments, conducted in three consecutive years, included three sorghum varieties. All herbicide treatments were made 6-7 weeks after sowing. In general, 2,4-D, triclopyr, and ametryn/paraquat reduced Striga counts at 7-8 weeks after sowing and at harvest across all years and sorghum varieties. Buctril produced either no effect or reduced Striga numbers, depending on the year and variety.

Probability of Reproduction. Pre-emergence herbicides may affect the probability of reproduction by causing systemic damage that impedes the ability of Striga to reach its full reproductive capacity. More often, however, herbicides are employed as postemergence, knock-down applications that prevent reproduction by killing emerged Striga. Many chemicals have shown considerable activity in this regard (Langston and English, 1990).

Yaduraju and Hosmani (1979) found 2,4-D applied at 70 and 90 days after sowing (d.a.s.) sorghum significantly reduced $S$. asiatica infestations, as did an application of 2,4-D at 70 d.a.s. together with an application of paraquat at 90 d.a.s. Setty and Hosmani (1987) found that, after a pre-emergence application of atrazine, 2,4-D applied 40 d.a.s. 
provided additional control of S. asiatica in sorghum. Korwar and Friesen (1984) also found 2,4-D applied at the flowering stage of witchweed to be highly effective in killing S. asiatica.

2,4-D is also effective in controlling emerged $S$. hermonthica in both sorghum and millet, as is paraquat, glyphosate (active ingredient: isopropylamine salt of glyphosate), paraquat and glyphosate together, and 2,4-D and glyphosate together (Carson 1988). Spot spraying of paraquat and 2,4-D also reduced the number of emerged $S$. hermonthica (Carson 1988; Carson and Kunjo 1991).

Table 2.5 summarizes the chemical control studies reviewed above. The table is organized by active ingredient. Observed effects of each active ingredient on the stimulation, germination, attachment, and emergence of Striga seeds, as well as the ability of emerged Striga to reach reproductive maturity, are indicated. The references reporting each observation are also cited within the table.

Table 2.5 reveals that, from a practical perspective, the ability of synthetic chemicals affect the stimulation of Striga seeds is limited. However, several compounds, including 2,4-D, MCPA, and thidiazuron have shown promising activity related to Striga germination. Successful reductions in the number of attached Striga have also been obtained by applying 2,4-D, atrazine, dicamba, and thidiazuron.

A number of chemicals have been able to prevent or impede Striga emergence in a variety of experimental settings. These chemicals include 2,4-D, ametryn, atrazine, buctril, chlorsulfuron, dicamba, DPX-9636, ethephon, metsulfuron methyl, nicosulfuron, oxyfluorfen, paraquat, and triclopyr. And, as post-emergence, knock-down herbicides, 2,4-D, DPX-9636, glyphosate, and paraquat have all shown considerable efficacy. 
Table 2.5: Summary of Studies Examining Effect of Chemical Control on Stages of Striga Development

\begin{tabular}{|c|c|c|c|c|c|c|}
\hline $\begin{array}{c}\text { Active } \\
\text { Ingredient }\end{array}$ & Stimulation & Germination & Attachment & Emergence & Reproduction & Comments \\
\hline \multirow[t]{2}{*}{$2,4-\mathrm{D}$} & & $\begin{array}{c}- \\
\text { Kasasian and } \\
\text { Parker (1971) }\end{array}$ & $\begin{array}{c}- \\
\text { Kasasian and } \\
\text { Parker (1971) } \\
\text { Yaduraju and } \\
\text { Hosmani (1979) }\end{array}$ & & & $\begin{array}{l}\text { Retarded germination and } \\
\text { inhibited radicle growth at } \\
\text { all application rates tested. } \\
\text { Damage to broad-leaf } \\
\text { crops prohibits use when } \\
\text { intercropping. }\end{array}$ \\
\hline & & & & $\begin{array}{c}\text { - and } ? \\
\text { Yaduraju and } \\
\text { Hosmani (1979) } \\
\text { Singh et al. } \\
\text { (1991) } \\
\text { Friesen and } \\
\text { Korwar (1991)* }\end{array}$ & & $\begin{array}{c}\text { Compared to no herbicide, } \\
\text { significantly reduced } \\
\text { emerged Striga at } 50 \text { d.a.s. } \\
\text { Difference in emerged } \\
\text { Striga counts at } 70 \text { d.a.s. } \\
\text { depends on application } \\
\text { rate. }\end{array}$ \\
\hline
\end{tabular}


Table 2.5 Continued

\begin{tabular}{|c|c|c|c|c|c|c|}
\hline $\begin{array}{c}\text { Active } \\
\text { Ingredient }\end{array}$ & Stimulation & Germination & Attachment & Emergence & Reproduction & Comments \\
\hline 2,4-D & & & & & $\begin{array}{c}- \\
\text { Yadaraju and } \\
\text { Hosmani (1979) } \\
\text { Setty and } \\
\text { Hosmani (1987) } \\
\text { Korwar and } \\
\text { Friesen (1984) } \\
\text { Carson (1988) } \\
\text { Carson and } \\
\text { Kunjo (1991) } \\
\end{array}$ & $\begin{array}{l}\text { Effective knock-down } \\
\text { herbicide both alone and in } \\
\text { conjunction with other } \\
\text { herbicide treatments. }\end{array}$ \\
\hline Ametryn & & & & $\begin{array}{c}- \\
\text { Singh et al. } \\
\text { (1991) }\end{array}$ & & $\begin{array}{c}\text { In multiple sorghum } \\
\text { varieties, Striga counts } \\
\text { were significantly reduced } \\
\text { at 7-8 weeks after sowing. } \\
\text { Pot experiments that } \\
\text { included } \mathrm{N} \text { and } \mathrm{P}_{2} \mathrm{O}_{5} \\
\text { applications. }\end{array}$ \\
\hline Atrazine & $\begin{array}{l}\text { No effect } \\
\text { Yadaraju and } \\
\text { Hosmani } \\
\text { (1979) }\end{array}$ & $\begin{array}{c}\text { No effect } \\
\text { Yadaraju and } \\
\text { Hosmani (1979) }\end{array}$ & $\begin{array}{c}- \\
\text { Setty and } \\
\text { Hosmani (1987) } \\
\text { Bebawi and } \\
\text { Farah (1981) } \\
\end{array}$ & $\begin{array}{c}\text { - and ? } \\
\text { Friesen and } \\
\text { Korwar }(1991)^{*}\end{array}$ & & $\begin{array}{l}\text { When applied } 1 \text { d.a.s., no } \\
\text { reduction in Striga } \\
\text { numbers were observed. } \\
\text { Application dates of other } \\
\text { experiments were unclear. }\end{array}$ \\
\hline
\end{tabular}


Table 2.5 Continued

\begin{tabular}{|c|c|c|c|c|c|c|}
\hline $\begin{array}{c}\text { Active } \\
\text { Ingredient }\end{array}$ & Stimulation & Germination & Attachment & Emergence & Reproduction & Comments \\
\hline Buctril & & & & $\begin{array}{c}\text { - and ? } \\
\text { Singh et al. } \\
(1991)\end{array}$ & & $\begin{array}{l}\text { Results depended on } \\
\text { sorghum variety and } \\
\text { experimental year }\end{array}$ \\
\hline Chlorsulfuron & & & & $\begin{array}{c}- \\
\text { Babiker and } \\
\text { Reda (1991)* } \\
\text { Adu-Tutu and } \\
\text { Drennan (1991) }\end{array}$ & & \\
\hline Dicamba & & & $\begin{array}{c}- \\
\text { Awad et al. } \\
(1991)^{*}\end{array}$ & $\begin{array}{c}- \\
\text { Babiker and } \\
\text { Reda (1991)* } \\
\text { Eplee and } \\
\text { Norris (1987b) }\end{array}$ & & \\
\hline DPX-9636 & & & & $\begin{array}{c}- \\
\text { Adu-Tutu and } \\
\text { Drennan (1991) }\end{array}$ & $\begin{array}{c}- \\
\text { Adu-Tutu and } \\
\text { Drennan (1991) }\end{array}$ & $\begin{array}{c}\text { Small effect from pre- } \\
\text { emergence treatment. } \\
\text { Post-emergence effect was } \\
\text { significant. }\end{array}$ \\
\hline
\end{tabular}


Table 2.5Continued

\begin{tabular}{|c|c|c|c|c|c|c|}
\hline $\begin{array}{c}\text { Active } \\
\text { Ingredient }\end{array}$ & Stimulation & Germination & Attachment & Emergence & Reproduction & Comments \\
\hline Ethephon & $\begin{array}{c}+ \\
\text { Egley and } \\
\text { Dale (1970) } \\
\text { Chancellor et } \\
\text { al. (1971) } \\
\text { Parker and } \\
\text { Riches (1992) }\end{array}$ & & & $\begin{array}{c}\text { - and } ? \\
\text { Friesen and } \\
\text { Korwar }(1991)^{*}\end{array}$ & & $\begin{array}{l}\text { Limited applicability, } \\
\text { unstable in acidic } \\
\text { conditions. }\end{array}$ \\
\hline Ethylene & $\begin{array}{c}+ \\
\text { Eplee (1975) } \\
\text { Eplee and } \\
\text { Norris (1987) }\end{array}$ & & & & & $\begin{array}{l}\text { Very expensive, } \\
\text { technologically demanding }\end{array}$ \\
\hline Glyphosate & & & & & $\begin{array}{c}- \\
\text { Carson (1988) }\end{array}$ & $\begin{array}{l}\text { Post-emergence treatments } \\
\text { alone and in conjunction } \\
\text { with } 2,4-\mathrm{D} \text { and/or paraquat. }\end{array}$ \\
\hline MCPA & & $\begin{array}{c}- \\
\text { Kasasian and } \\
\text { Parker (1971) }\end{array}$ & & & & $\begin{array}{l}\text { Retarded germination and } \\
\text { inhibited radicle growth at } \\
\text { all application rates tested. } \\
\text { Damage to broad-leaf } \\
\text { crops prohibits use when } \\
\text { intercropping. }\end{array}$ \\
\hline
\end{tabular}


Table 2.5 Continued

\begin{tabular}{|c|c|c|c|c|c|c|}
\hline $\begin{array}{c}\text { Active } \\
\text { Ingredient }\end{array}$ & Stimulation & Germination & Attachment & Emergence & Reproduction & Comments \\
\hline $\begin{array}{l}\text { Metsulfuron } \\
\text { Methyl }\end{array}$ & & & & $\begin{array}{c}- \\
\text { Adu-Tutu and } \\
\text { Drennan (1991) }\end{array}$ & & $\begin{array}{l}\text { Pot experiments with } \\
\text { fertilizer added } 3 \text { weeks } \\
\text { after planting. }\end{array}$ \\
\hline $\begin{array}{l}\text { Nicosulfuro } \\
\mathrm{n}\end{array}$ & & & & $\begin{array}{c}- \\
\text { Adu-Tutu and } \\
\text { Drennan (1991) }\end{array}$ & & $\begin{array}{l}\text { Pot experiments with } \\
\text { fertilizer added } 3 \text { weeks } \\
\text { after planting. }\end{array}$ \\
\hline Oxyfluorfen & & & & $\begin{array}{c}- \\
\text { Babiker and } \\
\text { Reda }(1991)^{*}\end{array}$ & & \\
\hline Paraquat & & & & $\begin{array}{c}- \\
\text { Singh et al. } \\
\text { (1991) }\end{array}$ & $\begin{array}{c}- \\
\text { Yadaraju and } \\
\text { Hosmani (1979) } \\
\text { Carson (1988) } \\
\text { Carson and } \\
\text { Kunjo (1984) }\end{array}$ & $\begin{array}{l}\text { Post-emergence treatments } \\
\text { alone and in conjunction } \\
\text { with } 2,4-\mathrm{D} \text { and/or } \\
\text { glyphosate. }\end{array}$ \\
\hline Thidiazuron & & $\begin{array}{c}+ \\
\text { Babiker et al. } \\
(1991)\end{array}$ & $\begin{array}{l}\text { Babiker et al. } \\
\text { (1991) }\end{array}$ & & & In vitro experiments only \\
\hline Triclopyr & & & & $\begin{array}{l}\text { - } \\
\text { Singh et al. } \\
\text { (1991) }\end{array}$ & & $\begin{array}{l}\text { Pot experiments that } \\
\text { included } \mathrm{N} \text { and } \mathrm{P}_{2} \mathrm{O}_{5} \\
\text { applications. }\end{array}$ \\
\hline
\end{tabular}




\section{Chapter 3: Methodology}

\section{Section 3.1 Introduction}

Chapter 3 is divided into six sections, including the introduction. The second section is the development of the biological component of the dynamic programming model. Section 3.3 is the development of the economic component of the model. Section 3.4 shows how the model can be used to estimate the value of Striga eradication. Section 3.5 illustrates how changes in the model's parameters can identify relevant barriers to the adoption of the optimal set of Striga control practices. The final section provides some concluding remarks regarding the methodology.

\section{Section 3.2 Modeling Striga Population Dynamics}

The model of Striga population dynamics developed below is based on the Kunisch, Smith, Holt, and Webb (SH\&W), and Smith and Webb (S\&W) models discussed in Chapter 2. The state variable is the number of viable Striga seeds in the ground, and the evolution of the state variable is governed by a series of transition probabilities. There are, however, several important distinctions between the model developed below and those that have preceded, each of which is discussed at the appropriate juncture in the model development.

To begin, the model assumes that, within a given field, seeds are evenly distributed in the soil. Each seed has an equal probability of being stimulated by host root exudate or synthetic stimulants. The most general form of the model is:

$$
\mathrm{X}_{\mathrm{t}+1}=\left(\mathrm{X}_{\mathrm{t}}-\mathrm{G}_{\mathrm{t}}\right) *\left(1-\mathrm{MR}_{\mathrm{OLD}, \mathrm{t}}\right)+\mathrm{NEW}_{\mathrm{t}} *\left(1-\mathrm{MR}_{\mathrm{NEW}, \mathrm{t}}\right)
$$

Where: $X_{t}=$ number of viable seeds in the soil at the beginning of season $\mathrm{t}$ (state variable)

$\mathrm{G}_{\mathrm{t}}=$ number of seeds that germinate at the beginning of season $\mathrm{t}$ 


$$
\begin{aligned}
& \mathrm{NEW}_{\mathrm{t}}=\text { number of new seeds introduced into the field at the end of } \\
& \text { season } \mathrm{t} \\
& \mathrm{MR}_{\mathrm{OLD}, \mathrm{t}}=\text { probability a seed that did not germinate during season } \mathrm{t} \text { dies } \\
& \text { before the beginning of season } \mathrm{t}+1 \text { (the mortality rate of old seeds) } \\
& \mathrm{MR}_{\mathrm{NEW}, \mathrm{t}}=\text { probability a new seed introduced to the field at the end of } \\
& \text { season t dies before the beginning of season } \mathrm{t}+1 \text { (the mortality } \\
& \text { rate of new seeds) }
\end{aligned}
$$

Equation (3.1) reveals the first unique feature of this model: reducing the bank of viable seeds by the number of seeds that germinate as opposed to the number of seeds that are "stimulated." The Kunisch, SH\&W, and S\&W models all begin with a bank of viable seeds in the soil, a proportion of which are stimulated. A proportion of the stimulated seeds then germinate. The viable seeds that were stimulated but did not germinate are no longer viable in those models. In other words, no viable Striga seed exposed to a stimulant this season can carry over into next season, regardless of whether or not it germinates this season. In reality, however, viable seeds do not lose their viability due simply to exposure to a germination stimulant.

A Striga seed may be in any of three states in the soil: (1) viable and active (that is, properly preconditioned); (2) viable and dormant; or (3) not viable. Viable and active seeds germinate when exposed to the proper stimulant. Dormant seeds do not germinate when "stimulated" but may be viable in the future given proper preconditioning (Reid and Parker, 1979; Vallance, 1950). By not allowing stimulated seeds that do not germinate (dormant seeds) to carry over into the next season as viable seeds, the seedbank in these models is declining faster than it should. Equation 3.1 accounts for seed dormancy by reducing the seedbank by the number of seeds that germinate rather than the number that are stimulated.

The number of seeds that germinate is equal to the number of viable seeds in the soil times the probability a seed will be exposed to a germination stimulant $\left(\mathrm{P}_{\mathrm{S}}\right)$ times the probability the seed is active $\left(\mathrm{P}_{\mathrm{G}}\right)$. Control measures exist that affect both the probability 
of stimulation and the probability of germination. Therefore, $\mathrm{G}_{\mathrm{t}}$ is a function of control measures employed in season $\mathrm{t}: \mathrm{G}_{\mathrm{t}}=\mathrm{X}_{\mathrm{t}} * \mathrm{P}_{\mathrm{S}}\left(\right.$ Control $\left._{\mathrm{t}}\right) * \mathrm{P}_{\mathrm{G}}\left(\right.$ Control $\left._{\mathrm{t}}\right)$, where Control $\mathrm{l}_{\mathrm{t}}$ is the vector of control practices employed during season t. Viable seeds that do not germinate during season $t$ are subject to a mortality rate $\left(\mathrm{MR}_{\mathrm{OLD}, \mathrm{t}}\right)$ that reflects the probability that the seed will die before the beginning of season $t+1$.

Embedded in Equation 3.1 is the second unique feature of this model: the seed externality. Striga seeds are mobile not only within fields, but also between fields. Vectors of Striga seed migration include wind, soil and water runoff, adherence to farm equipment, the movement of contaminated crop commodities, and the digestive tracts of animals such as cows, pigs and horses (Sand and Manley, 1990). Seeds consumed by wild birds and chickens are, however, unlikely to be viable when excreted (Eplee, 1966; Eplee et al., 1973).

In Equation 3.1, the number of new seeds introduced into the field $\left(\mathrm{NEW}_{\mathrm{t}}\right)$ is comprised of three elements: (1) the number of seeds produced by one's own plants in season that remain in the field (New STAY, $\left._{t}\right)$; (2) the number of seeds produced by one's own plants in season $t$ that migrate out of the field (New $\mathrm{NUT}_{\mathrm{t}}$ ); and (3) the number of seeds produced by

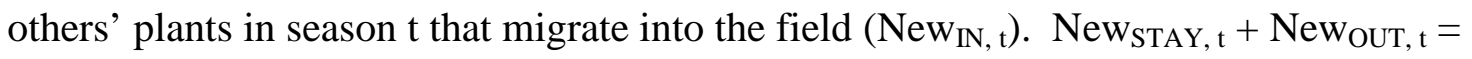
New $_{\text {Own, t }}$. New ${ }_{\text {IN, } t}$ is an exogenous variable, dependent on the level of Striga infestation in and control practices employed on the fields of one's neighbors. New Own, $t_{\mathrm{t}}$ is determined endogenously, and New OUT, $_{\mathrm{t}}$ is assumed to be a fixed proportion of New Own, $t$.

By not accounting for the seed externality, the Kunisch, SH\&W and S\&W models reflect the Striga population dynamics of a field in isolation. Some have argued, however, that increased population pressure is primarily responsible for the increase in Striga infestations throughout the Sahel (Ayensu et al., 1984; Ogborn, 1987). In other words, the seed externality is becoming increasingly relevant. 
New $_{\text {OwN, t }}$, the total number of viable seeds produced by one's own Striga plants, is equal to the number of Striga plants in one's field that set seed $\left(\right.$ Setter $\left._{t}\right)$ times the average number of viable seeds set per plant $\left(\operatorname{Seeds}_{\mathrm{t}}\right)$. Not all stimulated seeds $\left(\mathrm{S}_{\mathrm{t}}\right)$ survive to set new seed. A stimulated seed must germinate, attach to a host root, emerge from the soil, and develop to reproductive capacity to set new seeds. The number of setters is equal to the number of stimulated seeds times the probability of germination $\left(\mathrm{P}_{\mathrm{G}}\right)$, the probability of attachment $\left(\mathrm{P}_{\mathrm{A}}\right)$, the probability of emergence $\left(\mathrm{P}_{\mathrm{E}}\right)$, and the probability of development to reproductive capacity $\left(\mathrm{P}_{\mathrm{SET}}\right)$. Each of these probabilities may be affected by Striga control measures as shown in Equation 3.2.

$$
\begin{gathered}
\text { Setter }_{\mathrm{t}}=\mathrm{X}_{\mathrm{t}} * \mathrm{P}_{\mathrm{s}}\left(\text { Control }_{\mathrm{t}}\right) * \mathrm{P}_{\mathrm{G}}\left(\text { Control }_{\mathrm{t}}\right) * \mathrm{P}_{\mathrm{A}}\left(\text { Control }_{\mathrm{t}}\right) \\
* \mathrm{P}_{\mathrm{E}}\left(\text { Control }_{\mathrm{t}}\right) * \mathrm{P}_{\mathrm{SET}}\left(\text { Control }_{\mathrm{t}}\right)
\end{gathered}
$$

Average seed production per plant may also be affected by control measures - SH\&W and $\mathrm{S} \& \mathrm{~W}$ both model seed production as a function of the presence (and appetite) of the biological control agent Sm. umbrinus. Furthermore, seed production may be inversely related to Striga density per host, with an asymptotic maximum number of seeds per plant. As discussed in Chapter 2, Kunisch, et al. and SH\&W assume seed production is an inverse function of Striga density, although SH\&W also model seed production as a constant. In 1996, however, Webb and Smith attempted to estimate the relationship between Striga density and seed production. They found no evidence of a correlation between the two variables. In light of this, seed production per Striga plant is assumed to be a function of control measures, but not Striga density.

$$
\text { Seed }=\text { Seed }\left(\text { Control }_{\mathrm{t}}\right)
$$

Farmers not only have opportunities to prevent/reduce the introduction of new Striga seeds, they also have opportunities to affect the ability of seeds to survive between seasons ( $\mathrm{MR}_{\mathrm{OLD}}$ and $\left.\mathrm{MR}_{\mathrm{NEW}}\right)$. Equation 3.4 illustrates the biological parameters farmers may affect through their choice of Striga control practices. 


$$
\begin{aligned}
& \mathrm{X}_{\mathrm{t}+1}=\left(\mathrm{X}_{\mathrm{t}}-\mathrm{G}_{\mathrm{t}}\right) *\left(1-\mathrm{MR}_{\mathrm{OLD}, \mathrm{t}}\right)+\left(\mathrm{New}_{\mathrm{OWN}, \mathrm{t}}-\mathrm{New}_{\mathrm{OUT}, \mathrm{t}}+\mathrm{New}_{\mathrm{IN}, \mathrm{t}}\right) \\
& \text { * }\left(1-\mathrm{MR}_{\mathrm{NEW}, \mathrm{t}}\right) \\
& =\mathrm{X}_{\mathrm{t}} *\left(1-\mathrm{P}_{\mathrm{S}}\left(\text { Control }_{\mathrm{t}}\right) * \mathrm{P}_{\mathrm{G}}\left(\text { Control }_{\mathrm{t}}\right)\right) *\left(1-\mathrm{MR}_{\mathrm{OLD}, \mathrm{t}}\left(\text { Control }_{\mathrm{t}}\right)\right) \\
& +\left[\mathrm{X}_{\mathrm{t}} * \mathrm{P}_{\mathrm{S}}\left(\text { Control }_{\mathrm{t}}\right) * \mathrm{P}_{\mathrm{G}}\left(\text { Control }_{\mathrm{t}}\right) * \mathrm{P}_{\mathrm{A}}\left(\text { Control }_{\mathrm{t}}\right) * \mathrm{P}_{\mathrm{E}}\left(\text { Control }_{\mathrm{t}}\right)\right. \\
& \text { * } \left.\mathrm{P}_{\mathrm{SET}}\left(\text { Control }_{\mathrm{t}}\right) * \operatorname{Seed}_{\mathrm{t}}\left(\text { Control }_{\mathrm{t}}\right)-\mathrm{New}_{\mathrm{OUT}, \mathrm{t}}+\mathrm{New}_{\mathrm{IN}, \mathrm{t}}\right] \\
& \text { * }\left(1-\mathrm{MR}_{\mathrm{NEW}, \mathrm{t}}\left(\text { Control }_{\mathrm{t}}\right)\right)
\end{aligned}
$$

While Kunisch et al. mention that fixed parameters in their model may be adjusted to reflect the influence of Striga control measures, the only control measure that is incorporated directly into the model is host plant density. Likewise, SH\&W and S\&W model only one control measure - the influence of the biological agent Sm. umbrinus. In contrast, the effects of all potential Striga control practices on the model's transition probabilities are incorporated into the model developed for this study.

\section{Section 3.3 The Economic Component}

The objective of the economic model is constrained profit maximization. Prices, discount rate, and time horizon are exogenously determined, as is the initial level of Striga infestation. The profit maximizing set of practices and the final level of Striga infestation are determined endogenously. Relevant constraints are added to apply the model.

$$
\begin{aligned}
& \max _{\text {controlt }} \sum_{t=1}^{n} \sum_{i} B^{t-1}\left\{\mathrm{P}_{\mathrm{i}, \mathrm{t}} * \mathrm{Y}_{\mathrm{i}, \mathrm{t}}\left(\mathrm{X}_{\mathrm{t}}, \text { Controli, } \mathrm{t}\right)-\text { Cost }_{\mathrm{i}, \mathrm{t}}\left(\text { Controli, }_{\mathrm{t}}\right)\right\} \\
& \text { Subject to: } \quad \mathrm{X}_{\mathrm{t}+1}=f\left(\mathrm{X}_{\mathrm{t}}, \mathrm{Control}_{\mathrm{t}}, \mathrm{New}_{\mathrm{IN}, \mathrm{t}}, \mathrm{MR}_{\mathrm{OLD}, \mathrm{t}}, \mathrm{MR}_{\mathrm{NEW}, \mathrm{t}}\right) \text { as } \\
& \text { described above } \\
& Y_{i, t} \geq \text { Minimum Family Cereal Requirements } \\
& \bullet_{\mathrm{i}} \text { Cost }_{\mathrm{i}, \mathrm{t}} \leq \text { Budget Constraint } \\
& \mathrm{X}_{1}=\mathrm{X}_{1}{ }^{*} \text {, given }
\end{aligned}
$$

Where: $\beta=$ the discount rate 
$\mathrm{P}_{\mathrm{i}, \mathrm{t}}=$ unit price of commodity $\mathrm{i}$ at time $\mathrm{t}$

$\mathrm{Y}_{\mathrm{i}, \mathrm{t}}=$ harvested yield of commodity $\mathrm{i}$ at time $\mathrm{t}$, a function of

Striga control and the number of emerged Striga plants.

Cost $_{\mathrm{i}, \mathrm{t}}=$ cost of producing commodity $\mathrm{i}$ at time $\mathrm{t}$

Control $_{\mathrm{i}, \mathrm{t}}=$ Striga control measures employed in the production of commodity $i$ at time $\mathrm{t}$

$\mathrm{n}=$ number of years in the farmer's planning horizon

All other variables are as described in the preceding section.

\section{Section 3.4 Estimating the Value of Striga Eradication}

Estimating the value of Striga eradication requires information regarding conventional, or status quo, production practices, and an estimate of the average density of the Striga seedbank in the study area. Given this information, the model can be run under three scenarios.

$\underline{\text { Scenario I. }}$. The first scenario establishes the baseline by estimating the expected value of net returns to status quo production $\left(\Pi_{\mathrm{SQ}}\right.$, Striga $)$ with an initial seedbank density, $\mathrm{X}^{*}{ }_{1}$, equal to the average found in the study area. Using expected yields from status quo production, a nutritional baseline can also be established, either in absolute or relative terms. An absolute nutritional baseline would transform yields into volumes of nutrients. For example, a yield of $100 \mathrm{~kg}$ of millet could be expressed as $3.63 \mathrm{M}$ Kcals of energy, $110 \mathrm{~g}$ of iron, 118,000 $\mathrm{g}$ of protein, etc. (Food and Agriculture Organization of the United Nations, 1995). A relative nutritional baseline would transform yields into nutrients and then express that as a percentage of a household's yearly requirement. For example, a $100 \mathrm{~kg}$ yield of millet could be expressed as $50 \%$ of the annual energy needs of a household requiring 7.26 M Kcals of energy per year.

$\underline{\text { Scenario II }}$. The second scenario sets the seedbank density equal to zero and estimates expected net returns and yields under status quo production. The difference between expected net returns here and those in Scenario I provides an estimate of the value of 
Striga eradication when status quo production persists $\left(\Pi_{\mathrm{SQ}, \text { NO Striga }}\right)$. Absolute and relative nutritional gains from Striga eradication could also be estimated by comparing Scenarios I and II. Equation 3.6 represents the hypothesis that there are gains to be made from Striga eradication. ${ }^{21}$

$$
\begin{array}{ll}
\mathrm{H}_{0}: & \Pi_{\mathrm{SQ}, \text { NO Striga }}=\Pi_{\mathrm{SQ}, \text { Striga }} \\
\mathrm{H}_{1}: & \Pi_{\mathrm{SQ}, \text { NO Striga }}>\Pi_{\mathrm{SQ}, \text { Striga }}
\end{array}
$$

The persistence of status quo production in the absence of Striga would imply either that Striga infestation does not influence farmers' production decisions, or that status quo production is "optimal" in the absence of Striga. While either of these may be the case, the model can help answer the following questions: "Should Striga infestation influence farmers' production decisions?" and "Is status quo production optimal in the absence of Striga?" The third scenario focuses on the latter of these two questions.

Scenario III. In the third scenario, seedbank density is set to zero and the model is permitted to choose the set of practices that maximize the expected returns to production (П $\Pi_{\mathrm{OPT}, \text { NO Striga }}$ ). Two hypotheses, represented by Equations 3.7 and 3.8, are associated with this scenario. ${ }^{22,23}$

$$
\begin{array}{ll}
\mathrm{H}_{0}: & \Pi_{\mathrm{OPT}, \text { NO Striga }}=\Pi_{\mathrm{SQ}, \text { Striga }} \\
\mathrm{H}_{1}: & \Pi_{\mathrm{OPT}, \text { NO Striga }}>\Pi_{\mathrm{SQ}, \text { Striga }} \\
\mathrm{H}_{0}: & \Pi_{\mathrm{OPT}, \text { NO Striga }}=\Pi_{\mathrm{SQ}, \text { NO Striga }} \\
\mathrm{H}_{1}: & \Pi_{\mathrm{OPT}, \text { NO Striga }}>\Pi_{\mathrm{SQ}, \text { NO Striga }}
\end{array}
$$

\footnotetext{
${ }^{21} \Pi_{\mathrm{SQ} \text {, NO Striga }}<\Pi_{\mathrm{SQ} \text {, Striga }}$, implying Striga is beneficial, is mathematically impossible within the context of the model and highly unlikely in reality.

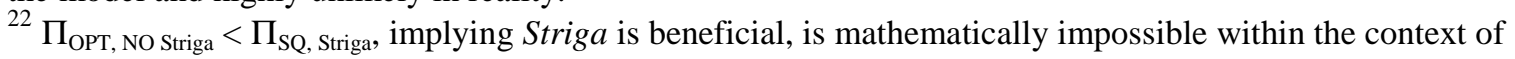
the model and highly unlikely in reality.

${ }^{23}$ Status quo production may either be optimal, in which case $\mathrm{H}_{0}$ holds, or sub-optimal, in which case $\mathrm{H}_{1}$ holds.
} 
The null hypothesis of Equation 3.7 states that expected net returns from the optimal set of practices in the absence of Striga are equal to expected net returns to status quo production in the presence of average Striga infestation. If the null hypothesis of Equation 3.7 is rejected, the difference between $\Pi_{\mathrm{OPT} \text {, NO Striga }}$ and $\Pi_{\mathrm{SQ} \text {, Striga }}$ represents an estimate of the benefits, in monetary terms, of Striga eradication when producers optimize in accordance with the objective function of the model. In other words, the difference estimates the value of realizing two potential Striga-related policy objectives: (1) Striga eradication; and (2) adoption of the optimal set of practices in the absence of Striga. The benefits may also be expressed in absolute and relative nutritional terms.

The alternative hypothesis of Equation 3.8 states that expected returns in the absence of Striga under the optimal set of practices are greater than they are under status quo production. In other words, status quo production would not be optimal if Striga were eradicated. The difference between Scenarios II and III isolates the potential benefits of extension efforts promoting the optimal set of practices in the absence of Striga. As before, these benefits may also be expressed in absolute or relative nutritional terms.

\section{Section 3.5 Identifying Barriers to Adoption}

In this section, a process for identifying the barriers to adoption of the optimal set of practices is developed. The first step in the process is to determine if status quo production is optimal within the context of the model. This requires specification of the seed externality.

Given an initial seedbank $\left(\mathrm{X}_{1}\right)$ that is evenly distributed across fields, identical resources, and an exogenous $\mathrm{New}_{\mathrm{IN}, \mathrm{t}}$ that is the same for all producers, all profit maximizers will employ the same controls at the same level. Therefore, Newout, $t$ will be the same for all producers, and New OUT, $\mathrm{t}^{-} \mathrm{New}_{\mathrm{IN}, \mathrm{t}} \geq 0 .{ }^{24}$ The minimum returns to the optimal set of practices occur when New $\mathrm{OUT}, \mathrm{t}-\mathrm{New}_{\mathrm{IN}, \mathrm{t}}=0 .{ }^{25}$ This shall be referred to as a "perfectly

\footnotetext{
${ }^{24}$ Producers either exchange all of their seeds, in which case New $\mathrm{OUT}_{\mathrm{t}, \mathrm{t}}=\mathrm{New}_{\mathrm{IN}, \mathrm{t}}$, or they exchange some proportion of their seeds and the rest are distributed on uncultivated land, in which case $\mathrm{New}_{\text {OUT, }}>\mathrm{New}_{\mathrm{IN}}$, t. This assumes that no producer receives a disproportionate amount of the total number of migrating seeds.

${ }^{25}$ Returns are decreasing in $\mathrm{New}_{\mathrm{IN}, \mathrm{t}}$.
} 
symmetric" seed externality, which, from the producer's perspective, is identical to a situation in which seeds do not migrate.

If all producers do not adopt the same practices, the sign of New $\mathrm{NUT}_{\mathrm{t}}-\mathrm{New}_{\mathrm{IN}, \mathrm{t}}$ can not be determined for all producers, ex ante. Producers for whom New OuT, $\mathrm{t}-\mathrm{New}_{\text {IN, } \mathrm{t}}<0$ are realizing a negative seed externality. Depending on the disparity between the expected benefits of the optimal set of practices under a perfectly symmetric seed externality and the expected benefits under an asymmetric externality, a community may realize a Pareto improvement by ensuring that all producers adopt the optimal set of practices. ${ }^{26}$

Before examining potential Pareto improvements from adoption of the optimal set of practices, we must first determine whether or not status quo production is optimal in the presence of average Striga infestation. Scenarios IV and V are designed for this purpose.

$\underline{\text { Scenario } I V}$. Scenario IV sets the initial seedbank density to the average infestation level and allows the model to choose the optimal set of practices under a perfectly symmetric seed externality. Expected net returns ( $\left.\Pi_{\mathrm{OPT}, \mathrm{SYM}}\right)$ are estimated and compared to $\Pi_{\mathrm{SQ}}$, Striga from Scenario I. The difference between $\Pi_{\mathrm{OPT}, \mathrm{SYM}}$ and $\Pi_{\mathrm{SQ}}$, Striga provides an estimate of the value of extension efforts to ensure all producers adopt the optimal set of practices, given average Striga infestation. Equation 3.9 represents the null and alternative hypotheses associated with comparing Scenarios I and IV.

$$
\begin{array}{ll}
\mathrm{H}_{0}: & \Pi_{\mathrm{OPT}, \mathrm{SYM}}=\Pi_{\mathrm{SQ}, \text { Striga }} \\
\mathrm{H}_{1}: & \Pi_{\mathrm{OPT}, \mathrm{SYM}}>\Pi_{\mathrm{SQ}, \text { Striga }}
\end{array}
$$

If the null hypothesis in Equation 3.9 is rejected, it suggests producers can do better than they are presently if everyone were to adopt the optimal set of practices. The question then becomes, "Why haven't all producers adopted the practices associated with $\Pi_{\mathrm{OPT}}$, sYM?" Assuming the model's objective function is properly specified, there are a number

\footnotetext{
${ }^{26}$ A policy or action results in a Pareto improvement when no party is made worse off by the policy or action, and at least one party is made better off (Pearce and Turner, 1990).
} 
of possible explanations ${ }^{27}$ : (1) production constraints may preclude adoption of the optimal set of practices; (2) the discount rate may be poorly specified; (3) the mechanics of the model may be poorly specified; (4) any of the three information-oriented barriers to adoption may be in effect; or (5) the seed externality may prevent any one producer from adopting without an assurance that the other producers will also adopt. The model's parameters may be adjusted to examine the relevance of each potential barrier to adoption.

Producer surveys should be conducted prior to specifying the model to determine the levels at which to set the production constraints. Given the accuracy of the production constraints, they can be ruled out as a barrier to adoption of the optimal set of practices. Nonetheless, sensitivity analysis may be conducted to determine how the production constraints affect the optimal set of practices chosen by the model. The discount rate may also be adjusted to determine its influence on the optimal set of practices.

Having eliminated the production constraints as barriers to adoption and determined the influence of the discount rate on the optimal set of practices, Scenario V specifies an asymmetric seed externality to examine the relevance of the information-oriented barriers and the externality in preventing adoption of the optimal set of practices.

$\underline{\text { Scenario } V}$. In this scenario, the model is asked to choose the optimal set of practices assuming all other producers are operating under status quo production. This assumption sets $\mathrm{New}_{\mathrm{IN}, \mathrm{t}}$ equal to the number of new seeds migrating out of a field operating under status quo production (New ${ }_{\text {OUT, }} \mathrm{t}$ from Scenario I). Given $\mathrm{New}_{\mathrm{IN}, \mathrm{t}}$, the model chooses the optimal set of practices that maximize expected net returns (П

Comparing the results from Scenario V with Scenarios I and IV, there are six possible states which may occur. Table 3.1 presents for each possible state the Nash Equilibrium

\footnotetext{
${ }^{27}$ The model's objective function may be validated by conducting producer surveys. If the survey results indicate the objective function is mis-specified, the model should be redesigned and run again. Another approach would be to run the model under all alternative objective functions, and compare the results from each to status quo production.
} 
production decision of each producer, and the implied barriers preventing adoption of the Nash Equilibrium given all producers begin at status quo production. ${ }^{28}$

In State 1, status quo production generates the same benefits as the optimal set of practices with either a symmetric or asymmetric externality. Therefore, status quo production is optimal. By definition, there are no barriers to its adoption.

In State 2, each producer benefits from adopting the optimal set of practices if and only if the other producers do not adopt them as well. Anticipating that all producers will adopt, thereby eliminating the benefits of adoption, no producer will adopt. ${ }^{29}$ Status quo production, therefore, is the Nash Equilibrium outcome and there are no barriers to adoption.

In State 3, every producer has an incentive to adopt the optimal set of practices regardless of what the other producers do. As a result, the Nash Equilibrium outcome is the set of practices associated with $\Pi_{\mathrm{OPT} \text {, SYM }}$, and all producers adopt. ${ }^{30}$ If we are in State 3 , why do we observe status quo production rather than the practices associated with $\Pi_{\text {OPT, SYM? }}$ The seed externality is not preventing producers from adopting - they derive even greater benefits with an asymmetric than with a symmetric seed externality. The only explanation, therefore, is that producers lack adequate information regarding the existence of, expected returns to, or implementation of the optimal set of practices.

\footnotetext{
28 "A Nash Equilibrium is a vector of strategies, one for each player [UP], with the property that no player [UP] can increase his/her own payoff [net returns] through a unilateral deviation from the equilibrium strategy" (Davis and Holt, 1993, p. 105).

${ }^{29}$ This assumes there is some disutility associated with abandoning status quo production. If there is no disutility, the Nash Equilibrium would be the set of practices associated with $\Pi_{\mathrm{OPT}, \mathrm{SYM}}$, and information would be a barrier to adoption. The value of this information would, however, be zero.

${ }^{30}$ This assumes the benefits from adopting the optimal set of practices are sufficient to compensate for any disutility associated with abandoning status quo production.
} 
Table 3.1: Possible States when Comparing Scenarios I, IV, and V, Nash Equilibrium Production Associated with each State, and Barriers Preventing Adoption of Nash Equilibrium Production

\begin{tabular}{|l|l|l|l|}
\hline State & & $\begin{array}{l}\text { Nash } \\
\text { Equilibrium }\end{array}$ & $\begin{array}{l}\text { Barrier(s) to } \\
\text { Adoption }\end{array}$ \\
\hline 1 & $\Pi_{\mathrm{OPT}, \mathrm{ASYM}}=\Pi_{\mathrm{OPT}, \mathrm{SYM}}=\Pi_{\mathrm{SQ} \text {, Striga }}$ & $\Pi_{\mathrm{SQ} \text {, Striga }}$ & None \\
\hline 2 & $\Pi_{\mathrm{OPT}, \mathrm{ASYM}}>\Pi_{\mathrm{OPT}, \mathrm{SYM}}=\Pi_{\mathrm{SQ}, \text { Striga }}$ & $\Pi_{\mathrm{SQ}, \text { Striga }}$ & None \\
\hline 3 & $\Pi_{\mathrm{OPT}, \mathrm{ASYM}}>\Pi_{\mathrm{OPT}, \mathrm{SYM}}>\Pi_{\mathrm{SQ}, \text { Striga }}$ & $\Pi_{\mathrm{OPT}, \mathrm{SYM}}$ & Information \\
\hline 4 & $\Pi_{\mathrm{OPT}, \mathrm{ASYM}}=\Pi_{\mathrm{OPT}, \mathrm{SYM}}>\Pi_{\mathrm{SQ}, \text { Striga }}$ & $\Pi_{\mathrm{OPT}, \mathrm{SYM}}$ & Information \\
\hline 5 & $\Pi_{\mathrm{OPT}, \mathrm{SYM}}>\Pi_{\mathrm{OPT}, \mathrm{ASYM}}=\Pi_{\mathrm{SQ}, \text { Striga }}$ & $\Pi_{\mathrm{OPT}, \mathrm{SYM}}$ & Seed Externality \\
\hline 6 & $\Pi_{\mathrm{OPT}, \mathrm{SYM}}>\Pi_{\mathrm{OPT}, \mathrm{ASYM}}>\Pi_{\mathrm{SQ}, \text { Striga }}$ & $\Pi_{\mathrm{OPT}, \mathrm{SYM}}$ & Information \\
\hline
\end{tabular}


State 4 is identical to State 3, although here there is no additional benefit from being the first producer to adopt. Each producer is better off adopting the optimal set of practices than operating under the status quo, irrespective of what the other producers do. The seed externality is irrelevant to the producers' adoption decision; therefore, the information-oriented barriers must be preventing adoption of the optimal set of practices.

In State 5, no producer wants to adopt the optimal set of practices unless all of the other producers also adopt them. ${ }^{31}$ The producers' reticence is due to the asymmetric seed externality. A coordination effort would be required to ensure all producers adopt the optimal set of practices.

State 6 is similar to States 3 and 4, but here each producer has more to gain when everyone adopts the optimal set of practices than when they adopt alone. Again, the externality is irrelevant to the adoption decision. ${ }^{32}$ Imperfect information regarding the optimal set of practices is the only remaining explanation for the persistence of status quo production in State 6.

The difference between $\Pi_{\mathrm{OPT}}$, SYM and $\Pi_{\mathrm{SQ}}$, Striga, in each state, represents an estimate of the value of overcoming the barrier to adoption associated with that state. If this difference is greater than the costs of overcoming the barrier, a Pareto improvement is possible. Each state may also be evaluated in either absolute or relative nutritional terms.

\section{Section 3.6 Concluding Remarks on the Methodology}

In this chapter a new model of Striga population dynamics has been developed. The model improves on its predecessors, the Kunisch, SH\&W, and S\&W models, in three important ways: (1) by accounting for seed dormancy; (2) by modeling seed migration and its potential repercussions; and (3) by incorporating all potential Striga control practices into the model. Including these aspects results in both a more accurate

\footnotetext{
${ }^{31}$ This assumes there is some disutitlity associated with abandoning status quo production. If there is not, $\Pi_{\mathrm{OPT} \text {, sYM }}$ is the Nash Equilibrium and information is the barrier to adoption.
} 
depiction of Striga population dynamics, and a model that is more easily adapted to new production environments.

A methodology has also been developed to estimate the benefits of Striga eradication, as well as the value of information regarding optimal production practices with or without Striga. These benefits may be expressed in monetary or nutritional terms. Using five distinct production scenarios, the methodology is able to identify barriers to the adoption of optimal production practices, and the benefits of overcoming those barriers.

\footnotetext{
${ }^{32}$ This assumes that the benefits of adopting the optimal set of practices in the presence of an asymmetric externality are sufficient to compensate for any disutility associated with abandoning status quo production. If they are not, than State 6 is identical to State 5.
} 


\section{Chapter 4: The Economic Component}

\section{Section 4.1 Introduction}

The economic component of the model, including input and output prices, production constraints, and crop production functions, is specified in this chapter. A great deal of the data used come from the 1995 IPM-CRSP/Mali Socio-Economic Baseline Survey. In Section 4.2, the demographic composition of the representative production unit (UP) for each zone is derived. Section 4.3 defines the land constraint facing the representative production unit in each zone. Section 4.4 identifies the crop associations available for use in the model, and Section 4.5 constructs labor constraints for the UP's. In Section 4.6, the production functions for each crop association are derived. The cash and nutritional constraints faced by each UP are presented in Sections 4.7 and 4.8, respectively. The input and output prices used in the model, as well as the UP's rate of time preference are determined in section 4.9. Section 4.10 estimates the length of the UP's planning horizon, and the final section provides some concluding remarks regarding the strengths and weaknesses of the economic component.

\section{Section 4.2 Defining the Representative Agricultural Production Unit}

Agricultural production in both zones is undertaken by production units comprised of members of an extended family. There is considerable variation in UP size both between and within zones. In addition to the sheer size of the UP, the gender and age distribution of its members also dictate the UP's nutritional demands, available stock of labor, and, ultimately, its production possibilities.

Using data from the 1995 IPM-CRSP Socio-Economic Baseline Survey, this study recognizes five age classifications: (1) baby (0-2 years); (2) child (3-7 years); (3) teenager (7-14 years); (4) adult (14-60 years); and (5) old (greater than 60 years). Teenage and adult individuals are further designated by gender and as either "working" or "non-working," reflecting their participation in agricultural production. Babies, 
children, old men and old women are considered "non-working." 33 The result is twelve distinct age/gender/labor categories which are used to describe the representative UP for each zone.

Representative UP's for six different UP sizes (extra small (XS), small (S), medium (M), large (L), extra large (XL), and extra-extra large (XXL)) are constructed in each zone. Extra small UP's have 5 or fewer members. Small UP's are those with 6 to 11 members - not enough to have one of each age/gender/labor category. Medium UP's have 12 to 23 members, L UP's have 24 to 35, XL have 36 to 60, and XXL have greater than 60 members.

To construct the representative UP's, the production unit data from the IPM-CRSP SocioEconomic Baseline Survey are sorted and indexed by size (I) and zone (Z). A representative $\mathrm{UP}_{\mathrm{I}, \mathrm{Z}}$ is then constructed by averaging the number of individuals of each age/gender/labor category (rounding to the nearest integer) across all UP's of given I and Z. For example, there are six UP's in Sirakorola with five or fewer members. Table 4.1 lists the demographic composition of each of these extra small UP's, as well as the composition of the average UP and the resulting representative XS UP for Sirakorola. Table 4.2 presents the demographic composition of all 12 representative $\mathrm{UP}_{\mathrm{I}, \mathrm{Z} \cdot{ }^{34}}$

\footnotetext{
${ }^{33}$ Children, old men and old women likely contribute to agricultural labor indirectly by performing household duties, thereby allowing teens and adults to spend more time in the fields. Unfortunately, the available data set is not rich enough to identify these indirect effects.

${ }^{34}$ The number of UP's in each category are as follows: $\mathrm{XSM}=6, \mathrm{SM}=22, \mathrm{MM}=29, \mathrm{LM}=6, \mathrm{XLM}=4$, $\mathrm{XXLM}=2, \mathrm{XSS}=6, \mathrm{SS}=40, \mathrm{MS}=19, \mathrm{LS}=2$.
} 
Table 4.1: Distribution of Age/Gender/Labor Categories for Each $\mathrm{UP}_{\mathrm{XS}}$, Sirakorola, Average $\mathrm{UP}_{\mathrm{XS}}$, Sirakorola, and the Representative $\mathrm{UP}_{\mathrm{XS}}$, Sirakorola

\begin{tabular}{|c|c|c|c|c|c|c|c|c|c|c|c|c|c|}
\hline UP & Baby & Child & NWG & NWB & WG & WB & NWW & NWM & WW & WM & OW & $\mathrm{OM}$ & Total \\
\hline 1 & 0 & 0 & 0 & 0 & 0 & 0 & 0 & 0 & 0 & 1 & 0 & 1 & 2 \\
\hline 2 & 1 & 0 & 0 & 0 & 0 & 0 & 0 & 0 & 1 & 2 & 0 & 0 & 4 \\
\hline 3 & 0 & 0 & 0 & 0 & 1 & 0 & 0 & 0 & 0 & 3 & 1 & 0 & 5 \\
\hline 4 & 0 & 0 & 0 & 0 & 2 & 0 & 0 & 0 & 2 & 1 & 0 & 0 & 5 \\
\hline 5 & 0 & 0 & 0 & 0 & 1 & 0 & 0 & 0 & 2 & 2 & 0 & 0 & 5 \\
\hline 6 & 0 & 0 & 0 & 0 & 0 & 0 & 0 & 0 & 3 & 2 & 0 & 0 & 5 \\
\hline Average & 0.17 & 0 & 0 & 0 & 0.67 & 0 & 0 & 0 & 1.33 & 1.83 & 0.17 & 0.17 & 4.33 \\
\hline Representative & 0 & 0 & 0 & 0 & 1 & 0 & 0 & 0 & 1 & 2 & 0 & 0 & 4 \\
\hline
\end{tabular}

NWG: Non-Working Girlteen; NWB: Non-Working Boyteen; WG: Working Girlteen; WB: Working Boyteen; NWW: Non-Working Woman; NWM: Non-Working Man; OW: Old Woman; OM: Old Man 
Table 4.2: Demographic Composition of Each $\mathrm{UP}_{\mathrm{I}, \mathrm{Z}}$

\begin{tabular}{|c|c|c|c|c|c|c|c|c|c|c|c|c|c|}
\hline UP & Baby & Child & NWG & NWB & $\mathrm{WG}$ & WB & NWW & NWM & WW & WM & OW & $\mathrm{OM}$ & Total \\
\hline XS, Sirakorola & 0 & 0 & 0 & 0 & 1 & 0 & 0 & 0 & 1 & 2 & 0 & 0 & 4 \\
\hline XS, Mourdiah & 0 & 0 & 0 & 0 & 0 & 0 & 0 & 0 & 1 & 2 & 1 & 0 & 4 \\
\hline S, Sirakorola & 0 & 1 & 1 & 0 & 1 & 0 & 0 & 0 & 1 & 2 & 2 & 0 & 8 \\
\hline S, Mourdiah & 1 & 1 & 0 & 0 & 1 & 1 & 0 & 0 & 2 & 2 & 0 & 0 & 8 \\
\hline M, Sirakorola & 2 & 3 & 2 & 1 & 0 & 1 & 0 & 0 & 3 & 4 & 1 & 0 & 17 \\
\hline M, Mourdiah & 1 & 3 & 1 & 1 & 1 & 1 & 0 & 0 & 5 & 5 & 1 & 0 & 19 \\
\hline L, Sirakorola & 2 & 4 & 4 & 3 & 0 & 0 & 0 & 0 & 5 & 9 & 2 & 1 & 30 \\
\hline $\mathrm{L}$, Mourdiah & 1 & 5 & 1 & 2 & 2 & 2 & 0 & 0 & 7 & 6 & 1 & 0 & 27 \\
\hline XL, Sirakorola & NA & & & & & & & & & & & & \\
\hline XL, Mourdiah & 3 & 7 & 1 & 1 & 6 & 5 & 0 & 0 & 11 & 14 & 1 & 0 & 49 \\
\hline $\begin{array}{l}\text { XXL, } \\
\text { Sirakorola }\end{array}$ & NA & & & & & & & & & & & & \\
\hline $\begin{array}{l}\text { XXL, } \\
\text { Mourdiah }\end{array}$ & 4 & 6 & 2 & 2 & 7 & 9 & 0 & 0 & 23 & 23 & 4 & 3 & 83 \\
\hline
\end{tabular}

NWG: Non-Working Girlteen; NWB: Non-Working Boyteen; WG: Working Girlteen; WB: Working Boyteen; NWW: Non-Working Woman; NWM: Non-Working Man; OW: Old Woman; OM: Old Man 


\section{Section 4.3 Defining the Land Constraint}

Land is allocated to UP's by a village council comprised of the chief and village elders.

Within each UP, there are two types of plots: individual plots and communal plots. Table 4.3 shows the average, for each UP size, of total acreage available to the UP, acreage cultivated under communal production, and acreage cultivated as individual plots in both zones. Data are from the 1995 IPM-CRSP/Mali Socio-Economic Baseline Survey.

Within the UP, individual plots are distributed to adults who have autonomy regarding the crops grown and other production decisions undertaken on their individual plot(s). The communal plots - the bulk of the UP's acreage - is dedicated primarily to cereal production (see Section 4.4 and Table 4.4 below). The Head of the UP and other adult males within the UP make decisions regarding the crops grown and inputs used on the communal plots.

The model assumes that all UP land that is not cultivated as individual plots is available for communal production. The amount of land available for communal production may then be calculated by subtracting the amount of land under individual cultivation from the total amount of land available to the UP (see Table 4.3). Equation 4.1 represents the general form of the land constraint used in the model.

$$
\begin{aligned}
& \sum_{\mathrm{J}} \mathrm{HA}\left(\text { Crop }_{\mathrm{J}, \mathrm{I}, \mathrm{Z}}\right) \leq \mathrm{HA}\left(\text { Available }_{\mathrm{I}, \mathrm{Z}} \mathrm{z}\right) \forall \mathrm{I}, \mathrm{Z} \\
& \text { Where } \mathrm{HA}\left(\text { Crop }_{\mathrm{J}, \mathrm{I}, \mathrm{Z}}\right)=\text { number of communal hectares planted to crop J } \\
& \qquad \text { by UP of size I in zone } \mathrm{Z} \\
& \mathrm{HA}\left(\text { Available }_{\mathrm{I}, \mathrm{Z}}\right)=\text { Total number of hectares available to } \mathrm{UP}_{\mathrm{I}, \mathrm{Z}} \\
& \text { for communal production }
\end{aligned}
$$


Table 4.3 Hectares Available and Cultivated, Averaged over Plot Type, UP Size, and Zone

\begin{tabular}{|c|c|c|c|c|c|c|c|c|}
\hline \multirow{2}{*}{ UP Size } & \multicolumn{9}{|c|}{ Mourdiah } & \multicolumn{4}{c|}{ Sirakorola } \\
\cline { 2 - 10 } & Total & $\begin{array}{c}\text { Individual } \\
\text { Cultivated }\end{array}$ & $\begin{array}{c}\text { Communal } \\
\text { Cultivated }\end{array}$ & $\begin{array}{c}\text { Communal } \\
\text { Available }\end{array}$ & Total & $\begin{array}{c}\text { Individual } \\
\text { Cultivated }\end{array}$ & $\begin{array}{c}\text { Communal } \\
\text { Cultivated }\end{array}$ & $\begin{array}{c}\text { Communal } \\
\text { Available }\end{array}$ \\
\hline XS & 5.3 & 0.6 & 3.6 & 4.7 & 9 & 1 & 4.6 & 8 \\
\hline S & 7 & 0.6 & 4.8 & 6.4 & 12 & 1.7 & 5.6 & 10.3 \\
\hline M & 14.5 & 3.2 & 9.1 & 11.3 & 12.9 & 1.8 & 6.9 & 11.1 \\
\hline L & 11.9 & 3.1 & 6 & 8.8 & 62.5 & 5.6 & & 14.3 \\
\hline XL & 29.3 & 9 & 17.6 & 20.3 & NA & & & 56.9 \\
\hline XXL & 22.5 & 8.5 & 14 & 14 & NA & & & \\
\hline
\end{tabular}




\section{Section 4.4 Crops Associations Available in the Model}

The IPM-CRSP Socio-Economic Baseline Survey collected data on the acreage planted to different crops in each type of field: men's individual, women's individual, and communal. While information on all three field types was collected for Sirakorola, the data for Mourdiah does not include communal fields. Table 4.4 presents the survey results for communal fields in Sirakorola.

The data clearly show millet is the predominant cereal grown in the communal fields of Sirakorola $-100 \%$ of the survey respondents reported planting millet in their communal fields. While sorghum is grown in Sirakorola, more than four times as many communal hectares are planted to millet than to sorghum. In Mourdiah, the more arid growing conditions naturally favor millet over sorghum, and millet is the dominant cereal crop there as well (Dembele et al., 1997; Smith, Holt and Webb, 1993; Smith and Webb, 1996; Webb and Smith, 1996; Kremer and Lock, 1993).

As discussed in Chapter 3, the model's objective function is profit maximization to cereal production in the communal fields. While it would be preferable to include sorghum in the model's opportunity set of crops, the literature search for this study was unable to uncover sufficient data to develop a relevant production function for sorghum (see Section 4.5). Instead, three crop associations are considered in the model: (1) millet in a pure stand; (2) millet inter-cropped with cowpea variety "IT 89KD 245;" and (3) millet inter-cropped with groundnut.

\section{Section 4.5 Defining the Labor Constraint}

The labor constraint reflects the amount of labor available for use on communal fields. Three factors must be taken into account when deriving the labor constraint: (1) the number of active agricultural laborers in the UP; (2) the proportion of labor time each laborer spends on the production of communal fields; and (3) the relative productivity of each laborer. The demographic composition of each representative $\mathrm{UP}_{\mathrm{I}, \mathrm{Z}}$, as described in Table 4.2, is used to determine the number of active agricultural laborers of each age and gender category. 
Table 4.4: Hectares Planted and Percentage of Respondents Growing Crops on Communal Fields in Sirakorola

\begin{tabular}{|c|c|c|}
\hline Crop & Hectares & Percentage of Respondents \\
\hline Millet & 150 & 100 \\
\hline Sorghum & 33 & 57.5 \\
\hline Groundnut & 17 & 70 \\
\hline Cowpea & 3 & 12.5 \\
\hline Fonio & 3 & 15 \\
\hline Bambara Nut & 2 & 17.5 \\
\hline Watermelon & 2 & 2.5 \\
\hline Dah & 1 & 5 \\
\hline Maize & 1 & 10 \\
\hline Cotton & 1 & 2.5 \\
\hline
\end{tabular}


The land constraint and the distribution of land between communal and individual fields are used to determine the proportion of their total agricultural labor each laborer spends on the communal versus the individual fields. One difficulty in constructing the labor constraint is the lack of data regarding the distribution of individual land between male and female plots. This is particularly acute in Mourdiah, although it is also a problem for UP's of size XS and L in Sirakorola. To overcome the data gap, it is hypothesized that the individual land is equally divided between the men and women of the UP. This hypothesis is tested for the two $\mathrm{UP}_{\mathrm{I}, \mathrm{Z}}$ with sufficient data. Table A4.1 of the Appendix presents the statistical results of the hypothesis tests; in both cases the hypothesis of an equal distribution of individual land among men and women is supported by the data.

It is further assumed that the proportion of agricultural labor a man spends on the communal fields is equal to the ratio of communal land to individual land per working adult. For example, there are two men and one woman who equally divide the individual land of $\mathrm{UP}_{\mathrm{XS}}$, Sirakorola, each receiving 0.33 hectares. With 4.6 hectares of communal land under cultivation, the proportion of each man's agricultural labor spent in the communal fields is assumed to be $0.93=1-(0.33 / 4.6)$.

During the growing season, it is assumed that men could spend up to 6 person-days engaged in agricultural activities - one person-day being set aside for religious and/or social activities. Given these assumptions, for $\mathrm{UP}_{\mathrm{XS}}$, Sirakorola the men contribute up to 11.1 person-days of labor per week to the production of communal fields.

Women and working teens, on the other hand, are assumed to have other responsibilities beside agricultural production. To reflect the allocation of labor to household chores, women are assumed to provide up to 3 person-days of agricultural labor per week. To account for time spent in school and lower productivity of labor, working teens are also assumed to provide no more than 3 person-days of agricultural labor per week.

Women have their own individual fields, and are therefore assumed to divide their labor between individual and communal fields in the same manner as the men. Working teens, 
however, do not have their own fields. As a teen is likely to have a mother and father, each with individual land, a teen's time is assumed to be spent proportionately between three types of fields: men's individual fields, women's individual fields, and communal fields. For example, in $\mathrm{UP}_{\mathrm{XS}}$, Sirakorola, the one woman is assumed to provide 2.8 persondays of labor to the production of communal fields, while the working teen provides 2.6 person-days. Table 4.5 presents the number of person-days per week available to each $\mathrm{UP}_{\mathrm{I}, \mathrm{Z}}$, for communal production.

In addition to their labor endowment, UP's may hire extra labor during times of peak demand from a "casual" labor market (Kremer and Lock, 1993). ${ }^{35}$ Times of peak labor demand coincide with specific, seasonal activities such as field preparation and sowing, weeding, harvest, and post-harvest activities. Labor budgets for Mali often further distinguish between a "first" weeding, conducted during the last two weeks of July, and a "second" weeding conducted during the first two weeks of August (Kremer and Lock, 1993; Bade et al., 1997; Hughes et al. 1990). In fact, Kremer and Lock argue that it is the availability of labor for the first weeding, not the availability of land, that constrains cereal production.

To reflect both the potential for labor to constrain the amount of land cultivated and the need to perform each seasonal task to secure a yield, a series of labor/land constraints are constructed corresponding to each of the required seasonal tasks. The constraints account for the labor endowment of the UP, the UP's access to the casual labor market, the window of opportunity for performing the required task, and the productivity of labor in performing the task. The general form of the land/labor constraint is represented by Equation 4.2.

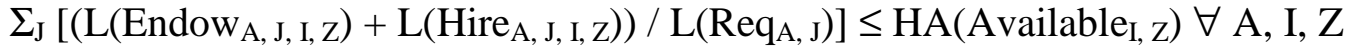
Where $A=\{$ Perparation and Sowing, First Weeding, Second Weeding, Harvest, Post-Harvest\} 
$\mathrm{J}=\{$ Millet, Millet-Cowpea, Millet-Groundnut $\}$

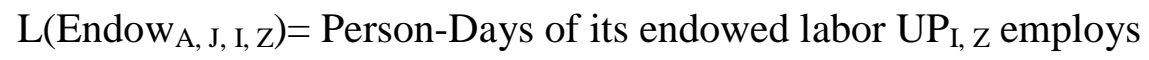
to perform task A on crop J

L $\left(\right.$ Hire $\left._{\mathrm{A}, \mathrm{J}, \mathrm{I}, \mathrm{Z}}\right)=$ Person-Days hired by $\mathrm{UP}_{\mathrm{I}, \mathrm{Z}}$ to perform task A on crop J $\mathrm{L}\left(\operatorname{Req}_{\mathrm{A}, \mathrm{J}}\right)=$ Person-Days required to perform task A per hectare of crop $\mathrm{J}$

$\mathrm{HA}\left(\right.$ Available $\left._{\mathrm{I}, \mathrm{z}}\right)=$ Hectares of communal land available to $\mathrm{UP}_{\mathrm{I}, \mathrm{Z}}$

The number of person-days available to $\mathrm{UP}_{\mathrm{I}, \mathrm{Z}}$ to perform task $\mathrm{A}$ is dependent on the duration of time within which task A must be performed. Based on Kremer and Lock (1993) each UP is assumed to have up to 10 days to prepare and sow a field, 14 days to perform the first weeding, 14 days to perform the second weeding, seven days to harvest, and seven days to perform post-harvest activities.

The number of person-days per hectare required to perform each task is estimated based on reports from Yeboah and Guthrie (1995) and Kremer and Lock (1993). Table 4.6 presents, for the three crop association in the model, estimates of the amount of time a UP has to perform each task and the number of person-days per hectare required to perform the task.

An auxiliary set of constraints must also be added to ensure the amount of endowed labor $\mathrm{UP}_{\mathrm{I}, \mathrm{Z}}$ employs to perform task A does not exceed the amount of endowed labor the UP has. These constraints are represented, generally, by Equation 4.3. The right hand side of Equation (4.3) may be calculated by dividing the weekly total labor endowment for $\mathrm{UP}_{\mathrm{I}, \mathrm{Z}}$, presented in Table 4.5, by seven and multiplying by the length of time during which task A must be performed, as presented in Table 4.6.

\footnotetext{
${ }^{35}$ It is important to note that none of the families selling labor in the casual market also hired labor (Kremer and Lock, 1993). Therefore, UP's in the model are permitted to hire labor but not to sell their labor endowment.
} 


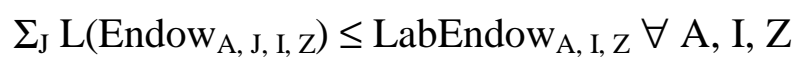

Where $\mathrm{L}\left(\right.$ Endow $\left._{\mathrm{A}}, \mathrm{J}, \mathrm{I}, \mathrm{Z}\right)$ is as defined above

$$
\text { LabEndow }_{\text {A, I, }} \text { = Person-Days of endowed labor to which UP } \mathrm{I}, \mathrm{Z}
$$

has access for the duration of task A

\section{Section 4.6 Crop Production Functions}

The specification of the production functions for each of the model's crop associations, millet in a pure stand, millet inter-cropped with cowpea, and millet intercropped with groundnut, is discussed below. In all three associations, the production of millet is modeled to reflect the effects of the crop-related Striga control practices (millet density and nitrogen application) and the number of emerged Striga parasites. Cowpea and groundnut yields are set to fixed values.

Millet in Pure Stand. In 1985, Cousens compared several functional forms for relating crop yields to weed and crop density. "It became clear at an early stage that there were very few published data of an appropriate form for such a study" (p. 514). To circumvent this problem, he conducted an experiment to generate the necessary data and found that a three parameter model of the form in Equation 4.4 provided an adequate description of the data. Published data for similar studies remains scarce.

$$
\begin{aligned}
& \mathrm{Y}=\mathrm{a} * \mathrm{C} /(1+\mathrm{b} * \mathrm{C}+\mathrm{f} * \mathrm{X}) \\
& \text { Where } \mathrm{Y}=\text { crop yield }(\mathrm{kg} / \mathrm{ha}) \\
& \mathrm{C}=\text { crop density }\left(\mathrm{plants} / \mathrm{m}^{2}\right) \\
& \mathrm{X}=\text { weed density }\left(\mathrm{plants} / \mathrm{m}^{2}\right) \\
& \mathrm{a}=\text { degree to which yield increases as a result of increased } \\
& \quad \text { crop density } \\
& \mathrm{b}=\text { degree to which yield decreases as a result of increased } \\
& \quad \text { crop density } \\
& \mathrm{f}=\text { effect of weed density on yield }
\end{aligned}
$$


Table 4.5: Person-Days of Communal Labor Endowed per Week by Age, Gender, and UP Size

\begin{tabular}{|c|c|c|c|c|c|c|c|c|}
\hline \multirow{2}{*}{ UP Size } & \multicolumn{4}{|c|}{ Mourdiah } & \multicolumn{4}{c|}{ Sirakorola } \\
\cline { 2 - 9 } & Teens & Men & Women & Total & Teens & Men & Women & Total \\
\hline XS & 0 & 11.3 & 2.8 & 14.1 & 2.6 & 11.1 & 2.8 & 16.5 \\
\hline S & 5.6 & 11.6 & 5.8 & 23 & 2.4 & 10.8 & 2.7 & 8.7 \\
\hline M & 5.6 & 28.9 & 14.5 & 49 & 2.8 & 23.1 & 5.9 & 14.6 \\
\hline L & 11 & 34.6 & 20.2 & 65.8 & 0 & 52.5 & & \\
\hline XL & 31.7 & 82.3 & 32.3 & 146.3 & NA & & & \\
\hline XXL & 46.7 & 136.2 & 68.1 & 251 & NA & & & \\
\hline
\end{tabular}


Table 4.6: Duration of Time (Days) Within Which Each Agricultural Task must be Performed, and Number of Person-Days per Hectare Required to Perform Each Task

\begin{tabular}{|c|c|c|c|c|c|c|}
\hline \multicolumn{2}{|l|}{ Crop } & \multirow{2}{*}{$\begin{array}{l}\text { Preparation / } \\
\text { Sowing } \\
10\end{array}$} & \multirow{2}{*}{$\begin{array}{l}\text { First Weeding } \\
14\end{array}$} & \multirow{2}{*}{$\begin{array}{l}\text { Second } \\
\text { Weeding }\end{array}$} & \multirow{2}{*}{$\begin{array}{l}\text { Harvest } \\
7\end{array}$} & \multirow{2}{*}{$\begin{array}{l}\text { Post-Harvest } \\
7\end{array}$} \\
\hline Millet & Time to Perform ${ }^{\mathrm{a}}$ & & & & & \\
\hline & Person-Days / ha ${ }^{\mathrm{a}}$ & 10 & 21 & 14 & 4 & 6 \\
\hline \multirow{2}{*}{$\begin{array}{l}\text { Millet- } \\
\text { Cowpea }\end{array}$} & Time to Perform ${ }^{\mathrm{a}}$ & 10 & 14 & 14 & 7 & 7 \\
\hline & Person-Days / ha ${ }^{\mathrm{b}}$ & 12.7 & 24.2 & 16.2 & 9.6 & 14.5 \\
\hline \multirow{2}{*}{$\begin{array}{l}\text { Millet- } \\
\text { Groundnut }\end{array}$} & Time to Perform ${ }^{\mathrm{a}}$ & 10 & 14 & 14 & 7 & 7 \\
\hline & Person Days / ha ${ }^{\mathrm{c}}$ & 16.5 & 38.4 & 25.6 & 29.3 & 44 \\
\hline
\end{tabular}

a: Kremer and Lock (1993).

b: Yeboah and Guthrie (1995). First weeding assumed to take $60 \%$ of total weeding, while second weeding requires $40 \%$ of total. Harvest assumed to take $40 \%$ of "harvesting" labor and post-harvest the other $60 \%$.

c: Yeboah and Guthrie (1995), using values from cowpea-peanut association as proxies. First weeding assumed to take $60 \%$ of total weeding, while second weeding requires $40 \%$ of total. Harvest assumed to take $40 \%$ of "harvesting" labor and post-harvest the other $60 \%$. 
Webb and Smith (1996) estimated the effect of millet and Striga densities on millet yields, using data from field experiments conducted in 1991 and 1992 in Mourdiah. Following Cousens (1985), they examined several functional forms. The form that best fit the Webb and Smith data, represented by Equation 4.5, is a slight modification of Equation 4.4. This equation explained approximately $43 \%$ of the variation in the data. Table A4.1 of the Appendix presents the parameter estimates generated by the data in each year.

$$
\begin{aligned}
\mathrm{Y}=\beta * \mathrm{C} & +\mathrm{A} /(1+\mathrm{S} * \mathrm{X}) \\
\text { Where } \mathrm{Y} & =\text { millet head weight }(\mathrm{kg}) \mathrm{m}^{-2} \\
\mathrm{C} & =\text { millet density } \mathrm{m}^{-2} \\
\mathrm{X} & =\text { emerged Striga } \text { density } \mathrm{m}^{-2} \\
\beta & =\text { degree to which yield increases due to increased crop density } \\
\mathrm{A} & =\text { yield that is vulnerable to Striga infestation } \\
\mathrm{S} & =\text { effect of Striga density on vulnerable yield }
\end{aligned}
$$

Unlike the Cousens and Webb and Smith studies, we are interested in the effect of three variables on crop yields, namely, millet density, Striga density, and nitrogen application rates. Data for estimating the effect of all three of these variables are even more difficult to come by than are data for estimating the effect of crop and weed densities alone. Christianson and Vlek (1991), however, estimated the effect of nitrogen (N), millet density $(\mathrm{C})$, and rainfall $(\mathrm{R})$ on millet yield $(\mathrm{kg} / \mathrm{ha})$ in Niger. The estimated equation is presented in Equation 4.6. ${ }^{36}$ As the presence of weeds in general, and Striga in particular, in the experimental plots which generated the data is not mentioned by Christianson and Vlek, it is assumed that the plots were Striga-free.

\footnotetext{
${ }^{36} R^{2}=0.75 . S E=283$. Standard errors of the parameter estimates are not provided in the article.
} 
Table 4.7 Estimated Parameter Values of Equation 4.5

\begin{tabular}{|c|c|c|c|c|}
\hline \multirow{2}{*}{ Parameter } & \multicolumn{2}{|c|}{$1991(\mathrm{n}=41)$} & \multicolumn{2}{c|}{$1992(\mathrm{n}=196)$} \\
\cline { 2 - 5 } & Estimate & Standard Error & Estimate & Standard Error \\
\hline $\mathrm{S}$ & 0.1098 & 0.0983 & 0.373 & 0.231 \\
\hline$\beta$ & 36.95 & 5.99 & 32.59 & 2.27 \\
\hline $\mathrm{A}$ & 191.5 & 87.9 & 67.4 & 20.1 \\
\hline
\end{tabular}




$$
\begin{aligned}
& \mathrm{Y}=1,085-8.65 * \mathrm{~N}-51.13 * \mathrm{C}-2.73 * \mathrm{R}+0.071 * \mathrm{~N} * \mathrm{R} \\
& +0.304 * \mathrm{C} * \mathrm{R} \\
& \text { Where } \mathrm{Y}=\mathrm{kg} \text { millet per ha } \\
& \qquad \begin{aligned}
\mathrm{C} & =\text { millet density per } 10 \mathrm{~m}^{-2} \\
\mathrm{R} & =\text { mm rainfall "during critical growth stage" (p. 30) } \\
\mathrm{N} & =\mathrm{kg} \text { of nitrogen applied per ha }
\end{aligned}
\end{aligned}
$$

Based on the results of Chritianson and Vlek (1991) and Webb and Smith (1996), millet production functions conditioned on millet density, Striga density, and nitrogen application rates are fashioned for use in this study - one for each zone. Interpreting the "critical growth stage" of millet in Mourdiah and Sirakorola to be from the second half of July through August, $\mathrm{R}$ in Equation 4.6 is calculated for each zone using average rainfall data during that time period. ${ }^{37}$ The result is a separate millet production function for Mourdiah and Sirakorola, represented by Equations 4.7M and 4.7S, respectively.

$$
\begin{aligned}
& \mathrm{Y}=348.6+10.5 * \mathrm{~N}+30.9 * \mathrm{C} \\
& \mathrm{Y}=134.4+16.1 * \mathrm{~N}+54.7 * \mathrm{C}
\end{aligned}
$$

Where $\mathrm{Y}, \mathrm{N}$, and $\mathrm{C}$ are as defined above

In the estimated equation in Webb and Smith (1996), the effect of millet density on yield is independent of the level of Striga infestation. The residual yield, expressed as the parameter A, is, however, dependent on Striga infestation levels. A can be interpreted as encompassing the effect of all other variables (e.g., weather and fertilizer rates) on yield beside crop and Striga density. As such, Equations 4.7M and 4.7S may be viewed as Striga-free analogues to Equation 4.5, analogues which expressly account for the effect of nitrogen on millet yield.

\footnotetext{
${ }^{37}$ Average rainfall during the critical growth period in Mourdiah $=269.75 \mathrm{~mm}$, and Sirakorola $=348.2$ (ICRISAT, 1984). (Rainfall in Banamba is used as a proxy for rainfall in Sirakorola.)
} 
The effect of Striga density is incorporated into Equations 4.7M and 4.7S based on the functional form of Equation 4.5. Including Striga density, Equations 4.8M and 4.8S represent the millet production function for each zone.

$$
\begin{aligned}
& \mathrm{Y}=30.9 * \mathrm{C}+(348.6+10.5 * \mathrm{~N}) /(1+\mathrm{S} * \mathrm{X}) \\
& \mathrm{Y}=54.7 * \mathrm{C}+(134.4+16.1 * \mathrm{~N}) /(1+\mathrm{S} * \mathrm{X})
\end{aligned}
$$

The value of S used in this study is equal to the average of Webb and Smith's estimates of $\mathrm{S}$ over the two seasons in which they conducted their experiment. Equations 4.9M and 4.9S represent the millet production functions used in the model.

$$
\begin{aligned}
& \mathrm{Y}=30.9 * \mathrm{C}+(348.6+10.5 * \mathrm{~N}) /(1+0.24 * \mathrm{X}) \\
& \mathrm{Y}=54.7 * \mathrm{C}+(134.4+16.1 * \mathrm{~N}) /(1+0.24 * \mathrm{X}) \\
& \text { Where } \mathrm{Y}=\text { millet yield }(\mathrm{kg}) \text { per ha } \\
& \mathrm{C}=\text { millet density per } \mathrm{m}^{2} \\
& \mathrm{~N}=\text { kg nitrogen applied per ha } \\
& \mathrm{X}=\text { number of emerged Striga per } \mathrm{m}^{2}
\end{aligned}
$$

Millet-Cowpea Association. In 1995 and 1996, the IPM-CRSP conducted field trials of millet inter-cropped with the Striga-resistant cowpea variety "IT 89KD 245" in Mali. In each trial, millet was planted at a density of 2.6 per $\mathrm{m}^{2}$. In both seasons, the intercropped millet yields were not statistically different than the yields from the pure stand millet plots (also planted at 2.6 per $\mathrm{m}^{2}$ ). Based on these results, Equations 4.9M and 4.9S are used as the millet production functions for the millet-cowpea association as well. However, because the IPM-CRSP field trials only examined one planting density, millet density is fixed at 2.6 per $\mathrm{m}^{2}$ in the millet-cowpea association.

The IPM-CRSP team did not analyze cowpea yield data from the field trials. Cowpea yields within a millet-cowpea association are reported by Yeboah and Gutherie (1995) for 
three consecutive years. Averaging their results over the three years, cowpea yield is modeled as a constant $30 \mathrm{~kg} / \mathrm{ha}$ from a cowpea density of 2.9 per $\mathrm{m}^{2}$.

Millet-Groundnut Association. At a density of 2.5 plants per $\mathrm{m}^{2}$, millet inter-cropped with groundnut appears to generate yields that are approximately $50 \%$ lower than when grown in a pure stand (Salle et al., 1987; Konate, 1987). In light of these reports, millet production in the millet-groundnut association is modeled by dividing Equations $4.9 \mathrm{M}$ and $4.9 \mathrm{~S}$ by a factor of 2 and fixing millet density at 2.5 plants per $\mathrm{m}^{2}$.

Konate (1987) does not report yields of groundnut in pure stands for comparison with yields in the millet-groundnut association. When grown in a pure stand in Mali, groundnut is conventionally planted at a density of 23.5 plants per $\mathrm{m}^{2}$ (Salle et al., 1987). When inter-cropped with millet at a density of 20 per $\mathrm{m}^{2}$, groundnut yields were approximately $25 \%$ lower than when planted in a pure stand (Salle et al., 1987). However, directly applying the groundnut yields from the Salle et al. experiments may not be the best estimate of expected yields in Mourdiah and Sirakorola.

Salle et al. conducted their experiments in the Cinzana area of Mali, whereas Mourdiah and Sirakorola are located in the Operation Haute Valle (OHV) area. Yeboah and Guthrie (1995) report groundnut yields for pure stands in the OHV zone for three consecutive years, 1988-1990. Averaging groundnut yields over these three years, and discounting them by a factor of 0.75 due to inter-cropping (based on Salle et al, 1987), groundnut yields in the millet-groundnut association enter the model as a fixed value equal to $350 \mathrm{~kg} / \mathrm{ha}$. Groundnut density is also fixed at 20 plants per $\mathrm{m}^{2}$.

\section{Section 4.7 Defining the Cash Constraint}

The model recognizes three inputs that must be purchased with cash: "casual" labor, fertilizers, and crop seed. Unfortunately, the IPM-CRSP Socio-Economic Baseline Survey did not collect data pertaining to input expenditures on communal fields. A search of the literature was also unable to uncover data sufficient for constructing a realistic cash constraint for each UP size in the Mourdiah and Sirakorola zones. As a 
result, the amount of cash available to each $\mathrm{UP}_{\mathrm{I}, \mathrm{Z}}$ is initially set to zero and sensitivity analysis is conducted to determine the level of cash at which changes in the solution occur.

\section{Section 4.8 Defining the Nutritional Constraint}

The nutritional needs of each $\mathrm{UP}_{\mathrm{I}, \mathrm{Z}}$ are expressed in terms of daily requirements for the entire UP. This is calculated by multiplying the daily amount of each nutrient required by each age/gender/labor category times the number of members of $\mathrm{UP}_{\mathrm{I}, \mathrm{Z}}$ in each category, and summing over all age/gender/labor categories. The result is a daily requirement of each nutrient for each $\mathrm{UP}_{\mathrm{I}, \mathrm{Z}}$.

While food from the communal fields is shared by all of the members of the UP, each member may also be receiving food from their own individual field and/or the individual field of their spouse, parent(s), or guardian(s). As such, the ability of an individual to meet their nutritional needs is not solely dependent on the communal field production. Furthermore, the percentage of one's nutritional needs that is met by sources other than communal field production varies with the individual. With this in mind, the model does not constrain production on the communal fields to meet any specific portion of the UP's nutritional needs. Rather, the proportion of the UP's needs that are met by the model's solution is calculated for each nutrient. This information is ultimately used to evaluate the benefits of eliminating the seed externality and extending the farmer's planning horizon. The daily nutrient requirements for each age and gender category, the daily nutrient requirements for each $\mathrm{UP}_{\mathrm{I}, \mathrm{Z}}$, and the nutrient levels provided by a $100 \mathrm{~g}$ serving of each of the three crops available in the model are presented in Appendix Tables A4.2 A4.4, respectively.

\section{Section 4.9 Input and Output Prices and the Discount Rate}

The price parameters used in the model are presented in Table 4.8. The output prices (millet, groundnut, and cowpea) and the price of urea come from the Institute d'Economie Rurale's 
Table 4.8: Input and Output Prices and Discount Rate

\begin{tabular}{|c|c|c|}
\hline Parameter & Value & Source \\
\hline Discount Rate $(B)$ & 0.9 & Estimated \\
\hline Price of Millet (CFA/kg) & 50 & I. E. R. (1996) \\
\hline Price of Groundnut (CFA/kg) & 61 & I. E. R. (1996) \\
\hline Price of Cowpea (CFA/kg) & 55 & I. E. R. (1996) \\
\hline Price of Urea (CFA/kg) 38 & 178.5 & I. E. R. (1996) \\
\hline Price of Weeding Labor (CFA/day) & 750 & Kremer and Lock (1993) \\
\hline $\begin{array}{c}\text { Price of Non-Weeding Labor } \\
(\text { CFA/day) }\end{array}$ & 500 & Kremer and Lock (1993) \\
\hline
\end{tabular}

${ }^{38}$ Urea has the highest nitrogen content and is also the cheapest of all nitrogen fertilizers. For this reason other fertilizers, e.g. ammonium phosphate, are not incorporated into the model. 
1996 "Decision de Direction a Tous Directuers Rigionaux, Chefs Sections Material Agricole." The daily wage of hired labor is from Kremer and Lock (1993).

The UP's rate of time preference is estimated indirectly using the interest rate charged for agricultural loans. In 1994, the Institute d'Economie Rurale reported an annual rate of interest of $11 \%$ for a 5 -year agricultural loan. ${ }^{39}$ This translates into a discount rate of approximately 0.9 for the production unit.

\section{Section 4.10 Estimating the UP's "Planning Horizon"}

Controlling Striga is a long-run problem, as argued in Chapter 1. Furthermore, returns to most Striga control measures are not realized in the season in which they are employed, but rather in some future season. As the over-riding objective of this study is to design an effective, affordable Striga control package for farmers in Sirakorola and Mourdiah, it is important to determine how many seasons a control package can encompass and still be attractive to farmers. The length of the farmers' economic planning horizon is assumed to represent the upper bound for the duration of a Striga control package.

To assess whether subsistence farmers in Mourdiah and Sirakorola have a "long-run" planning horizon, and if so, how long it may be, a questionnaire was designed and administered during the IPM-CRSP/Mali 1996 Farmer Evaluation Surveys. The text of the questionnaire is presented in the Appendix.

In designing the questionnaire, the concept of an economic planning horizon was considered too abstract to ask farmers directly, so a proxy was employed. Planned crop rotations were considered a reasonable proxy for the lower bound of a farmer's planning horizon - a farmer may be planning beyond the length of a rotation, but if a rotation is used it is evidence of planned economic activity for at least as long as the duration of the rotation.

\footnotetext{
${ }^{39}$ As the publication does not state whether this is a real or nominal interest rate, it is assumed to be a real rate of interest.
} 
In the 1980's, Caldwell et al. tried to elicit rotational information from farmers in Mali and found that the farmers did not employ fixed crop rotations (Caldwell, 1996). Rather, rotational decisions were made on a yearly basis. With that in mind, planned fallowcultivation cycles were used as the proxy for the lower bound of the planning horizon. ${ }^{40}$

A strategy was devised in which the lower bound would be established by determining the length of a fallow-cultivation rotation. That lower bound would then be "stressed" using a series of iterative questions regarding the farmer's willingness to undertake certain Striga control practices, the returns to which would be realized at various times in the future. Unfortunately, as this was a supplement to the larger Farmer Evaluation Survey, time was a serious consideration. The "stress" questions were dropped from the questionnaire. The supplement focused exclusively on the number of years of cultivation between fallow periods (i.e., from the termination of fallow to the subsequent recommencement of fallow on a given field) rather than the full fallow-cultivation rotation.

Figure 4.1 plots the sample frequency distribution of the data. These data may be used to examine the following hypotheses: (1) the duration of cultivation between fallow periods is the same both villages; and (2) the length of time between fallow periods, that is, the UP's planning horizon, is greater than one year.

Table 4.9 shows the mean, standard deviation, and number of observations $(\mathrm{N})$ of the duration of cultivation between fallow periods for each zone. As reported in Table 4.9, the hypothesis that the duration of cultivation is the same for each zone cannot be rejected by the data. That the second hypothesis (the duration of cultivation is greater than 1 year) is also supported by the data is evident in Figure 4.1 - the minimum number of years of cultivation between fallow periods in either zone is 2 .

\footnotetext{
40 The notion of a "planning horizon" is used loosely in this context. We do not contend that farmers are planning all of their economic activity over the duration of the fallow period. The farmers' lack of planned rotations is evidence that they are not doing so. However, the planned fallow period reveals that farmers are making some economic decisions, such as which fields to take out of production, over that period. It is, therefore, reasoned that they would be willing to make other economic decisions (for example, the allocation of resources for Striga control) over that period as well.
} 
Although the means are not statistically different from each other, Figure 4.1 illustrates the disparity in the distribution of the duration of cultivation between the two zones. As a result, the two zones are treated differently in the model. Using the rounded integer value of the mean for each zone, $\mathrm{T}$, the number of seasons over which the model is run, is set to 3 for Mourdiah and 4 for Sirakorola.

\section{Section 4.11 Concluding Remarks on the Economic Component}

The economic component models the response of crop yields to Striga infestation levels, the price parameters faced by production units in Mali's Mourdiah and Sirakorola zones, and constraints to communal production. While a whole-farm model, including production on individual and communal fields for the entire UP, would have been preferable, data considerations dictated the model focus on communal cereal production.

The model's production constraints rely heavily on data generated by the IPM-CRSP Socio-Economic Baseline Survey. This survey has provided valuable insights into the demographic composition of the production units in each zone, as well as information regarding land use and distribution within the UP's. Due to the efforts of the IPM-CRSP, the model's land and labor constraints are based on the most current information available for each zone. Data for the cash constraint, however, are lacking. As a result, sensitivity analysis is used to examine how changes in a UP's cash endowment affect the model's solution.

Data considerations have also dictated the specification of the millet production functions used in the model. Without sufficient data to estimate a new millet production function, the model is forced to employ a function that is an amalgamation of previously estimated models. While this is less than ideal, the functions used were estimated from millet production data collected in Mourdiah and Niger. Ultimately, the accuracy of the production functions may be checked by comparing the expected yields from the model with yields recorded in Mourdiah and Sirakorola. 


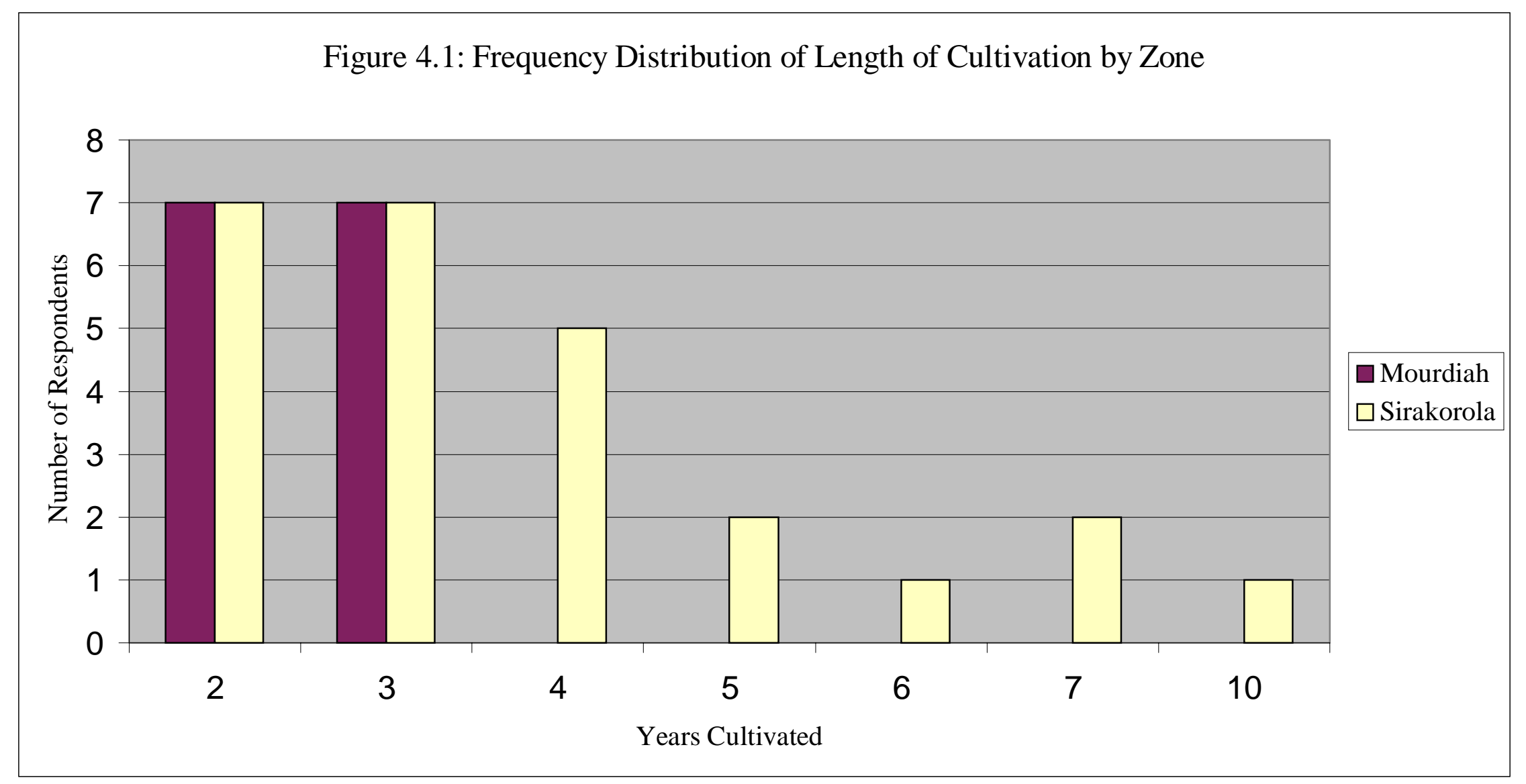


Table 4.9: Testing Equality of Average Duration of Cultivation Between Fallow Periods in Mourdiah and Sirakorola

\begin{tabular}{|c|c|c|}
\hline & Mourdiah & Sirakorola \\
\hline Mean & 2.5 & 3.8 \\
\hline Std. Dev. & 0.52 & 1.98 \\
\hline $\mathrm{N}$ & 14 & 25 \\
\hline \multicolumn{2}{|c|}{$\mathrm{H}_{0}$ : Mean Duration of Cultivation Between Fallow Periods is the Same in Both Zones } \\
\\
$\begin{array}{c}\mathrm{t}_{\text {obs }}=0.7997 \\
\text { Conclusion: Fail to Reject } \mathrm{H}_{0}\end{array}$ \\
\hline
\end{tabular}


Overall, there were a number of compromises necessary to make the economic component of the model fully operational. Nonetheless, designing and specifying the economic component has led to: (1) a new technique for estimating the lower bound of a subsistence farmer's planning horizon; (2) the identification and specification of relevant production constraints and prices; and (3) a description of the demographic composition of production units, as well as land use and distribution within a UP. 


\section{Chapter 5: The Biological Component}

\section{Section $5.1 \quad$ Introduction}

In the absence of definitive studies regarding the parameters of the biological model, evidence available from the literature must be examined and weighed with respect to its applicability to the Mourdiah and Sirakorola zones. In Chapter 2, an extensive review of the literature related to the effects of Striga control practices on the parameters of the biological model was presented. In this chapter, that body of literature is synthesized to specify the parameters of the biological model to the Mourdiah and Sirakorola (M-S) zones.

The chapter is broken into sections, with each section focused on the specification of a single parameter of the M-S biological model. The final section provides a brief overview of the specified model and discusses it's strengths and weaknesses.

\section{Section 5.2 Probability of Stimulation}

There are, essentially, two components to the probability of stimulation: (1) the exposure of Striga seeds to a stimulant, and (2) the activity of the stimulant. Kunisch et al. explicitly model the exposure of Striga seeds to root exudate, with $\mathrm{P}_{\mathrm{S}}$ dependent on host plant density. SH\&W and S\&W also model the exposure of Striga seeds to root exudate, albeit implicitly - the fixed value of $\mathrm{P}_{\mathrm{S}} \mathrm{SH} \& \mathrm{~W}$ and $\mathrm{S} \& \mathrm{~W}$ adopt is nearly identical to the density-dependent probability the Kunisch model would assign given the density of the host crop, millet. In light of the similarity between the Kunisch, SH\&W and S\&W specifications of $\mathrm{P}_{\mathrm{S}}$, the density-dependent parameter used in the Kunisch model is adopted here as the baseline of the exposure of Striga seeds to root exudate. None of the previous models, however, account for the activity of the stimulant.

There are three potential practices that can affect the activity of the stimulant: (1) the application of nitrogen; (2) the use of resistant varieties; and (3) the use of synthetic 
stimulants or inhibitors. As the literature review conducted for this study was unable to uncover any published results of Striga-resistant millet varieties, millet variety is not considered a choice variable in the M-S biological model.

Several synthetic stimulants, including strigol and its analogues, have demonstrated considerable activity in germinating Striga seeds in vitro. The effect of synthetic stimulants on the probability of stimulation, however, depends not only on the stimulatory activity of the chemicals, but also on the application methodology and the stability and dispersion of the chemicals under field conditions. As mentioned in Chapter 2, the application of Ethylene, a gas, requires expensive, technically sophisticated equipment; and the stability of strigol and its analogues under field conditions has greatly reduced their ability to stimulate Striga seeds in situ. Ethephon, on the other hand, is stable under the acidic conditions found in Mourdiah and Sirakorola. As a result, it does not break down into Ethylene gas and does not stimulate Striga seeds. For these reasons, Ethylene, Ethephon, and strigol and its analogues are not considered in the M-S biological model.

Thidiazuron has shown promise as a stimulant of several Striga strains (Babiker et al., 1991), however, its activity on strains of S. hermonthica from Burkina Faso has been marginal. As no Striga strains from Mali were tested and Burkina Faso is the closest to Mali, geographically, of the strains that were tested, it is assumed that the activity of Thidiazuron on Malian Striga strains would also be marginal. Furthermore, the activity of Thidiazuron was tested in soils with a $\mathrm{pH}$ of 7.8, whereas the soils in Mourdiah and Sirakorola are decidedly acidic. For these reasons, Thidiazuron is also not considered in the M-S biological model.

As mentioned in Chapter 2, the literature review uncovered three studies (Raju et al., 1990; Bebawi et al., 1991; Cechin and Press, 1993) that have examined the effect of nitrogen on the stimulatory activity of sorghum root exudate. Each of these studies found nitrogen reduced the stimulatory activity of the root exudate. All three of these studies were, however, conducted in vitro. As the biological model simulates field conditions, 
the nitrogen application rates used in these studies must be converted into field application rates (e.g., $\mathrm{kg} \mathrm{N} / \mathrm{ha}$ or $\mathrm{lb} \mathrm{N} / \mathrm{a}$ ) in order to incorporate their results into the biological model.

In both the Cechin and Press (1993) and the Raju et al. (1990) experiments, sorghum seedlings were placed in ammonium nitrate solutions and allowed to incubate for seven days before root exudate was extracted and tested. As it is impossible to replicate these conditions in the field, the results of these experiments are not incorporated into the probability of stimulation.

Bebawi et al. (1991), however, applied urea $\mathrm{N}$ to sorghum seedlings grown in plastic cups filled with $250 \mathrm{~g}$ of sterile sand. As a result, their in vitro application rates can be converted to field application rates. ${ }^{41}$ The field application rates can then be used to examine the relationship between the stimulatory activity of sorghum root exudate and nitrogen application.

Equation (5.1) represents the hypothesized relationship between kilograms of urea applied per hectare (Urea) and the stimulatory activity of sorghum root exudate (Y). By converting the data presented in Table 2.3 into field application rates and using the proportion of Striga seeds that germinated as a proxy for Y, we can estimate Equation (5.1) using non-linear least squares. ${ }^{42}$

$$
\mathrm{Y}=\beta_{0} * \exp \left\{\beta_{1} * \text { Urea }\right\}
$$

\footnotetext{
${ }^{41} 30 \mathrm{ml}$ solution $*(1 \mathrm{~kg} / \mathrm{l})=0.03 \mathrm{~kg}$ solution. $5 \mathrm{mg} \mathrm{N} / \mathrm{kg}$ solution $* 0.03 \mathrm{~kg}$ solution $=0.15 \mathrm{mg} \mathrm{N}$. 2,000,000 lb. soil/acre (Alley, 1998)*0.454 kg/lb. * 2.47 acre $/ \mathrm{ha} \bullet 2,242,760 \mathrm{~kg}$ soil $/ \mathrm{ha} . \quad\left(1.5 * 10^{-7} \mathrm{~kg}\right.$ $\mathrm{N} / 0.25 \mathrm{~kg}$ soil $* 2,242,760 \mathrm{~kg}$ soil $/ \mathrm{ha}) /(0.45 \mathrm{~kg} \mathrm{~N} / \mathrm{kg}$ Urea $) \cdot 3 \mathrm{~kg}$ Urea/ha.

The authors state that the sorghum pots were irrigated daily, but do not indicate how many days they were irrigated before extracting the sorghum exudate. Two trials were run: one "during" April and the other "during" May. It is assumed that the experiments began on the first and ended on the last day of the month during which they were conducted. As a result, the total amount of urea applied is equal to 30 and 31 times the daily application rate for April and May, respectively.

${ }^{42}$ Bebawi et al. do not report the number of Striga seeds treated in each treatment. They do, however, say that each treatment consisted of 30 Striga seeds, on average. To estimate Equation (5.1), Y is computed by
} 
Because $\mathrm{Y}$ is a proportion, it is bound between zero and one. Three hypotheses must hold to ensure the estimation results of Equation (5.1) are logically consistent. These hypotheses are represented by Equations (5.2) - (5.4).

$$
\begin{array}{ll}
\mathrm{H}_{0}: \beta_{0} \bullet 0 & \mathrm{H}_{1}: \beta_{0}<0 \\
\mathrm{H}_{0}: \beta_{0} \bullet 1 & \mathrm{H}_{1}: \beta_{0}>1 \\
\mathrm{H}_{0}: \beta_{1} \bullet 0 & \mathrm{H}_{1}: \beta_{1}>0
\end{array}
$$

Tables A5.1 and A5.2 of the Appendix present the data used and the results of the estimation, respectively. ${ }^{43}$ The null hypotheses of Equations (5.2) - (5.4) are all supported by the results.

Using the results of the estimation of Equation (5.1), Equation (5.5) represents the probability of stimulation for the M-S biological model, given a crop is planted. Figure 5.1 illustrates the effect of urea on the probability of stimulation given a planting density (W) of 1 .

$$
\begin{aligned}
\mathrm{P}_{\mathrm{S}} & =(1-\exp \{-0.1 \mathrm{~W}\}) * \mathrm{Y} \\
& =(1-\exp \{-0.1 \mathrm{~W}\}) *(0.878 * \exp \{-0.003 * \text { Urea }\})
\end{aligned}
$$

The application of nitrogenous fertilizers is also likely to improve crop vigor. If the root system is affected by nitrogen, then both the exposure and stimulant activity components of the probability of stimulation would be influenced by nitrogen application. Myers (1980), however, found that nitrogenous fertilizer improved the growth of sorghum tops without markedly affecting root growth. As a result, nitrogen application need not be incorporated into the exposure component of $\mathrm{P}_{\mathrm{S}}$, and Equation (5.5) remains unchanged.

dividing the number of germinated Striga by 30; if the number of germinated seeds observed in a treatment is greater than 30, it is assumed that all of the seeds germinated and $Y$ is set equal to 1 .

${ }^{43}$ Equation (5.1) was solved using SAS. To facilitate convergence, $\beta_{0}$ and $\beta_{1}$ were set to starting values of 0.0001 and -0.0001 , respectively. 


\section{Section 5.3 Probability of Germination}

In both the Kunisch and SH\&W models, the probability of germination is set to an arbitrary, fixed value ( 0.5 and 0.45 , respectively). The rationale given for this is that the literature provides contradictory evidence. Using the control treatments of the germination studies reviewed in Chapter 2, one finds the percent of stimulated seeds that germinate to fall between 30 and 80\% (Babiker et al., 1991; Bebawi et al. 1991; Cechin and Press, 1993; Pesch and Pieterse, 1982). Egbers et al. (1991) report an even greater range of germination rates, between 0 and $85 \%$. Considering the wide range, the baseline for $\mathrm{P}_{\mathrm{G}}$ in the M-S biological model is set to 0.5 .

As with the probability of stimulation, there is considerable evidence indicating that nitrogen may affect the probability of germination (Babiker et al., 1991; Bebawi et al. 1991; Cechin and Press, 1993; Pesch and Pieterse, 1982). All of these studies were, however, conducted in vitro, immersing Striga seeds in nitrogenous solutions. The nitrogen application rates in these studies can not, therefore, be converted to field application rates. As a result, the probability of germination in the M-S biological model is set to a fixed value, independent of Striga control practices $\left(\mathrm{P}_{\mathrm{G}}=0.5\right)$.

\section{Section 5.4 Probability of Attachment}

Both Kunisch et al. and SH\&W model the probability of attachment $\left(\mathrm{P}_{\mathrm{A}}\right)$ as a fixed value, although Kunisch et al. acknowledge studies have shown nitrogen affects $\mathrm{P}_{\mathrm{A}}$. Kunisch et al. base their value of $\mathrm{P}_{\mathrm{A}}$ on unpublished data, while $\mathrm{SH} \& \mathrm{~W}$ reference Kunisch et al. in selecting their value of $\mathrm{P}_{\mathrm{A}} . \mathrm{S} \& \mathrm{~W}$, on the other hand, estimate the product of the probability of germination and the probability of attachment, the parameter $\mathrm{k}_{1}$ in their model. They do not, however, distinguish between the contribution each of the two probabilities is making toward the final parameter value. 
Figure 5.1: Probability of Stimulation vs. Urea (Host Plant Density $=1$ per sq $\mathrm{m}$ )

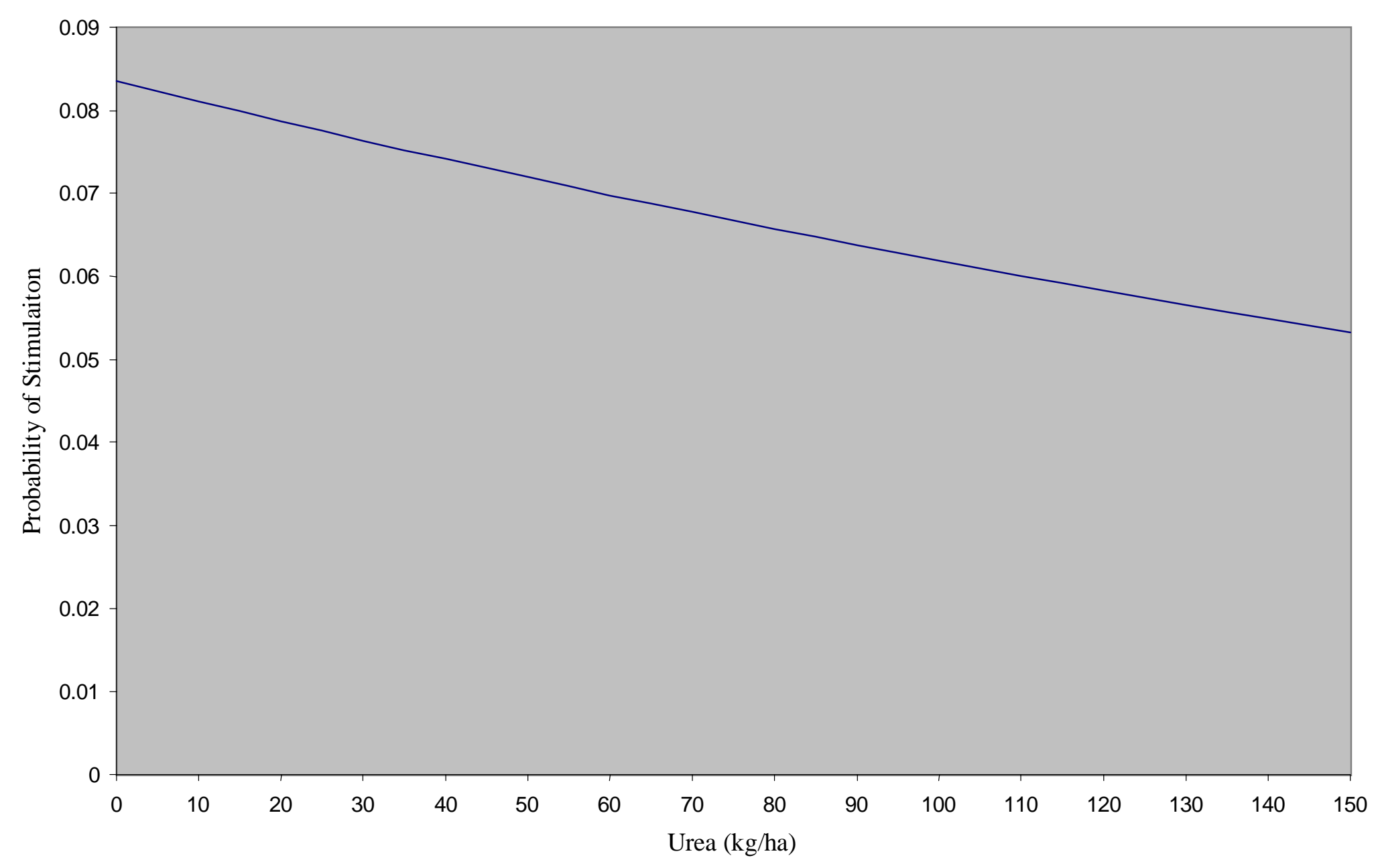


The estimated value of $\mathrm{k}_{1}$ in the $\mathrm{S} \& \mathrm{~W}$ model is 0.012 . Assuming $\mathrm{P}_{\mathrm{G}}=0.5$, the baseline value of $\mathrm{P}_{\mathrm{A}}$ is set equal to 0.024 .

As with the probability of germination, there is evidence to suggest that the probability of stimulation is affected by nitrogen. In fact, if one plots reported results across experiments, the shape of the relationship between nitrogen and the probability of attachment resembles that of nitrogen and the probability of germination: initially increasing in nitrogen and then decreasing exponentially to a lower bound of zero (Awad et al., 1991; Bebawi et al., 1991; Boukar et al., 1996; Cechin and Press, 1993). The similarity between the two relationships suggests that the effect of nitrogen on the probability of germination may be driving the observed nitrogen-attachment effect. A search of the literature was unable to locate sufficient data to quantify either of these observed relationships. As a result, the probability of attachment enters the M-S biological model as a fixed value, independent of Striga control practices $\left(\mathrm{P}_{\mathrm{A}}=0.012\right)$.

\section{Section 5.5 Probability of Emergence}

Kunisch et al., SH\&W, and S\&W all model the probability of emergence as a function of the asymptotic maximum number of Striga a host plant can support. While the asymptote is different in each of these models, the functional form is identical. That functional form, represented by Equation (5.6), is adopted for the M-S biological model as well.

Kunisch et al. chose 50 as the maximum number of Striga a host can support. They did so as, essentially, an educated guess, in the absence of hard data. SH\&W recorded observations from millet fields in Mourdiah. In badly infested fields they found an average of approximately 50 emerged $S$. hermonthica per millet hill. This they considered an underestimate, as the Striga counts were taken at the end of the season after some emerged plants had undoubtedly died. To compensate for Striga deaths, SH\&W set the maximum host carrying capacity equal to 60 . 
When Smith and Webb (1996) reassessed the SH\&W model they fit a rectangular hyperbola to estimates of Striga seedbank density and emerged Striga per millet hill. Estimation of this relationship caused them to set the maximum carrying capacity per millet hill to 20 emerged Striga plants, despite the fact that they had observations of millet hills supporting more than 50 emerged Striga.

Considering the fact that observations from SH\&W and S\&W support the parameter choice of Kunisch et al., the asymptotic maximum number of emerged Striga per host in the M-S biological model is set to 50. Equation (5.6) represents the baseline for the probability of emergence in the M-S biological model.

$$
\begin{aligned}
& \mathrm{P}_{\mathrm{E}}=50 * \mathrm{~W} /\left(50 \mathrm{~W}+\mathrm{X}_{\mathrm{A}}\right) \\
& \text { Where } \mathrm{X}_{\mathrm{A}}=\text { number of attached parasites } / \mathrm{m}^{2} \\
& \qquad \mathrm{~W}=\text { host crop density }\left(\mathrm{m}^{-2}\right)
\end{aligned}
$$

As with the germination and attachment of Striga seeds, the emergence of the parasite appears to be affected by the application of nitrogen. In fact, the relationship between nitrogen and changes in the number of emerged parasites follows the same general pattern as the relationship between nitrogen and both germination and attachment - low application rates facilitate emergence while high rates impede it. Unlike the germination and attachment studies, however, there are sufficient published results to estimate this relationship.

Equation (5.7) represents the hypothesized effect of nitrogen on the number of emerged parasites. Equations (5.8) and (5.9) represent the hypotheses associated with the model parameters. If the alternative hypotheses $\left(\mathrm{H}_{1}\right)$ are supported, low rates of nitrogen would increase the number of emerged parasites above the baseline and high rates of nitrogen would decrease it. 


$$
\begin{aligned}
& \mathrm{Z}=\exp \left\{\beta_{1} * \mathrm{~N}+\beta_{2} * \mathrm{~N}^{2}\right\} \\
& \text { Where } \mathrm{N}=\mathrm{kg} \text { nitrogen } / \mathrm{ha} \\
& \qquad \mathrm{Z}=\text { proportion of emerged parasites at } 0 \mathrm{~kg} \mathrm{~N} / \mathrm{ha} \text { that } \\
& \quad \text { emerge for any } \mathrm{N}
\end{aligned}
$$

$$
\begin{array}{ll}
\mathrm{H}_{0}: \beta_{1}=0 & \mathrm{H}_{1}: \beta_{1}>0 \\
\mathrm{H}_{0}: \beta_{2}=0 & \mathrm{H}_{1}: \beta_{2}<0
\end{array}
$$

Equation (5.7) is estimated by non-linear least squares using data from Ogborn (1987), Hess and Ejeta (1987), Boukar, Hess and Payne (1996), and Gworgwor and Weber (1991a). ${ }^{44}$ All application rates are converted to $\mathrm{kg} \mathrm{N} / \mathrm{ha}$. The dependent variable is calculated by dividing the observed number of emerged Striga in the $0 \mathrm{~kg} \mathrm{~N} / \mathrm{ha}$ treatment by the observed number in each of the other treatments. If the difference between the 0$\mathrm{N}$ treatment and another treatment is not significantly different than zero (at $\mathrm{p}=0.05$ ), the dependent variable is set equal to one.

The Hess and Ejeta and Boukar, Hess and Payne studies both used urea as the form of nitrogen. As noted earlier, however, urea affects the probability of stimulation. The data from these two studies must, therefore, be adjusted to avoid including the stimulatory effects of urea into the estimation of nitrogen's effects on the probability of emergence. To adjust the data, the number of emerged Striga in the control group is multiplied by $\exp (-0.003 *$ Urea), where Urea is the amount of urea $(\mathrm{kg} / \mathrm{ha})$ in a given treatment. The number of emerged Striga observed in a treatment is then divided by the adjusted number in the control to generate an estimate of the dependent variable free of the stimulatory effects of urea.

\footnotetext{
${ }^{44}$ These studies were chosen because they are the only published results from West Africa that had sufficient statistical analyses presented with the results to generate data for the variables of Equation (5.7). Data from the high water treatments in the Boukar, Hess, and Payne study were not used because they were not representative of growing conditions in Mourdiah and Sirakorola, whereas the low water treatments were representative.
} 
The results of the estimation are presented in Table A5.4 of the Appendix. The alternative hypotheses of Equations (5.8) and (5.9) are both supported by the results. ${ }^{45}$ Equation (5.10) represents the probability of emergence including the effects of nitrogen.

$$
\mathrm{P}_{\mathrm{E}}=50 * \mathrm{~W} /\left(50 \mathrm{~W}+\mathrm{X}_{\mathrm{A}}\right) * \exp \left\{0.07111 * \mathrm{~N}-0.00068 * \mathrm{~N}^{2}\right\}
$$

\section{Section 5.6 Probability of Reproduction}

All three of the previous Striga population models set the probability of an emerged plant reaching reproductive maturity ( $\mathrm{P}_{\mathrm{SET}}$ in the $\mathrm{M}-\mathrm{S}$ biological model) to a fixed value.

Kunisch et al. do not cite any references for the value to which they set $\mathrm{P}_{\text {SET }}$. SH\&W and $\mathrm{S} \& \mathrm{~W}$ cite unpublished data to establish $\mathrm{P}_{\mathrm{SET}}=0.25$. In 1996, however, Webb and Smith estimated the value of $\mathrm{P}_{\mathrm{SET}}$ in millet fields in Mourdiah to be 0.34 . The latter is the baseline level of $\mathrm{P}_{\mathrm{SET}}$ adopted for the M-S biological model $\left(\mathrm{P}_{\mathrm{SET}}=0.34\right)$.

In Chapter 2, several studies are cited that document the potential for hand-pulling to reduce the number of Striga that set seed. The timing of hand-pulling appears to be critical to it's efficacy - weeding prior to the flowering of Striga increases the number of reproducing plants (Babiker and Reda, 1991; Bebawi, 1987), while weeding during or after the flowering stage reduces the number of Striga that set seed (Carson, 1988). With that in mind, hand-pulling during or after the flowering stage is the practice that is considered in the M-S biological model.

The effect of hand-pulling is dependent on three factors: (1) the number of emerged Striga, $\mathrm{X}_{\mathrm{E}}$; (2) the number of person-days employed weeding; and (3) the number of emerged Striga one can pull per person-day. The first two factors are endogenously determined $-\mathrm{X}_{\mathrm{E}}$ is contingent on the size of the seedbank and the level of control practices employed, while the number of person-days employed to weed is a decision making variable. The third factor, however, is a parameter that must be specified.

\footnotetext{
${ }^{45}$ The model was solved in SAS. Starting values of $\beta_{1}=0.0001$ and $\beta_{2}=-0.0001$ were provided to facilitate solution of the model.
} 
Babiker and Reda (1991) provide data that can be converted into the number of Striga hand-pulled per person-day during the flowering stage. Their data come from two locations in Ethiopia. In one location a person pulled between 2,300 and 3,200 flowering plants per day; in the other location a person pulled between 3,850 and 5,350 plants per day. Considering the need to properly dispose of the uprooted plants, the number of plants one can pull per person-day is set, conservatively, to 2,500 in the M-S biological model.

Not all Striga enter the flowering stage at the same time. In Mourdiah, the earliest Striga to flower generally do so about two weeks prior to millet harvest, the latest bloom about two weeks after millet harvest (Webb and Smith, 1996). The Striga reproductive cycle does not, however, end with the flowering stage: the plants must still set and disperse their seeds, which requires an additional two weeks. The early bloomers are beginning to set and disperse their seed just prior to and during harvest; late bloomers set and disperse their seed after harvest. Recognizing that harvesting takes precedence over weeding, and to account for early and late blooming plants, hand-pulling is incorporated into the model as two distinct practices: early (pre-harvest) weeding and late (post-harvest) weeding.

Assuming half of the total emerged Striga are early bloomers, the probability of an early bloomer reaching reproductive maturity can be written as Equation 5.11E. Similarly, the probability of a late bloomer reaching reproductive maturity reproduction can be written as Equation 5.11L. ${ }^{46}$

$$
\begin{aligned}
& \mathrm{P}_{\mathrm{SET}, \mathrm{E}}=0.34 *(1-2,500 * \text { EarlyWeed } /(0.5 * \text { Emerged })) \\
& \mathrm{P}_{\mathrm{SET}, \mathrm{L}}=0.34 *(1-2,500 * \text { LateWeed } /(0.5 * \text { Emerged }))
\end{aligned}
$$

Where EarlyWeed = number of person-days spent hand-pulling during the week immediately prior to harvest

LateWeed $=$ number of person-days spent hand-pulling during the week immediately following harvest

Emerged $=$ total number of emerged Striga in communal fields 
In Chapter 3, the general form used to calculate the number of Striga per $\mathrm{m}^{2}$ to set seed in season $\mathrm{t}$, Setter $\mathrm{t}_{\mathrm{t}}$, is represented by Equation 3.2. Equations 5.12E and 5.12L represent the general form for calculating the number $\left(\right.$ per $\mathrm{m}^{2}$ ) of early and late bloomers to set seed in season $\mathrm{t}$, respectively.

$$
\begin{gathered}
\text { Setter }_{\mathrm{E}, \mathrm{t}}=\mathrm{X}_{\mathrm{t}} * \mathrm{P}_{\mathrm{S}}\left(\text { Control }_{\mathrm{t}}\right) * \mathrm{P}_{\mathrm{G}}\left(\text { Control }_{\mathrm{t}}\right) * \\
\mathrm{P}_{\mathrm{A}}\left(\mathrm{Control}_{\mathrm{t}}\right) * \mathrm{P}_{\mathrm{E}}\left(\mathrm{Control}_{\mathrm{t}}\right) * \mathrm{P}_{\mathrm{SET}, \mathrm{E}}\left(\text { Control }_{\mathrm{t}}\right) / 2 \\
\text { Setter }_{\mathrm{L}, \mathrm{t}}=\mathrm{X}_{\mathrm{t}} * \mathrm{P}_{\mathrm{S}}\left(\mathrm{Control}_{\mathrm{t}}\right) * \mathrm{P}_{\mathrm{G}}\left(\mathrm{Control}_{\mathrm{t}}\right) * \\
\mathrm{P}_{\mathrm{A}}\left(\mathrm{Control}_{\mathrm{t}}\right) * \mathrm{P}_{\mathrm{E}}\left(\mathrm{Control}_{\mathrm{t}}\right) * \mathrm{P}_{\mathrm{SET}, \mathrm{L}}\left(\mathrm{Control}_{\mathrm{t}}\right) / 2 \\
\text { Where } \mathrm{X}_{\mathrm{t}}={\text { number of viable Striga } \text { seeds per } \mathrm{m}^{2} \text { at the beginning }}^{\text {of season } \mathrm{t}} \\
\text { Control }_{\mathrm{t}}=\text { vector of Striga control practices employed in season } \mathrm{t}
\end{gathered}
$$

Combining Equations 5.12E and 5.12L, and including the effects of nitrogen and millet density on the transition probabilities, the total number of Striga to set seed per $\mathrm{m}^{2}$ in season $\mathrm{t}$ is calculated using Equation 5.13. This equation is used for millet in a pure stand. The effect of inter-cropping with cowpea and groundnut must also be considered to determine whether Equation 5.13 is appropriate for the other two associations as well.

$$
\begin{aligned}
\text { Setter }_{\mathrm{t}}=\mathrm{X}_{\mathrm{t}} *\left(1-\exp \left\{-0.1 * \mathrm{~W}_{\mathrm{t}}\right\}\right) * \exp \left\{-0.003 * \text { Urea }_{\mathrm{t}}\right\} * 0.5 * 0.012 * \\
\left(50 * \mathrm{~W}_{\mathrm{t}} /\left(50 * \mathrm{~W}_{\mathrm{t}}+\mathrm{X}_{\mathrm{A}, \mathrm{t}}\right)\right) * \\
\exp \left\{0.0711 * \mathrm{~N}_{\mathrm{t}}-0.00068 * \mathrm{~N}_{\mathrm{t}}^{2}\right\} * \\
0.34 *\left[\left(1-2,500 * \text { EarlyWeed }_{\mathrm{t}} /\left(0.5 * \text { Emerged }_{\mathrm{t}}\right)\right)+\right. \\
\left.\quad\left(1-2,500 * \text { LateWeed }_{\mathrm{t}} /\left(0.5 * \text { Emerged }_{\mathrm{t}}\right)\right)\right] / 2
\end{aligned}
$$

Where all variables are as defined above.

The IPM-CRSP millet-cowpea field trials were conducted in Mourdiah in three consecutive seasons, 1995, 1996, and 1997. In all three years the trials included treatments in which cowpea was planted in alternate rows with millet. In 1996 and 1997 , an additional treatment was added in which cowpea was planted within the same row as

\footnotetext{
${ }^{46}$ A logical constraint is included in the model's program to ensure $1 \geq \mathrm{P}_{\mathrm{SET}} \geq 0$.
} 
millet. In 1997, both the alternate row and "intra-row" treatments were conducted in Sirakorola as well as Mourdiah. The results, for each season, of the trials are presented in Table 5.1.

Inter-cropping cowpea with millet significantly reduced the level of Striga infestation (p $=0.05)$ in only one of the three experimental seasons (1996). In absolute terms, the effects of the inter-cropping treatments varied between villages in 1995 and 1997. Although the differences in Striga infestation levels were not statistically significant $(\mathrm{p}=$ 0.05), in some trials the inter-cropped treatments had higher levels of Striga and in others they had lower levels compared to the pure millet control. Considering the inconsistent effects of the inter-cropping treatments, Striga population dynamics are assumed to be unaffected by the cowpea-millet association. As a result, Equation 5.13 is used to model Striga in the millet-cowpea association as well as in stands of pure millet.

A search of the literature uncovered four trials examining the effects of a milletgroundnut association on Striga infestation in Mali, summarized in Table 5.2. All four trials were conducted in the Cinzana region. In all four trials, the millet-groundnut treatment resulted in significant reductions in Striga numbers compared to the pure millet control. On average, Striga numbers were reduced $57 \%$ by the millet-groundnut association.

The experiments conducted by Konate (1986) report Striga counts at harvest, whereas it is unclear when Striga were counted in the Salle et al. (1987) experiments. As it is not possible to deduce which of the transition probabilities are affected by the association from the data at hand, it is assumed the association reduces the probability of stimulation by $57 \%$. Equation 5.14 is used to calculate the number of Striga/m ${ }^{2}$ to set seed in the millet-groundnut association. 


$$
\begin{aligned}
& \text { Setter }_{\mathrm{t}}=\mathrm{X}_{\mathrm{t}} * 0.43 *\left(1-\exp \left\{-0.1 * \mathrm{~W}_{\mathrm{t}}\right\}\right) * \exp \left\{-0.003 * \text { Urea }_{\mathrm{t}}\right\} * \\
& 0.5 * 0.012 *\left(50 * \mathrm{~W}_{\mathrm{t}} /\left(50 * \mathrm{~W}_{\mathrm{t}}+\mathrm{X}_{\mathrm{A}, \mathrm{t}}\right)\right) * \\
& \exp \left\{0.0711 * \mathrm{~N}_{\mathrm{t}}-0.00068 * \mathrm{~N}_{\mathrm{t}}^{2}\right\} * \\
& 0.34 *\left[\left(1-2,500 * \text { EarlyWeed }_{\mathrm{t}} /\left(0.5 * \text { Emerged }_{\mathrm{t}}\right)\right)+\right. \\
&\left.\quad\left(1-2,500 * \text { LateWeed }_{\mathrm{t}} /\left(0.5 * \text { Emerged }_{\mathrm{t}}\right)\right)\right] / 2
\end{aligned}
$$

Where all variables are as defined above.

\section{Section 5.7 Plant Fecundity}

Estimates of Striga seed production vary widely. Andrews (1945) estimated 42,000 per seeds plant; Laing (1984) estimated between 7,800 and 84,000 seeds per plant. Neither of these studies, however, reported non-viable capsules (Webb and Smith, 1996). Webb and Smith (1996) estimated the number of seeds per plant to be 11,000, accounting only for viable capsules. As the Webb and Smith study was conducted in Mourdiah, the number of viable seeds set per mature Striga is set to 11,000 in the M-S biological model.

\section{Section 5.8 Probability of Survival of New and Old Seeds}

Kunisch et al. distinguish between the inter-seasonal mortality rate of old seeds (seeds in the soil that do not germinate at the beginning of season $t$ ) and new seeds (seeds that are produced at the end of season t). The Kunisch model cites several studies (Kust, 1963; Mussa, 1987; Saunders, 1933) to establish an estimate of the mortality rate of new seeds $\left(\mathrm{MR}_{\mathrm{NEW}}\right)$. The value to which the mortality rate of old seeds (MROLD) is set is derived by assuming a seedbank equilibrium level is reached after 12 years.

In contrast, the SH\&W and $\mathrm{S} \& \mathrm{~W}$ models do not distinguish between the two mortality rates (see Table 2.1), nor do they cite any studies to justify the value to which their single seed mortality rate is set. Given the disparity in the mortality rates of old and new seeds in the Kunisch model and the fact that their estimates are based on experimental results, the M-S biological model does distinguish between the two mortality rates. The values to which MR $\mathrm{OLD}_{\text {and }} \mathrm{MR}_{\mathrm{NEW}}$ are set in the M-S biological model are the same as those in the Kunisch model: $\mathrm{MR}_{\mathrm{OLD}}=0.45$ and $\mathrm{MR}_{\mathrm{NEW}}=0.1$. 
Table 5.1: Effect of Millet-Cowpea Association on Striga Infestation, 1995 - 1997

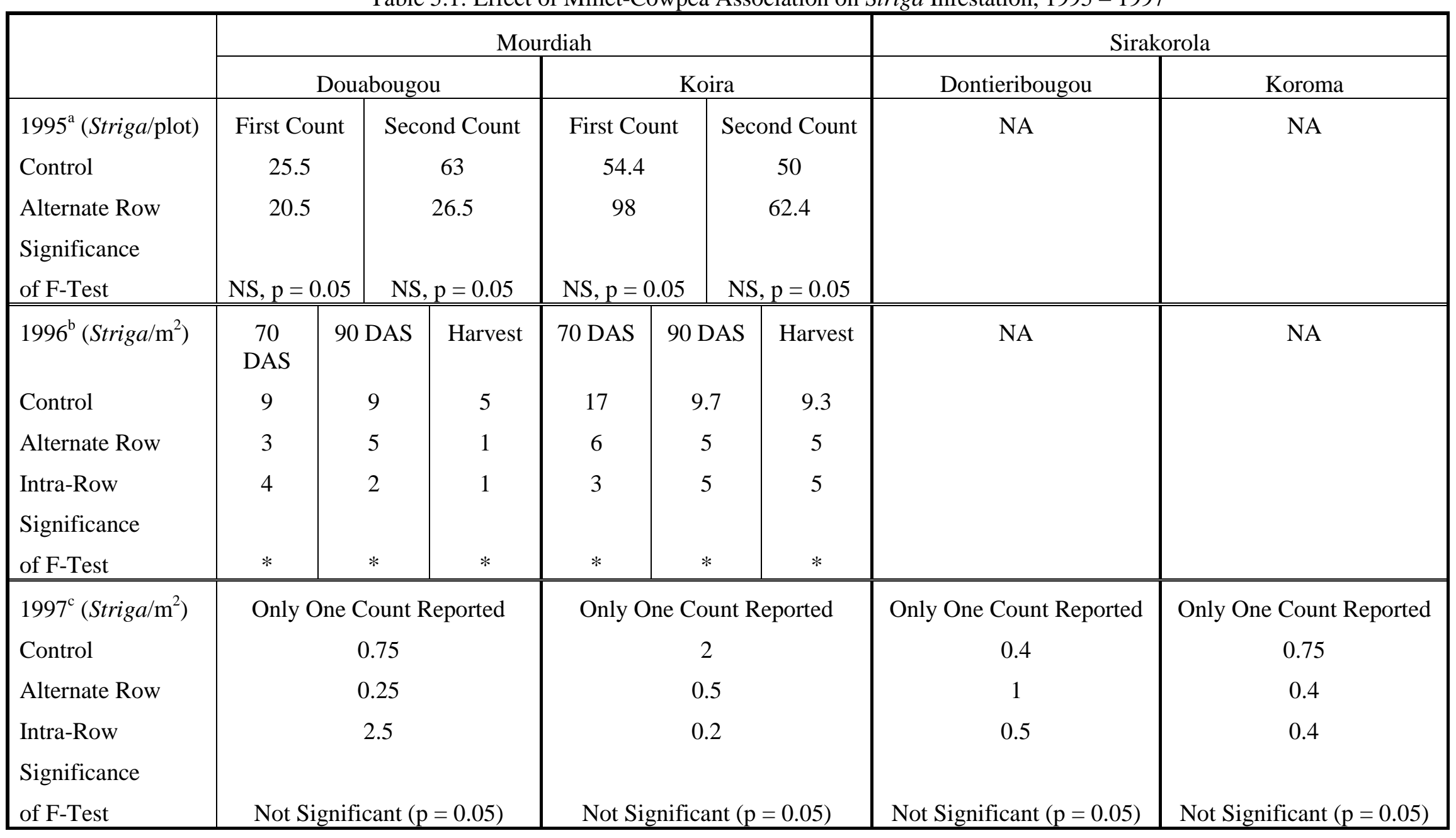


Table 5.2: Effect of Millet-Groundnut Association on Striga Infestation

\begin{tabular}{|l|c|c|c|}
\hline Source & Treatment & Number of Striga & Percent Reduction \\
\hline \multirow{2}{*}{ Konate, 1986 } & Pure Millet Control & 18.2 / plot & $6.8 /$ plot \\
& Millet-Groundnut & 20.7 / plot & $63 \%$ \\
\hline \multirow{2}{*}{ Konate, 1986 } & Pure Millet Control & $7.3 /$ plot & $65 \%$ \\
& Millet-Groundnut & $16.8 /$ plot & $43 \%$ \\
\hline \multirow{2}{*}{ Salle et al., 1987 } & Pure Millet Control & $9.5 /$ plot & \\
& Millet-Groundnut & $1018 /$ plot & $57 \%$ \\
\hline
\end{tabular}




\section{Section 5.9 Modeling the Seed Externality}

Several vectors have been hypothesized to contribute to the dispersion of Striga seeds: wind (Howe and Smallwood, 1982; Pieterse and Pesch, 1983), crop seeds (Berner et al., 1994), the dung of wild and domestic animals (Sand and Manley, 1990; Eplee, 1996; Eplee et al., 1973), and adherence to farm equipment, laborers, and domestic and wild animals. Scientific studies examining the validity of these hypotheses are rare.

Eplee (1966) and Eplee et al. (1973) showed that seeds ingested by wild birds and chickens are unlikely to be viable upon excretion. Berner et al. (1994) found similar results when examining the dung of domestic cattle - only about $8 \%$ of the ingested Striga seeds were viable after passing through the digestive track. Furthermore, the dung contained very few seeds - the authors estimate 46 viable seeds per infested field would migrate out of the field via cattle dung.

Berner et al. (1994) also examined the relevance of wind as a vector of seed dispersion. They conclude that wind is of "relative unimportance" as a dispersal agent. ${ }^{47}$

That leaves the adherence of Striga seeds to farm equipment, laborers, and wild and domestic animals as potential vectors of seed dispersion between fields. Without data regarding seed movement via these vectors, an initial seed migration rate of $1 \%$ is set. That is, $1 \%$ of new seeds are assumed to migrate out of the fields in which they are produced. Where they migrate to is another issue that must be addressed.

The seeds that leave a field may come to rest in another field that is under cultivation or in fallow, or they may settle on non-agricultural land. There are, literally, an infinite number of ways one could model the exchange of migrating seeds between agricultural fields and their dispersion onto non-agricultural land. For simplicity, the M-S Biological model considers a closed system of two equal sized producers; all of one's migrating

\footnotetext{
${ }^{47}$ Berner et al. (1994) did find Striga seeds in many of the crop seed samples they examined in Nigeria. Crop seed, however, is not an external vector of infestation. The farmer who plants Striga-contaminated crop seed has internalized the infestation.
} 
seeds are assumed to come to rest on the fields of the other producer. ${ }^{48}$ In effect, there is a net exchange of seeds. Given these assumptions, the number of new seeds entering a field may be calculated.

As discussed in Chapter 3, $\mathrm{NEW}_{\mathrm{t}}$ is comprised of three components: New STAY, $_{\mathrm{t}}$; New OUT, t; and New IN, t. In the first year of the planning horizon, given an initial Striga seedbank, $\mathrm{New}_{\mathrm{IN}, \mathrm{t}}$ is exogenously determined, multiplying the estimated number of new seeds produced under status quo production by 0.01 . In subsequent seasons, $\mathrm{New}_{\mathrm{IN}, \mathrm{t}}$ is endogenous, as the status quo producer's seedbank is dependent on the net exchange of seeds with the optimizing producer. The other two variables, New STAY, $t_{\text {and New }}$, are endogenously determined in each season, being fixed proportions of the endogenously determined New OwN, t.

\section{Section 5.10 Concluding Remarks on the Biological Component}

A new model of Striga population dynamics has been designed and specified to the production environment of Mali's Mourdiah and Sirakorola zones. Previous models have focused on the effect of a single Striga control practice - plant density in the Kunisch model, and a bio-control agent in the SH\&W model. The M-S biological model accounts for the effects of four control practices: nitrogen fertilizers, crop density, crop associations, and hand-pulling.

In contrast to its predecessors, within the probability of stimulation parameter, the M-S biological model distinguishes the stimulatory activity of the root exudate and the probability a seed is exposed to a stimulant. Furthermore, the effect of nitrogen on the stimulatory activity of the root exudate is estimated and incorporated into the model. The effect of nitrogen on the probability of emergence has also been estimated.

Hand-pulling Striga and crop density are the two control practices that are available to all farmers. The M-S biological model estimates the number of emerged Striga that can be

\footnotetext{
${ }^{48}$ The purpose of modeling the seed externality in this study is not to identify how seeds move, but rather to examine the potential for seed movement to influence the optimal set of practices.
} 
pulled in a person-day, and incorporates hand-pulling into the probability of

reproduction. The timing of weeding is also considered by accounting for both early- and late-blooming plants.

The number of seeds that carry over into the next season, is another distinction between the M-S biological model and its predecessors. The Kunisch and SH\&W models both consider seeds exposed to a stimulant that did not germinate to be rendered non-viable. The M-S biological model allows seeds that did not germinate to carry over into the next season, albeit after being subjected to the probability of survival between seasons.

The other distinguishing feature of the M-S biological model is the seed externality. By modeling the migration of seeds, the M-S biological model is able to examine the Striga population dynamics of a field within a multi-field environment. The isolated field of the Kunisch and SH\&W models may also be specified in the M-S biological model by adjusting the seed migration parameter. As such, a layer of complexity has been added while retaining the ability to model simpler scenarios.

With the Kunisch and SH\&W models as its foundation, the M-S biological model has advanced the modeling of Striga population dynamics. Additional data has been brought to bear on the estimation of certain parameters, subtleties in the mechanics of seed stimulation, germination, and viability have been incorporated, parameter responses to a multitude of control practices have been specified, and seed migration has been included in the model. These features have led to a more general and flexible model that better reflects the production environment of farmers cultivating Striga-infested fields. 


\section{Chapter 6: Results}

\section{Section 6.1: Introduction}

In this chapter, the results of the model are presented for the five production scenarios discussed in Chapter 3, with a separate section dedicated to each. The scenarios are specified for all UP sizes in both zones. For easy reference, Table 6.1 itemizes the type of information presented in each section of Chapter 6 .

The first scenario examines the nutritional and financial implications of status quo millet production practices in the presence of an average Striga infestation level. This information serves as the baseline for evaluating policies to control and/or eradicate Striga in Mourdiah and Sirakorola, policies that are analyzed within the other scenarios.

The second scenario estimates the expected financial and nutritional returns to status quo millet production in the absence of Striga. The difference between Scenario I and II provides estimates of the damages Striga imparts in both financial and nutritional terms. It also serves as an estimate of the value of eradicating Striga while retaining current millet production practices.

Scenario III allows the model to choose the optimal set of practices in the absence of Striga. When compared to Scenario I, the benefits of Striga eradication in conjunction with extension efforts promoting the optimal set of practices may be estimated.

Scenario IV allows the model to choose the optimal set of practices in the presence of an average Striga infestation level, but in the absence of the externality. This scenario may be interpreted in either of two ways: (1) seeds do not move between fields; or (2) seeds do move between fields, but all farmers have adopted the optimal control measures, so 
Table 6.1: Roadmap of Results Presented in Chapter 6

\begin{tabular}{|c|c|c|}
\hline Section & Scenario(s) & Data Presented \\
\hline \multirow{3}{*}{ Section 6.2} & \multirow{3}{*}{ Model Results of Scenario I } & Growth of Striga Seedbank (Figure 6.1) \\
\hline & & Production Practices Employed (Table 6.2) \\
\hline & & $\begin{array}{l}\text { Annual Acreage Cultivated, Millet Production, Percentage of each UP's Energy, } \\
\text { Protein and Iron Needs Met, and Present Value of Net Returns (Tables } 6.3 \text { and 6.4) }\end{array}$ \\
\hline \multirow{2}{*}{ Section 6.3} & Model Results of Scenario II & $\begin{array}{l}\text { Annual Acreage Cultivated, Millet Production, Percentage of each UP's Energy, } \\
\text { Protein and Iron Needs Met, and Present Value of Net Returns (Tables } 6.5 \text { and 6.6) }\end{array}$ \\
\hline & Comparison of Scenarios I and II & $\begin{array}{c}\text { Annual Nutritional and Financial Benefits of Striga Eradication Under Status Quo } \\
\text { Production (Appendix Tables A6.1 and A6.2, and Figures 6.2 through 6.4) }\end{array}$ \\
\hline \multirow{2}{*}{ Section 6.4} & Model Results of Scenario III & $\begin{array}{c}\text { Optimal Production Practices (Appendix Tables A6.3 through A6.12) } \\
\text { Evolution of Optimal Production Practices as Cash Endowment Grows (Figures } \\
6.5 \text { and 6.6) }\end{array}$ \\
\hline & Comparison of Scenarios II and III & $\begin{array}{l}\text { For Each Budget Level, Increase in Expected Net Returns when Shifting from } \\
\text { Status Quo to Optimal Practices in Absence of Striga (Tables } 6.8 \text { and 6.9) }\end{array}$ \\
\hline
\end{tabular}


Table 6.1 continued

\begin{tabular}{|c|c|c|}
\hline Section & Scenario(s) & Data Presented \\
\hline \multirow{3}{*}{ Section 6.5} & \multirow{2}{*}{ Model Results of Scenario IV } & $\begin{array}{l}\text { Optimal Production Practices for Each Budget Level (Tables } 6.10 \text { and 6.11, 6.16, } \\
6.19 \text { and 6.20, 6.25 and 6.26, 6.31 and 6.32) }\end{array}$ \\
\hline & & $\begin{array}{l}\text { Annual Seedbank Growth, Millet Production, Percentage of each UP's Energy, } \\
\text { Protein and Iron Needs Met, Expenditures, and Present Value of Net Returns for } \\
\text { each Budget Level (Tables 6.12 and 6.13,6.17 and 6.18,6.21 and 6.22, } 6.27 \text { and } \\
6.28,6.33 \text { and 6.34) }\end{array}$ \\
\hline & Comparison of Scenarios I and IV & $\begin{array}{l}\text { Annual Change in Acreage, Expenditures, Labor, Nutrient and Financial Returns } \\
\text { from Adopting Optimal Production Practices (Tables } 6.14 \text { and 6.15, 6.23 and 6.24, } \\
6.29 \text { and 6.30, } 6.35 \text { and 6.36, and Figures } 6.7 \text { through 6.22) }\end{array}$ \\
\hline \multirow{2}{*}{ Section 6.6} & Model Results of Scenario V & $\begin{array}{l}\text { Annual Seedbank Growth, Millet Production, Percentage of each UP's Energy, } \\
\text { Protein and Iron Needs Met, Expenditures, and Present Value of Net Returns for } \\
\text { each Budget Level (Table 6.37) }\end{array}$ \\
\hline & Comparison of Scenarios IV and V & $\begin{array}{c}\text { Annual Change in Nutrient and Financial Returns to Optimal Production } \\
\text { Attributable to Seed Externality (Figures 6.23 through 6.30) }\end{array}$ \\
\hline
\end{tabular}


the net seed gain or loss for a given field is zero. ${ }^{49}$ By comparing Scenario IV to Scenario I, the benefits (both financial and nutritional) from adopting the optimal set of practices can be estimated. These estimates may serve as a proxy for the benefits of extension efforts promoting the optimal practices.

The last scenario introduces the seed externality. Average Striga infestation is specified, and the model chooses the optimal set of practices when seeds are permitted to move between fields. The details of the seed externality are discussed in Section 6.6. Comparing Scenario IV to Scenario V generates an estimate of the cost of the seed externality. This estimate may be used to evaluate the benefits of policies aimed at alleviating the externality by either preventing seed movement or ensuring all farmers adopt the optimal set of practices.

The final section offers some concluding remarks regarding the results.

\section{Section 6.2 Scenario I: Returns to Status Quo Production Under Average Striga Infestation}

The first scenario examined in this chapter estimates expected financial returns and the nutritional yield generated by current millet production practices in Mourdiah and Sirakorola. The decision making variables in the model (millet density, urea application rates, crop association(s), UP person-days of Striga weeding labor, and hired labor) are all set to fixed levels. The level of each variable is presented in Table 6.2.

The average density of the Striga seedbank in cereal fields in Mourdiah is estimated to be 40,000 seeds $/ \mathrm{m}^{2}$ (Webb and Smith, 1996). Figure 6.1 illustrates how the seedbank grows over time under status quo millet production practices. The growth of the seedbank has serious implications for net returns to millet production and the ability of the UP to meet its nutrient needs.

\footnotetext{
${ }^{49}$ In other words, the seed externality is assumed to be "perfectly symmetric" (see Chapter 3).
} 
Table 6.2: Conventional Input Levels for Millet Production in Sirakorola and Mourdiah

\begin{tabular}{|l|c|c|}
\hline Input & Level & Source \\
\hline Crop Association & Pure Millet & $\begin{array}{c}\text { IPM-CRSP (1995), } \\
\text { Smith, Holt and Webb } \\
(1993)\end{array}$ \\
\hline Millet Density & $1 \mathrm{~m}^{-2}$ & $\begin{array}{c}\text { Smith, Holt and Webb } \\
(1993)\end{array}$ \\
\hline Urea & 0 kg/ha & IPM-CRSP (1995) \\
\hline UP Striga Weeding & 0 Person-Days & IPM-CRSP (1995) \\
\hline Hired Sowing Labor & 0 Person-Days & IPM-CRSP (1995) \\
\hline Hired Weeding Labor & 0 Person-Days & IPM-CRSP (1995) \\
\hline $\begin{array}{l}\text { Hired Striga } \text { Weeding } \\
\text { Labor }\end{array}$ & 0 Person-Days & IPM-CRSP (1995) \\
\hline Hired Harvest Labor & 0 Person-Days & IPM-CRSP (1995) \\
\hline Hired Post-Harvest Labor & 0 Person-Days & IPM-CRSP (1995) \\
\hline
\end{tabular}


Figure 6.1: Seedbank Growth vs. Time Under Status Quo Millet Production

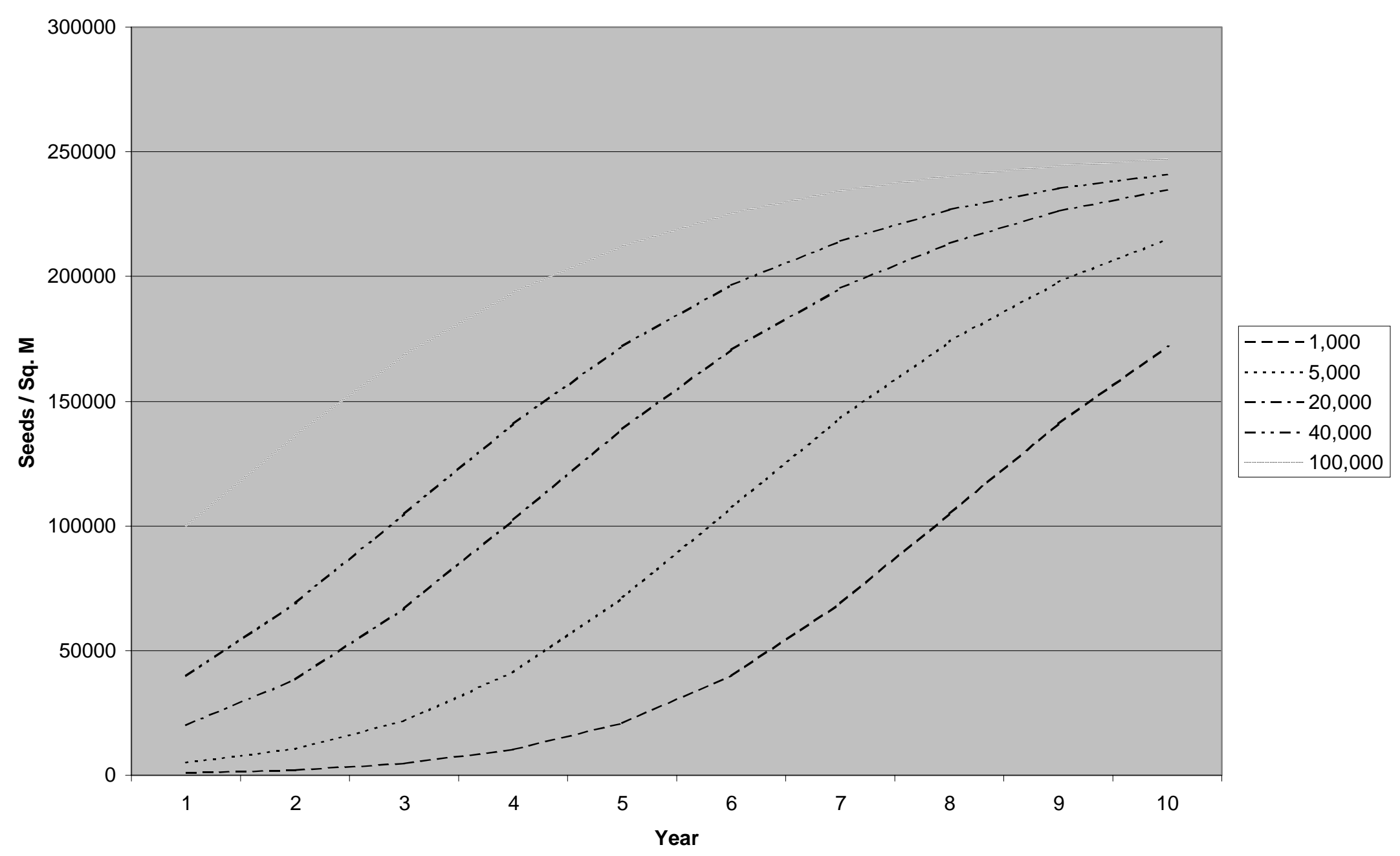


Status quo millet production is constrained first by the ability of the production unit to purchase (or save) seed for sowing. The second binding constraint is the availability of labor to conduct the first weeding. ${ }^{50}$ Under status quo production, seed can be purchased, but labor can not be hired. As a result, the budget constraint ceases to be binding above a certain level. That level is dependent on the amount of land the UP's own labor is able to cultivate.

Tables 6.2 and 6.3 present estimates of millet production and the present value of net returns for each season of the planning horizon in Mourdiah and Sirakorola, respectively. The decline in millet production in each successive season is due exclusively to the increase in the seedbank. In Mourdiah, millet production is nearly $20 \%$ lower in the second season than the first, and falls an additional $8 \%$ in the third season. In Sirakorola, millet production declines more slowly - approximately $10 \%$ in the second season - but has fallen by more than $16 \%$ in the last year of the planning horizon. ${ }^{51}$ Reductions in millet production translate directly into lower nutrient production.

Tables 6.2 and 6.3 also present estimates of the percentage of the UP's energy, protein, and iron needs that are met by status quo millet production in each season of the planning horizon. The UP's nutrient needs are dictated by its demographic composition. As a result, the percentage of nutrient needs met varies across UP size and zone. For all $\mathrm{UP}_{\mathrm{I}, \mathrm{Z}}$, however, the UP's ability to meet its nutrient needs is compromised by the growth of the seedbank. Estimating the magnitude of financial and nutritional losses due to Striga under status quo millet production is the focus of the next section.

\footnotetext{
${ }^{50}$ Striga is not pulled during the first weeding.

${ }^{51}$ The difference in the rate of decline of millet production between the two zones is due to differences the millet production functions, which are the result of different expected rainfall patterns.
} 
Table 6.3: Results of Scenario I (Status Quo Millet Production with Starting Seedbank $=40,000 / \mathrm{m}^{2}$ ) for Each UP Size in Mourdiah

\begin{tabular}{|c|c|c|c|c|c|c|c|}
\hline \multirow{2}{*}{ UP Size } & \multirow{2}{*}{ Year } & \multirow{2}{*}{$\begin{array}{l}\text { Hectares } \\
\text { Cultivated }\end{array}$} & \multirow{2}{*}{$\begin{array}{l}\text { Millet } \\
\text { Production } \\
\quad(\mathrm{kg})\end{array}$} & \multicolumn{3}{|c|}{$\begin{array}{c}\text { \% UP Nutrient } \\
\text { Requirement }\end{array}$} & \multirow{2}{*}{$\begin{array}{l}\text { Present Value of } \\
\text { Net Revenue } \\
\text { (CFA) }\end{array}$} \\
\hline & & & & Energy & Protein & Iron & \\
\hline \multirow[t]{3}{*}{ Extra Small } & 1 & 1.3 & 147 & 14.1 & 20.7 & 26.5 & 7,080 \\
\hline & 2 & 1.3 & 120 & 11.5 & 16.9 & 21.7 & 5,155 \\
\hline & 3 & 1.3 & 106 & 10.2 & 14.9 & 19.1 & 4,075 \\
\hline \multirow[t]{3}{*}{ Small } & 1 & 2.2 & 240 & 12.9 & 18.1 & 21.3 & 11,560 \\
\hline & 2 & 2.2 & 200 & 10.7 & 15.1 & 17.7 & 8,605 \\
\hline & 3 & 2.2 & 175 & 9.4 & 13.2 & 15.5 & 6,735 \\
\hline \multirow[t]{3}{*}{ Medium } & 1 & 4.7 & 510 & 11.3 & 15.9 & 19 & 24,570 \\
\hline & 2 & 4.7 & 420 & 9.3 & 13.1 & 15.6 & 18,060 \\
\hline & 3 & 4.7 & 370 & 8.2 & 11.5 & 13.8 & 14,230 \\
\hline \multirow[t]{3}{*}{ Large } & 1 & 6.3 & 685 & 10.8 & 15 & 18 & 33,000 \\
\hline & 2 & 6.3 & 560 & 8.8 & 12.2 & 14.7 & 24,075 \\
\hline & 3 & 6.3 & 500 & 7.9 & 10.9 & 13.1 & 19,240 \\
\hline \multirow[t]{3}{*}{ Extra Large } & 1 & 13.9 & 1,525 & 13 & 18.3 & 22.4 & 73,470 \\
\hline & 2 & 13.9 & 1,250 & 10.7 & 15 & 18.4 & 53,745 \\
\hline & 3 & 13.9 & 1,110 & 9.5 & 13.3 & 16.3 & 42,700 \\
\hline \multirow{3}{*}{$\begin{array}{l}\text { Extra-Extra } \\
\text { Large }\end{array}$} & 1 & 14 & 1,530 & 7.5 & 10.4 & 12.5 & 73,700 \\
\hline & 2 & 14 & 1,260 & 6.2 & 8.5 & 10.3 & 54,180 \\
\hline & 3 & 14 & 1,115 & 5.5 & 7.6 & 9.1 & 42,890 \\
\hline
\end{tabular}


Table 6.4: Results of Scenario I (Status Quo Millet Production with Starting Seedbank $=40,000 / \mathrm{m}^{2}$ ) for Each UP Size in Sirakorola

\begin{tabular}{|c|c|c|c|c|c|c|c|}
\hline \multirow{2}{*}{ UP Size } & \multirow{2}{*}{ Year } & \multirow{2}{*}{$\begin{array}{l}\text { Hectares } \\
\text { Cultivated }\end{array}$} & \multirow{2}{*}{$\begin{array}{l}\text { Millet } \\
\text { Production } \\
\quad(\mathrm{kg})\end{array}$} & \multicolumn{3}{|c|}{$\begin{array}{c}\text { \% UP Nutrient } \\
\text { Requirement }\end{array}$} & \multirow{2}{*}{$\begin{array}{l}\text { Present Value of } \\
\text { Net Revenue } \\
\text { (CFA) }\end{array}$} \\
\hline & & & & Energy & Protein & Iron & \\
\hline \multirow[t]{4}{*}{ Extra Small } & 1 & 1.6 & 134 & 12.6 & 17.8 & 24.9 & 6,385 \\
\hline & 2 & 1.6 & 122 & 11.5 & 16.2 & 22.7 & 5,210 \\
\hline & 3 & 1.6 & 115 & 10.8 & 15.2 & 21.4 & 4,405 \\
\hline & 4 & 1.6 & 112 & 10.5 & 14.8 & 20.8 & 3,850 \\
\hline \multirow[t]{4}{*}{ Small } & 1 & 1.5 & 129 & 7.1 & 10 & 13.6 & 6,150 \\
\hline & 2 & 1.5 & 117 & 6.5 & 8.8 & 12.4 & 4,995 \\
\hline & 3 & 1.5 & 111 & 6.1 & 8.3 & 11.7 & 4,255 \\
\hline & 4 & 1.5 & 108 & 6 & 8.1 & 11.4 & 3,715 \\
\hline \multirow[t]{4}{*}{ Medium } & 1 & 3.3 & 280 & 7.3 & 10.4 & 13.1 & 13,340 \\
\hline & 2 & 3.3 & 255 & 6.7 & 9.5 & 12 & 10,885 \\
\hline & 3 & 3.3 & 242 & 6.3 & 9 & 11.4 & 9,265 \\
\hline & 4 & 3.3 & 235 & 6.2 & 8.8 & 11 & 8,090 \\
\hline \multirow[t]{4}{*}{ Large } & 1 & 6.4 & 543 & 7.7 & 10.9 & 14.2 & 25,870 \\
\hline & 2 & 6.4 & 494 & 7 & 9.9 & 12.9 & 21,085 \\
\hline & 3 & 6.4 & 469 & 6.7 & 9.4 & 12.3 & 17,960 \\
\hline & 4 & 6.4 & 455 & 6.5 & 9 & 11.9 & 15,655 \\
\hline
\end{tabular}




\section{Section 6.3 Scenario II: Returns to Status Quo Production in the Absence of Striga}

A qualitative study has yet to be conducted to determine the extent to which status quo practices are influenced by Striga infestation levels. If Striga is not a consideration, then status quo practices would continue if Striga were eradicated. Scenario II is designed to estimate, in both financial and nutritional terms, the value of Striga eradication if status quo practices were to persist, post-eradication.

By restricting millet production to status quo practices and setting the seedbank equal to zero, the model estimates the expected returns to millet production in each season. Tables 6.4 and 6.5 present the results of Scenario II for Mourdiah and Sirakorola, respectively. Millet yields are the same in each season due to the production functions employed and the specification of the production scenario - nitrogen, millet density, and Striga infestation, the only variables within the production function, are all set to fixed values. Cultivated acreage is fixed, indirectly, by preventing the UP from hiring labor.

Tables A6.1 and A6.2 of the Appendix calculate the difference in nutritional and financial returns between Scenarios I and II. The benefits of Striga eradication vary by UP size and zone, and across years of the planning horizon. In Mourdiah, financial returns in the first season increase an average of $356 \%$ across all UP sizes. In Sirakorola, the increase is less dramatic, but still large, averaging just under $230 \%$. In each successive year of the planning horizon, the financial returns to eradication increase for all $\mathrm{UP}_{\mathrm{I}, \mathrm{Z}}$. Table 6.7 presents estimates of the increase in the present value of expected net returns to status quo millet production due to Striga eradication in Mourdiah and Sirakorola, respectively.

The story is the same when we look at the nutritional gains from Striga eradication. The production of energy, protein and iron more than triples for each UP in Mourdiah, and increases more than two-fold in Sirakorola in the first year. Subsequent years generate even larger nutritional gains compared to status quo production with average Striga infestation. For example, if Striga were eradicated, it is estimated that a XS UP in 
Mourdiah would be able to produce an additional $34.7 \%$ of its energy needs from communal cereal production in the first year of the planning horizon, an additional $37.3 \%$ in the second year, and an additional $38.6 \%$ in the third year. Additional protein production would amount to $50.7 \%, 54.5 \%$, and $56.5 \%$ of $\mathrm{UP}_{\mathrm{XS}}$, Mourdiah needs in the first second and third year, respectively. The difference in iron production would be even greater, adding $65.2 \%, 70 \%$, and $72.6 \%$ of the UP's requirement in the first, second and third year, respectively. Figures $6.2-6.4$ illustrate the expected nutritional benefits of Striga eradication.

While continuing to grow millet under status quo production practices generates substantial benefits when Striga is eradicated, the question remains, "Is status quo production optimal in the absence of Striga?" The next section is designed to answer that question.

\section{Section 6.4: Scenario III: Optimal Production in the Absence of Striga}

When the model is allowed to choose practices in the absence of Striga, status quo production practices are not selected. Pure millet is chosen over the other two associations for all $\mathrm{UP}_{\mathrm{I}, \mathrm{Z}}$, but the optimal level of each input varies across UP size and zone, and with the amount of cash the UP has available for the purchase of inputs. The optimal practices do not, however, vary across seasons. Tables A6.3-A6.12 of the Appendix present the optimal level of each input employed under different cash endowments for each $\mathrm{UP}_{\mathrm{I}, \mathrm{Z}}$.

While the level of the inputs employed varies across all $\mathrm{UP}_{\mathrm{I}, \mathrm{Z}}$, the evolution of the optimal practices as the UP's cash endowment grows is consistent across UP size within a zone. In other words, within zone $\mathrm{Z}$, the order in which $\mathrm{UP}_{\mathrm{I}, \mathrm{Z}}$ purchases inputs is the same for all I. Between zones, however, the order is different. Figures 6.5 and 6.6 illustrate the evolution of the optimal practices for $\mathrm{UP}_{\mathrm{XS}}$, Mourdian and $\mathrm{UP}_{\mathrm{XS}}$, Sirakorola, respectively, as the cash endowment grows. 
Table 6.5: Results of Scenario II (Status Quo Millet Production with Seedbank $=0 / \mathrm{m}^{2}$ ) for Each UP Size in Mourdiah

\begin{tabular}{|c|c|c|c|c|c|c|c|}
\hline \multirow{2}{*}{ UP Size } & \multirow{2}{*}{ Year } & \multirow{2}{*}{$\begin{array}{l}\text { Hectares } \\
\text { Cultivated }\end{array}$} & \multirow{2}{*}{$\begin{array}{l}\text { Millet } \\
\text { Production } \\
\quad(\mathrm{kg})\end{array}$} & \multicolumn{3}{|c|}{$\begin{array}{c}\% \text { UP Nutrient } \\
\text { Requirement }\end{array}$} & \multirow{2}{*}{$\begin{array}{l}\text { Present Value of } \\
\text { Net Revenue } \\
(1,000 \text { CFA })\end{array}$} \\
\hline & & & & Energy & Protein & Iron & \\
\hline \multirow[t]{3}{*}{ Extra Small } & 1 & 1.3 & 508 & 48.8 & 71.4 & 91.7 & 25.1 \\
\hline & 2 & 1.3 & 508 & 48.8 & 71.4 & 91.7 & 22.6 \\
\hline & 3 & 1.3 & 508 & 48.8 & 71.4 & 91.7 & 20.4 \\
\hline \multirow[t]{3}{*}{ Small } & 1 & 2.2 & 831 & 44.6 & 62.6 & 73.7 & 41.1 \\
\hline & 2 & 2.2 & 831 & 44.6 & 62.6 & 73.7 & 37.0 \\
\hline & 3 & 2.2 & 831 & 44.6 & 62.6 & 73.7 & 33.3 \\
\hline \multirow[t]{3}{*}{ Medium } & 1 & 4.7 & 1771 & 39.2 & 55.2 & 66 & 87.6 \\
\hline & 2 & 4.7 & 1771 & 39.2 & 55.2 & 66 & 78.9 \\
\hline & 3 & 4.7 & 1771 & 39.2 & 55.2 & 66 & 71.0 \\
\hline \multirow[t]{3}{*}{ Large } & 1 & 6.3 & 2378 & 37.3 & 51.9 & 62.5 & 117.6 \\
\hline & 2 & 6.3 & 2378 & 37.3 & 51.9 & 62.5 & 105.9 \\
\hline & 3 & 6.3 & 2378 & 37.3 & 51.9 & 62.5 & 95.3 \\
\hline \multirow[t]{3}{*}{ Extra Large } & 1 & 13.9 & 5288 & 45.2 & 63.5 & 77.7 & 261.6 \\
\hline & 2 & 13.9 & 5288 & 45.2 & 63.5 & 77.7 & 235.5 \\
\hline & 3 & 13.9 & 5288 & 45.2 & 63.5 & 77.7 & 211.9 \\
\hline \multirow{3}{*}{$\begin{array}{l}\text { Extra-Extra } \\
\text { Large }\end{array}$} & 1 & 14 & 5313 & 26.2 & 36 & 43.6 & 262.9 \\
\hline & 2 & 14 & 5313 & 26.2 & 36 & 43.6 & 236.6 \\
\hline & 3 & 14 & 5313 & 26.2 & 36 & 43.6 & 213.0 \\
\hline
\end{tabular}


Table 6.6: Results of Scenario II (Status Quo Millet Production with Seedbank $=0 / \mathrm{m}^{2}$ ) for Each UP Size in Sirakorola

\begin{tabular}{|c|c|c|c|c|c|c|c|}
\hline \multirow{2}{*}{ UP Size } & \multirow{2}{*}{ Year } & \multirow{2}{*}{$\begin{array}{c}\text { Hectares } \\
\text { Cultivated }\end{array}$} & \multirow{2}{*}{$\begin{array}{l}\text { Millet } \\
\text { Production } \\
\quad(\mathrm{kg})\end{array}$} & \multicolumn{3}{|c|}{$\begin{array}{c}\% \text { UP Nutrient } \\
\text { Requirement }\end{array}$} & \multirow{2}{*}{$\begin{array}{l}\text { Present Value of } \\
\text { Net Revenue } \\
(1,000 \text { CFA })\end{array}$} \\
\hline & & & & Energy & Protein & Iron & \\
\hline \multirow[t]{4}{*}{ Extra Small } & 1 & 1.6 & 297 & 27.9 & 39.4 & 55.3 & 14.5 \\
\hline & 2 & 1.6 & 297 & 27.9 & 39.4 & 55.3 & 13.1 \\
\hline & 3 & 1.6 & 297 & 27.9 & 39.4 & 55.3 & 11.8 \\
\hline & 4 & 1.6 & 297 & 27.9 & 39.4 & 55.3 & 10.6 \\
\hline \multirow[t]{4}{*}{ Small } & 1 & 1.5 & 286 & 15.8 & 21.4 & 30.2 & 14.0 \\
\hline & 2 & 1.5 & 286 & 15.8 & 21.4 & 30.2 & 12.6 \\
\hline & 3 & 1.5 & 286 & 15.8 & 21.4 & 30.2 & 11.3 \\
\hline & 4 & 1.5 & 286 & 15.8 & 21.4 & 30.2 & 10.2 \\
\hline \multirow[t]{4}{*}{ Medium } & 1 & 3.3 & 623 & 16.3 & 23.2 & 29.2 & 30.5 \\
\hline & 2 & 3.3 & 623 & 16.3 & 23.2 & 29.2 & 27.4 \\
\hline & 3 & 3.3 & 623 & 16.3 & 23.2 & 29.2 & 24.7 \\
\hline & 4 & 3.3 & 623 & 16.3 & 23.2 & 29.2 & 22.2 \\
\hline \multirow[t]{4}{*}{ Large } & 1 & 6.4 & 1208 & 17.2 & 24.2 & 31.6 & 59.2 \\
\hline & 2 & 6.4 & 1208 & 17.2 & 24.2 & 31.6 & 53.3 \\
\hline & 3 & 6.4 & 1208 & 17.2 & 24.2 & 31.6 & 48.0 \\
\hline & 4 & 6.4 & 1208 & 17.2 & 24.2 & 31.6 & 43.2 \\
\hline
\end{tabular}


Table 6.7: Estimates of the Net Present Value (1,000 CFA) of Striga Eradication under Status Quo Millet Production for Each UP ${ }_{\mathrm{I}, z}$

\begin{tabular}{|c|c|c|c|c|c|c|c|c|c|c|}
\hline \multirow[b]{2}{*}{ Year } & \multicolumn{4}{|c|}{ Sirakorola } & \multicolumn{6}{|c|}{ Mourdiah } \\
\hline & $\mathrm{XS}$ & $S$ & $\mathrm{M}$ & $\mathrm{L}$ & $\mathrm{XS}$ & $S$ & $\mathrm{M}$ & $\mathrm{L}$ & $\mathrm{XL}$ & XXL \\
\hline 1 & 8.2 & 7.9 & 17.2 & 33.4 & 18.1 & 29.6 & 63.0 & 84.6 & 188.1 & 189.2 \\
\hline 2 & 7.9 & 7.6 & 16.6 & 32.2 & 17.5 & 28.4 & 60.8 & 81.8 & 181.7 & 182.4 \\
\hline 3 & 7.4 & 7.1 & 15.4 & 30.0 & 16.3 & 26.6 & 56.7 & 76.1 & 169.2 & 170.1 \\
\hline 4 & 6.7 & 6.5 & 14.1 & 27.5 & NA & & & & & \\
\hline Total & 30.1 & 29.0 & 63.3 & 123.1 & 51.8 & 84.5 & 180.6 & 242.5 & 539.1 & 541.6 \\
\hline
\end{tabular}


Figure 6.2: Increase in Status Quo Production of Emergy Due to Striga Eradication as a Percentage of Total UP Needs

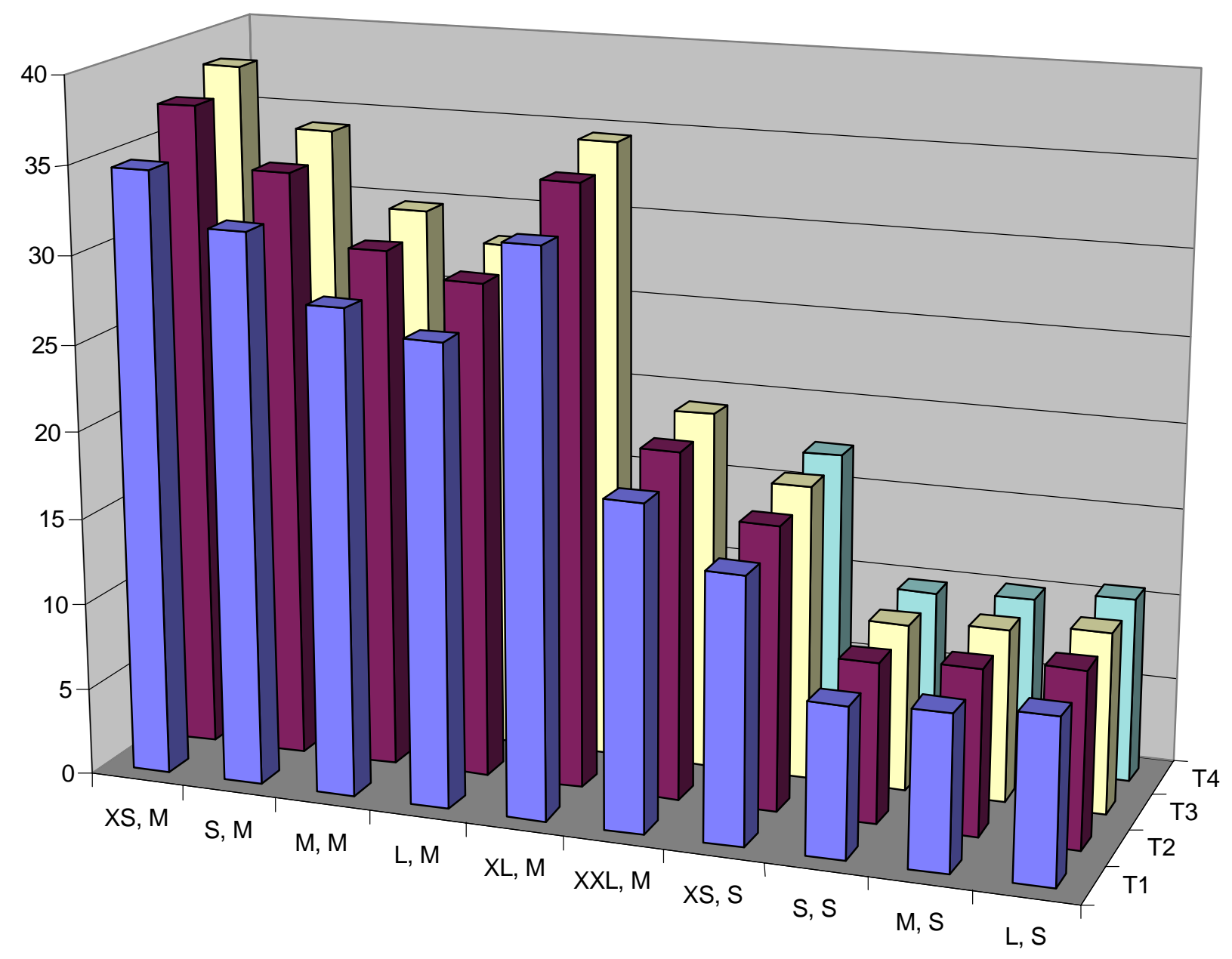


Figure 6.3: Increase in Status Quo Production of Protein Due to Striga Eradication as a Percentage of Total UP Needs

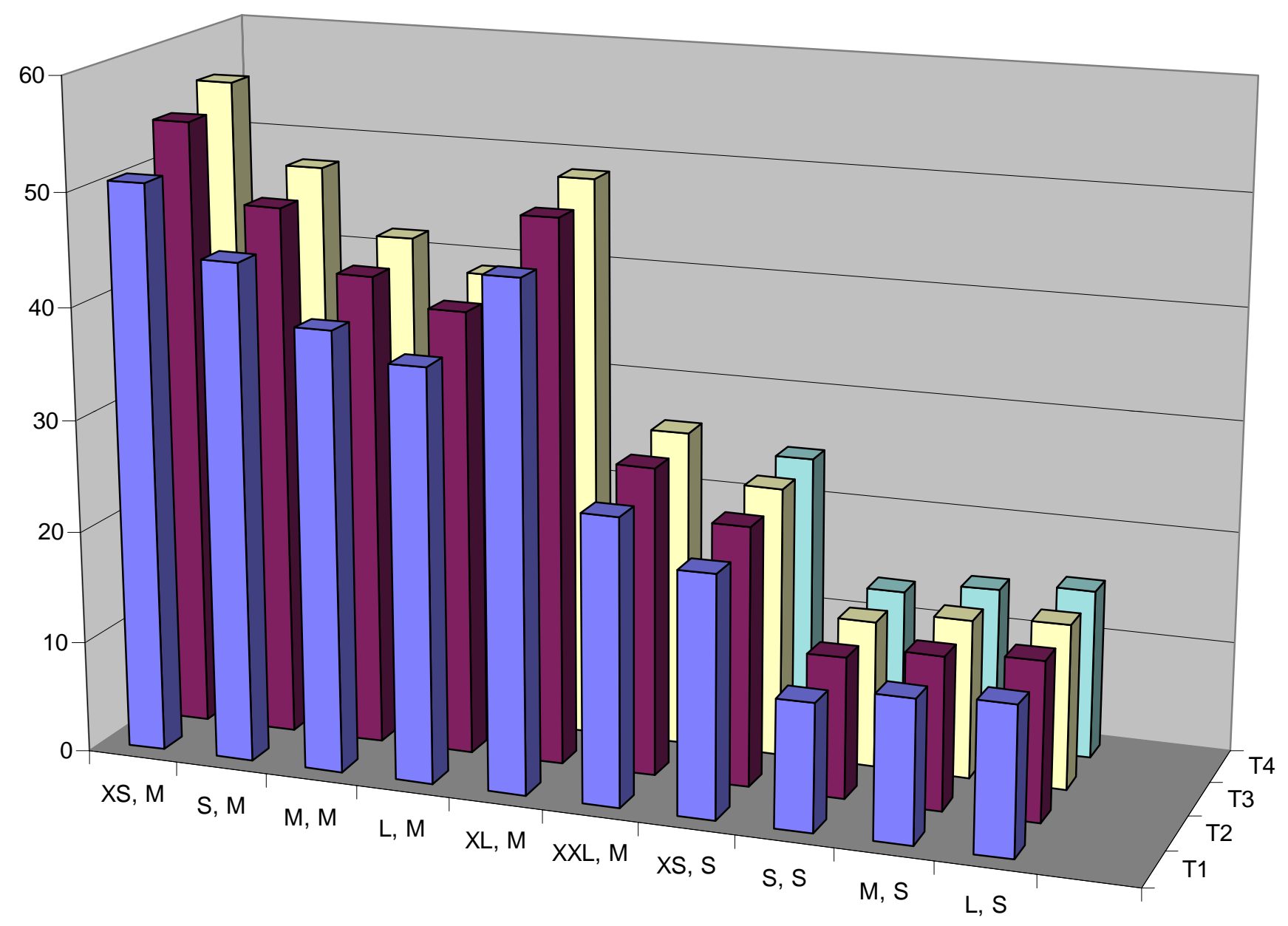


Figure 6.4: Increase in Status Quo Production of Iron Due to Striga Eradication as a Percentage of Total UP Needs

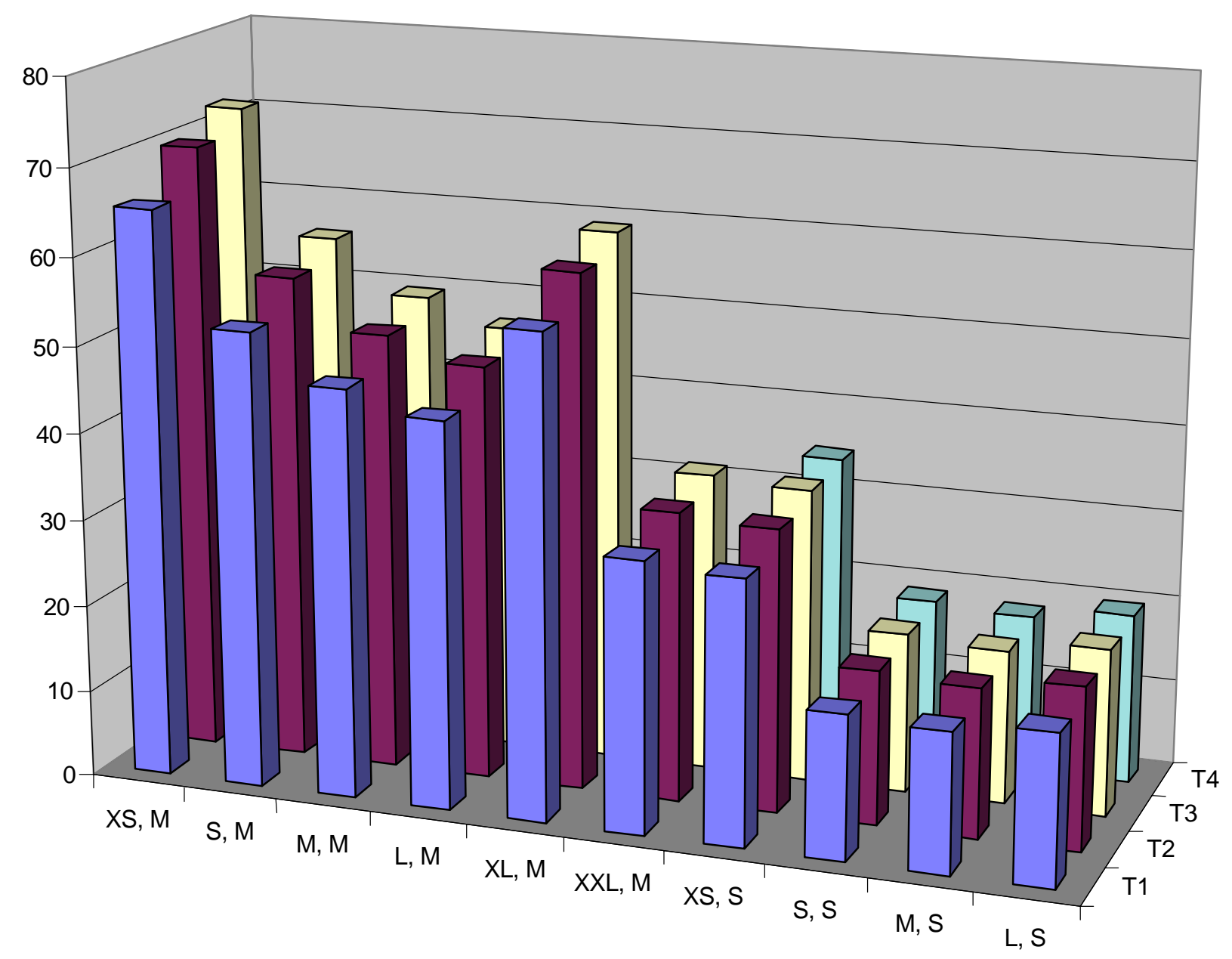


Figure 6.5: Evolution of Optimal Practices in Absence of Striga for XS UP in Mourdiah

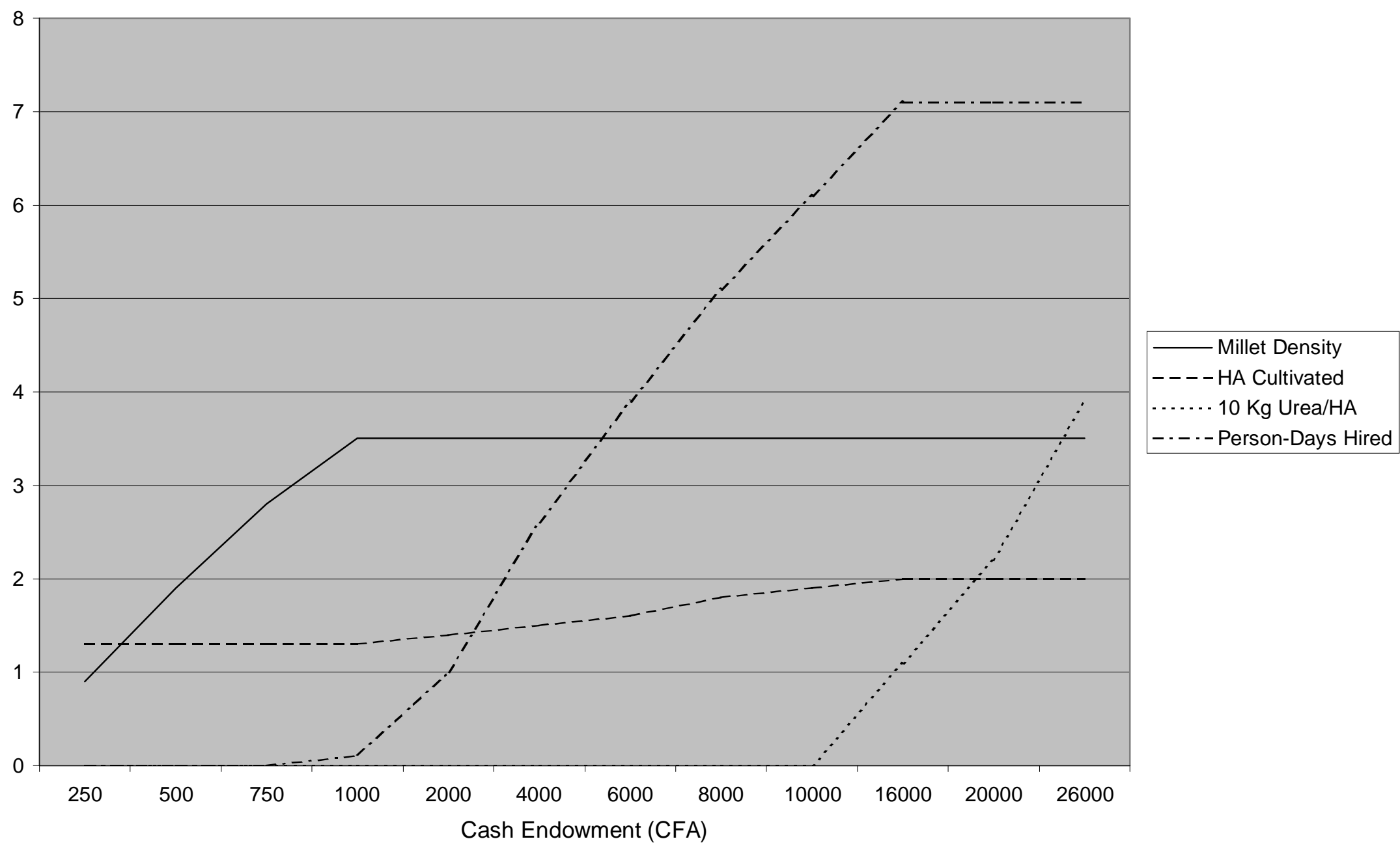


Figure 6.6: Evolution of Optimal Pracitces in Absence of Striga for XS UP in Sirakorola

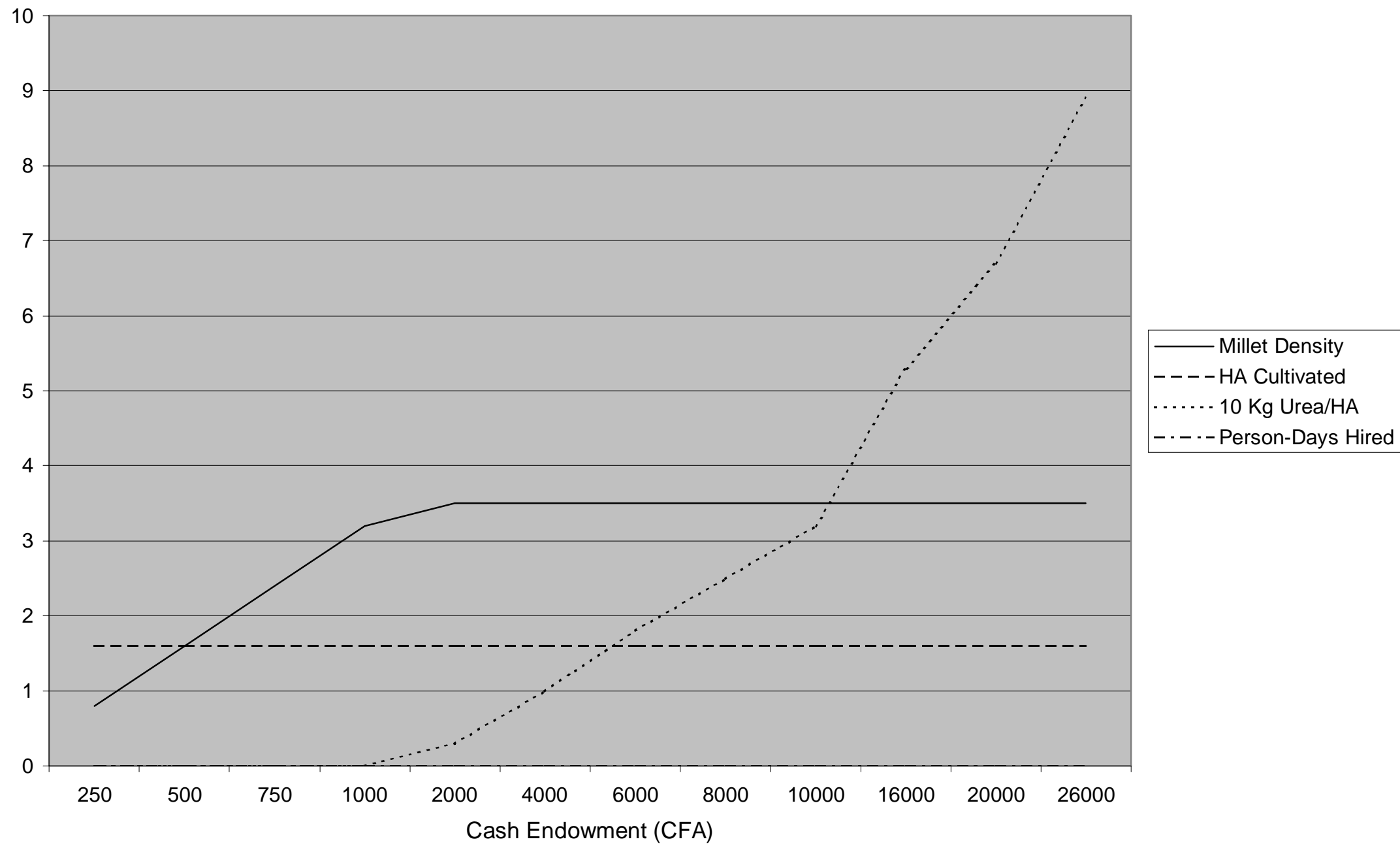


In Mourdiah, the UP first cultivates as many hectares as possible without hired labor, spending all of its cash on seed. The amount of land the UP can cultivate by itself is constrained by the UP's labor endowment during the first weeding. ${ }^{52}$ When the cash endowment exceeds the amount necessary to purchase seed to plant at the maximum allowable density $\left(3.5 / \mathrm{m}^{2}\right)$ on the acreage it can cultivate itself, the UP begins to hire labor to expand its cultivated land. The labor is hired to perform the first weeding.

As the UP expands its cultivated acreage, it eventually encounters the second labor-land constraint: labor for the second weeding. The UP must now purchase additional labor for both the first and second weeding in order to cultivate more land. As a result, the returns to increasing acreage fall below the returns to urea application. ${ }^{53}$ So, the UP first hires labor for the first weeding, and then spends the remainder of its cash on urea.

In Sirakorola, it does not pay to hire labor in this scenario. Cash is first spent to purchase millet seed. After the UP can afford enough seed to plant at the maximum density on the land it can cultivate by itself, extra cash is spent on urea fertilizer.

As the optimal practices in the absence of Striga depend on the cash endowment, the benefits of shifting from status quo production to the optimal practices also depend on the cash endowment. Five levels of cash endowment are considered below: (1) Very Low, where total expenditures are less than or equal to 2,000 CFA per year; (2) Low, with total expenditure less than or equal to 10,000 CFA per year; (3) Moderate, with yearly expenditure $\leq 25,000$; (4) High, with yearly expenditure $\leq 50,000$; and (5) Very High, with yearly expenditure $\leq 100,000$.

Tables 6.7 and 6.8 present, for each UP size and budget level, estimates of the yearly increase in expected net returns due to shifting from status quo production to the optimal practices in Mourdiah and Sirakorola, respectively. The increase in expected net returns

\footnotetext{
${ }^{52}$ The first weeding, performed in the middle of the season, does not include weeding Striga.

${ }^{53}$ The maximum number of hectares the UP can cultivate by hiring labor for the first weeding alone depends on the UP size.
} 
Table 6.8: Increases in Expected Net Revenue (1,000 CFA) Due to Shift from Status Quo to Optimal Millet Production in the Absence of Striga in Mourdiah

\begin{tabular}{|c|c|c|c|c|c|c|c|}
\hline \multirow[b]{2}{*}{$\begin{array}{l}\text { Budget } \\
\text { Level }\end{array}$} & \multirow[b]{2}{*}{ Year } & \multicolumn{6}{|c|}{ UP Size } \\
\hline & & $\begin{array}{l}\text { Extra } \\
\text { Small } \\
\end{array}$ & Small & Medium & Large & $\begin{array}{l}\text { Extra } \\
\text { Large }\end{array}$ & $\begin{array}{c}\text { Extra Extra } \\
\text { Large }\end{array}$ \\
\hline \multirow[t]{4}{*}{ Very Low } & 1 & 4.9 & 7.6 & 7.2 & 5 & 68.1 & 69.7 \\
\hline & 2 & 4.4 & 6.8 & 6.5 & 4.5 & 61.3 & 62.7 \\
\hline & 3 & 4 & 6.1 & 5.8 & 4.1 & 55.2 & 56.5 \\
\hline & Total & 13.3 & 20.5 & 19.5 & 13.6 & 184.5 & 188.8 \\
\hline \multirow[t]{4}{*}{ Low } & 1 & 8 & 10.7 & 18.3 & 23.3 & 46.9 & 47.2 \\
\hline & 2 & 7.2 & 9.6 & 16.5 & 20.9 & 42.3 & 42.4 \\
\hline & 3 & 6.5 & 8.6 & 14.8 & 18.9 & 38 & 38.2 \\
\hline & Total & 21.7 & 28.9 & 49.6 & 63.1 & 127.2 & 127.7 \\
\hline \multirow[t]{4}{*}{ Moderate } & 1 & 13.4 & 16.3 & 24.1 & 29.1 & 52.7 & 52.4 \\
\hline & 2 & 12.1 & 14.7 & 21.7 & 26.2 & 47.5 & 47.2 \\
\hline & 3 & 10.8 & 13.2 & 19.5 & 23.5 & 42.7 & 42.4 \\
\hline & Total & 36.3 & 44.2 & 65.4 & 78.8 & 142.9 & 142 \\
\hline \multirow[t]{4}{*}{ High } & 1 & 22.2 & 25.1 & 33.5 & 38.7 & 62.4 & 61.2 \\
\hline & 2 & 20 & 22.6 & 30.2 & 34.8 & 56.2 & 55.1 \\
\hline & 3 & 18 & 20.4 & 27.2 & 31.3 & 50.6 & 49.6 \\
\hline & Total & 60.2 & 68.1 & 90.9 & 104.8 & 169.2 & 165.9 \\
\hline \multirow[t]{4}{*}{ Very High } & 1 & 39.9 & 42.8 & 51.2 & 56.3 & 81.9 & 78.9 \\
\hline & 2 & 35.9 & 38.5 & 46.1 & 50.7 & 73.7 & 71 \\
\hline & 3 & 32.3 & 34.6 & 41.5 & 45.6 & 66.3 & 63.9 \\
\hline & Total & 108 & 115.9 & 138.8 & 152.6 & 221.9 & 213.8 \\
\hline
\end{tabular}


Table 6.9: Increase in Expected Net Returns (1,000 CFA) Due to Shift from Status Quo to Optimal Millet Production in the Absence of Striga in Sirakorola

\begin{tabular}{|c|c|c|c|c|c|}
\hline \multirow{2}{*}{$\begin{array}{l}\text { Budget } \\
\text { Level }\end{array}$} & \multirow[b]{2}{*}{ Year } & \multicolumn{4}{|c|}{ UP Size } \\
\hline & & Extra Small & Small & Medium & Large \\
\hline \multirow[t]{5}{*}{ Very Low } & 1 & 11 & 10.6 & 13.9 & 9.2 \\
\hline & 2 & 9.8 & 9.6 & 12.5 & 8.2 \\
\hline & 3 & 8.8 & 8.6 & 11.2 & 7.4 \\
\hline & 4 & 8 & 7.8 & 10.1 & 6.7 \\
\hline & Total & 37.6 & 36.6 & 47.8 & 31.5 \\
\hline \multirow[t]{5}{*}{ Low } & 1 & 19.6 & 19.2 & 24.8 & 46.8 \\
\hline & 2 & 17.6 & 17.3 & 22.3 & 42.1 \\
\hline & 3 & 15.8 & 15.6 & 20.1 & 37.9 \\
\hline & 4 & 14.2 & 14 & 18.1 & 34.1 \\
\hline & Total & 67.2 & 66.1 & 85.2 & 160.9 \\
\hline \multirow[t]{5}{*}{ Moderate } & 1 & 35.7 & 35.3 & 38.9 & 63.6 \\
\hline & 2 & 32.1 & 31.8 & 35 & 57.2 \\
\hline & 3 & 28.9 & 28.7 & 31.5 & 51.5 \\
\hline & 4 & 26 & 25.8 & 28.4 & 46.4 \\
\hline & Total & 122.6 & 121.6 & 133.9 & 218.7 \\
\hline \multirow[t]{5}{*}{ High } & 1 & 62.6 & 62.2 & 62.5 & 91.6 \\
\hline & 2 & 56.3 & 56 & 56.3 & 82.4 \\
\hline & 3 & 50.6 & 50.4 & 50.6 & 74.2 \\
\hline & 4 & 45.6 & 45.3 & 45.6 & 66.8 \\
\hline & Total & 215 & 213.9 & 215 & 315 \\
\hline \multirow[t]{5}{*}{ Very High } & 1 & 116.3 & 115.9 & 109.7 & 147.6 \\
\hline & 2 & 104.6 & 104.3 & 98.7 & 132.8 \\
\hline & 3 & 94.1 & 93.9 & 88.9 & 119.6 \\
\hline & 4 & 84.7 & 84.5 & 80 & 107.6 \\
\hline & Total & 399.7 & 398.7 & 377.3 & 507.6 \\
\hline
\end{tabular}


are generated by increases in expected yields. As a result, each $\mathrm{UP}_{\mathrm{I}, \mathrm{Z}}$ also realizes nutritional gains from adopting the optimal practices.

In the absence of Striga, the model recommends a different set of practices than are currently employed in Mourdiah and Sirakorola, and predicts substantial financial and nutritional benefits from adopting the optimal practices. Striga, however, is prevalent in both zones. The next section incorporates average Striga infestation into the production environment and requires the model to choose the optimal production practices.

\section{Section 6.5 Scenario IV: Optimal Practices with Average Striga Infestation}

Scenario IV is designed to represent the current production environment in Mourdiah and Sirakorola. Striga infestation in the first year of the planning horizon is set to 40,000 seeds $\mathrm{m}^{-2}$. The model is free to employ any of the three crop associations, to choose millet density and urea application rates, and to allocate the UP's own labor. Additional labor may also be hired to weed Striga or perform other required tasks.

When the UP is able purchase additional inputs, the budget constraint may or may not be binding at any given level. As in Scenario III, five budget levels are considered in Scenario IV: (1) Very Low, where total expenditures are less than or equal to 2,000 CFA per year; (2) Low, with total expenditure less than or equal to 10,000 CFA per year; (3) Moderate, with yearly expenditure $\leq 25,000$; (4) High, with yearly expenditure $\leq 50,000$; and (5) Very High, with yearly expenditure $\leq 100,000$. The results of each budget level are discussed, separately.

Optimal Production with a Very Low Budget. Even with a budget of 2,000 CFA per year, all of the UP's, irrespective of size and zone, can afford to cultivate as much acreage as their own labor is able to under status quo millet production. As it turns out, however, the model does not recommend status quo production for any $\mathrm{UP}_{\mathrm{I}, \mathrm{Z}}$ with average Striga infestation. Tables 6.9 and 6.10 present the practices chosen by the model in each year in Mourdiah and Sirakorola, respectively. 
Table 6.10: Optimal Practices in Mourdiah with Average Striga Infestation and a Very Low Budget

(Starting Seedbank $=40,000 / \mathrm{m}^{2}$, Expenditures $\leq 2,000$ CFA $/$ Year)

\begin{tabular}{|l|c|c|c|}
\hline Input & Year 1 & Year 2 & Year 3 \\
\hline Association & Pure Millet & Pure Millet & Pure Millet \\
\hline Millet Density $\left(\mathrm{m}^{-2}\right)$ & 0.5 & 0.5 & 0.5 \\
\hline Urea (kg/ha) & 0 & 0 & 0 \\
\hline $\begin{array}{l}\text { Hired Labor } \\
\text { (Person-Days/ha) }\end{array}$ & 0 & 0 & 0 \\
\hline $\begin{array}{l}\text { UP Labor by Task } \\
\text { (Person-Days/ha) }\end{array}$ & \multicolumn{3}{|l|}{} \\
\hline Sowing/Preparation & 10 & 10 & 10 \\
\hline First Weeding & 21 & 21 & 21 \\
\hline Second Weeding & 14 & 14 & 14 \\
\hline First Striga Weeding, XS - XL & 10.5 & 10.5 & 0 \\
\hline First Striga Weeding, XXL & 14.6 & 9.7 & 0 \\
\hline Harvest & 4 & 4 & 4 \\
\hline Second Striga Weeding, XS - XL & 4.5 & 4.5 & 0 \\
\hline Second Striga Weeding, XXL & 11.9 & 9.7 & 0 \\
\hline Post-Harvest & 6 & 6 & \\
\hline
\end{tabular}


Table 6.11: Optimal Practices in Sirakorola with Average Striga Infestation and a Very Low Budget

(Starting Seedbank $=40,000 / \mathrm{m}^{2}$, Expenditures $\leq 2,000 \mathrm{CFA} /$ Year)

\begin{tabular}{|l|c|c|c|c|}
\hline Input & Year 1 & Year 2 & Year 3 & Year 4 \\
\hline Association & Pure Millet & Pure Millet & Pure Millet & Pure Millet \\
\hline Millet Density $\left(\mathrm{m}^{-2}\right)$ & 3.5 & 3.5 & 3.5 & 3.5 \\
\hline Urea (kg/ha) & 0 & 0 & 0 & 0 \\
\hline $\begin{array}{l}\text { Hired Labor } \\
\text { (Person-Days/ha) }\end{array}$ & 0 & 0 & 0 & 0 \\
\hline $\begin{array}{l}\text { UP Labor by Task } \\
\text { (Person-Days/ha) }\end{array}$ & \multicolumn{5}{|l|}{} \\
\hline Sowing/Preparation & 10 & 10 & 10 & 10 \\
\hline First Weeding & 21 & 21 & 21 & 21 \\
\hline Second Weeding & 14 & 14 & 14 & 14 \\
\hline First Striga Weeding, XS - S & 10.5 & 10.5 & 10.5 & 0 \\
\hline First Striga Weeding, M & 12.1 & 12.1 & 12.1 & 0 \\
\hline First Striga Weeding, L & 23.5 & 23.5 & 23.5 & 0 \\
\hline Harvest & 4 & 4 & 4 & 4 \\
\hline Second Striga Weeding, XS -S & 4.5 & 4.5 & 4.5 & 0 \\
\hline Second Striga Weeding, M & 6.1 & 6.1 & 6.1 & 0 \\
\hline Second Striga Weeding, L & 17.5 & 17.5 & 17.5 & 0 \\
\hline Post-Harvest & 6 & 6 & 6 & 6 \\
\hline
\end{tabular}


In both zones, millet in a pure stand is chosen over the millet-cowpea and milletgroundnut associations. The reason for this can be seen in the model's selection of millet planting density. The optimal density, $0.5 \mathrm{~m}^{-2}$ in Mourdiah and $3.5 \mathrm{~m}^{-2}$ in Sirakorola, does not coincide with the fixed density of either of the inter-cropped associations. The losses in millet yield from adopting the density of either association is not compensated for by the additional cowpea yield of the millet-cowpea association, or by the combined benefits of reduced Striga stimulation and additional groundnut yield of the milletgroundnut association.

The difference in the optimal millet density in the two zones can be traced to the millet production functions. The production functions for Mourdiah and Sirakorola, developed in Chapter 4, are rewritten here as Equations (6.1M) and (6.1S), respectively. ${ }^{54}$

$$
\begin{aligned}
& \mathrm{Y}=30.9 * \mathrm{C}+(348.6+10.5 * \mathrm{~N}) /(1+0.24 * \mathrm{X}) \\
& \mathrm{Y}=54.7 * \mathrm{C}+(134.4+16.1 * \mathrm{~N}) /(1+0.24 * \mathrm{X}) \\
& \text { Where } \mathrm{Y}=\text { millet yield }(\mathrm{kg}) \text { per ha } \\
& \mathrm{C}=\text { millet density per } \mathrm{m}^{2} \\
& \mathrm{~N}=\text { kg nitrogen applied per ha } \\
& \mathrm{X}=\text { number of emerged Striga } \text { per } \mathrm{m}^{2}
\end{aligned}
$$

The model's selection of millet density is driven by three considerations: (1) the pure response of millet yield to millet density, represented by the first element on the righthand side of each equation; (2) the effect of millet density on the density of emerged Striga; and (3) the response of millet yield to the density of emerged Striga. In Mourdiah, the pure yield response to millet density is relatively low, whereas the negative yield response to Striga density is high. As Striga density is strictly increasing in millet density, the farmer has little to gain and a lot to lose by planting at a high density in Mourdiah.

\footnotetext{
${ }^{54}$ As mentioned in Chapter 4, the difference in the production functions is due to differences in average rainfall in the two zones.
} 
Farmers in Sirakorola face the opposite situation - a high pure yield response to millet density and low negative yield response to Striga. Here it pays for farmers to plant at a higher density and forfeit the losses due to increased Striga to realize the yield gains from high density production.

Urea application is not an optimal practice in either zone when the UP has a very low budget and is facing average Striga infestation levels. Two factors prevent urea from entering the low budget solution to Scenario IV: (1) the high level of the Striga seedbank; and (2) the low level of cash available for the purchase of urea.

Returns to urea are contingent on emerged Striga density. At the given prices of urea and millet, urea application is not profitable until the density of emerged Striga is below 4.5 $\mathrm{m}^{-2}$ in Sirakorola, and $1.5 \mathrm{~m}^{-2}$ in Mourdiah. The density of emerged Striga may be reduced by either reducing the seedbank, reducing millet density, or applying urea. The response of emerged Striga to urea, however, is quadratic: at low application rates emerged Striga increases; high rates (greater than $225 \mathrm{~kg} / \mathrm{ha}$ ) retard Striga emergence. With a very low budget, the UP cannot afford to purchase enough urea for it to be profitable.

Labor application rates for each of the required agricultural tasks, sowing, non-Striga weeding, harvest, and post-harvest activities, are the same in Scenario IV as they are under status quo production. Furthermore, it does not pay to hire additional labor to perform any of the agricultural tasks. The optimal practices do, however, require additional labor from the UP.

The additional labor is used to hand-pull the flowering Striga in all but the final season of the planning horizon. As long as there are Striga in the field, the model suggests the UP use its own labor to pull them, but hiring additional labor for weeding Striga is not profitable. 
Tables 6.11 and 6.12 present the financial and nutritional returns to the optimal set of practices for each UP size in Mourdiah and Sirakorola, respectively. Millet yield and expenditures are also presented for each season, along with estimated changes in the seedbank density.

In Mourdiah, optimal production practices lead to a marked decline in the seedbank. However, the reduced Striga seed density translates to modest yield increases in subsequent seasons, and the present value of net returns is, essentially, constant across seasons for all but $\mathrm{UP}_{\mathrm{XXL}}$, Mourdiah. ${ }^{55}$ The modest yield increases translate into modest nutritional gains for the UP.

The high millet density in Sirakorola has the opposite effects as the low density in Mourdiah, but with similar magnitudes. When millet is planted at $3.5 \mathrm{~m}^{-2}$, so many Striga emerge that the UP is unable to hand-pull enough to prevent the seedbank from growing four-fold in the first season alone. The effect of Striga on millet yields, however, is low compared to Mourdiah. The inter-seasonal decline in millet yield is modest, which translates to modest nutritional losses for the UP. The reduction in net returns between seasons is driven almost entirely by the UP's inter-temporal discount rate.

While the optimal practices generate modest inter-seasonal effects, they perform substantially better than status quo production practices, both financially and nutritionally. The extra revenue and nutrition comes at a cost, however. Tables 6.13 and 6.14 present estimates of the increase in expenditures and labor demands, and the financial and nutritional gains from adopting the optimal rather than status quo practices.

Expenditures are lower in Mourdiah because you are planting at a lower density and, therefore, spending less on seed. They are higher in Sirakorola for the same reason.

\footnotetext{
55 The land constraint for the XXL UP in Mourdiah is binding, allowing more labor to weed Striga, resulting in larger reductions in the seedbank and higher yields in each subsequent season.
} 
Table 6.12: Estimated Financial and Nutritional Returns, Millet Production, Seedbank Growth, and Expenditures in Mourdiah Under Optimal Practices with a Very Low Budget and Average Striga Infestation

\begin{tabular}{|c|c|c|c|c|c|c|c|c|c|}
\hline \multirow[b]{2}{*}{ UP Size } & \multirow[b]{2}{*}{ Year } & \multirow{2}{*}{$\begin{array}{c}\text { Seedbank } \\
\left(10^{3} \text { seeds } \mathrm{m}^{-2}\right)\end{array}$} & \multirow{2}{*}{$\begin{array}{l}\text { Area } \\
\text { (ha) }\end{array}$} & \multirow{2}{*}{$\begin{array}{c}\text { Millet } \\
\text { Production } \\
(\mathrm{kg})\end{array}$} & \multicolumn{3}{|c|}{$\%$ Nutrient Requirement } & \multirow{2}{*}{$\begin{array}{c}\text { Expenditures } \\
(1,000 \text { CFA })\end{array}$} & \multirow{2}{*}{$\begin{array}{c}\text { Present } \\
\text { Value of Net } \\
\text { Returns } \\
(1,000 \mathrm{CFA})\end{array}$} \\
\hline & & & & & Energy & Protein & Iron & & \\
\hline \multirow[t]{3}{*}{ Extra Small } & 1 & 40 & 1.34 & 191 & 18.3 & 26.8 & 34.5 & 0.134 & 9.4 \\
\hline & 2 & 33.6 & 1.34 & 205 & 19.7 & 28.8 & 37 & 0.134 & 9.1 \\
\hline & 3 & 27.1 & 1.34 & 224 & 21.5 & 31.5 & 40.4 & 0.134 & 9.0 \\
\hline \multirow[t]{3}{*}{ Small } & 1 & 40 & 2.19 & 312 & 16.7 & 23.5 & 27.7 & 0.219 & 15.4 \\
\hline & 2 & 33.5 & 2.19 & 335 & 18 & 25.2 & 29.7 & 0.219 & 14.9 \\
\hline & 3 & 27.1 & 2.19 & 365 & 19.6 & 27.5 & 32.4 & 0.219 & 14.6 \\
\hline \multirow[t]{3}{*}{ Medium } & 1 & 40 & 4.67 & 664 & 14.7 & 20.7 & 24.7 & 0.467 & 32.7 \\
\hline & 2 & 33.5 & 4.67 & 713 & 15.8 & 22.2 & 26.6 & 0.467 & 31.7 \\
\hline & 3 & 27 & 4.67 & 778 & 17.2 & 24.2 & 29 & 0.467 & 31.1 \\
\hline \multirow[t]{3}{*}{ Large } & 1 & 40 & 6.27 & 892 & 14 & 19.5 & 23.4 & 0.627 & 44.0 \\
\hline & 2 & 33.4 & 6.27 & 960 & 15.1 & 21 & 25.2 & 0.627 & 42.6 \\
\hline & 3 & 26.8 & 6.27 & 1049 & 16.5 & 22.9 & 27.6 & 0.627 & 42.0 \\
\hline \multirow[t]{3}{*}{ Extra Large } & 1 & 40 & 13.9 & 1983 & 17 & 23.8 & 29.1 & 1.390 & 97.8 \\
\hline & 2 & 33.4 & 13.9 & 2133 & 18.2 & 25.6 & 31.3 & 1.390 & 94.7 \\
\hline & 3 & 26.8 & 13.9 & 2331 & 20 & 28 & 34.3 & 1.390 & 93.3 \\
\hline \multirow{3}{*}{$\begin{array}{l}\text { Extra Extra } \\
\text { Large }\end{array}$} & 1 & 40 & 14 & 1992 & 9.8 & 13.5 & 16.3 & 1.400 & 98.2 \\
\hline & 2 & 23.6 & 14 & 2466 & 12.2 & 16.7 & 20.2 & 1.400 & 109.7 \\
\hline & 3 & 12.6 & 14 & 3110 & 15.3 & 21.1 & 25.5 & 1.400 & 124.8 \\
\hline
\end{tabular}


Table 6.13: Estimated Financial and Nutritional Returns, Millet Production, Seedbank Growth, and Expenditures in Sirakorola Under Optimal Practices with a Very Low Budget and Average Striga Infestation

\begin{tabular}{|c|c|c|c|c|c|c|c|c|c|}
\hline \multirow[b]{2}{*}{ UP Size } & \multirow[b]{2}{*}{ Year } & \multirow{2}{*}{$\begin{array}{c}\text { Seedbank } \\
\left(10^{3} \text { seeds } \mathrm{m}^{-2}\right)\end{array}$} & \multirow{2}{*}{$\begin{array}{c}\text { Area } \\
\text { (ha) }\end{array}$} & \multirow[b]{2}{*}{$\begin{array}{c}\text { Millet } \\
\text { Production } \\
(\mathrm{kg})\end{array}$} & \multicolumn{3}{|c|}{$\%$ Nutrient Requirement } & \multirow{2}{*}{$\begin{array}{c}\text { Expenditures } \\
(1,000 \text { CFA) }\end{array}$} & \multirow{2}{*}{$\begin{array}{l}\text { Present Value o } \\
\text { Net Returns } \\
(1,000 \text { CFA })\end{array}$} \\
\hline & & & & & Energy & Protein & Iron & & \\
\hline \multirow[t]{4}{*}{ Extra Small } & 1 & 40 & 1.57 & 318 & 29.9 & 42.1 & 59.2 & 1.100 & 14.8 \\
\hline & 2 & 156 & 1.57 & 309 & 29.1 & 40.9 & 57.5 & 1.100 & 12.9 \\
\hline & 3 & 405 & 1.57 & 307 & 28.9 & 40.7 & 57.1 & 1.100 & 11.5 \\
\hline & 4 & 650 & 1.57 & 307 & 28.9 & 40.7 & 57.1 & 1.100 & 10.4 \\
\hline \multirow[t]{4}{*}{ Small } & 1 & 40 & 1.51 & 307 & 17 & 23 & 32.5 & 1.060 & 14.3 \\
\hline & 2 & 163 & 1.51 & 298 & 16.5 & 22.3 & 31.5 & 1.060 & 12.5 \\
\hline & 3 & 423 & 1.51 & 296 & 16.4 & 22.2 & 31.3 & 1.060 & 11.1 \\
\hline & 4 & 679 & 1.51 & 295 & 16.3 & 22.1 & 31.2 & 1.060 & 10.0 \\
\hline \multirow[t]{4}{*}{ Medium } & 1 & 40 & 2.85 & 579 & 15.2 & 21.6 & 27.2 & 2.000 & 27.0 \\
\hline & 2 & 160 & 2.85 & 562 & 14.7 & 20.9 & 26.4 & 2.000 & 23.5 \\
\hline & 3 & 415 & 2.85 & 558 & 14.6 & 20.8 & 26.2 & 2.000 & 21.0 \\
\hline & 4 & 667 & 2.85 & 557 & 14.6 & 20.7 & 26.1 & 2.000 & 18.8 \\
\hline \multirow[t]{4}{*}{ Large } & 1 & 40 & 2.85 & 579 & 8.2 & 11.6 & 15.2 & 2.000 & 27.0 \\
\hline & 2 & 142 & 2.85 & 563 & 8 & 11.3 & 14.7 & 2.000 & 23.5 \\
\hline & 3 & 371 & 2.85 & 559 & 7.9 & 11.2 & 14.6 & 2.000 & 21.0 \\
\hline & 4 & 618 & 2.85 & 558 & 7.9 & 11.2 & 14.6 & 2.000 & 18.9 \\
\hline
\end{tabular}


Table 6.14: Estimated Changes in Expenditures, Labor Use, Nutritional and Financial Returns from Adopting the Optimal Practices in Mourdiah with a Very Low Budget and Average Striga Infestation

\begin{tabular}{|c|c|c|c|c|c|c|c|c|}
\hline \multirow[b]{2}{*}{ UP Size } & \multirow[b]{2}{*}{ Year } & \multirow{2}{*}{$\begin{array}{c}\text { Acreage } \\
\text { (HA) }\end{array}$} & \multirow{2}{*}{$\begin{array}{c}\text { Expenditures } \\
\text { (CFA) }\end{array}$} & \multirow{2}{*}{$\begin{array}{c}\text { Labor Use } \\
\text { (Person-Days) }\end{array}$} & \multicolumn{3}{|c|}{$\%$ Nutrient Requirement } & \multirow{2}{*}{$\begin{array}{c}\text { Present Value of } \\
\text { Net Returns } \\
(1,000 \text { CFA })\end{array}$} \\
\hline & & & & & Energy & Protein & Iron & \\
\hline \multirow[t]{3}{*}{ Extra Small } & 1 & 0 & -134 & 20 & 4.2 & 6.1 & 8 & 2.3 \\
\hline & 2 & 0 & -134 & 20 & 8.2 & 11.9 & 15.3 & 4.0 \\
\hline & 3 & 0 & -134 & 0 & 11.3 & 16.6 & 21.3 & 4.9 \\
\hline \multirow[t]{3}{*}{ Small } & 1 & 0 & -219 & 33 & 3.8 & 5.4 & 6.4 & 3.8 \\
\hline & 2 & 0 & -219 & 33 & 7.3 & 10.1 & 12 & 6.35 \\
\hline & 3 & 0 & -219 & 0 & 10.2 & 14.3 & 16.9 & 7.9 \\
\hline \multirow[t]{3}{*}{ Medium } & 1 & 0 & -467 & 70 & 3.4 & 4.8 & 5.7 & 8.2 \\
\hline & 2 & 0 & -467 & 70 & 6.5 & 9.1 & 8 & 13.6 \\
\hline & 3 & 0 & -467 & 0 & 9 & 12.7 & 15.2 & 16.9 \\
\hline \multirow[t]{3}{*}{ Large } & 1 & 0 & -627 & 94 & 3.2 & 4.5 & 5.4 & 11.0 \\
\hline & 2 & 0 & -627 & 94 & 6.7 & 8.8 & 10.5 & 18.6 \\
\hline & 3 & 0 & -627 & 0 & 8.6 & 12 & 14.5 & 22.7 \\
\hline \multirow[t]{3}{*}{ Extra Large } & 1 & 0 & -1390 & 208 & 4 & 5.5 & 6.7 & 24.3 \\
\hline & 2 & 0 & -1390 & 208 & 7.5 & 10.6 & 12.9 & 41.0 \\
\hline & 3 & 0 & -1390 & 0 & 10.5 & 14.7 & 18 & 50.6 \\
\hline \multirow{3}{*}{$\begin{array}{l}\text { Extra Extra } \\
\text { Large }\end{array}$} & 1 & 0 & -1400 & 210 & 2.3 & 3.1 & 3.8 & 24.5 \\
\hline & 2 & 0 & -1400 & 210 & 6 & 8.2 & 9.9 & 55.5 \\
\hline & 3 & 0 & -1400 & 0 & 9.8 & 13.5 & 16.4 & 81.9 \\
\hline
\end{tabular}


Table 6.15: Estimated Changes in Expenditures, Labor Use, Nutritional and Financial Returns from Adopting the Optimal Practices in Sirakorola with a Very Low Budget and Average Striga Infestation

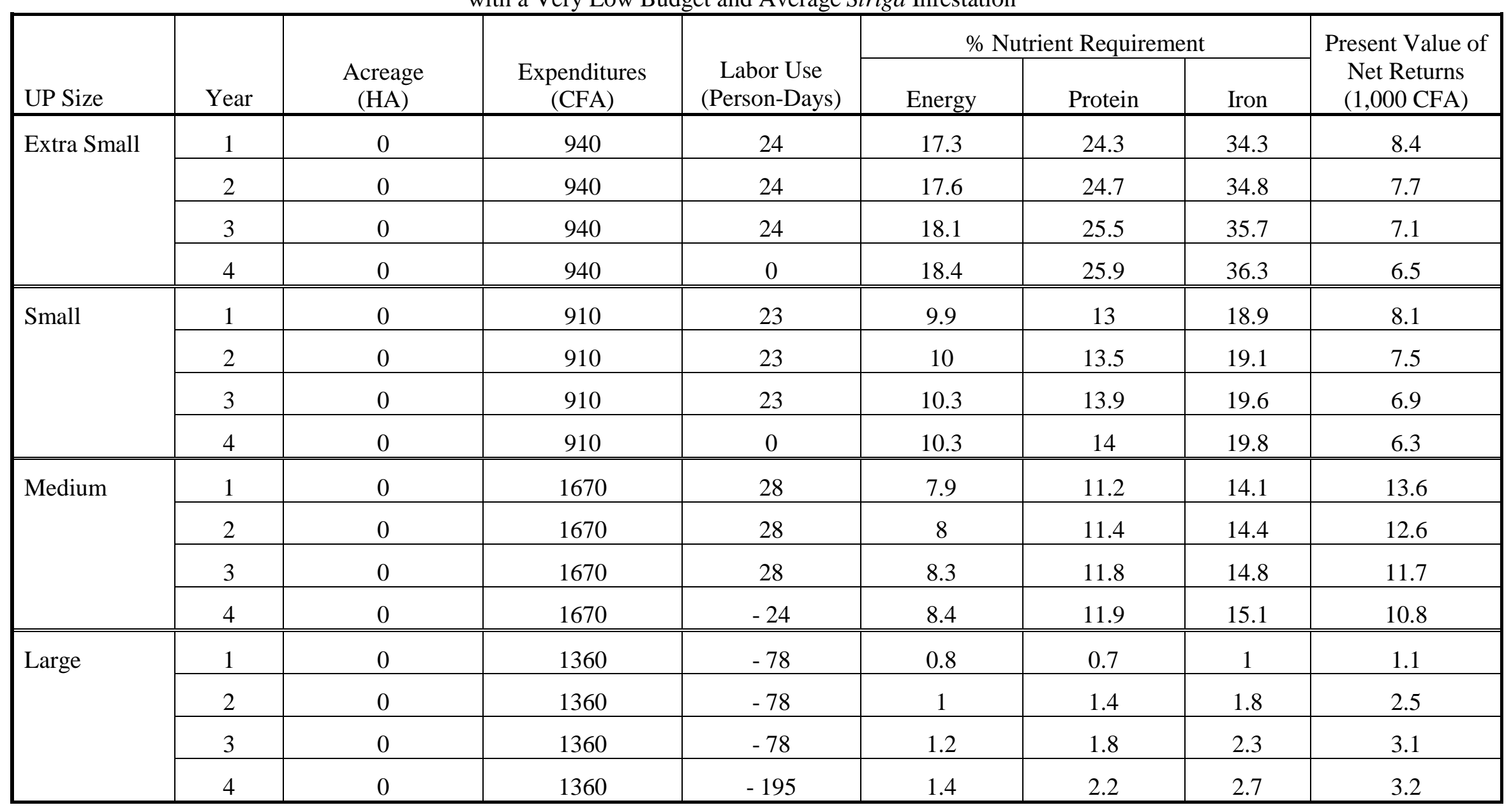


Labor demand is lower than under status quo production for Large UP's in Sirakorola because the budget constraint is binding. This forces them to plant fewer hectares which saves labor for the required tasks. Extra labor is used to weed Striga, but the net effect is a saving in total labor throughout the season. Although $\mathrm{UP}_{\mathrm{M} \text {, Sirakorola }}$ also realize labor savings from planting less acreage, additional labor is used to weed Striga in the first three seasons and the net effect is an increase in total agricultural labor; in the final season the UP does not weed Striga, leading to a net decrease in labor.

Figures $6.7-6.10$ illustrate the financial and nutritional gains generated by adoption of the optimal set of practices.

Returns to labor for weeding Striga are dependent on the size of the seedbank, the number of emerged Striga, and the UP's budget constraint. Need Separate Section for this discussion.

Optimal Production with a Low Budget. As the UP's budget grows, the opportunities for employing Striga control measures broaden. With a low level budget, the medium and large UP's in Sirakorola can afford to expand their acreage to the level they planted under status quo production. The budget is still too low, however, for the other UP's to invest in Striga control measures.

For all UP's in Mourdiah, the results presented in Tables 6.9, 6.11, and 6.13 are also valid when the UP has a low level budget. In Sirakorola, the low budget results are the same as presented in Tables 6.10, 6.12, and 6.14 for extra small and small UPs.

The low budget results for $\mathrm{UP}_{\mathrm{M}}$, Sirakorla and $\mathrm{UP}_{\mathrm{L} \text {, Sirakorla }}$ are presented in Tables 6.15, 6.16, and 6.17. The extra acreage the UP's are able to cultivate with the additional cash translates into higher millet yields, more nutrients, and greater profits. 
Figure 6.7: Change in Net Returns from Adopting Optimal Practices with Average Striga and Very Low Budget

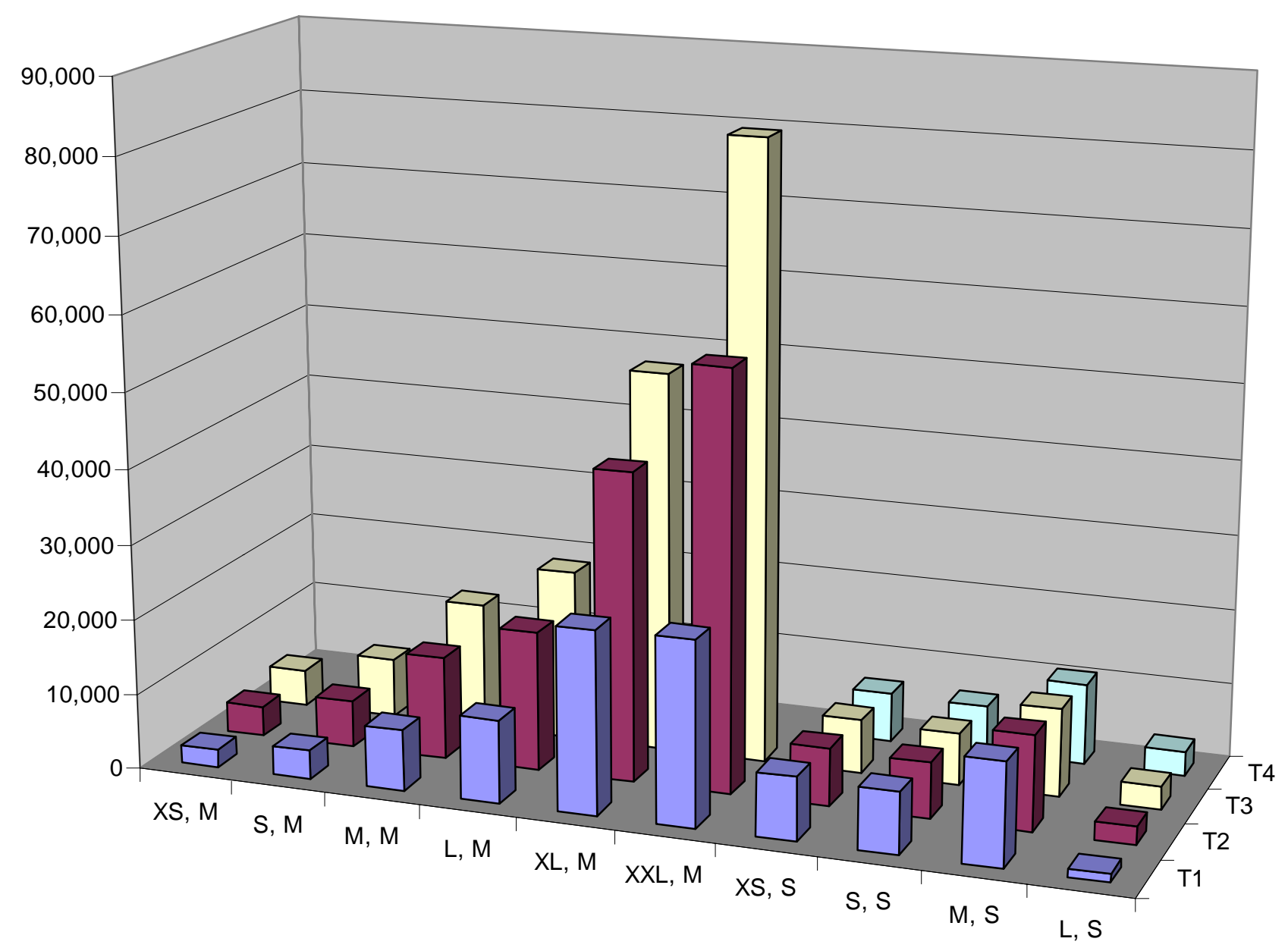


Figure 6.8: Change in \% UP KCal Requirement Met from Adopting Optimal Practices with Average Striga and Very Low Budget

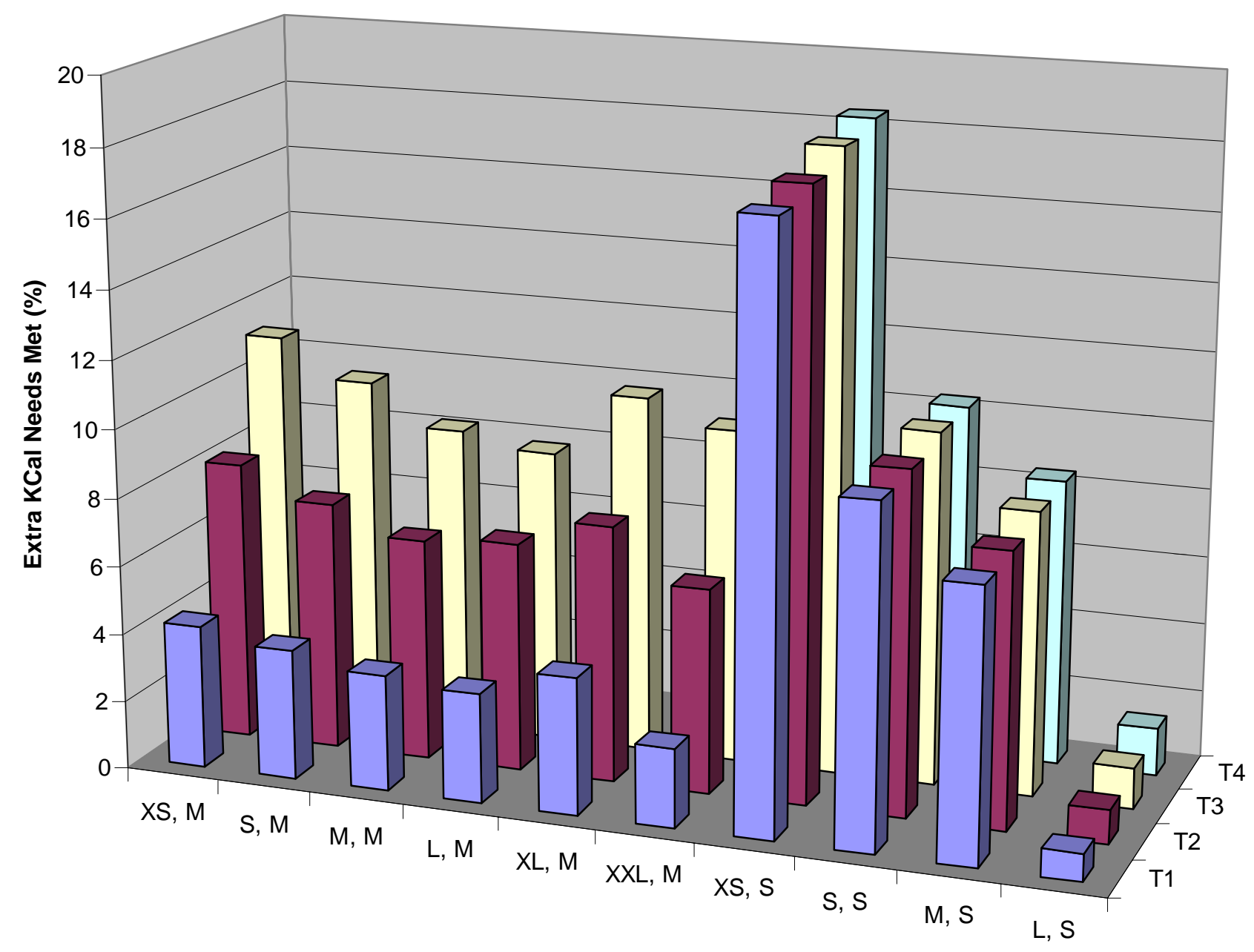


Figure 6.9: Change in \% UP Protein Requirement Met from Adopting Optimal Practices with Average Striga and Very Low Budget

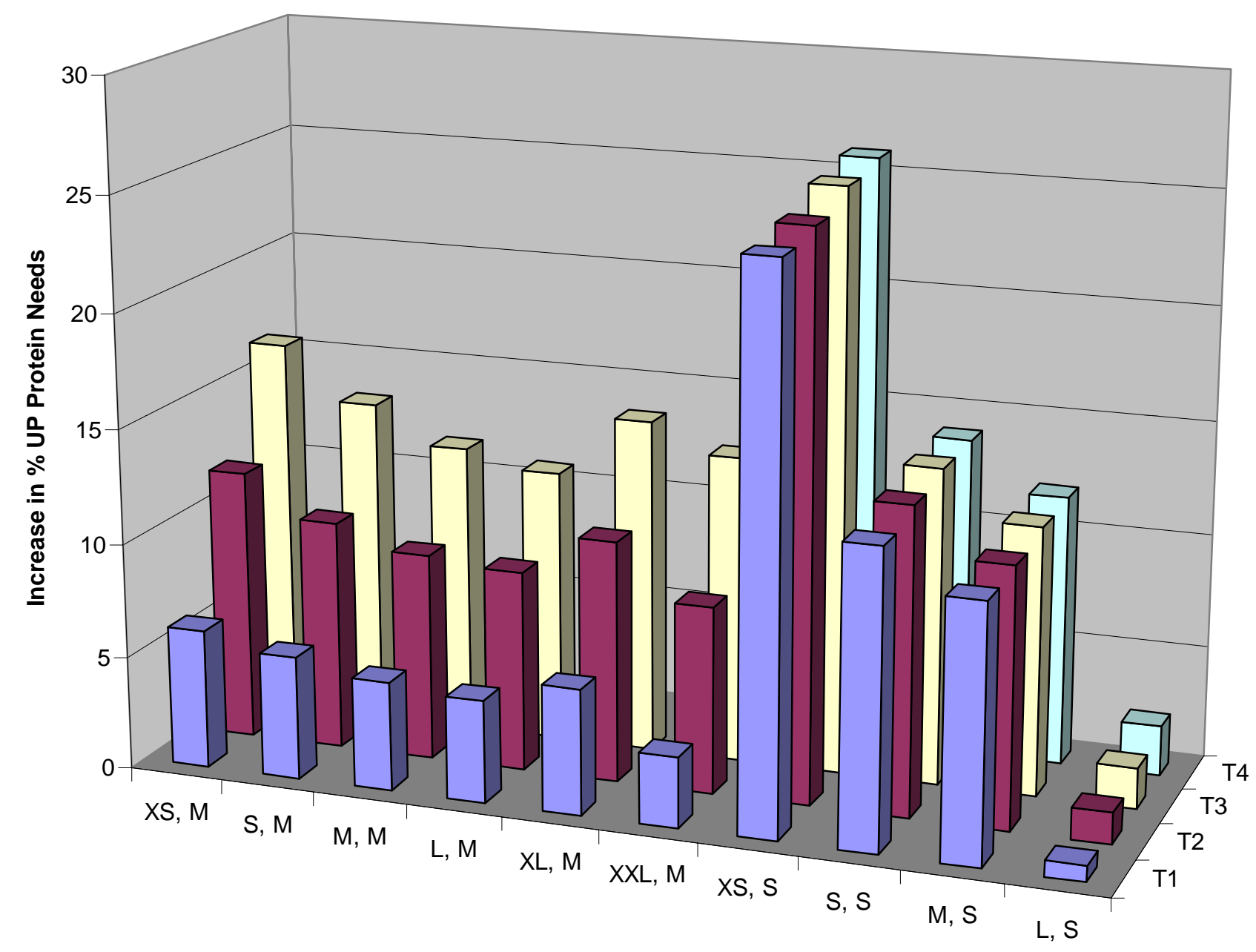


Firgure 6.10: Change in \% UP Iron Requirement Met from Adopting Optimal Practices with Average Striga and Very Low Budget

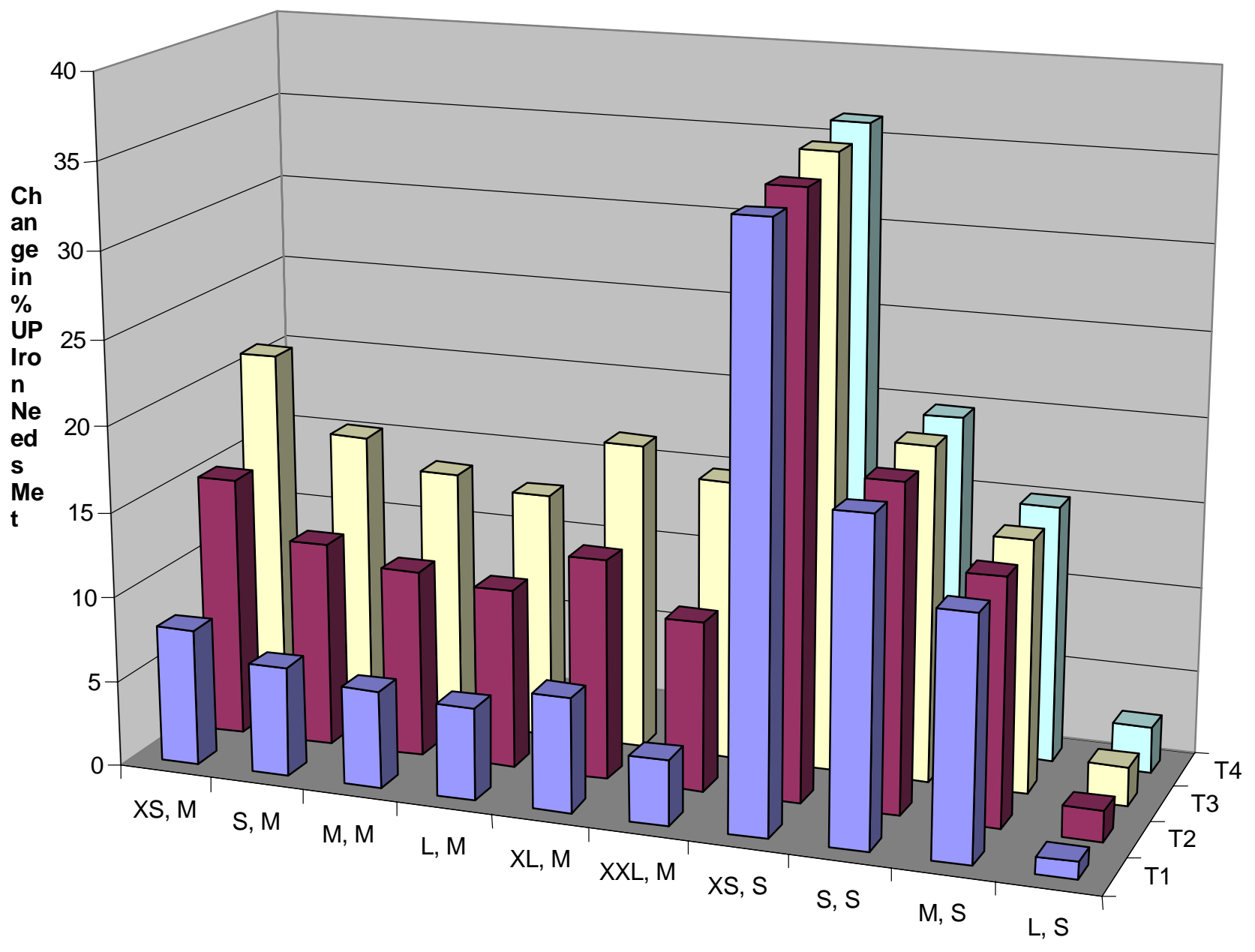


Table 6.16: Optimal Practices for Medium and Large UPs in Sirakorola with Average Striga Infestation and a Low Budget

(Starting Seedbank $=40,000 / \mathrm{m}^{2}$, Expenditures $\leq 10,000 \mathrm{CFA} /$ Year)

\begin{tabular}{|l|c|c|c|c|}
\hline Input & Year 1 & Year 2 & Year 3 & Year 4 \\
\hline Association & Pure Millet & Pure Millet & Pure Millet & Pure Millet \\
\hline Millet Density $\left(\mathrm{m}^{-2}\right)$ & 3.5 & 3.5 & 3.5 & 3.5 \\
\hline Urea (kg/ha) & 0 & 0 & 0 & 0 \\
\hline $\begin{array}{l}\text { Hired Labor } \\
\text { (Person-Days/ha) }\end{array}$ & 0 & 0 & 0 & 0 \\
\hline $\begin{array}{l}\text { UP Labor by Task } \\
\text { (Person-Days/ha) }\end{array}$ & \multicolumn{5}{|l}{} \\
\hline Sowing/Preparation & 10 & 10 & 10 & 10 \\
\hline First Weeding & 21 & 21 & 21 & 21 \\
\hline Second Weeding & 14 & 14 & 14 & 14 \\
\hline First Striga Weeding & 10.5 & 10.5 & 10.5 & 0 \\
\hline Harvest & 4 & 4 & 4 & 4 \\
\hline Second Striga Weeding & 4.5 & 4.5 & 4.5 & 0 \\
\hline Post-Harvest & 6 & 6 & 6 & 6 \\
\hline
\end{tabular}


Table 6.17: Estimated Financial and Nutritional Returns, Millet Production, Seedbank Growth, and Expenditures for Medium and Large UPs in Sirakorola Under Optimal Practices

with a Low Budget and Average Striga Infestation

\begin{tabular}{|c|c|c|c|c|c|c|c|c|c|}
\hline \multirow[b]{2}{*}{ UP Size } & \multirow[b]{2}{*}{ Year } & \multirow{2}{*}{$\begin{array}{c}\text { Seedbank } \\
\left(10^{3} \text { seeds } \mathrm{m}^{-2}\right)\end{array}$} & \multirow{2}{*}{$\begin{array}{c}\text { Area } \\
\text { (ha) }\end{array}$} & \multirow{2}{*}{$\begin{array}{c}\text { Millet } \\
\text { Production }(\mathrm{kg})\end{array}$} & \multicolumn{3}{|c|}{$\%$ Nutrient Requirement } & \multirow{2}{*}{$\begin{array}{l}\text { Expenditures } \\
(1,000 \text { CFA }) \\
\end{array}$} & \multirow{2}{*}{$\begin{array}{c}\text { Present Value } \\
\text { of Net Returns } \\
(1,000 \mathrm{CFA})\end{array}$} \\
\hline & & & & & Energy & Protein & Iron & & \\
\hline \multirow[t]{4}{*}{ Extra Small } & 1 & & & & & & & & \\
\hline & 2 & Same & As & Very & Low & & & & \\
\hline & 3 & & & & & & & & \\
\hline & 4 & & & & & & & & \\
\hline \multirow[t]{4}{*}{ Small } & 1 & & & & & & & & \\
\hline & 2 & Same & As & Very & Low & & & & \\
\hline & 3 & & & & & & & & \\
\hline & 4 & & & & & & & & \\
\hline \multirow[t]{4}{*}{ Medium } & 1 & 40 & 3.28 & 667 & 17.5 & 24.9 & 31.3 & 2.3 & 31.1 \\
\hline & 2 & 163 & 3.28 & 648 & 17 & 24.2 & 30.5 & 2.3 & 27.1 \\
\hline & 3 & 421 & 3.28 & 644 & 16.9 & 24 & 30.3 & 2.3 & 24.2 \\
\hline & 4 & 673 & 3.28 & 643 & 16.9 & 24 & 30.3 & 2.3 & 21.8 \\
\hline \multirow[t]{4}{*}{ Large } & 1 & 40 & 6.42 & 1295 & 18.3 & 25.9 & 34 & 4.5 & 60.3 \\
\hline & 2 & 163 & 6.42 & 1257 & 17.8 & 25.2 & 33 & 4.5 & 52.5 \\
\hline & 3 & 424 & 6.42 & 1249 & 17.7 & 25 & 32.8 & 4.5 & 47.0 \\
\hline & 4 & 681 & 6.42 & 1247 & 17.7 & 25 & 32.7 & 4.5 & 42.2 \\
\hline
\end{tabular}


Table 6.18: Estimated Changes in Expenditures, Labor Use, Nutritional and Financial Returns for Medium and Large UPs in Sirakorola with a Low Budget and Average Striga Infestation from Adopting the Optimal Practices

\begin{tabular}{|c|c|c|c|c|c|c|c|}
\hline \multirow[b]{2}{*}{ UP Size } & \multirow[b]{2}{*}{ Year } & \multirow{2}{*}{$\begin{array}{l}\text { Expenditures } \\
(1,000 \text { CFA }) \\
\end{array}$} & \multirow{2}{*}{$\begin{array}{c}\text { Labor Use } \\
\text { (Person-Days) }\end{array}$} & \multicolumn{3}{|c|}{$\%$ Nutrient Requirement } & \multirow{2}{*}{$\begin{array}{l}\text { Present Value of } \\
\text { Net Returns } \\
(1,000 \text { CFA }) \\
\end{array}$} \\
\hline & & & & Energy & Protein & Iron & \\
\hline \multirow[t]{4}{*}{ Extra Small } & 1 & & & & & & \\
\hline & 2 & Same & As & Very & Low & & \\
\hline & 3 & & & & & & \\
\hline & 4 & & & & & & \\
\hline \multirow[t]{4}{*}{ Small } & 1 & & & & & & \\
\hline & 2 & Same & As & Very & Low & & \\
\hline & 3 & & & & & & \\
\hline & 4 & & & & & & \\
\hline \multirow[t]{4}{*}{ Medium } & 1 & 2.0 & 49 & 9.6 & 14.5 & 18.2 & 17.7 \\
\hline & 2 & 2.0 & 49 & 10.3 & 14.7 & 18.5 & 16.2 \\
\hline & 3 & 2.0 & 49 & 10.6 & 15 & 18.9 & 15.0 \\
\hline & 4 & 2.0 & 0 & 10.7 & 15.2 & 19.3 & 13.7 \\
\hline \multirow[t]{4}{*}{ Large } & 1 & 3.8 & 96 & 10.9 & 15 & 19.8 & 34.4 \\
\hline & 2 & 3.8 & 96 & 10.8 & 15.3 & 20.1 & 31.5 \\
\hline & 3 & 3.8 & 96 & 11 & 15.6 & 20.5 & 29.0 \\
\hline & 4 & 3.8 & 0 & 11.2 & 16 & 20.8 & 26.5 \\
\hline
\end{tabular}


Optimal Production with a Moderate Budget. When the UP's budget reaches 25,000 $\mathrm{CFA} / \mathrm{year}$, the optimal set of practices for the smaller UP sizes in both zones shifts from an extensive to an intensive approach. The XS and S UP's in Mourdiah, and the XS, S, and M UP's in Sirakorola reduce their acreage and apply urea in sufficient quantities to retard Striga development and induce significant increases in millet yields. Tables 6.18 and 6.19 present the optimal level of each input in Mourdiah and Sirakorola, respectively.

In Mourdiah, the application of urea is accompanied by an increase in millet planting density, from $0.5 / \mathrm{m}^{2}$ to $3.5 / \mathrm{m}^{2}$. At a rate of $353 \mathrm{~kg} / \mathrm{ha}$, urea suppresses Striga development by reducing both the probability of stimulation and the probability of emergence. The number of emerged Striga is reduced to such a degree that the UP's own labor is able to weed them all, preventing the introduction of new Striga seed. As a result, the seedbank declines in each successive season.

As the seedbank declines, so does the optimal urea application rate, allowing the UP to cultivate more acreage with the same budget. The yearly increase in millet yields, shown in Table 6.21, are a result of both the decline in the Striga seedbank and the increase in cultivated land. Figure 6.11 illustrates the increase in net revenues, compared to status quo production, from adopting the optimal set of practices with a moderate budget; Figures 6.12 through 6.14 illustrate the nutritional gains

The increase in cultivated land each season increases the UP's labor requirement. However, the total amount of labor demanded throughout a season never exceeds that required for status quo production, as shown in Table 6.23.

In Sirakorola, the optimal urea application rate is higher for a given Striga seedbank density than it is in Mourdiah. The reason for this stems from the difference in the production functions for each zone. The higher average rainfall in Sirakorola leads to greater nitrogen productivity. As a result, when a UP in Sirakorola has enough cash, it is better off applying more urea to fewer hectares, compared to Mourdiah. 
Table 6.19: Optimal Practices in Mourdiah with Average Striga Infestation and a Moderate Budget

(Starting Seedbank $=40,000 / \mathrm{m}^{2}$, Expenditures $\leq 25,000 \mathrm{CFA} /$ Year)

\begin{tabular}{|c|c|c|c|}
\hline Input & Year 1 & Year 2 & Year 3 \\
\hline Association & Pure Millet & Pure Millet & Pure Millet \\
\hline Millet Density $\left(\mathrm{m}^{-2}\right), \mathrm{XS}-\mathrm{S}$ & 3.5 & 3.5 & 3.5 \\
\hline Urea (kg/ha), XS - S & 352 & 343 & 330 \\
\hline Millet Density $\left(\mathrm{m}^{-2}\right), \mathrm{M}-\mathrm{XXL}$ & 0.5 & 0.5 & 0.5 \\
\hline Urea (kg/ha), M - XXL & 0 & 0 & 0 \\
\hline $\begin{array}{l}\text { Hired Labor } \\
\text { (Person-Days/ha) }\end{array}$ & 0 & 0 & 0 \\
\hline \multicolumn{4}{|l|}{$\begin{array}{l}\text { UP Labor by Task } \\
\text { (Person-Days/ha) }\end{array}$} \\
\hline Sowing/Preparation & 10 & 10 & 10 \\
\hline First Weeding & 21 & 21 & 21 \\
\hline Second Weeding & 14 & 14 & 14 \\
\hline First Striga Weeding, XS - S & 0.1 & 0.1 & 0 \\
\hline First Striga Weeding, M - XXL & 10.5 & 10.5 & 0 \\
\hline Harvest & 4 & 4 & 4 \\
\hline Second Striga Weeding, XS - S & 0.1 & 0.1 & 0 \\
\hline Second Striga Weeding, M - XXL & 4.5 & 4.5 & 0 \\
\hline Post-Harvest & 6 & 6 & 6 \\
\hline
\end{tabular}


Table 6.20: Optimal Practices in Sirakorola with Average Striga Infestation and a Moderate Budget

(Starting Seedbank $=40,000 / \mathrm{m}^{2}$, Expenditures $\leq 25,000 \mathrm{CFA} /$ Year $)$

\begin{tabular}{|l|c|c|c|c|}
\hline Input & Year 1 & Year 2 & Year 3 & Year 4 \\
\hline Association & Pure Millet & Pure Millet & Pure Millet & Pure Millet \\
\hline Millet Density (m-2) & 3.5 & 3.5 & 3.5 & 3.5 \\
\hline Urea (kg/ha), XS - M & 360 & 352 & 343 & 334 \\
\hline Urea (kg/ha), L & 0 & 0 & 0 & 0 \\
\hline $\begin{array}{l}\text { Hired Labor } \\
\text { (Person-Days/ha) }\end{array}$ & 0 & 0 & 0 & 0 \\
\hline $\begin{array}{l}\text { UP Labor by Task } \\
\text { (Person-Days/ha) }\end{array}$ & 10 & 10 & & \\
\hline Sowing/Preparation & 21 & 21 & 21 & 21 \\
\hline First Weeding & 14 & 14 & 14 & 14 \\
\hline Second Weeding & 0.1 & 0.1 & 0.1 & 0 \\
\hline First Striga Weeding, XS - M & 10.5 & 10.5 & 10.5 & 0 \\
\hline First Striga Weeding, L & 4 & 4 & 4 & 4 \\
\hline Harvest & 0.1 & 0.1 & 0.1 & 0 \\
\hline Second Striga Weeding, XS - M & 4.5 & 4.5 & 4.5 & 0 \\
\hline Second Striga Weeding, L & 6 & 6 & 6 & 6 \\
\hline Post-Harvest & & & & \\
\hline
\end{tabular}


Table 6.21: Estimated Financial and Nutritional Returns, Millet Production, Seedbank Growth, and Expenditures in Mourdiah Under Optimal Practices with a Moderate Budget and Average Striga Infestation

\begin{tabular}{|c|c|c|c|c|c|c|c|c|c|}
\hline \multirow[b]{2}{*}{ UP Size } & \multirow[b]{2}{*}{ Year } & \multirow{2}{*}{$\begin{array}{c}\text { Seedbank } \\
\left(10^{3} \text { seeds } \mathrm{m}^{-2}\right) \\
\end{array}$} & \multirow{2}{*}{$\begin{array}{l}\text { Area } \\
\text { (ha) }\end{array}$} & \multirow{2}{*}{$\begin{array}{c}\text { Millet } \\
\text { Production }(\mathrm{kg})\end{array}$} & \multicolumn{3}{|c|}{$\%$ Nutrient Requirement } & \multirow{2}{*}{$\begin{array}{c}\text { Expenditures } \\
(1,000 \mathrm{CFA}) \\
\end{array}$} & \multirow{2}{*}{$\begin{array}{c}\text { Present Value of } \\
\text { Net Returns } \\
(1,000 \text { CFA })\end{array}$} \\
\hline & & & & & Energy & Protein & Iron & & \\
\hline \multirow[t]{3}{*}{ Extra Small } & 1 & 40 & 0.39 & 842 & 80.8 & 118 & 152 & 25.0 & 17.1 \\
\hline & 2 & 21.7 & 0.40 & 846 & 81.2 & 119 & 153 & 25.0 & 15.6 \\
\hline & 3 & 11.8 & 0.42 & 860 & 82.6 & 121 & 155 & 25.0 & 14.6 \\
\hline \multirow[t]{3}{*}{ Small } & 1 & 40 & 0.39 & 842 & 45.2 & 63.5 & 74.6 & 25.0 & 17.1 \\
\hline & 2 & 21.7 & 0.40 & 846 & 45.4 & 63.8 & 75.0 & 25.0 & 15.6 \\
\hline & 3 & 11.8 & 0.42 & 860 & 46.2 & 64.8 & 76.2 & 25.0 & 14.6 \\
\hline \multirow[t]{3}{*}{ Medium } & 1 & & & & & & & & \\
\hline & 2 & & Same & As & Very & Low & & & \\
\hline & 3 & & & & & & & & \\
\hline \multirow[t]{3}{*}{ Large } & 1 & & & & & & & & \\
\hline & 2 & & Same & As & Very & Low & & & \\
\hline & 3 & & & & & & & & \\
\hline \multirow[t]{3}{*}{ Extra Large } & 1 & & & & & & & & \\
\hline & 2 & & Same & As & Very & Low & & & \\
\hline & 3 & & & & & & & & \\
\hline \multirow{3}{*}{$\begin{array}{l}\text { Extra Extra } \\
\text { Large }\end{array}$} & 1 & & & & & & & & \\
\hline & 2 & & Same & As & Very & Low & & & \\
\hline & 3 & & & & & & & & \\
\hline
\end{tabular}


Table 6.22: Estimated Financial and Nutritional Returns, Millet Production, Seedbank Growth, and Expenditures in Sirakorola Under Optimal Practices with a Moderate Budget and Average Striga Infestation

\begin{tabular}{|c|c|c|c|c|c|c|c|c|c|}
\hline \multirow[b]{2}{*}{ UP Size } & \multirow[b]{2}{*}{ Year } & \multirow{2}{*}{$\begin{array}{c}\text { Seedbank } \\
\left(10^{3} \text { seeds } \mathrm{m}^{-2}\right) \\
\end{array}$} & \multirow{2}{*}{$\begin{array}{c}\text { Area } \\
\text { (ha) }\end{array}$} & \multirow{2}{*}{$\begin{array}{c}\text { Millet } \\
\text { Production }(\mathrm{kg}) \\
\end{array}$} & \multicolumn{3}{|c|}{$\%$ Nutrient Requirement } & \multirow{2}{*}{$\begin{array}{l}\text { Expenditures } \\
(1,000 \mathrm{CFA}) \\
\end{array}$} & \multirow{2}{*}{$\begin{array}{c}\text { Present Value } \\
\text { of Net Return } \\
(1,000 \text { CFA })\end{array}$} \\
\hline & & & & & Energy & Protein & Iron & & \\
\hline \multirow[t]{4}{*}{ Extra Small } & 1 & 40 & 0.38 & 1146 & 108 & 152 & 213 & 25.0 & 32.3 \\
\hline & 2 & 21.8 & 0.39 & 1154 & 109 & 153 & 215 & 25.0 & 29.4 \\
\hline & 3 & 11.9 & 0.40 & 1157 & 109 & 153 & 215 & 25.0 & 26.6 \\
\hline & 4 & 6.5 & 0.41 & 1160 & 109 & 154 & 216 & 25.0 & 24.1 \\
\hline \multirow[t]{4}{*}{ Small } & 1 & 40 & 0.38 & 1146 & 63.4 & 85.8 & 121 & 25.0 & 32.3 \\
\hline & 2 & 21.8 & 0.39 & 1154 & 63.8 & 86.4 & 122 & 25.0 & 29.4 \\
\hline & 3 & 11.9 & 0.40 & 1157 & 64 & 86.6 & 122 & 25.0 & 26.6 \\
\hline & 4 & 6.5 & 0.41 & 1160 & 64.2 & 86.8 & 123 & 25.0 & 24.1 \\
\hline \multirow[t]{4}{*}{ Medium } & 1 & 40 & 0.38 & 1146 & 30 & 42.7 & 53.8 & 25.0 & 32.3 \\
\hline & 2 & 21.8 & 0.39 & 1154 & 30.2 & 43 & 54.2 & 25.0 & 29.4 \\
\hline & 3 & 11.9 & 0.40 & 1157 & 30.3 & 43.1 & 54.3 & 25.0 & 26.6 \\
\hline & 4 & 6.5 & 0.41 & 1160 & 30.4 & 43.2 & 54.5 & 25.0 & 24.1 \\
\hline \multirow[t]{4}{*}{ Large } & 1 & & & & & & & & \\
\hline & 2 & & Same & As & Low & & & & \\
\hline & 3 & & & & & & & & \\
\hline & 4 & & & & & & & & \\
\hline
\end{tabular}


Table 6.23: Estimated Changes in Expenditures, Labor Use, Nutritional and Financial Returns from Adopting the Optimal Practices in Mourdiah with a Moderate Budget and Average Striga Infestation

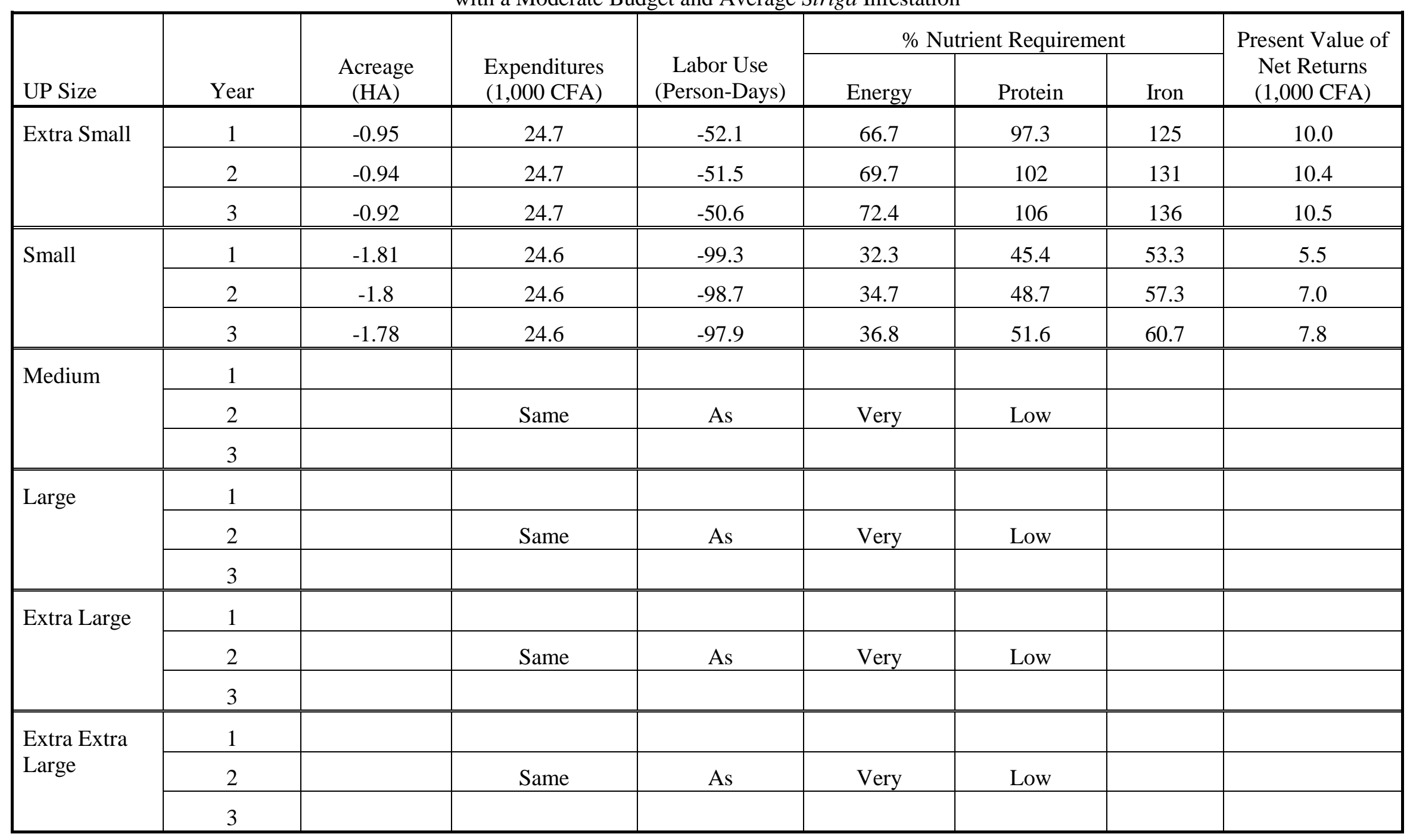


Table 6.24: Estimated Changes in Expenditures, Labor Use, Nutritional and Financial Returns from Adopting the Optimal Practices in Sirakorola with a Moderate Budget and Average Striga Infestation

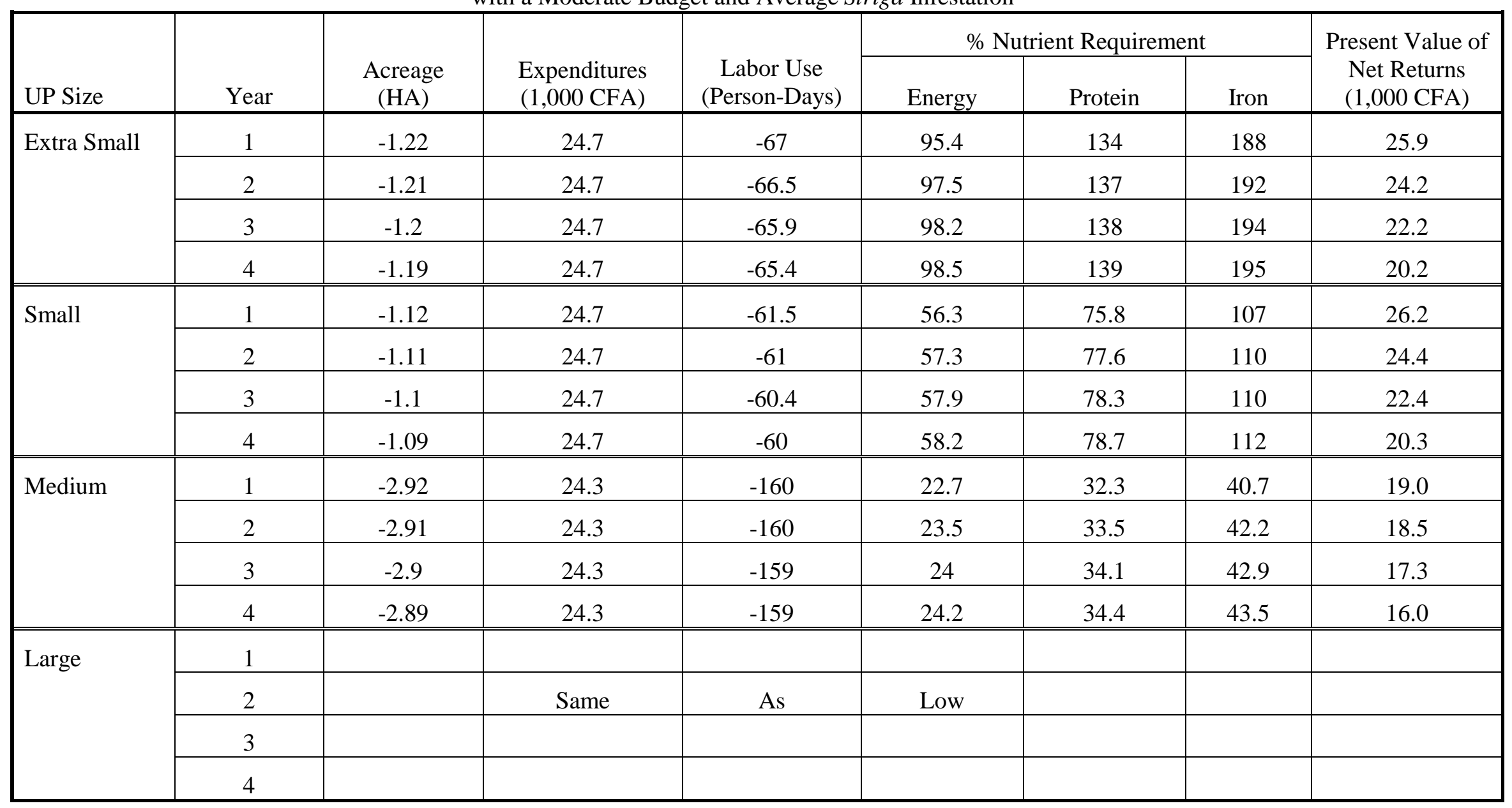


Figure 6.11: Change in Net Revenue from Adopting Optimal Practices with Average Striga and Moderate Budget

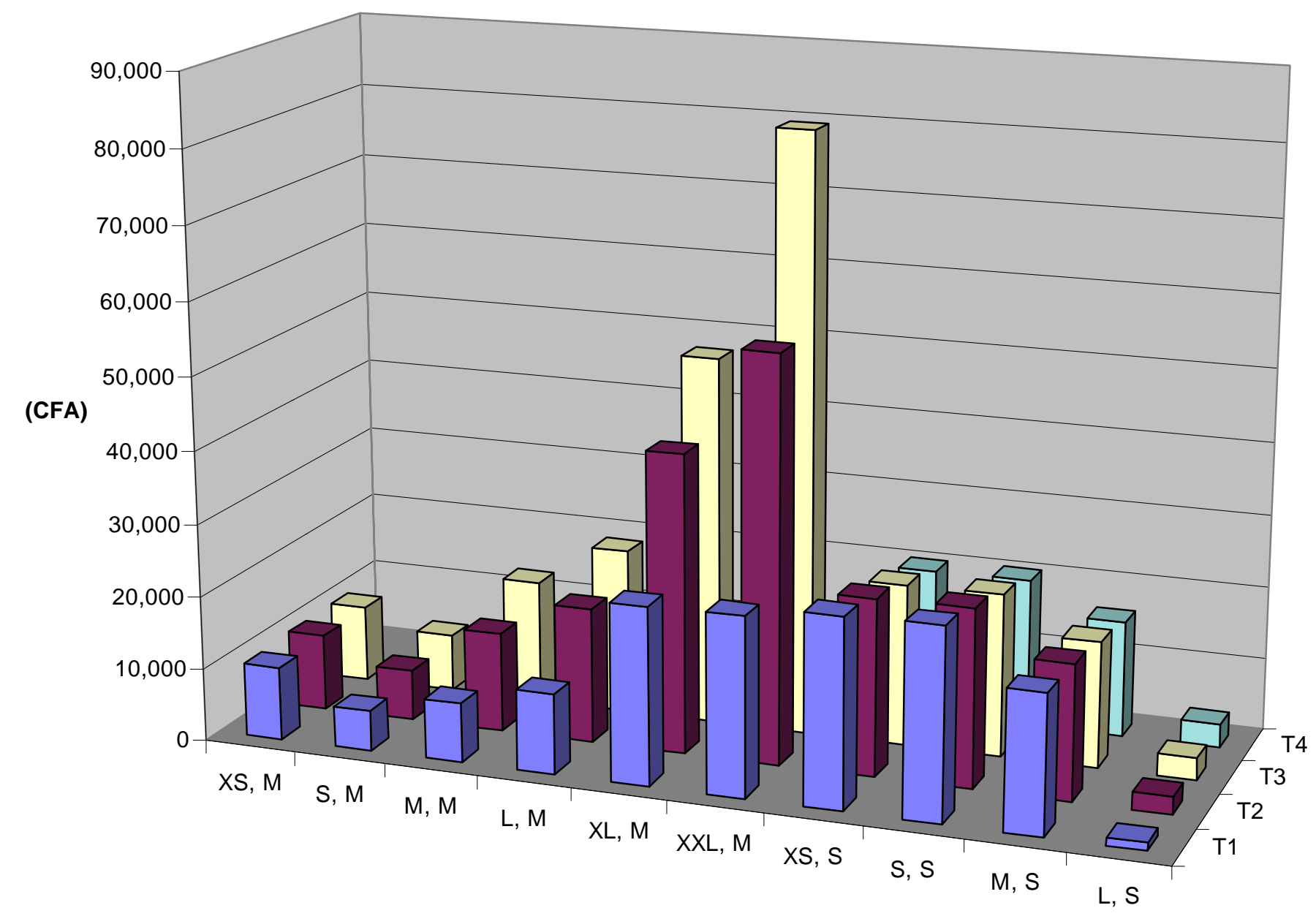


Figure 6.12: Change in \% UP KCal Requirement Met from Adopting Optimal Practices with Average Striga and Moderate Budget

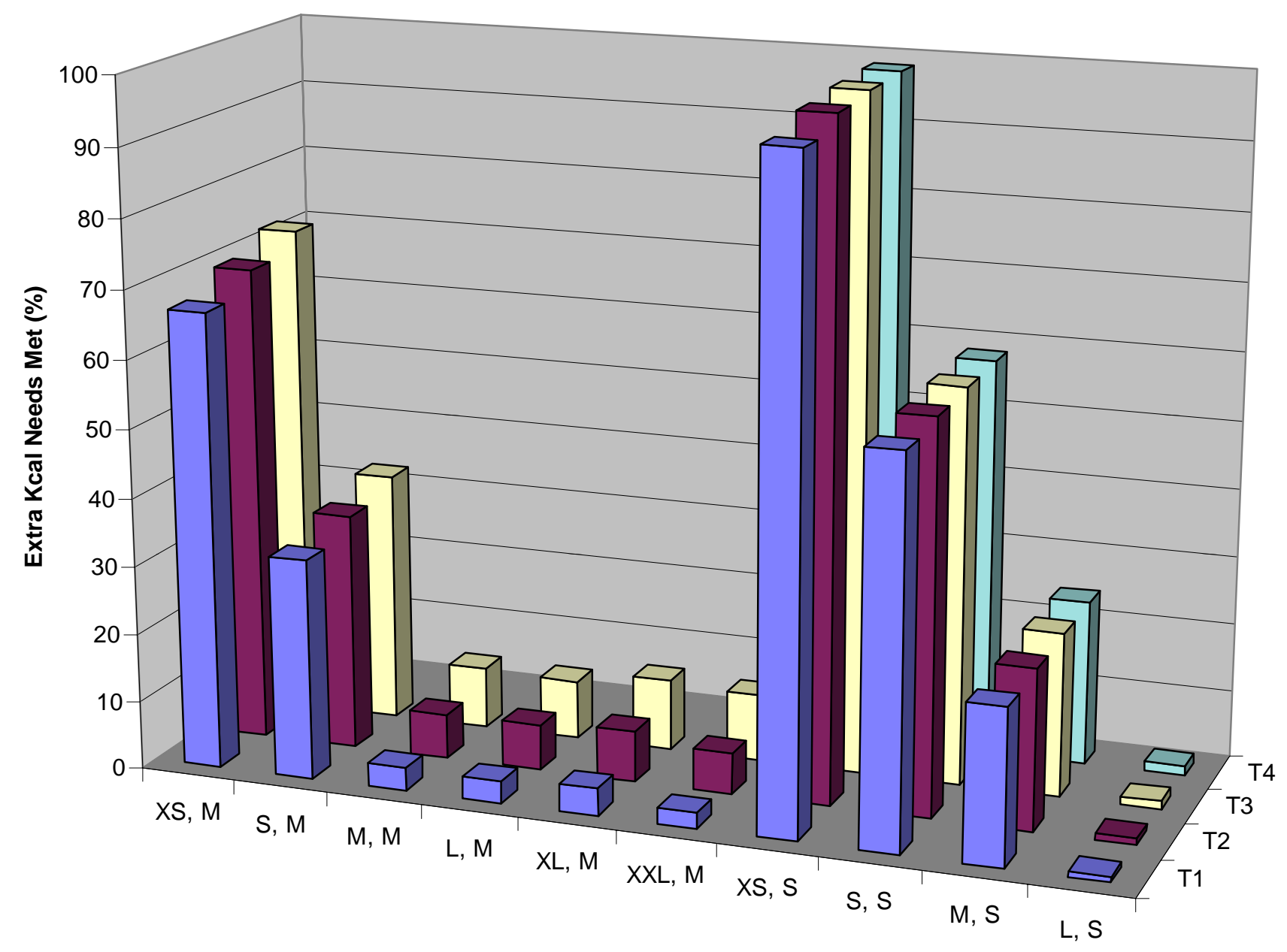


Figure 6.13: Change in \% UP Protein Requirement Met from Adopting Optimal Practices with Average Striga and Moderate Budget

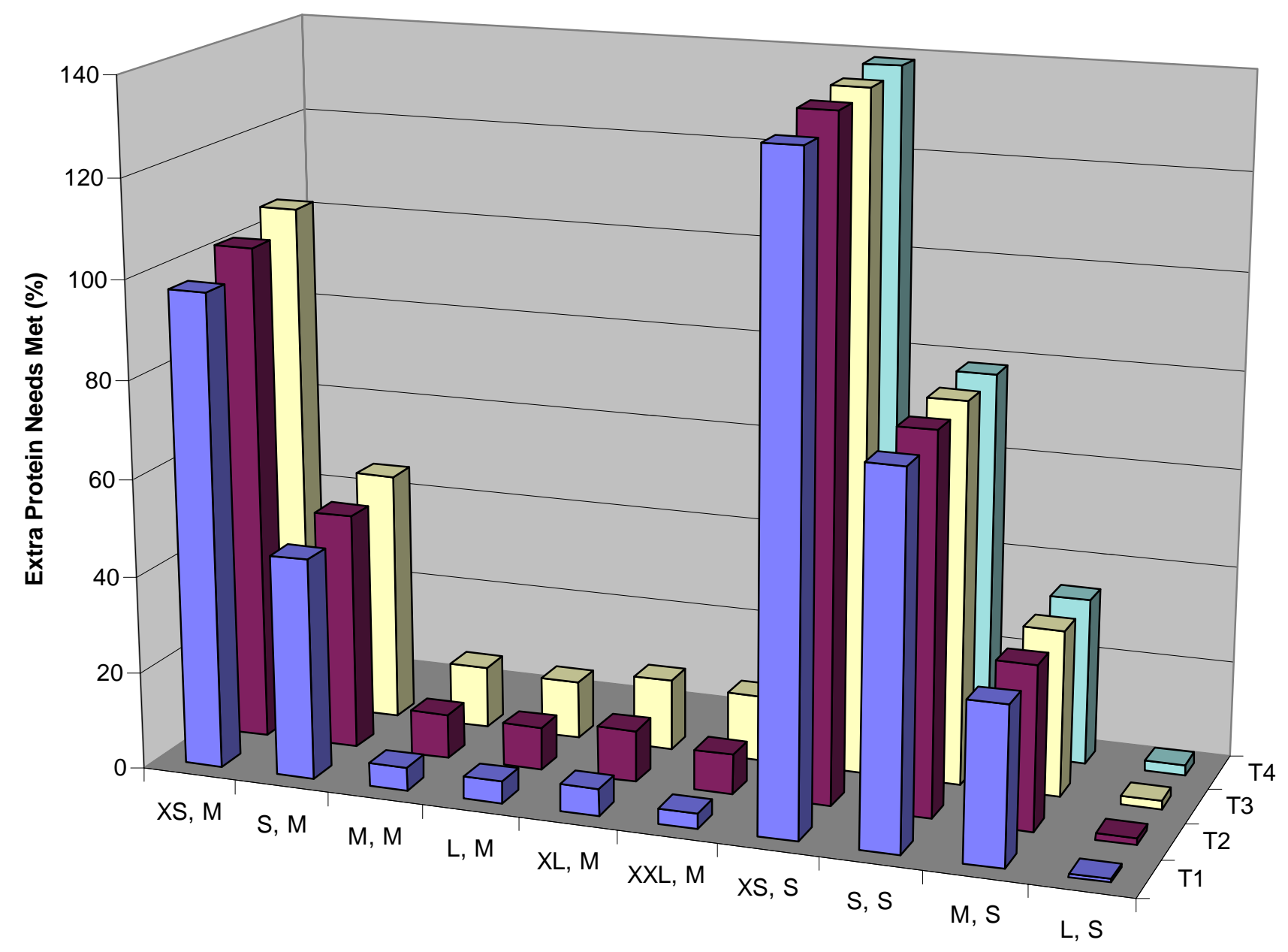


Figure 6.14: Change in \% UP Iron Requirement Met from Adopting Optimal Practices with Average Striga and Moderate Budget

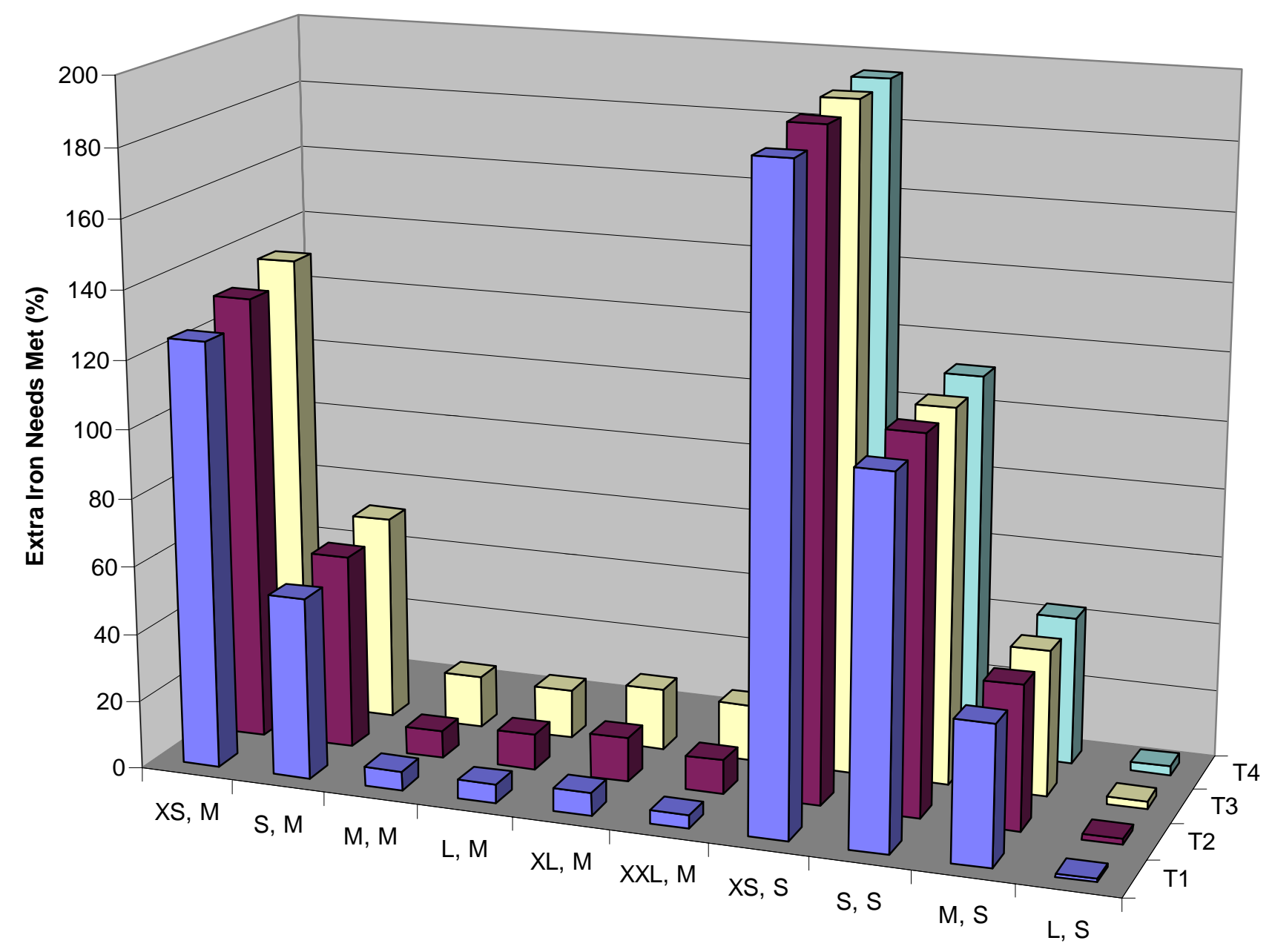


The high urea application rates retard Striga development, and the seedbank in Sirakorola declines in each successive season. The lower seedbank leads to lower optimal urea application rates, more cultivated land, and higher millet yields. Due to the lower acreage, the optimal set of practices requires less labor than status quo production. Tables 6.21 and 6.23 present the results of this budget level for the UP's in Sirakorola. The nutritional gains, compared to status quo production, are illustrated in Figures 6.11 through 6.13 .

Optimal Production with a High Budget. When the UP's budget doubles again, to 50,000 CFA/year, the XS and S UP's in Mourdiah, and the XS, S, and M UP's in Sirakorola apply the same set of practices as they did with a moderate budget, doubling their cultivated acreage. With twice as many hectares, net revenues double and the highdensity, urea-based set of practices becomes optimal for the M UP's in Mourdiah and the L UP's in Sirakorola, as well. The optimal practices, financial and nutritional returns to optimal production, and financial and nutritional benefits of adopting the optimal set of practices are presented in Table 6.25 through 6.30 .

The extra acreage doubles the total millet yield, and the nutritional returns to the optimal set of practices increase as a result. Figures 6.15 through 6.18 illustrate the additional financial and nutritional returns to millet production from adopting the optimal set of practices with a high budget.

For the UP's that adopt the high-density, urea-based set of practices, production is constrained by their budget. For the other UP's, it is labor for the first (non-Striga) weeding rather than the budget constraint that is binding.

The high-density, urea-based practices require an additional 0.1 person-day of labor per hectare compared to status quo production. However, the binding budget constraint limits the number of hectares the UP is able to cultivate. With a high budget, the UP's adopting the high-density, urea-based practices plant fewer hectares than they do under status quo production, resulting in a net reduction in labor (see Tables 6.28 and 6.29). 
Table 6.25: Optimal Practices in Mourdiah with Average Striga Infestation and a High Budget

(Starting Seedbank $=40,000 / \mathrm{m}^{2}$, Expenditures $\leq 50,000 \mathrm{CFA} /$ Year $)$

\begin{tabular}{|c|c|c|c|}
\hline Input & Year 1 & Year 2 & Year 3 \\
\hline Association & Pure Millet & Pure Millet & Pure Millet \\
\hline Millet Density $\left(\mathrm{m}^{-2}\right), \mathrm{XS}-\mathrm{M}$ & 3.5 & 3.5 & 3.5 \\
\hline Urea (kg/ha), XS - M & 352 & 343 & 330 \\
\hline Millet Density $\left(\mathrm{m}^{-2}\right), \mathrm{L}-\mathrm{XXL}$ & 0.5 & 0.5 & 0.5 \\
\hline Urea (kg/ha), L - XXL & 0 & 0 & 0 \\
\hline $\begin{array}{l}\text { Hired Labor } \\
\text { (Person-Days/ha) }\end{array}$ & 0 & 0 & 0 \\
\hline \multicolumn{4}{|l|}{$\begin{array}{l}\text { UP Labor by Task } \\
\text { (Person-Days/ha) }\end{array}$} \\
\hline Sowing/Preparation & 10 & 10 & 10 \\
\hline First Weeding & 21 & 21 & 21 \\
\hline Second Weeding & 14 & 14 & 14 \\
\hline First Striga Weeding, XS - M & 0.1 & 0.1 & 0 \\
\hline First Striga Weeding, L - XL & 10.5 & 10.5 & 0 \\
\hline First Striga Weeding, XXL & 14.6 & 9.7 & 0 \\
\hline Harvest & 4 & 4 & 4 \\
\hline Second Striga Weeding, XS - M & 0.1 & 0.1 & 0 \\
\hline Second Striga Weeding, L - XL & 4.5 & 4.5 & 0 \\
\hline Second Striga Weeding, XXL & 11.9 & 9.7 & 0 \\
\hline Post-Harvest & 6 & 6 & 6 \\
\hline
\end{tabular}


Table 6.26: Optimal Practices in Sirakorola with Average Striga Infestation and a High Budget

(Starting Seedbank $=40,000 / \mathrm{m}^{2}$, Expenditures $\leq 50,000 \mathrm{CFA} /$ Year)

\begin{tabular}{|l|c|c|c|c|}
\hline Input & Year 1 & Year 2 & Year 3 & Year 4 \\
\hline Association & Pure Millet & Pure Millet & Pure Millet & Pure Millet \\
\hline Millet Density $\left(\mathrm{m}^{-2}\right)$ & 3.5 & 3.5 & 3.5 & 3.5 \\
\hline Urea (kg/ha) & 360 & 352 & 343 & 334 \\
\hline $\begin{array}{l}\text { Hired Labor } \\
\text { (Person-Days/ha) }\end{array}$ & 0 & 0 & 0 & 0 \\
\hline $\begin{array}{l}\text { UP Labor by Task } \\
\text { (Person-Days/ha) }\end{array}$ & \multicolumn{5}{|l|}{} \\
\hline Sowing/Preparation & 10 & 10 & 10 & 10 \\
\hline First Weeding & 21 & 21 & 21 & 21 \\
\hline Second Weeding & 14 & 14 & 14 & 14 \\
\hline First Striga Weeding & 0.1 & 0.1 & 0.1 & 0 \\
\hline Harvest & 4 & 4 & 4 & 4 \\
\hline Second Striga Weeding & 0.1 & 0.1 & 0.1 & 0 \\
\hline Post-Harvest & 6 & 6 & 6 & 6 \\
\hline
\end{tabular}


Table 6.27: Estimated Financial and Nutritional Returns, Millet Production, Seedbank Growth, and Expenditures in Mourdiah Under Optimal Practices with a High Budget and Average Striga Infestation

\begin{tabular}{|c|c|c|c|c|c|c|c|c|c|}
\hline \multirow[b]{2}{*}{ UP Size } & \multirow[b]{2}{*}{ Year } & \multirow{2}{*}{$\begin{array}{c}\text { Seedbank } \\
\left(10^{3} \text { seeds } \mathrm{m}^{-2}\right) \\
\end{array}$} & \multirow{2}{*}{$\begin{array}{c}\text { Area } \\
\text { (ha) }\end{array}$} & \multirow{2}{*}{$\begin{array}{c}\text { Millet } \\
\text { Production }(\mathrm{kg}) \\
\end{array}$} & \multicolumn{3}{|c|}{$\%$ Nutrient Requirement } & \multirow{2}{*}{$\begin{array}{l}\text { Expenditures } \\
(1,000 \text { CFA }) \\
\end{array}$} & \multirow{2}{*}{$\begin{array}{c}\text { Present Value } \\
\text { of Net Returns } \\
(1,000 \text { CFA })\end{array}$} \\
\hline & & & & & Energy & Protein & Iron & & \\
\hline \multirow[t]{3}{*}{ Extra Small } & 1 & 40 & 0.78 & 1684 & 162 & 237 & 304 & 50.0 & 34.2 \\
\hline & 2 & 21.6 & 0.80 & 1692 & 163 & 238 & 305 & 50.0 & 31.1 \\
\hline & 3 & 11.7 & 0.84 & 1701 & 163 & 239 & 307 & 50.0 & 28.4 \\
\hline \multirow[t]{3}{*}{ Small } & 1 & 40 & 0.78 & 1684 & 90.4 & 127 & 149 & 50.0 & 34.2 \\
\hline & 2 & 21.6 & 0.80 & 1692 & 90.8 & 128 & 150 & 50.0 & 31.1 \\
\hline & 3 & 11.7 & 0.84 & 1701 & 91.3 & 128 & 151 & 50.0 & 28.4 \\
\hline \multirow[t]{3}{*}{ Medium } & 1 & 40 & 0.78 & 1684 & 37.3 & 52.4 & 62.7 & 50.0 & 34.2 \\
\hline & 2 & 21.6 & 0.80 & 1692 & 37.5 & 52.7 & 63.0 & 50.0 & 31.1 \\
\hline & 3 & 11.7 & 0.84 & 1701 & 37.7 & 53.0 & 63.4 & 50.0 & 28.4 \\
\hline \multirow[t]{3}{*}{ Large } & 1 & & & & & & & & \\
\hline & 2 & Same & As & Low & And & Very & Low & & \\
\hline & 3 & & & & & & & & \\
\hline \multirow[t]{3}{*}{ Extra Large } & 1 & & & & & & & & \\
\hline & 2 & Same & As & Low & And & Very & Low & & \\
\hline & 3 & & & & & & & & \\
\hline \multirow{3}{*}{$\begin{array}{l}\text { Extra Extra } \\
\text { Large }\end{array}$} & 1 & & & & & & & & \\
\hline & 2 & Same & As & Low & And & Very & Low & & \\
\hline & 3 & & & & & & & & \\
\hline
\end{tabular}


Table 6.28: Estimated Financial and Nutritional Returns, Millet Production, Seedbank Growth, and Expenditures in Sirakorola Under Optimal Practices with a High Budget and Average Striga Infestation

\begin{tabular}{|c|c|c|c|c|c|c|c|c|c|}
\hline \multirow[b]{2}{*}{ UP Size } & \multirow[b]{2}{*}{ Year } & \multirow{2}{*}{$\begin{array}{c}\text { Seedbank } \\
\left(10^{3} \text { seeds } \mathrm{m}^{-2}\right) \\
\end{array}$} & \multirow{2}{*}{$\begin{array}{c}\text { Area } \\
\text { (ha) }\end{array}$} & \multirow{2}{*}{$\begin{array}{c}\text { Millet } \\
\text { Production }(\mathrm{kg}) \\
\end{array}$} & \multicolumn{3}{|c|}{$\%$ Nutrient Requirement } & \multirow{2}{*}{$\begin{array}{l}\text { Expenditures } \\
(1,000 \mathrm{CFA}) \\
\end{array}$} & \multirow{2}{*}{$\begin{array}{c}\text { Present Value o } \\
\text { Net Returns } \\
(1,000 \text { CFA }) \\
\end{array}$} \\
\hline & & & & & Energy & Protein & Iron & & \\
\hline \multirow[t]{4}{*}{ Extra Small } & 1 & 40 & 0.77 & 2293 & 216 & 304 & 427 & 50.0 & 64.7 \\
\hline & 2 & 21.8 & 0.78 & 2308 & 217 & 306 & 429 & 50.0 & 58.9 \\
\hline & 3 & 11.8 & 0.80 & 2314 & 218 & 307 & 430 & 50.0 & 53.2 \\
\hline & 4 & 6.4 & 0.82 & 2320 & 218 & 307 & 432 & 50.0 & 48.1 \\
\hline \multirow[t]{4}{*}{ Small } & 1 & 40 & 0.77 & 2293 & 127 & 172 & 242 & 50.0 & 64.7 \\
\hline & 2 & 21.8 & 0.78 & 2308 & 128 & 173 & 244 & 50.0 & 58.9 \\
\hline & 3 & 11.8 & 0.80 & 2314 & 128 & 173 & 245 & 50.0 & 53.2 \\
\hline & 4 & 6.4 & 0.82 & 2320 & 128 & 174 & 245 & 50.0 & 48.1 \\
\hline \multirow[t]{4}{*}{ Medium } & 1 & 40 & 0.77 & 2293 & 60 & 85.4 & 108 & 50.0 & 64.7 \\
\hline & 2 & 21.8 & 0.78 & 2308 & 60.5 & 86 & 108 & 50.0 & 58.9 \\
\hline & 3 & 11.8 & 0.80 & 2314 & 60.6 & 86.2 & 109 & 50.0 & 53.2 \\
\hline & 4 & 6.4 & 0.82 & 2320 & 60.8 & 86.4 & 109 & 50.0 & 48.1 \\
\hline \multirow[t]{4}{*}{ Large } & 1 & 40 & 0.77 & 2293 & 32.6 & 46 & 60 & 50.0 & 64.7 \\
\hline & 2 & 21.8 & 0.78 & 2308 & 32.8 & 46.3 & 60.4 & 50.0 & 58.9 \\
\hline & 3 & 11.8 & 0.80 & 2314 & 32.9 & 46.4 & 60.6 & 50.0 & 53.2 \\
\hline & 4 & 6.4 & 0.82 & 2320 & 33 & 46.5 & 60.7 & 50.0 & 48.1 \\
\hline
\end{tabular}


Table 6.29: Estimated Changes in Expenditures, Labor Use, Nutritional and Financial Returns from Adopting the Optimal Practices in Mourdiah with a High Budget and Average Striga Infestation

\begin{tabular}{|c|c|c|c|c|c|c|c|c|}
\hline \multirow[b]{2}{*}{ UP Size } & \multirow[b]{2}{*}{ Year } & \multirow{2}{*}{$\begin{array}{c}\text { Acreage } \\
(\mathrm{HA})\end{array}$} & \multirow{2}{*}{$\begin{array}{c}\text { Expenditures } \\
(1,000 \mathrm{CFA}) \\
\end{array}$} & \multirow{2}{*}{$\begin{array}{c}\text { Labor Use } \\
\text { (Person-Days) }\end{array}$} & \multicolumn{3}{|c|}{$\%$ Nutrient Requirement } & \multirow{2}{*}{$\begin{array}{c}\text { Present Value of } \\
\text { Net Returns } \\
(1,000 \text { CFA }) \\
\end{array}$} \\
\hline & & & & & Energy & Protein & Iron & \\
\hline \multirow[t]{3}{*}{ Extra Small } & 1 & -0.6 & 49.7 & -32.9 & 148 & 216 & 278 & 27.1 \\
\hline & 2 & -0.58 & 49.7 & -31.8 & 151 & 221 & 283 & 26.0 \\
\hline & 3 & -0.54 & 49.7 & -29.7 & 153 & 224 & 288 & 24.3 \\
\hline \multirow[t]{3}{*}{ Small } & 1 & -1.5 & 49.6 & -82.4 & 77.5 & 109 & 128 & 22.6 \\
\hline & 2 & -1.48 & 49.6 & -81.3 & 80.1 & 113 & 132 & 22.5 \\
\hline & 3 & -1.44 & 49.6 & -79.2 & 81.9 & 115 & 136 & 21.7 \\
\hline \multirow[t]{3}{*}{ Medium } & 1 & -4 & 49.1 & -219.3 & 26 & 36.5 & 43.7 & 9.6 \\
\hline & 2 & -3.98 & 49.1 & -218.8 & 28.2 & 39.6 & 47.4 & 13.1 \\
\hline & 3 & -3.96 & 49.1 & -217.8 & 29.5 & 41.5 & 49.6 & 14.2 \\
\hline \multirow[t]{3}{*}{ Large } & 1 & & & & & & & \\
\hline & 2 & & Same & As & Very & Low & & \\
\hline & 3 & & & & & & & \\
\hline \multirow[t]{3}{*}{ Extra Large } & 1 & & & & & & & \\
\hline & 2 & & Same & As & Very & Low & & \\
\hline & 3 & & & & & & & \\
\hline \multirow{3}{*}{$\begin{array}{l}\text { Extra Extra } \\
\text { Large }\end{array}$} & 1 & & & & & & & \\
\hline & 2 & & Same & As & Very & Low & & \\
\hline & 3 & & & & & & & \\
\hline
\end{tabular}


Table 6.30: Estimated Changes in Expenditures, Labor Use, Nutritional and Financial Returns from Adopting the Optimal Practices in Sirakorola with a High Budget and Average Striga Infestation

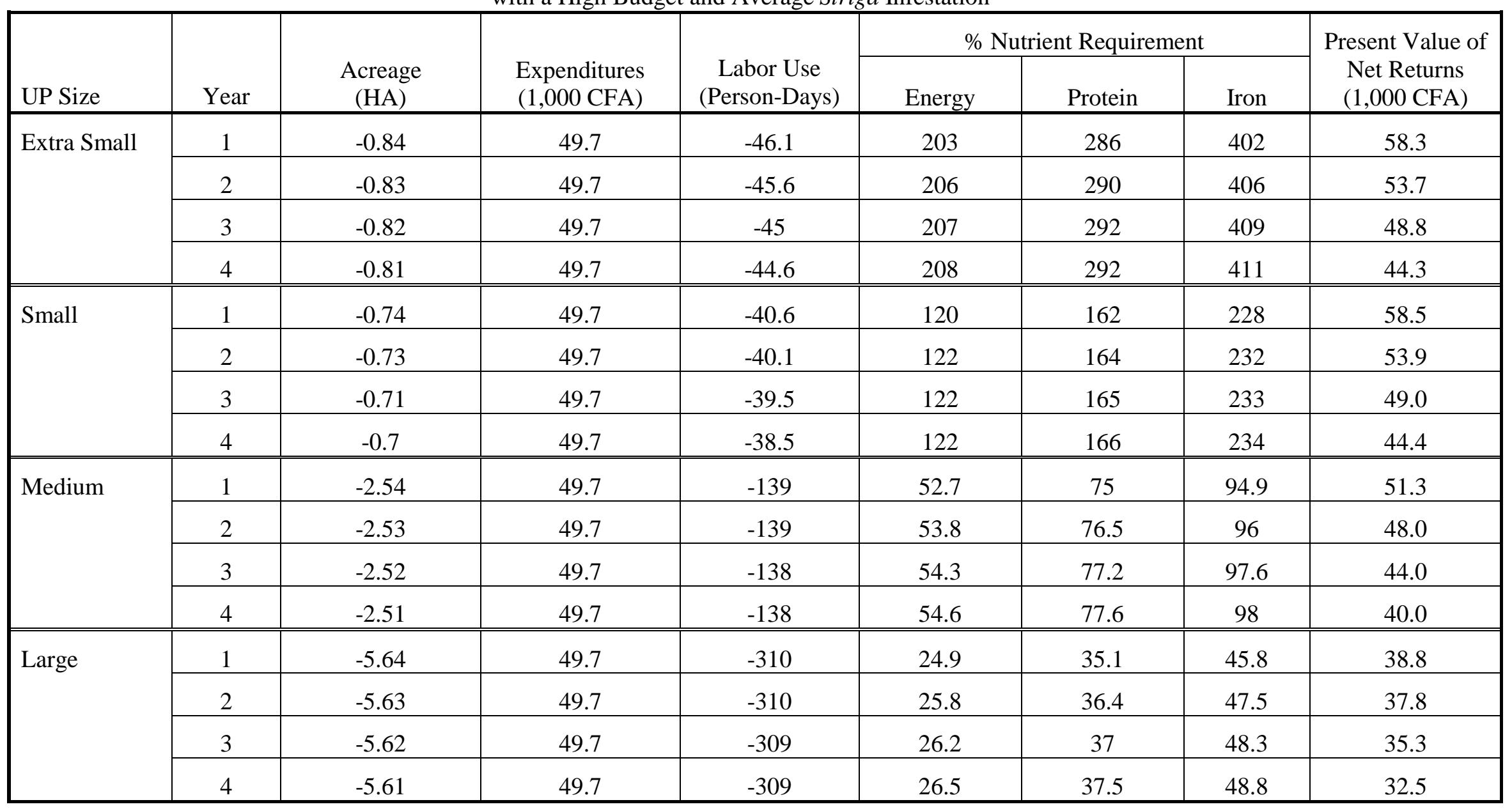


Figure 6.15: Change in Net Revenue from Adopting Optimal Practices with Average Striga and High Budget

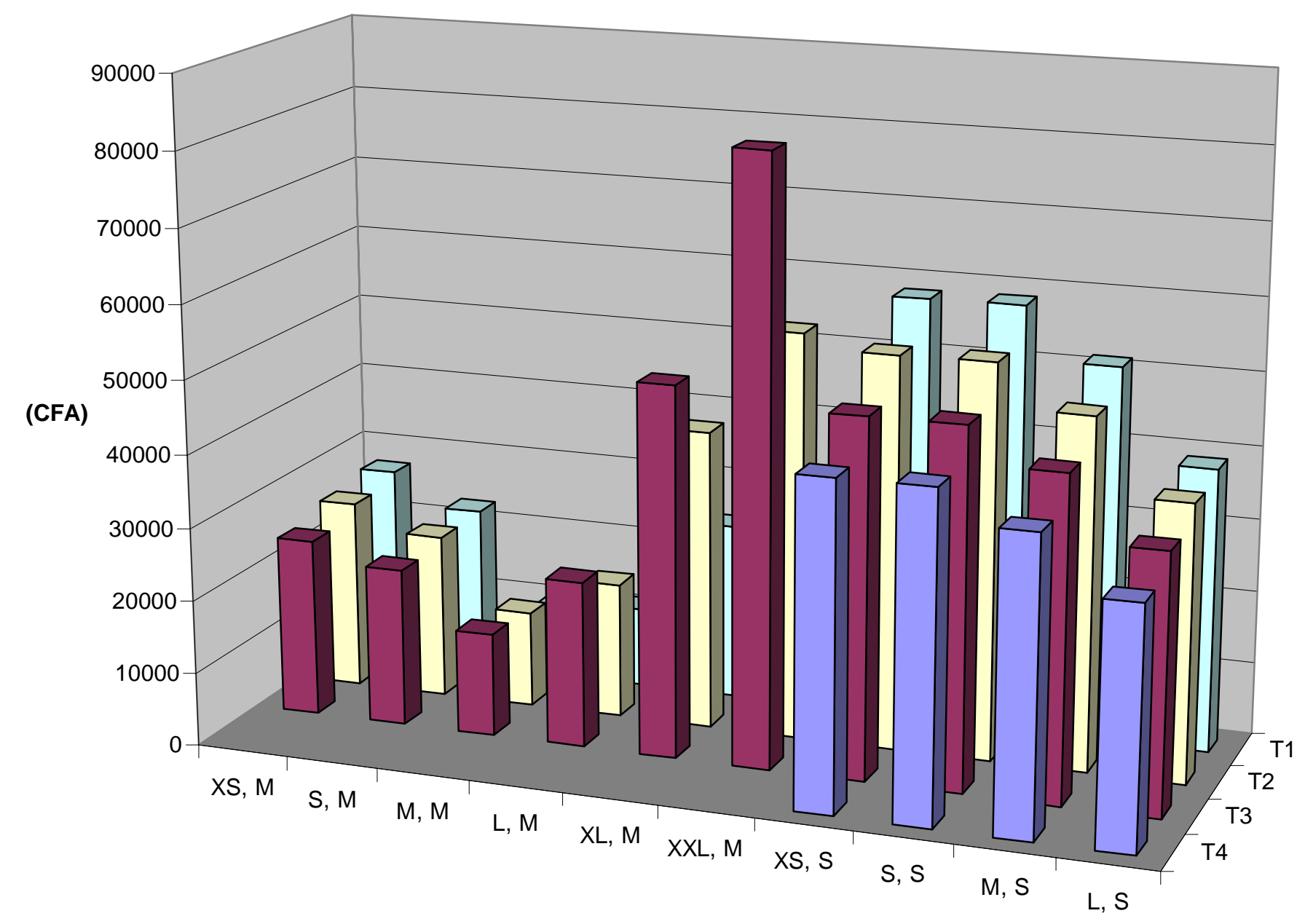


Figure 6.16: Change in \% UP KCal Requirement Met from Adopting Optimal Practices with Average Striga and Moderate Budget

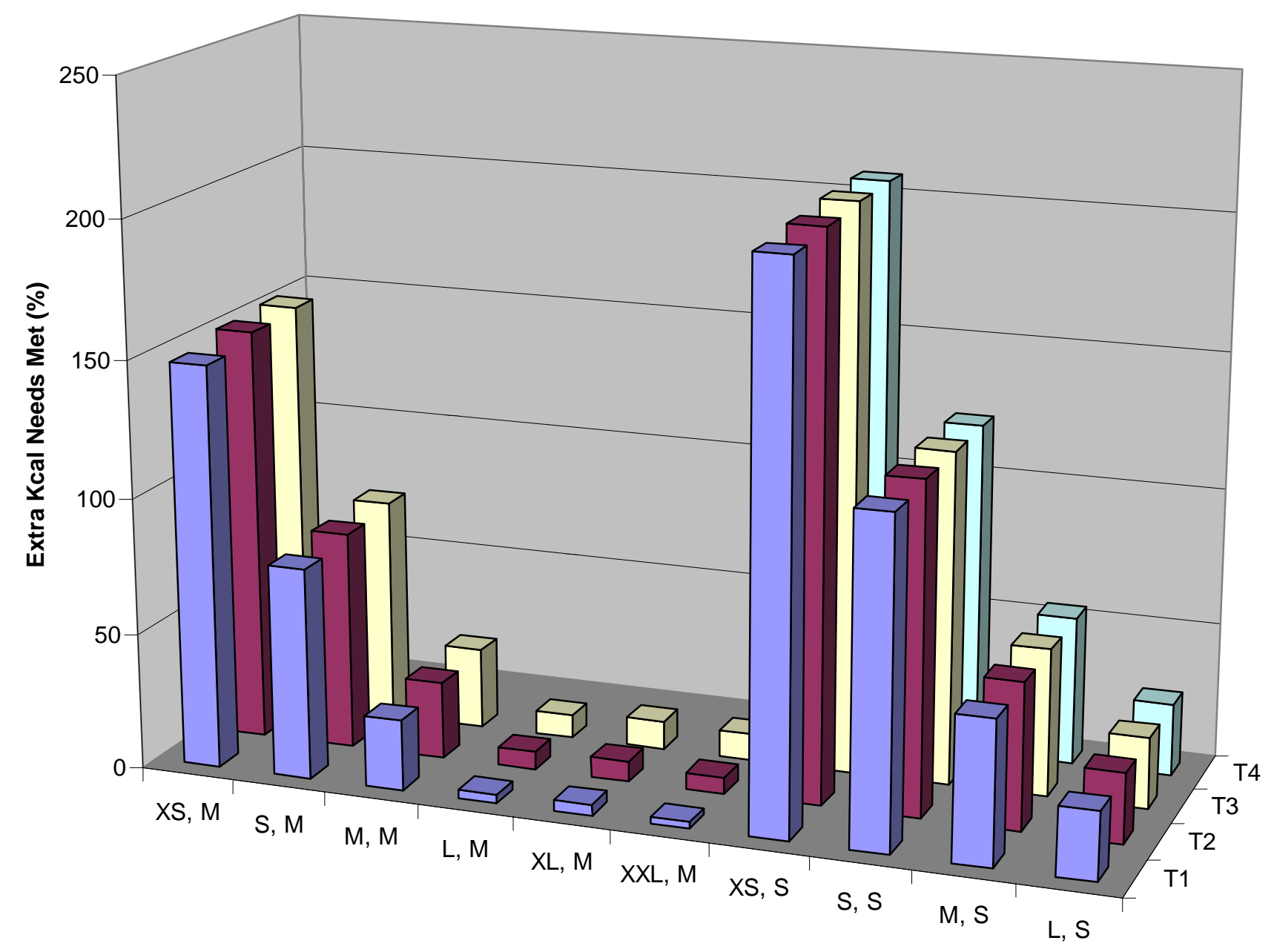


Figure 6.17: Change in \% UP Protein Requirement Met from Adopting Optimal Practices with Average Striga and High Budget

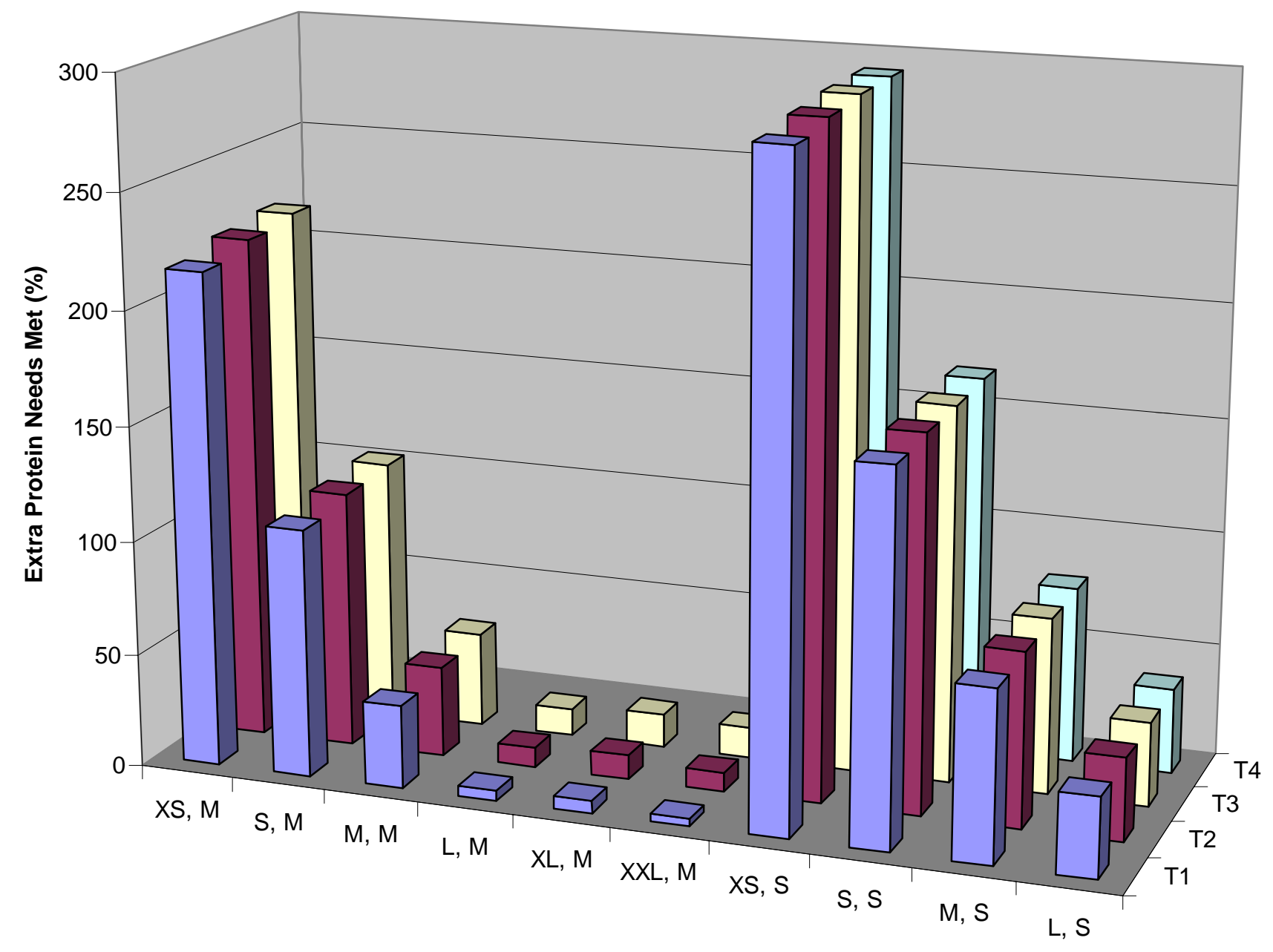


Figure 6.18: Change in \% UP Iron Requirement Met from Adopting Optimal Practices with Average Striga and High Budget

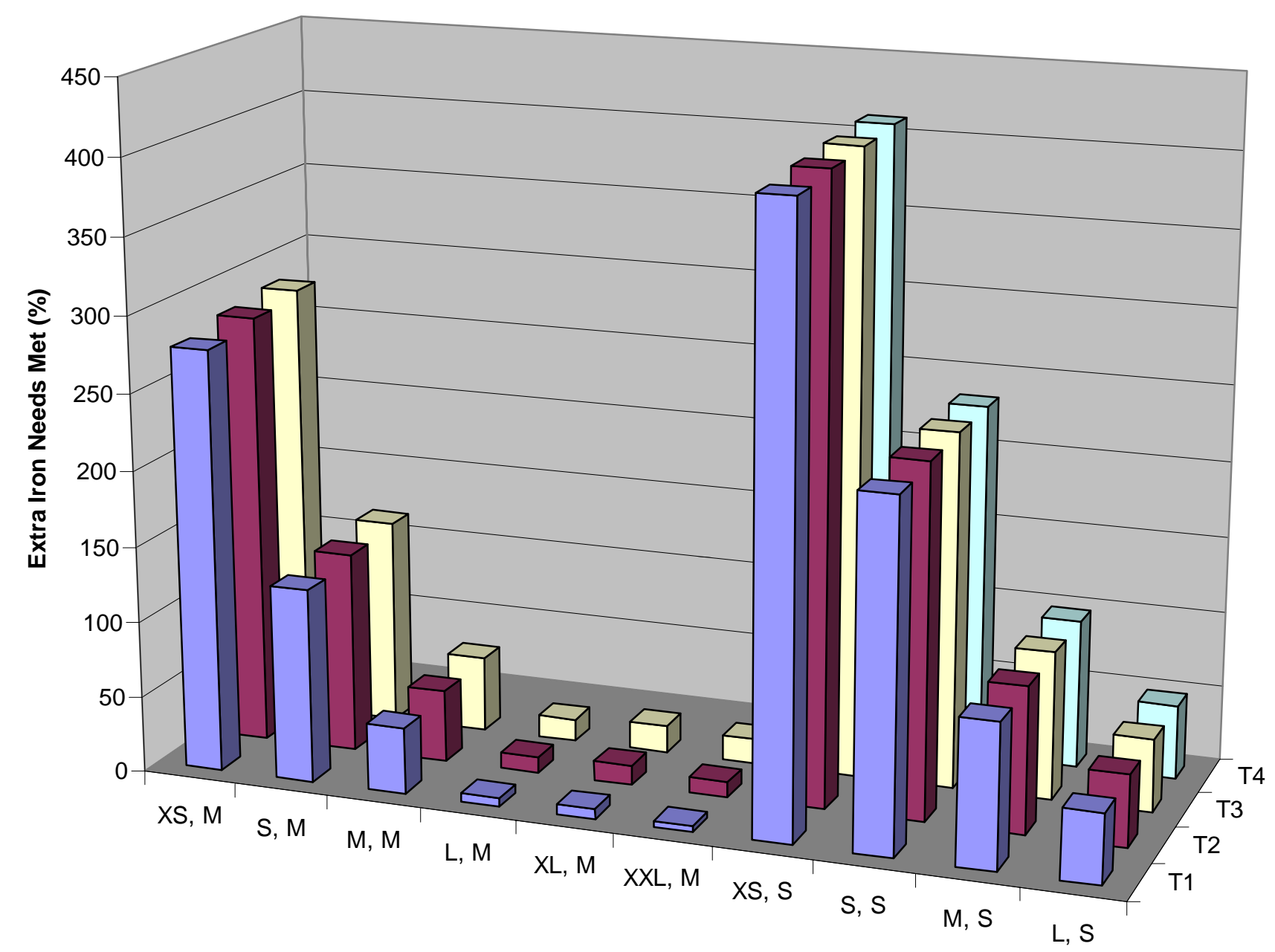


The optimal set of practices for the other UP's require a net increase in both total labor and person-days per hectare.

Optimal Production with a Very High Budget. With a budget of 100,000 CFA/year, the XL and XXL UP's in Mourdiah continue to plant millet at a low density, without urea. The S, M and L UP's in Mourdiah and the M and L UP's in Sirakorola apply the highdensity, urea based set of practices to twice as many hectares as they did with a high budget, generating twice the net revenues and twice the nutrient yield. The XS UP's in Mourdiah and the XS and S UP's in Sirakorola, however, face a new economic decision at this budget level.

The smaller UP's in both zones now have enough money to apply the high-density, ureabased set of practices to more acreage than they are able to cultivate with their own labor. In other words, their labor constraint becomes binding before their budget constraint. The decision facing these UP's is whether to increase the urea application rate, hire labor to cultivate more acreage, do both, or do neither. In Sirakorola, the model suggests the XS and S UP's increase their urea application rate rather than hiring labor. In Mourdiah, the model suggests the XS UP increase the urea application rate and hire additional labor.

In both zones, the marginal returns to a kilogram of urea, evaluated at the optimal application rate for the high-density, urea-based set of practices, are greater than the marginal returns to a person day of hired labor. ${ }^{56}$ There is, however, a threshold above which it is more profitable to increase acreage than it is to increase urea application rates. The threshold depends on the size of the Striga seedbank.

Tables 6.30 and 6.31 present the optimal set of practices for each UP size in Mourdiah and Sirakorola, respectively. In Year 1 in Mourdiah, the XS UP's increase the urea application rate to $404 \mathrm{~kg} / \mathrm{ha}$ and employ all of their own available labor. Purchasing this amount of urea for the acreage it is able to cultivate with its own labor does not consume 
the UP's entire budget. With the remaining cash, the model suggests the UP purchase both urea and labor in sufficient quantities to expand the cultivated acreage while applying $404 \mathrm{~kg}$ urea/ha. In Year 2, with a lower seedbank, the model suggests the UP apply only $400 \mathrm{~kg}$ urea/ha and hire more labor, cultivating more hectares, than it did in Year 1. In Year 3, the seedbank drops again, and so does the optimal urea application rate - now $391 \mathrm{~kg} / \mathrm{ha}$. The amount of hired labor increases, accordingly.

In Sirakorola, the XS UP's actually have more agricultural labor than the S UP's, due to the demographic composition of each. With a very high budget, the labor constraint for the S UP's becomes binding before the budget constraint in every year of the planning horizon. In each year, these UP's employ all of their own labor, and apply $369 \mathrm{~kg}$ urea/ha. Additional labor is not hired to expand the cultivated acreage.

The XS UP's do not face a binding labor constraint until Year 2, after the seedbank and, consequently, the optimal urea application rate have dropped. As a result, in Year 1, the XS UP's employ the same set of practices on the same number of hectares as the M and $\mathrm{L}$ UP's. In Year 2, the XS UP's increase the urea application rate after exhausting their own available labor, applying more urea to fewer hectares than the M and L UP's, but less urea to more hectares than the S UP's.

The expected financial and nutritional returns to the optimal set of practices for each UP size in Mourdiah and Sirakorola are presented in Tables 6.32 and 6.33, respectively. The changes, compared to status quo production are presented in Tables 6.34 and 6.35, and illustrated in Figures 6.19 through 6.22.

\footnotetext{
${ }^{56}$ The optimal urea application rate is the rate that would be applied if the labor constraint were not binding. For example, in Year 1, the optimal urea application rate in Mourdiah is $352 \mathrm{~kg} / \mathrm{ha}$; in Year 2 it is $343 \mathrm{~kg} / \mathrm{ha}$.
} 
Table 6.31: Optimal Practices in Mourdiah with Average Striga Infestation and a Very High Budget

(Starting Seedbank $=40,000 / \mathrm{m}^{2}$, Expenditures $\leq 100,000$ CFA $/$ Year)

\begin{tabular}{|c|c|c|c|}
\hline Input & Year 1 & Year 2 & Year 3 \\
\hline Association & Pure Millet & Pure Millet & Pure Millet \\
\hline Millet Density $\left(\mathrm{m}^{-2}\right), \mathrm{XS}-\mathrm{L}$ & 3.5 & 3.5 & 3.5 \\
\hline Millet Density $\left(\mathrm{m}^{-2}\right), \mathrm{XL}-\mathrm{XXL}$ & 0.5 & 0.5 & 0.5 \\
\hline Urea $(\mathrm{kg} / \mathrm{ha}), \mathrm{XS}$ & 404 & 400 & 391 \\
\hline Urea (kg/ha), S - L & 352 & 343 & 330 \\
\hline Urea (kg/ha), XL - XXL & 0 & 0 & 0 \\
\hline $\begin{array}{l}\text { Hired Labor } \\
\text { (Person-Days/ha) XS }\end{array}$ & 0.5 & 0.76 & 1.3 \\
\hline $\begin{array}{l}\text { Hired Labor } \\
\text { (Person-Days/ha) S-XXL }\end{array}$ & 0 & 0 & 0 \\
\hline \multicolumn{4}{|l|}{$\begin{array}{l}\text { UP Labor by Task } \\
\text { (Person-Days/ha) }\end{array}$} \\
\hline Sowing/Preparation & 10 & 10 & 10 \\
\hline First Weeding & 21 & 21 & 21 \\
\hline Second Weeding & 14 & 14 & 14 \\
\hline First Striga Weeding, XS - L & 0.1 & 0.1 & 0 \\
\hline First Striga Weeding, XL & 10.5 & 10.5 & 0 \\
\hline First Striga Weeding, XXL & 14.6 & 9.7 & 0 \\
\hline Harvest & 4 & 4 & 4 \\
\hline Second Striga Weeding, XS - L & 0.1 & 0.1 & 0 \\
\hline Second Striga Weeding, XL & 4.5 & 4.5 & 0 \\
\hline Second Striga Weeding, XXL & 11.9 & 9.7 & 0 \\
\hline Post-Harvest & 6 & 6 & 6 \\
\hline
\end{tabular}


Table 6.32: Optimal Practices in Sirakorola with Average Striga Infestation and a Very High Budget

(Starting Seedbank $=40,000 / \mathrm{m}^{2}$, Expenditures $\leq 100,000 \mathrm{CFA} /$ Year)

\begin{tabular}{|l|c|c|c|c|}
\hline Input & Year 1 & Year 2 & Year 3 & Year 4 \\
\hline Association & Pure Millet & Pure Millet & Pure Millet & Pure Millet \\
\hline Millet Density $\left(\mathrm{m}^{-2}\right)$ & 3.5 & 3.5 & 3.5 & 3.5 \\
\hline Urea (kg/ha), XS & 360 & 356 & 356 & 356 \\
\hline Urea (kg/ha), S & 369 & 369 & 369 & 369 \\
\hline Urea (kg/ha), M - L & 360 & 352 & 343 & 334 \\
\hline $\begin{array}{l}\text { Hired Labor } \\
\text { (Person-Days/ha) }\end{array}$ & 0 & 0 & 0 & 0 \\
\hline $\begin{array}{l}\text { UP Labor by Task } \\
\text { (Person-Days/ha) }\end{array}$ & 10 & 10 & 10 & 10 \\
\hline Sowing/Preparation & 21 & 21 & 21 & 21 \\
\hline First Weeding & 14 & 14 & 14 & 14 \\
\hline Second Weeding & 0.1 & 0.1 & 0.1 & 0 \\
\hline First Striga Weeding & 4 & 4 & 4 & 4 \\
\hline Harvest & 0.1 & 0.1 & 0.1 & 0 \\
\hline Second Striga Weeding & 6 & 6 & 6 & 6 \\
\hline Post-Harvest & & & & \\
\hline
\end{tabular}


Table 6.33: Estimated Financial and Nutritional Returns, Millet Production, Seedbank Growth, and Expenditures in Mourdiah Under Optimal Practices with a Very High Budget and Average Striga Infestation

\begin{tabular}{|c|c|c|c|c|c|c|c|c|c|}
\hline \multirow[b]{2}{*}{ UP Size } & \multirow[b]{2}{*}{ Year } & \multirow{2}{*}{$\begin{array}{c}\text { Seedbank } \\
\left(10^{3} \text { seeds } \mathrm{m}^{-2}\right) \\
\end{array}$} & \multirow{2}{*}{$\begin{array}{c}\text { Area } \\
\text { (ha) }\end{array}$} & \multirow{2}{*}{$\begin{array}{c}\text { Millet } \\
\text { Production }(\mathrm{kg}) \\
\end{array}$} & \multicolumn{3}{|c|}{$\%$ Nutrient Requirement } & \multirow{2}{*}{$\begin{array}{l}\text { Expenditures } \\
(1,000 \mathrm{CFA}) \\
\end{array}$} & \multirow{2}{*}{$\begin{array}{c}\text { Present Value o } \\
\text { Net Returns } \\
(1,000 \text { CFA) } \\
\end{array}$} \\
\hline & & & & & Energy & Protein & Iron & & \\
\hline \multirow[t]{3}{*}{ Extra Small } & 1 & 40 & 1.37 & 3294 & 316 & 463 & 594 & 100.0 & 64.6 \\
\hline & 2 & 21 & 1.38 & 3294 & 316 & 463 & 594 & 100.0 & 58.1 \\
\hline & 3 & 11 & 1.4 & 3294 & 316 & 463 & 594 & 100.0 & 53.0 \\
\hline \multirow[t]{3}{*}{ Small } & 1 & 40 & 1.56 & 3368 & 180 & 254 & 299 & 100.0 & 68.4 \\
\hline & 2 & 21.6 & 1.6 & 3413 & 183 & 257 & 303 & 100.0 & 63.6 \\
\hline & 3 & 11.6 & 1.68 & 3440 & 184 & 259 & 305 & 100.0 & 58.3 \\
\hline \multirow[t]{3}{*}{ Medium } & 1 & 40 & 1.56 & 3368 & 74.6 & 104 & 125 & 100.0 & 68.4 \\
\hline & 2 & 21.6 & 1.6 & 3413 & 75.5 & 106 & 127 & 100.0 & 63.6 \\
\hline & 3 & 11.6 & 1.68 & 3440 & 76.1 & 107 & 128 & 100.0 & 58.3 \\
\hline \multirow[t]{3}{*}{ Large } & 1 & 40 & 1.56 & 3368 & 52.9 & 73.5 & 88.5 & 100.0 & 68.4 \\
\hline & 2 & 21.6 & 1.6 & 3413 & 53.6 & 74.5 & 89.7 & 100.0 & 63.6 \\
\hline & 3 & 11.6 & 1.68 & 3440 & 54.0 & 75.1 & 90.4 & 100.0 & 58.3 \\
\hline \multirow[t]{3}{*}{ Extra Large } & 1 & & & & & & & & \\
\hline & 2 & & Same & As & Low & And & Very & Low & \\
\hline & 3 & & & & & & & & \\
\hline \multirow{3}{*}{$\begin{array}{l}\text { Extra Extra } \\
\text { Large }\end{array}$} & 1 & & & & & & & & \\
\hline & 2 & & Same & As & Low & And & Very & Low & \\
\hline & 3 & & & & & & & & \\
\hline
\end{tabular}


Table 6.34: Estimated Financial and Nutritional Returns, Millet Production, Seedbank Growth, and Expenditures in Sirakorola Under Optimal Practices with a Very High Budget and Average Striga Infestation

\begin{tabular}{|c|c|c|c|c|c|c|c|c|c|}
\hline \multirow[b]{2}{*}{ UP Size } & \multirow[b]{2}{*}{ Year } & \multirow{2}{*}{$\begin{array}{c}\text { Seedbank } \\
\left(10^{3} \text { seeds } \mathrm{m}^{-2}\right) \\
\end{array}$} & \multirow{2}{*}{$\begin{array}{l}\text { Area } \\
\text { (ha) } \\
\end{array}$} & \multirow{2}{*}{$\begin{array}{c}\text { Millet } \\
\text { Production }(\mathrm{kg}) \\
\end{array}$} & \multicolumn{3}{|c|}{$\%$ Nutrient Requirement } & \multirow{2}{*}{$\begin{array}{c}\text { Expenditures } \\
(1,000 \mathrm{CFA}) \\
\end{array}$} & \multirow{2}{*}{$\begin{array}{c}\text { Present Value } \\
\text { of Net Returns } \\
(1,000 \mathrm{CFA})\end{array}$} \\
\hline & & & & & Energy & Protein & Iron & & \\
\hline \multirow[t]{4}{*}{ Extra Small } & 1 & 40 & 1.54 & 4586 & 432 & 608 & 853 & 100.0 & 129.3 \\
\hline & 2 & 21.6 & 1.56 & 4595 & 432 & 609 & 855 & 100.0 & 116.8 \\
\hline & 3 & 11.7 & 1.6 & 4601 & 433 & 610 & 856 & 100.0 & 105.3 \\
\hline & 4 & 6.3 & 1.64 & 4605 & 433 & 610 & 857 & 100.0 & 95.0 \\
\hline \multirow[t]{4}{*}{ Small } & 1 & 40 & 1.54 & 4584 & 254 & 343 & 485 & 100.0 & 129.2 \\
\hline & 2 & 21.6 & 1.56 & 4589 & 254 & 343 & 485 & 100.0 & 116.5 \\
\hline & 3 & 11.7 & 1.6 & 4591 & 254 & 344 & 485 & 100.0 & 104.9 \\
\hline & 4 & 6.4 & 1.64 & 4593 & 254 & 344 & 486 & 100.0 & 94.5 \\
\hline \multirow[t]{4}{*}{ Medium } & 1 & 40 & 1.54 & 4586 & 120 & 171 & 215 & 100.0 & 129.3 \\
\hline & 2 & 21.7 & 1.56 & 4596 & 120 & 171 & 216 & 100.0 & 116.8 \\
\hline & 3 & 11.8 & 1.6 & 4607 & 121 & 172 & 216 & 100.0 & 105.6 \\
\hline & 4 & 6.4 & 1.64 & 4619 & 121 & 172 & 217 & 100.0 & 95.5 \\
\hline \multirow[t]{4}{*}{ Large } & 1 & 40 & 1.54 & 4586 & 65.2 & 92.0 & 120.1 & 100.0 & 129.3 \\
\hline & 2 & 21.7 & 1.56 & 4596 & 65.3 & 92.2 & 120.3 & 100.0 & 116.8 \\
\hline & 3 & 11.8 & 1.6 & 4607 & 65.5 & 92.4 & 120.6 & 100.0 & 105.6 \\
\hline & 4 & 6.4 & 1.64 & 4619 & 65.6 & 92.6 & 120.9 & 100.0 & 95.5 \\
\hline
\end{tabular}


Table 6.35: Estimated Changes in Expenditures, Labor Use, Nutritional and Financial Returns from Adopting the Optimal Practices in Mourdiah with a Very High Budget and Average Striga Infestation

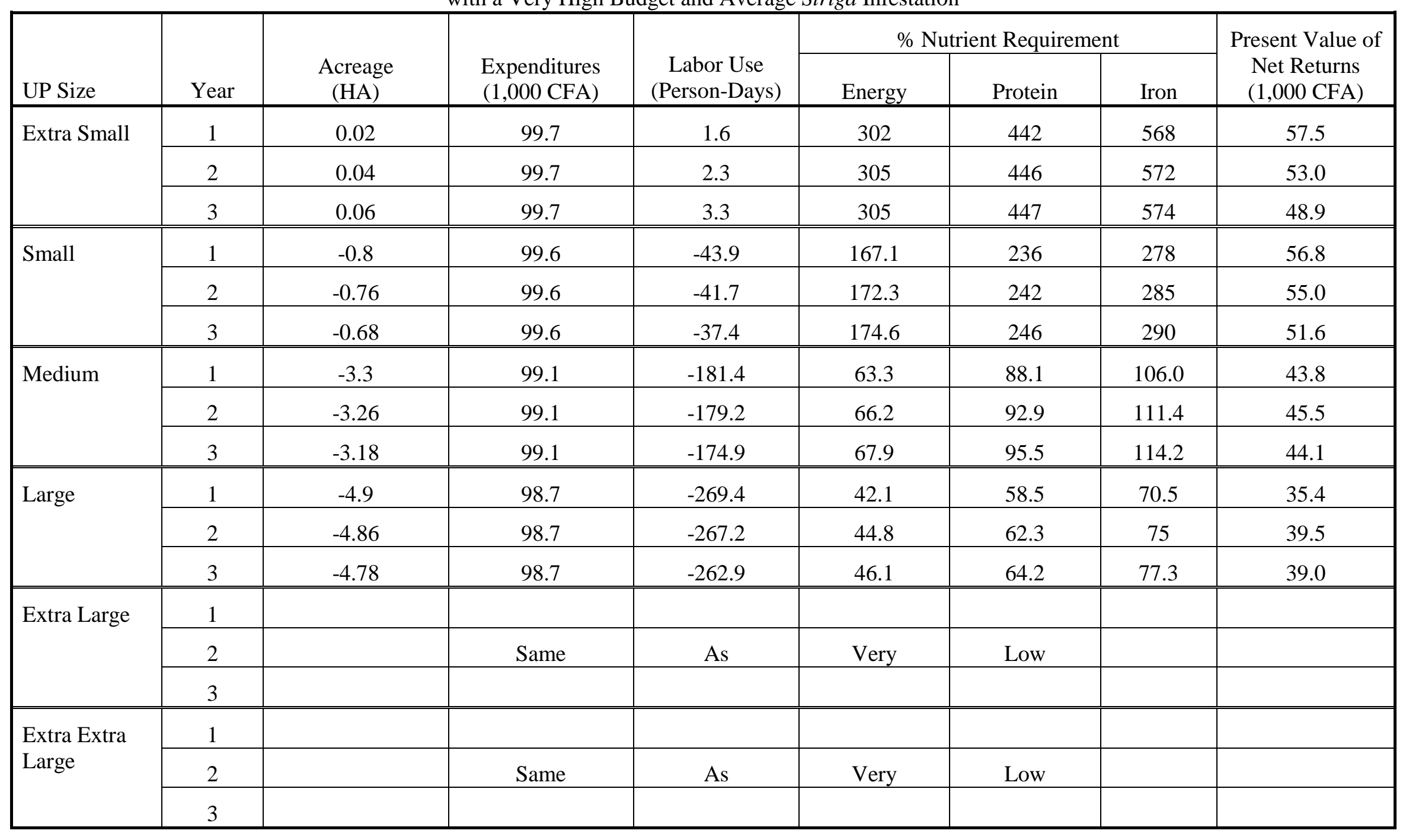


Table 6.36: Estimated Changes in Expenditures, Labor Use, Nutritional and Financial Returns from Adopting the Optimal Practices in Sirakorola with a Very High Budget and Average Striga Infestation

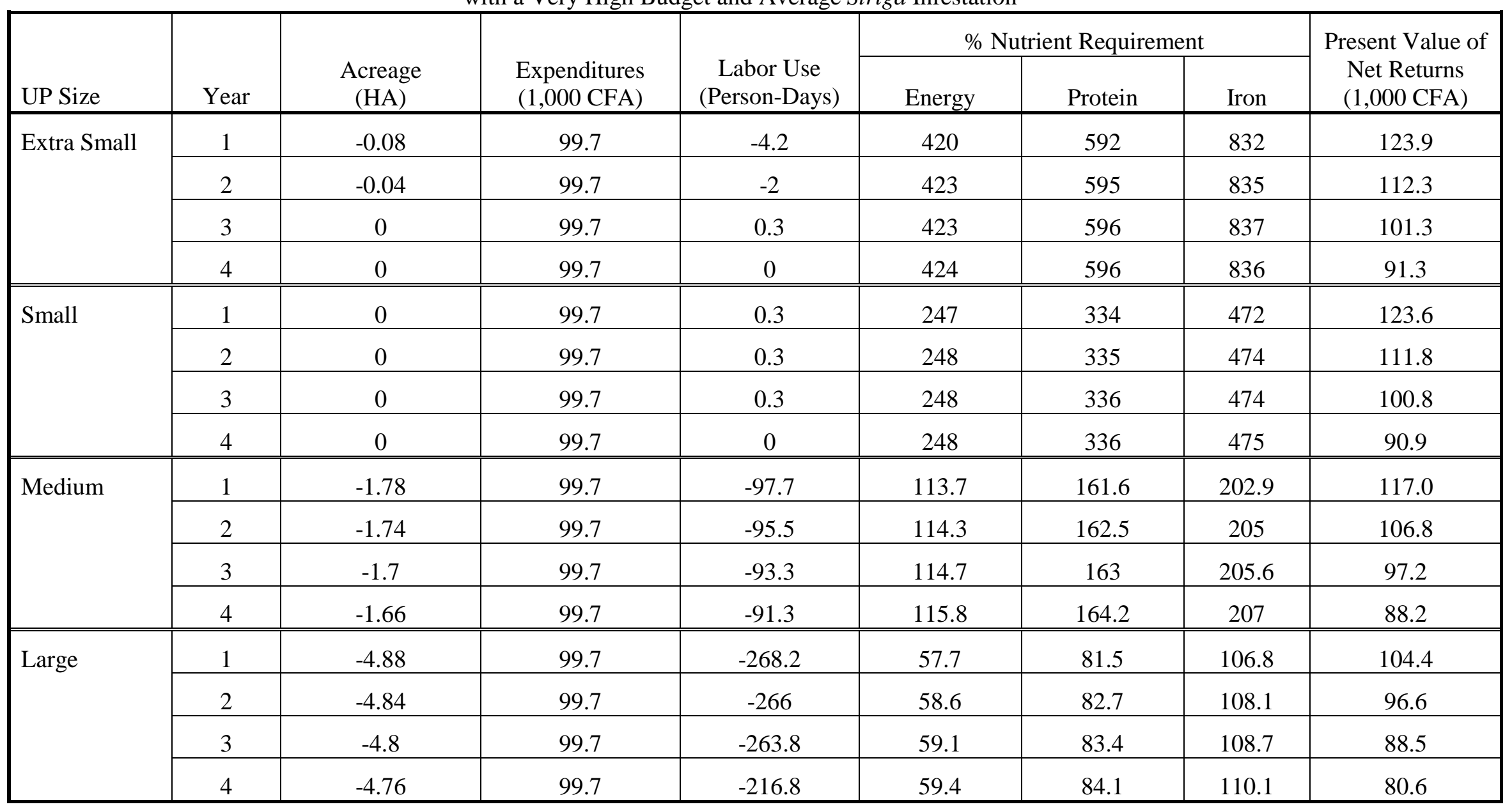


Figure 6.19: Change in Net Revenue from Adopting Optimal Practices with Average Striga and Very High Budget

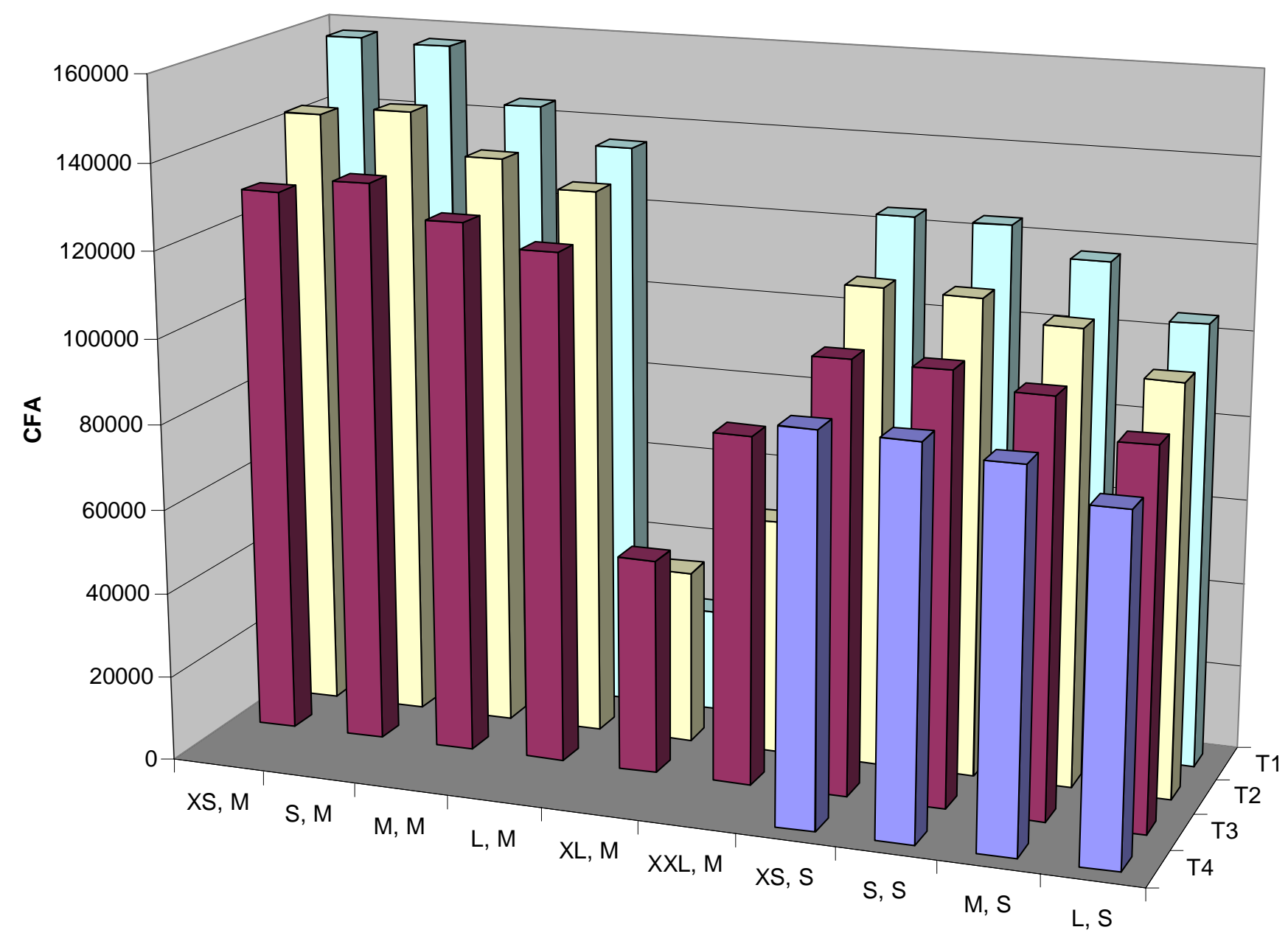


Figure 6.20: Change in \% UP KCal Requirement Met from Adopting Optimal Practices with Average Striga and Very High Budget

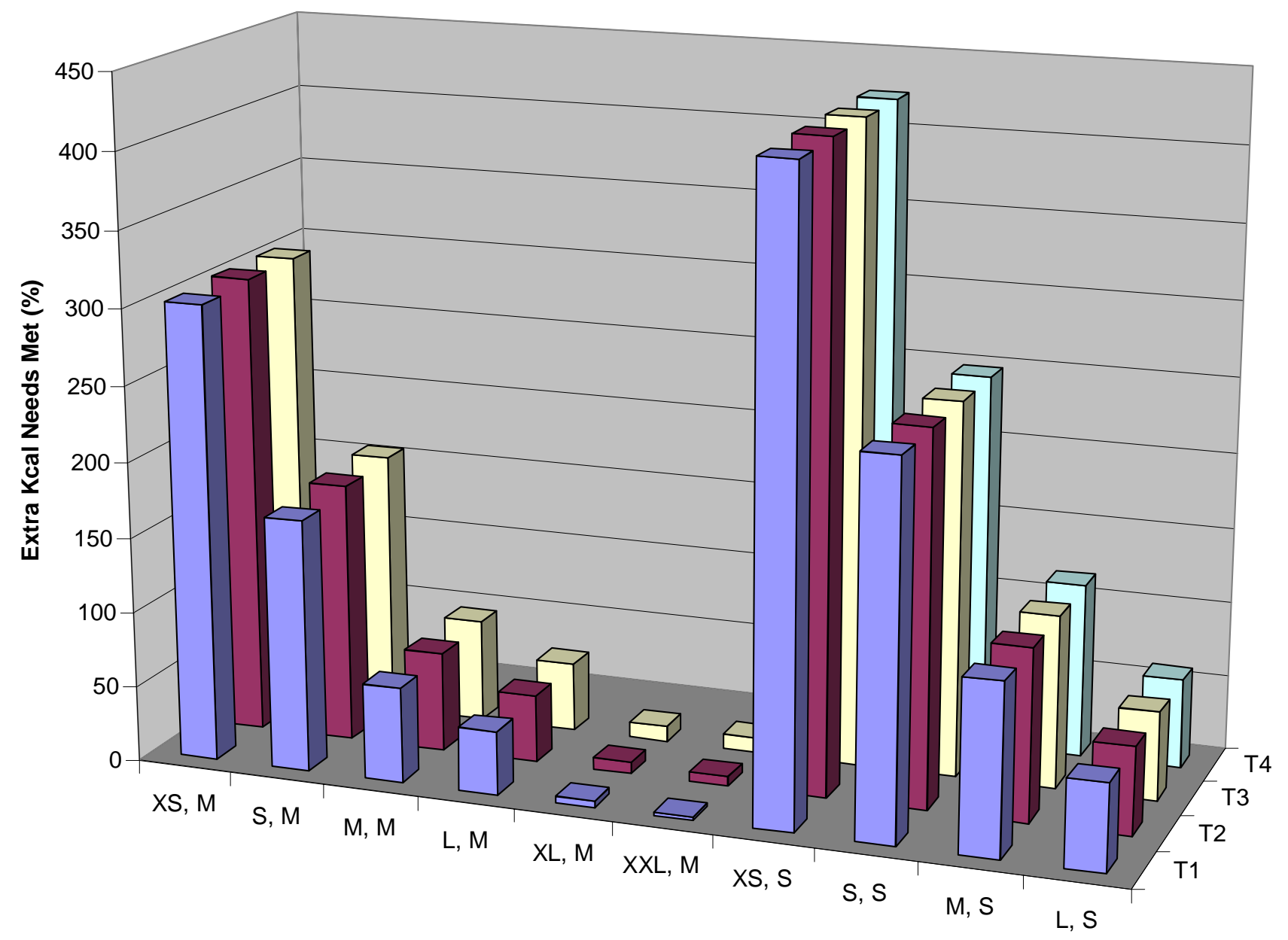


Figure 6.21: Change in \% UP Protein Requirement Met from Adopting Optimal Practices with Average Striga and Very High Budget

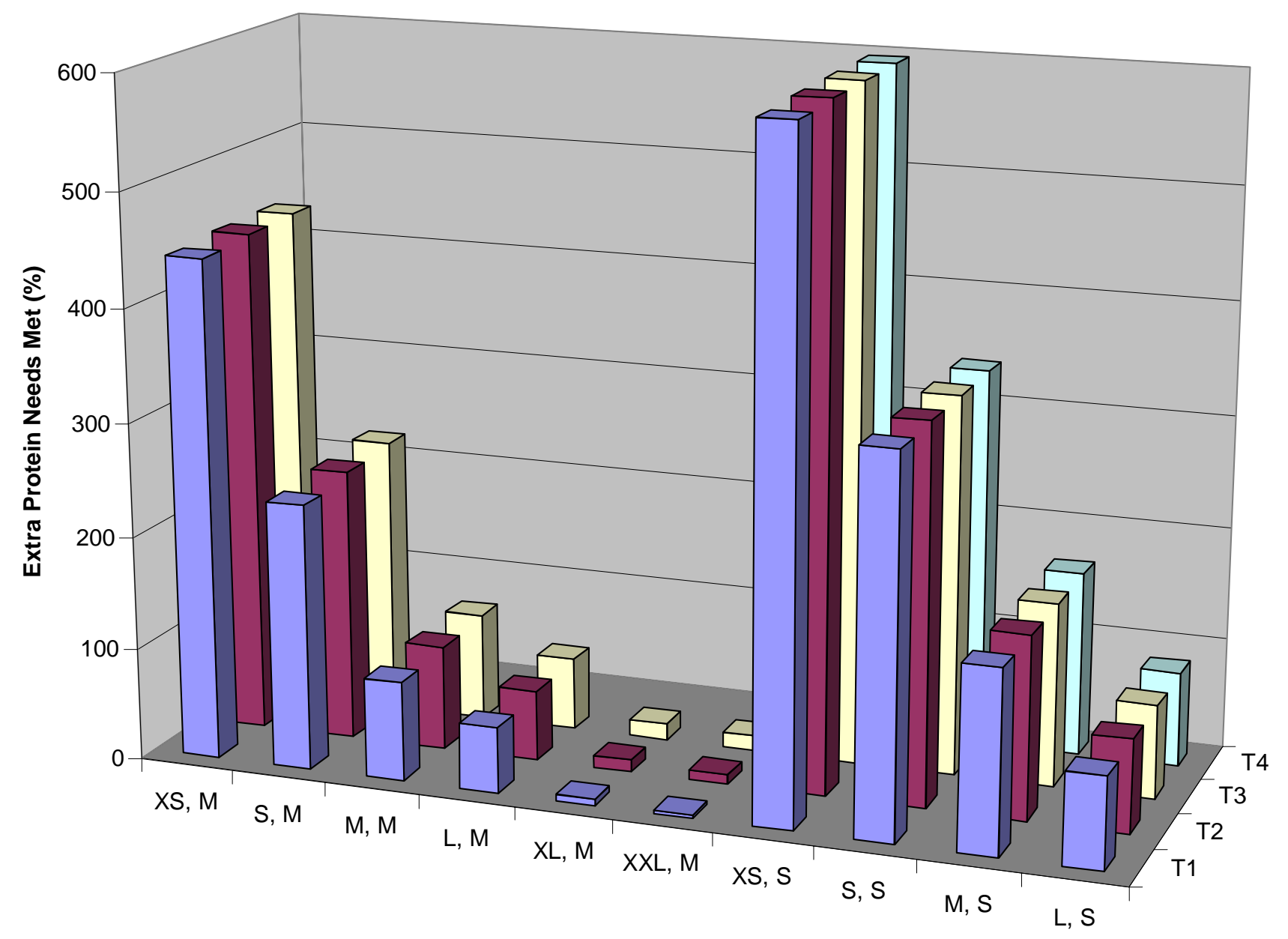


Figure 6.22: Change in \% UP Iron Requirement Met from Adopting Optimal Practices with Average Striga and Very High Budget

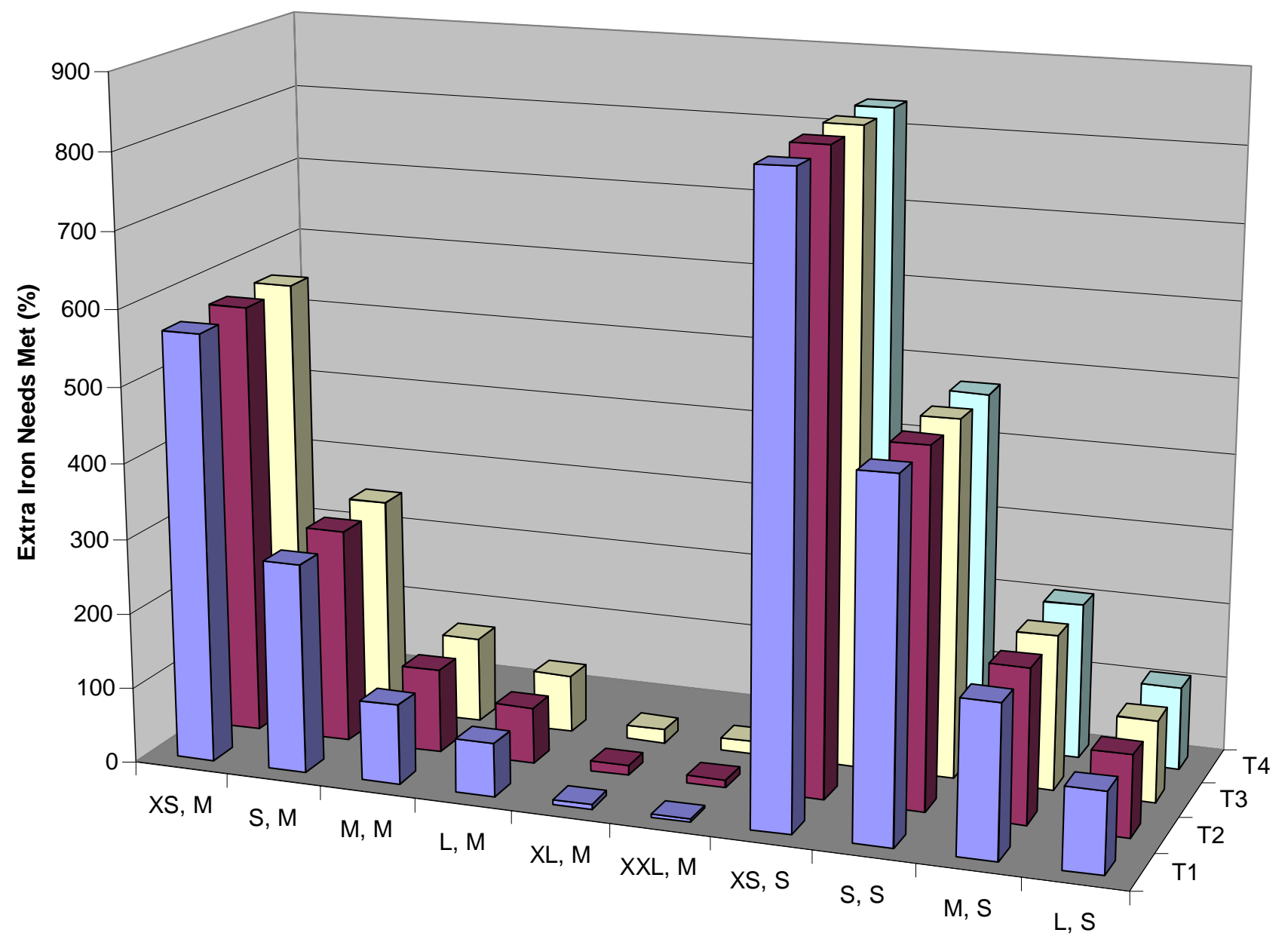




\section{Section 6.6 Scenario V: Optimal Practices with Average Striga Infestation and Seed Externality}

The final scenario examined by the model builds on Scenario IV by allowing the asymmetric movement of seed between fields. Asymmetric seed movement may arise when UP's within a zone adopt different production practices, or as the result of environmental conditions. As there are an infinite number of environmental conditions that may influence seed movement, Scenario $\mathrm{V}$ focuses on the repercussions of asymmetric seed movement due to the use of different production practices within a zone. $^{57}$

Optimal Production with a Very Low Budget. The optimal set of practices for all $\mathrm{UP}_{\mathrm{I}, \mathrm{Z}}$ are the same with the seed externality as they are in Scenario IV. UP's in Mourdiah plant pure millet at low density, causing the seedbank to shrink in each successive season, and UP's in Sirakorola plant pure millet at a high density, causing their seedbank to grow. Because of the externality, however, the seedbank of optimal producers in Mourdiah decreases at a slightly lower rate, while the seedbank of optimal producers increases at a slightly lower rate in Sirakorola. ${ }^{58}$

\footnotetext{
${ }^{57}$ It is assumed environmental factors impact all fields equally, causing all migrating seeds to be exchanged between agricultural fields.

${ }^{58}$ Optimal producers in Sirakorola actually have a net loss of seeds, as the higher millet density leads to a higher production of seeds than status quo practices. In other words, with a very low budget, optimal producers in Sirakorola face a positive seed externality in Scenario V.
} 
In Sirakorola, the seedbank is growing so quickly for both optimal and status quo producers, that the net exchange of seeds has no effect on millet production or net revenues. In Mourdiah, the slower rate of decline of the seedbank due to the externality has very modest nutritional effects - no UP loses more than 2 percent of their needs of any nutrient in any year due to the externality. The financial effects are also modest losses across the planning horizon do not exceed 6,000 CFA ( $2 \%$ of income) for any UP size. Table 6.37 presents the financial and nutritional returns to optimal production in Mourdiah. Figures 6.23 through 6.26 illustrate the cost of the externality by comparing the results from the very low budget level in Scenario IV to those of Scenario V. 
Table 6.37: Estimated Financial and Nutritional Returns, Millet Production, Seedbank Growth, and Expenditures in Mourdiah Under Optimal Practices with a Very Low Budget, Average Striga Infestation and Seed Externality

\begin{tabular}{|c|c|c|c|c|c|c|c|c|}
\hline \multirow[b]{2}{*}{ UP Size } & \multirow[b]{2}{*}{ Year } & \multirow{2}{*}{$\begin{array}{c}\text { Seedbank } \\
\left(10^{3} \text { seeds } \mathrm{m}^{-2}\right) \\
\end{array}$} & \multirow{2}{*}{$\begin{array}{c}\text { Millet } \\
\text { Production }(\mathrm{kg})\end{array}$} & \multicolumn{3}{|c|}{$\%$ Nutrient Requirement } & \multirow{2}{*}{$\begin{array}{l}\text { Expenditures } \\
(1,000 \text { CFA }) \\
\end{array}$} & \multirow{2}{*}{$\begin{array}{l}\text { Present Value of } \\
\text { Net Returns } \\
(1,000 \text { CFA }) \\
\end{array}$} \\
\hline & & & & Energy & Protein & Iron & & \\
\hline \multirow[t]{3}{*}{ Extra Small } & 1 & 40 & 191 & 18.3 & 26.8 & 34.5 & 0.134 & 9.4 \\
\hline & 2 & 34 & 201 & 19.3 & 28.3 & 36.3 & 0.134 & 9.1 \\
\hline & 3 & 30.6 & 213 & 20.5 & 29.9 & 38.4 & 0.134 & 8.5 \\
\hline \multirow[t]{3}{*}{ Small } & 1 & 40 & 312 & 16.7 & 23.5 & 27.7 & 0.219 & 15.4 \\
\hline & 2 & 34 & 333 & 17.9 & 25.1 & 29.5 & 0.219 & 14.8 \\
\hline & 3 & 30.6 & 347 & 18.6 & 26.1 & 30.8 & 0.219 & 13.9 \\
\hline \multirow[t]{3}{*}{ Medium } & 1 & 40 & 664 & 14.7 & 20.7 & 24.7 & 0.467 & 32.7 \\
\hline & 2 & 34 & 709 & 15.7 & 22.1 & 26.4 & 0.467 & 31.5 \\
\hline & 3 & 30.5 & 740 & 16.4 & 23.0 & 27.6 & 0.467 & 29.6 \\
\hline \multirow[t]{3}{*}{ Large } & 1 & 40 & 892 & 14 & 19.5 & 23.4 & 0.627 & 44.0 \\
\hline & 2 & 34 & 952 & 14.9 & 20.8 & 25.0 & 0.627 & 42.3 \\
\hline & 3 & 30.5 & 994 & 15.6 & 21.7 & 26.1 & 0.627 & 39.7 \\
\hline \multirow[t]{3}{*}{ Extra Large } & 1 & 40 & 1983 & 17 & 23.8 & 29.1 & 1.390 & 97.8 \\
\hline & 2 & 34 & 2117 & 18.1 & 25.4 & 31.1 & 1.390 & 94.0 \\
\hline & 3 & 30.5 & 2209 & 18.9 & 26.5 & 32.5 & 1.390 & 88.4 \\
\hline \multirow{3}{*}{$\begin{array}{l}\text { Extra Extra } \\
\text { Large }\end{array}$} & 1 & 40 & 1992 & 9.8 & 13.5 & 16.3 & 1.400 & 98.2 \\
\hline & 2 & 24 & 2448 & 12.1 & 16.6 & 20.1 & 1.400 & 108.9 \\
\hline & 3 & 13.6 & 3028 & 14.9 & 20.5 & 24.8 & 1.400 & 121.5 \\
\hline
\end{tabular}


Figure 6.23: Change in Percentage of Energy Needs Met Due to Seed Externality, with a Very Low Budget

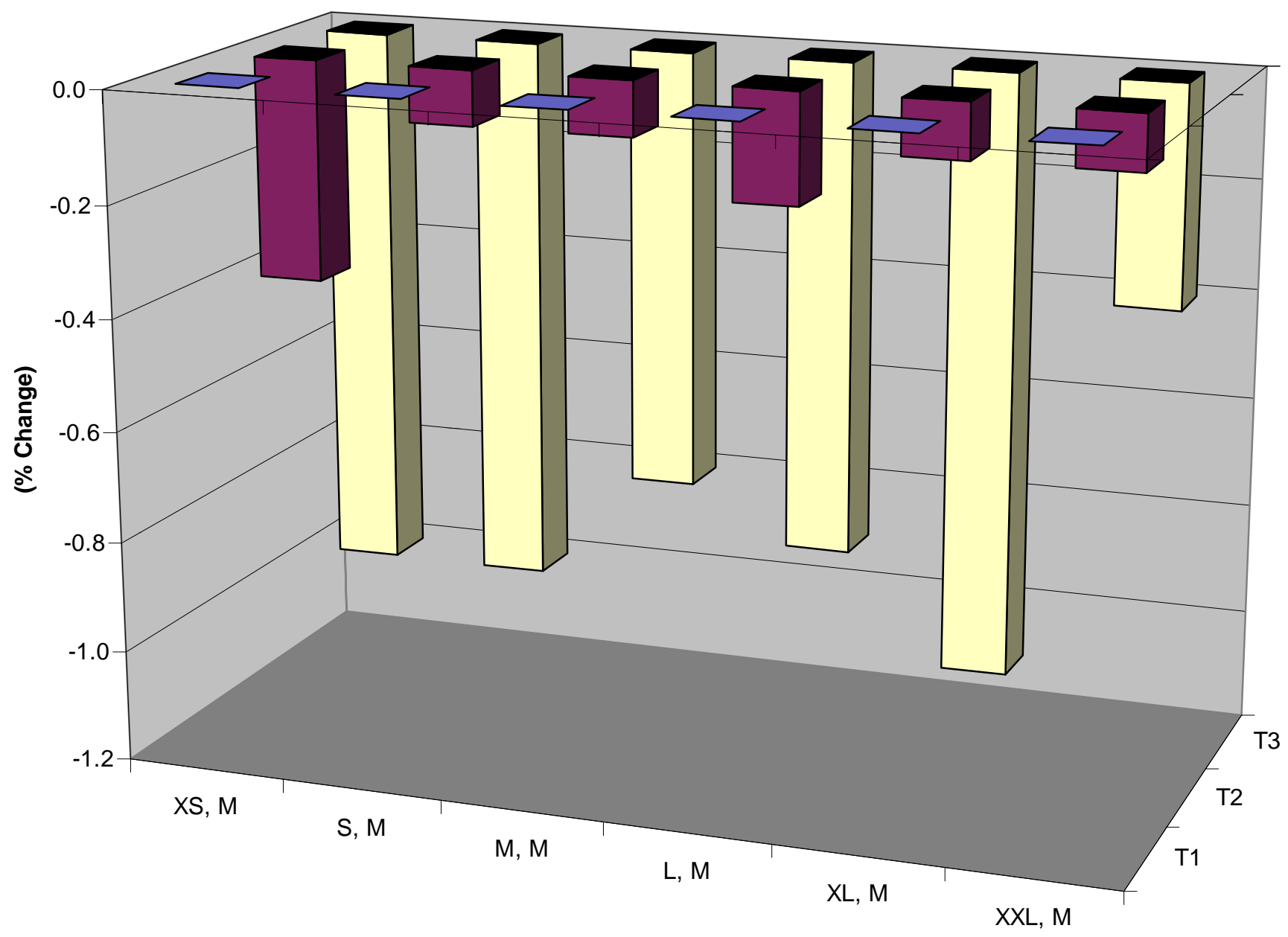


Figure 6.24: Change in Percentage of Protein Needs Met Due to Seed Externality, with Very Low Budget

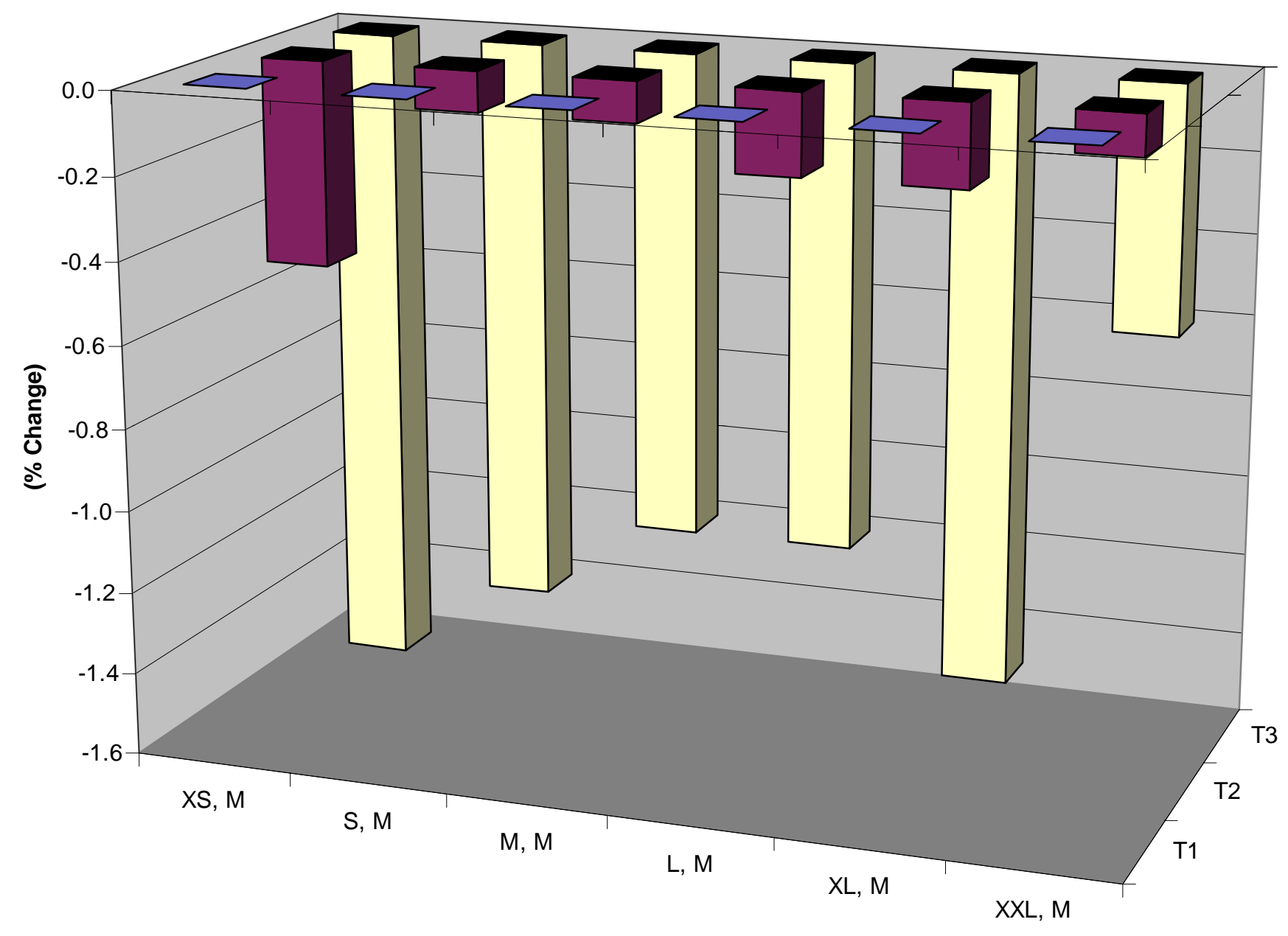


Figure 6.25: Change in Percentage of Iron Needs Met Due to Seed Externality, with Very Low Budget

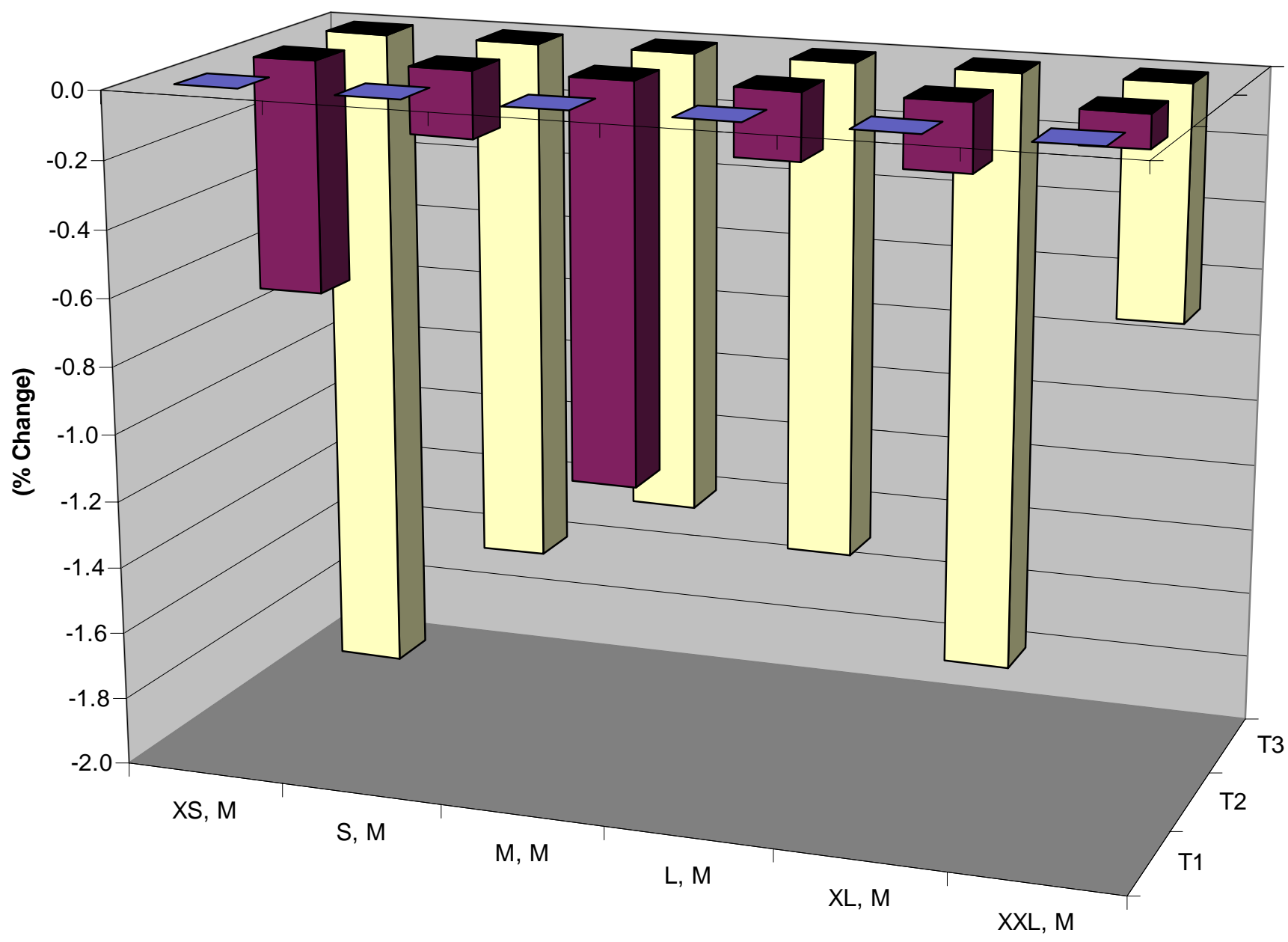


Figure 6.26: Change in Net Revenue Due to the Seed Externality, with a Very Low Budget

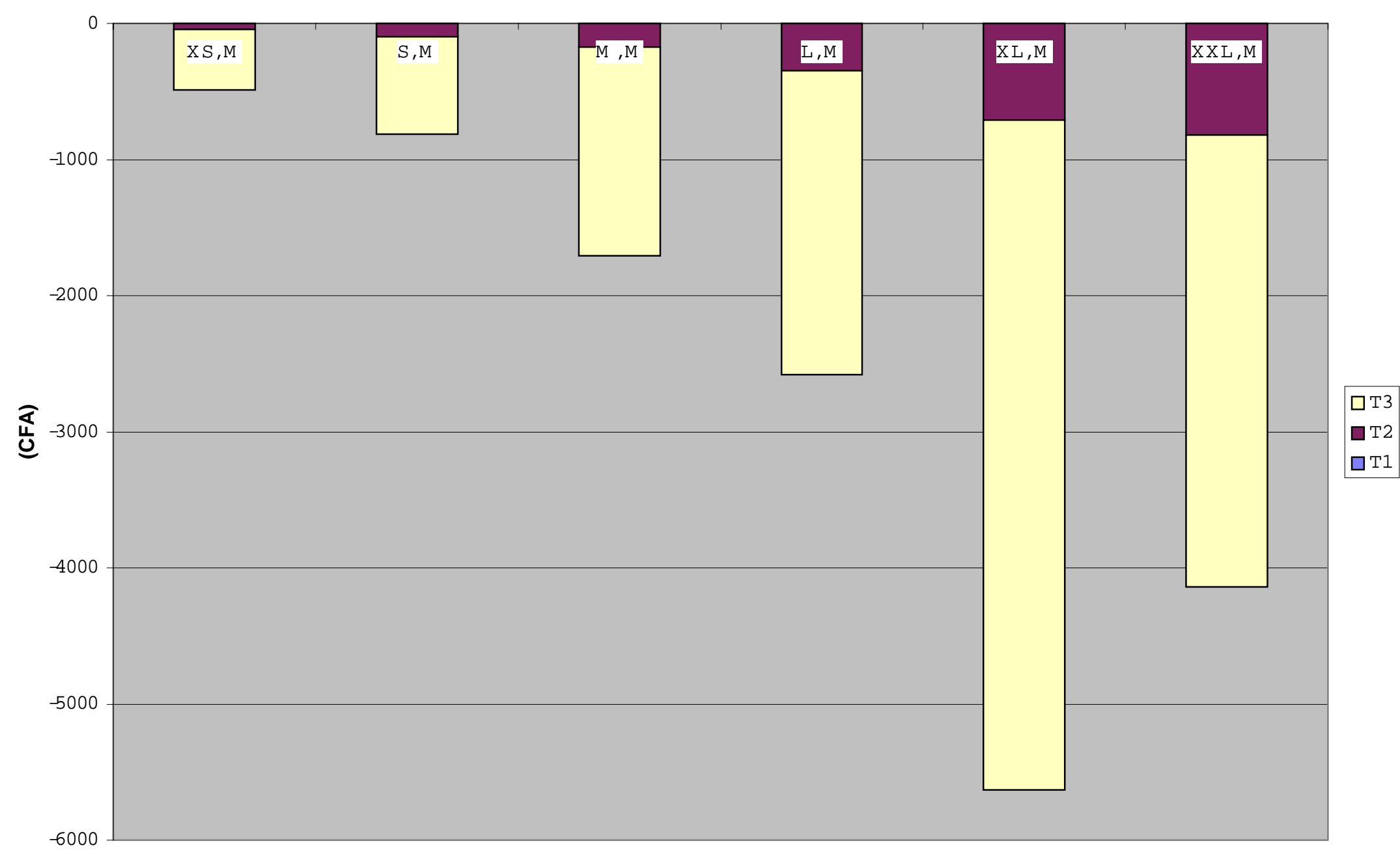


Optimal Production with a Low Budget. As in Scenario IV, access to a low rather than a very low budget does not alter the optimal set of practices in the presence of a seed externality. As a result, the producers harvest the same amount of millet and earn the same net revenues as they did with a very low budget. The costs of the seed externality are also the same as with a very low budget.

Optimal Production with a Moderate, High, or Very High Budget. When the budget reaches 25,000 CFA/year, the smaller UP's begin to adopt the same high-density, ureabased set of practices as they did in Scenario IV. Introduction of the seed externality does not affect the optimal use of any input in any season of the planning horizon, for any $\mathrm{UP}_{\mathrm{I}, \mathrm{Z}}$. The slightly larger seedbank due to the seed externality does have modest effects on millet production in Mourdiah, leading to modest losses in net revenues. In Sirakorola, the seed externality has no effect on millet production. ${ }^{59}$

The financial and nutritional returns to optimal production in the presence of the seed externality are presented in Tables A6.10 through A6.15 of the Appendix. As the effects of the seed externality increase with increases in the budget, production with a very high budget represents the greatest potential cost of the seed externality considered in the model. Figures 6.27 through 6.30 illustrate these costs in financial and nutritional terms.

The costs to the XS UP are negated at this budget level because of the practices employed. The binding labor constraint restricts acreage and forces the UP to apply very high rates of urea; so high that the effect of Striga on yields virtually eliminated. The marginal difference in the size of the seedbank due to the externality translates into no change in millet yield.

\footnotetext{
${ }^{59}$ Millet production in Sirakorola is unaffected because (1) very few Striga seeds are added to the seedbank due to the externality and (2) the yield response of millet to Striga is relatively low.
} 
Figure 6.27: Change in Percent of Energy Needs Met Due to Seed Externality, with Very High Budget

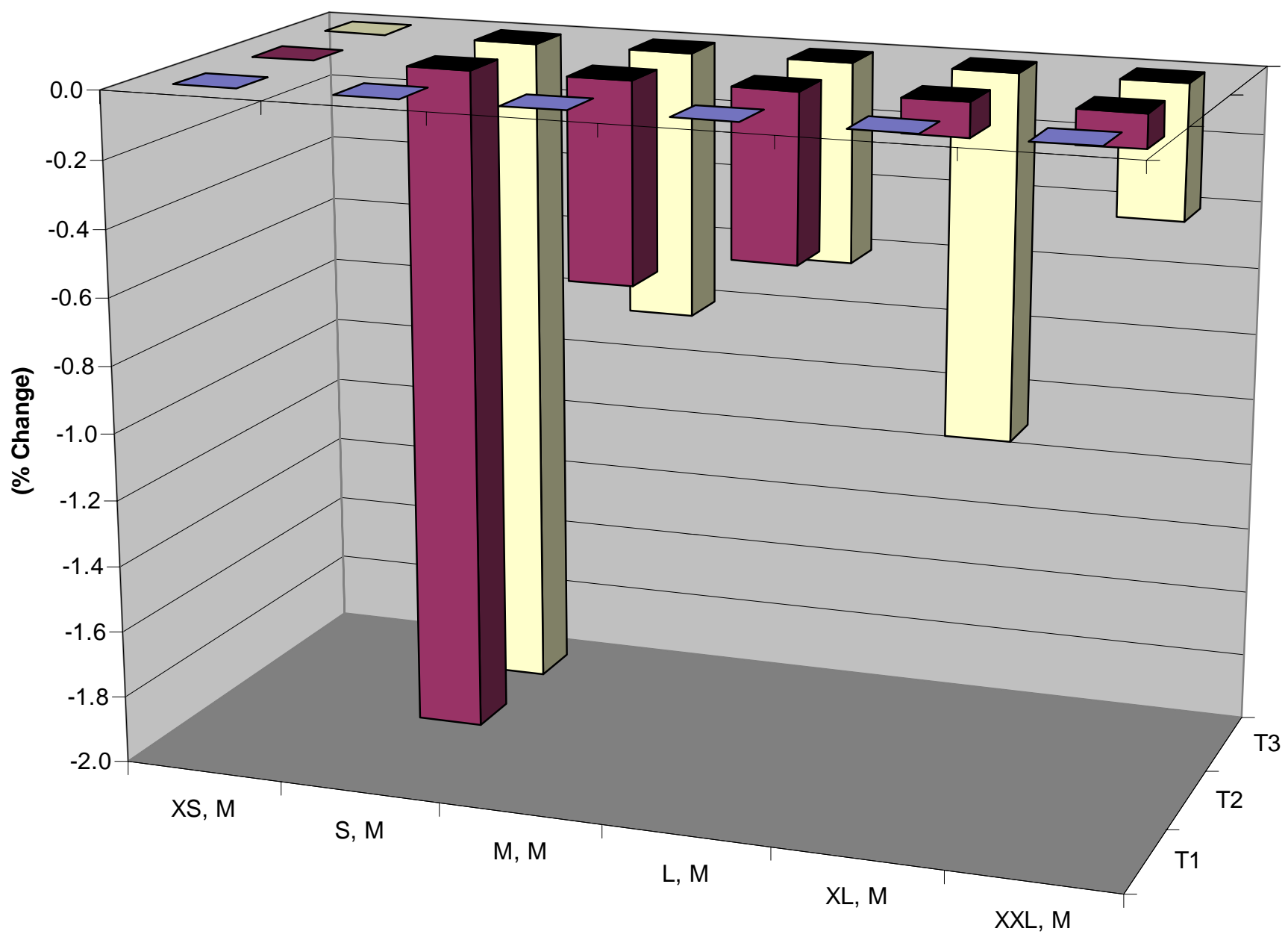


Figure 6.28: Change in Percent Protein Needs Met Due to Seed Externality, with Very High Budget

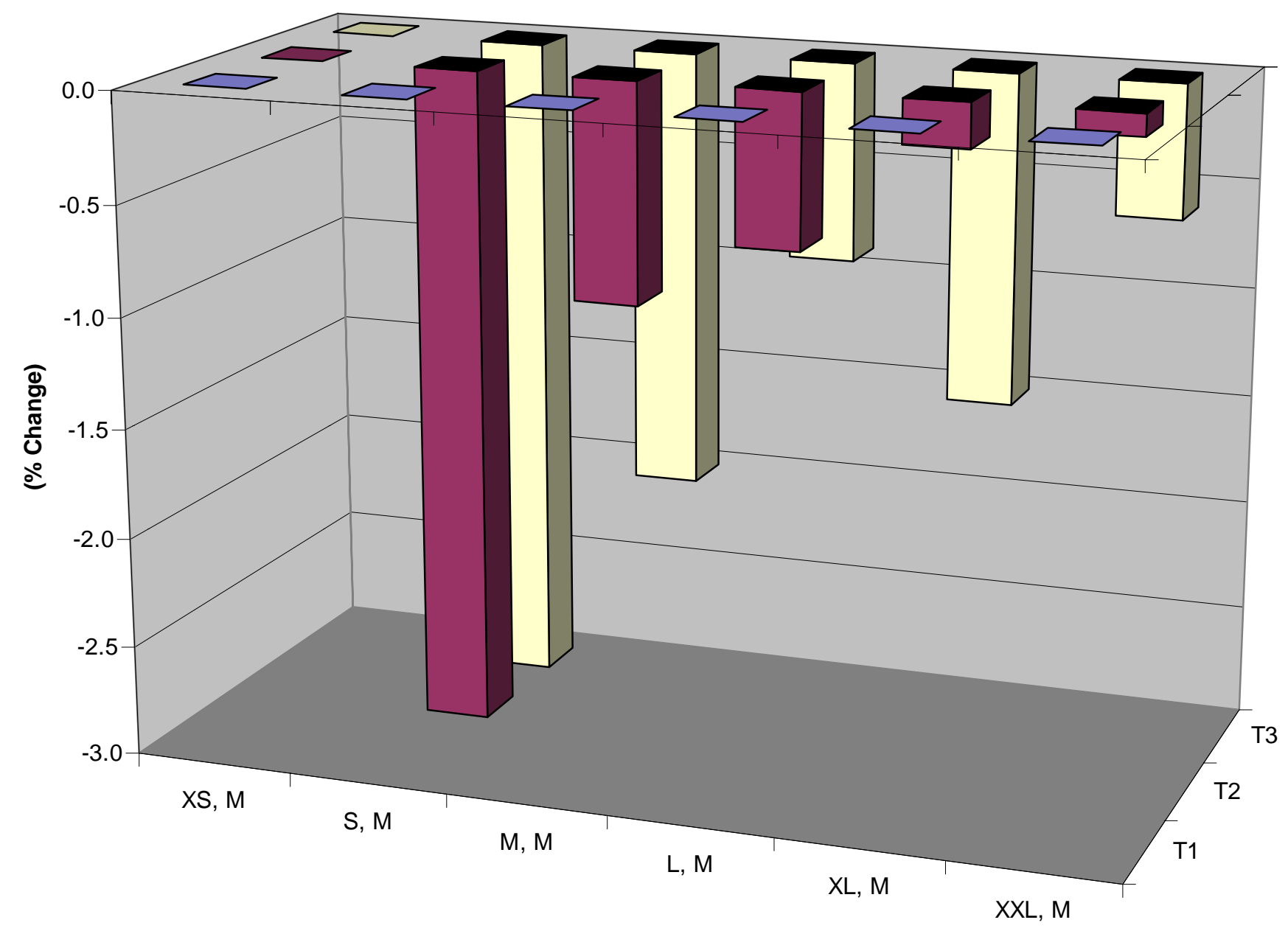


Figure 6.25: Change in Percentage of Iron Needs Met Due to Seed Externality, with Very Low Budget

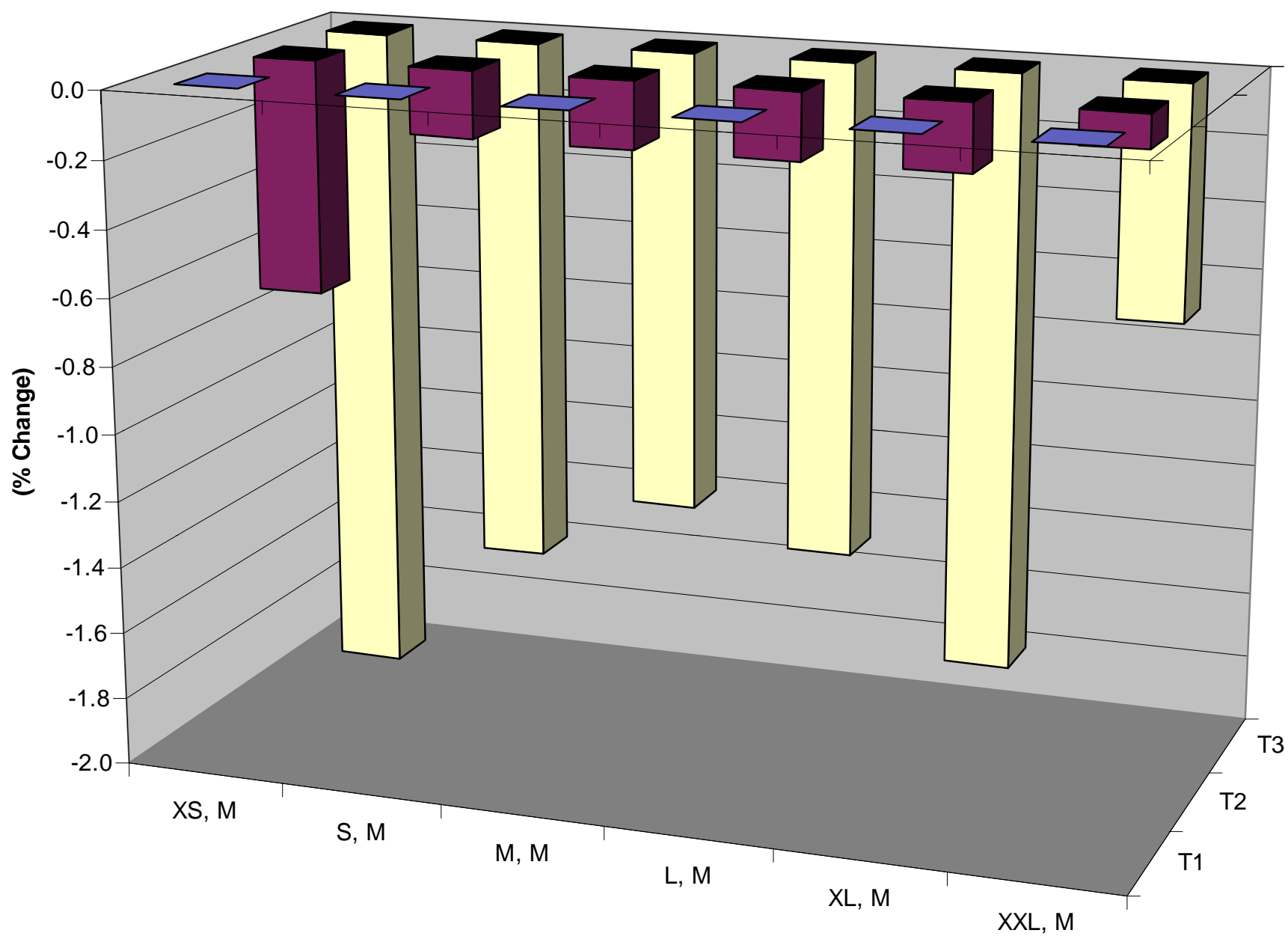


Figure 6.30: Change in Net Revenue Due to Seed Externality, with Very High Budget

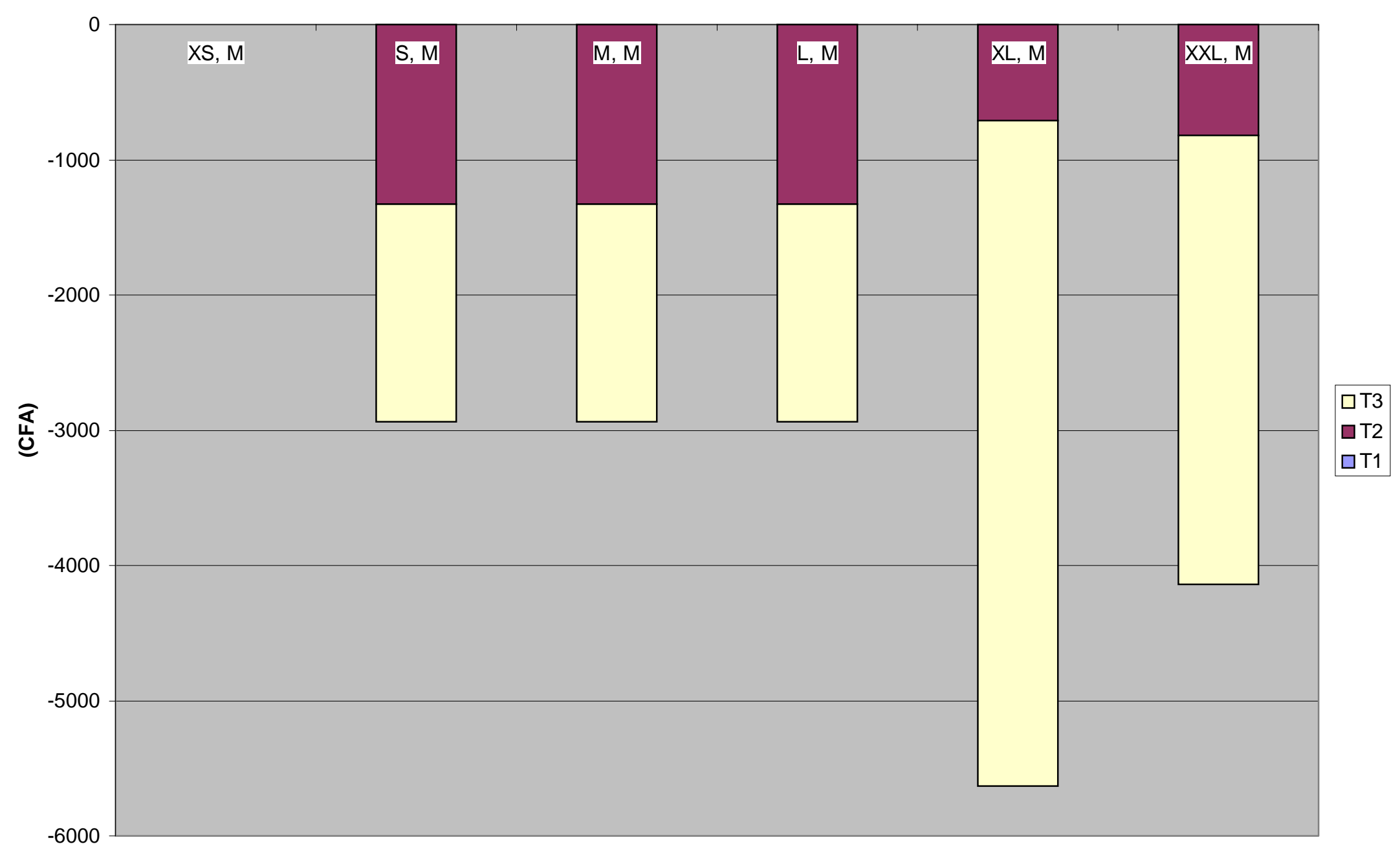


The costs of the seed externality for the XL and XXL UP's is identical to those realized with a very low budget because these UP's employ the same production practices at both budget levels. The costs for the UP's that adopt the high-density, urea-based set of practices are higher than they are with a very low budget, but still modest - no UP loses more than 4 percent of their requirements of any nutrient, nor more than 6,000 CFA over the length of the planning horizon.

\section{Section 6.7 Concluding Remarks on the Results}

The model of cereal production in communal fields in Mourdiah and Sirakorola was run under five production scenarios, at five budget levels. With respect to the game theoretic states discussed in Chapter 3, the results indicate that producers in Mourdiah are in State

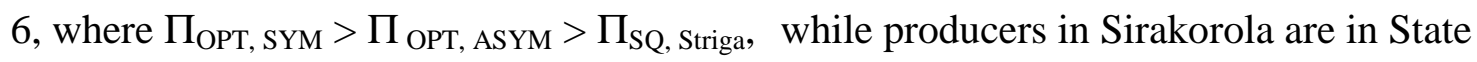

4, where $\Pi_{\mathrm{OPT}, \mathrm{SYM}}=\Pi_{\mathrm{OPT}, \mathrm{ASYM}}>\Pi_{\mathrm{SQ} \text {, Striga. }}$. In both of these states it is information, not the seed externality, that serves as the barrier to adoption of the optimal set of practices identified by the model. There is, however, evidence that the model results must be treated with caution.

The results of Scenario I, status quo production with an average Striga infestation, serve as the baseline against which results from the other scenarios are compared. Tables 6.2 and 6.3 show the model estimates millet yields to be dependent on, and decreasing in the size of the Striga seedbank, as one would expect. The per hectare yield predicted by the model is, however, extremely low - from 113 to $70 \mathrm{~kg} / \mathrm{ha}$ depending on the seedbank level and zone.

The IPM-CRSP conducted millet field trials in Mourdiah in which the experimental control was "peasant farming practices." The control of the trials recorded millet yields between 900 and $1100 \mathrm{~kg} / \mathrm{ha}$. The disparity between the model estimates and the recorded yields from the field trials may be due to a number of factors. First, the "peasant farming practices" of the field trials may not be the same as the model's status quo practices - millet density may have been greater or less than $1 \mathrm{hill} \mathrm{m}^{-2}$, or nitrogen 
may have been added. ${ }^{60}$ Second, the average Striga seedbank used in the first season of the model may be greater than the seedbank of the trial plots. Third, the millet production functions used in the model may over-estimate the response of millet yield to Striga infestation levels. Fourth, rainfall in the trial season may have been substantially greater than average, so the model's production function is inappropriate for that season. Fifth, some combination of these factors may have led to the yield disparity; or the millet production functions used in the model may not be accurate under any circumstances.

The fourth factor does not appear to be the cause of the yield disparity - rainfall during the trial season (1995) was not substantially greater than average. ${ }^{61}$ Information is not presently available to investigate the relevance of the first factor. The level of the initial seedbank may not be ruled out as a contributing factor, although it is certainly not the sole source of the disparity between observed millet yields and those predicted by the model - the model predicts yields of less than $400 \mathrm{~kg} / \mathrm{ha}$ for status quo production even in the absence of Striga (Scenario II). The low predicted yields in Scenario II also indicate that an over-estimation of the yield response to Striga cannot exclusively account for the disparity.

Data constraints dictated the specification of the millet production functions. In Chapter 4, it is acknowledged that the functions used in the model are less than ideal, and the very low baseline results illustrate that point. Nonetheless, the yields generated in Scenario IV using the high-density urea-based set of practices are within the range of yields observed in the nitrogen treatments of the Mourdiah field trials - 2000 to $2200 \mathrm{~kg} / \mathrm{ha}$ in Scenario IV compared to 1300 to $2700 \mathrm{~kg} / \mathrm{ha}$ in the field trials. In and of themselves, the results of Scenario IV do not validate the model; nor do they further discredit it. Scenario IV reinforces the point that the model results must be interpreted with care, but also suggests they should not be entirely disregarded.

\footnotetext{
${ }^{60}$ Documentation describing exactly what constituted "peasant farming practices" for the field experiments has yet to be found

${ }^{61}$ I need to confirm the rainfall estimates I found on the Internet.
} 
The estimates of the financial and nutritional benefits of Striga eradication and control are all influenced by the baseline results of Scenario I. These estimates, therefore, should not be the basis of policy decisions. The value of the results is in the identification of the "optimal set of practices." Given the uncertainty regarding the source of the low yield estimates in Scenario I, the optimal set of practices may not, in reality, be optimal. The objective of this study was not, however, to identify a set of practices to take directly to the farmer. Rather, the objective was to use the model as an ex ante tool for guiding the design of Striga field trials. That being said, the model's recommendations with respect to Striga-control treatments for field trials are discussed in Chapter 7. 


\section{Chapter 7: Conclusions}

\section{Section 7.1: Introduction}

The overriding objective of this study has been to develop a dynamic programming model capable of conducting ex ante evaluations of multiple-season Striga control measures, and to apply the model to Mali's Mourdiah and Sirakorola zones.

Development and application of the model required an extensive literature review of the relationship between Striga control practices, Striga population dynamics, and millet yields. This information was synthesized into a new biological model of Striga population dynamics. The Striga population model was coupled to an economic model of communal cereal production in Mourdiah and Sirakorola, and run under five production scenarios and five budget levels. The strengths and weaknesses of the biological and economic components of the model, and the implications of the results for future research are discussed below.

\section{Section 7.2 The Economic Component}

The economic component models the response of crop yields to Striga infestation levels, the price parameters faced by production units in Mali's Mourdiah and Sirakorola zones, and constraints to communal production. The design and specification of the economic component led to: (1) a new technique for estimating the lower bound of a subsistence farmer's planning horizon; (2) the identification and specification of relevant production constraints and prices; and (3) a description of the demographic composition of production units, as well as land use and distribution within a UP.

Data considerations dictated the specification of the millet production functions used in the model. Without sufficient data to estimate a new millet production function, the model was forced to employ a function that is an amalgamation of previously estimated models. The functions used were based on estimated models of millet production in Mourdiah and Niger, in an effort to ensure they were as accurate as possible under the 
circumstances. Despite those efforts, the results of Chapter 6 indicate that the production functions used did not generate realistic yields in the absence of nitrogen. At high nitrogen application rates, however, the model's predicted yields were consistent with yields observed in the field.

\section{Section 7.3 The Biological Component}

While the economic component is the weakest link in the model, the biological component is certainly the strongest. A new model of Striga population dynamics has been designed and specified to the production environment of Mali's Mourdiah and Sirakorola zones. Previous models focused on the effect of a single Striga control practice - plant density in the Kunisch model, and a bio-control agent in the SH\&W model. The M-S biological model accounts for the effects of four control practices: nitrogen fertilizers, crop density, crop associations, and hand-pulling.

In contrast to its predecessors, within the probability of stimulation parameter, the M-S biological model makes an important new distinction, parsing the parameter into the stimulatory activity of the root exudate and the probability a seed is exposed to a stimulant. The effect of nitrogen on the stimulatory activity of the root exudate was also estimated and incorporated into the model.

The M-S biological model estimated the effect of nitrogen on the probability of emergence, leading to a richer description of how Striga emergence is affected by control practices. Estimating the effect of nitrogen on the probability of emergence also captures some of the observed effects of the relationship between nitrogen and both rates of germination and attachment - relationships for which there are insufficient data to estimate.

Hand-pulling Striga and crop density are the two control practices that are available to all farmers. The M-S biological model estimates the number of emerged Striga that can be pulled in a person-day, and incorporates hand-pulling into the probability of 
reproduction. The timing of weeding is also considered by accounting for both early- and late-blooming plants.

The number of seeds that carry over into the next season, is another distinction between the M-S biological model and its predecessors. The Kunisch and SH\&W models both consider seeds exposed to a stimulant that did not germinate to be rendered non-viable. The M-S biological model allows seeds that did not germinate to carry over into the next season, albeit after being subjected to the probability of survival between seasons.

The other distinguishing feature of the M-S biological model is the seed externality. By modeling the migration of seeds, the M-S biological model is able to examine the Striga population dynamics of a field within a multi-field environment. The isolated field of the Kunisch and SH\&W models may also be specified in the M-S biological model by adjusting the seed migration parameter. As such, a layer of complexity has been added while retaining the ability to model simpler scenarios.

With the Kunisch and SH\&W models as its foundation, the M-S biological model has advanced the modeling of Striga population dynamics. Additional data has been brought to bear on the estimation of certain parameters, subtleties in the mechanics of seed stimulation, germination, and viability have been incorporated, parameter responses to a multitude of control practices have been specified, and seed migration has been included in the model. These features have led to a more general and flexible model that better reflects the production environment of farmers cultivating Striga-infested fields.

\section{Section 7.4 Implications for Future Research}

Applying the model to Mourdiah and Sirakorola, and running it under the different production scenarios and budget levels has led to estimates of the value of Striga eradication, the benefits of adopting the optimal set of practices, identification of information as the barrier to adoption of the optimal set of practices, and the value of overcoming the seed externality. Comparing the model's baseline estimates of millet yield with observed values, however, indicates that, at the very least, the baseline is 
skewed downward. While the yield predictions of the model when it is able to apply nitrogen at high levels (greater than $260 \mathrm{~kg}$ urea/ha) are within the range of observed yields for Mourdiah, this does not negate the low baseline predictions. As a result, the estimates of the benefits of Striga eradication and adoption of the optimal set of practices should not be used for policy decisions. The model's performance has, however, illustrated the lack of information regarding the yield response of millet to Striga and efforts to control the weed.

The model results indicate that, with a migration rate of $1 \%$, including the seed externality has a very marginal effect on the value of production. Even with the uncertainty regarding the millet production functions, this result should be considered carefully. The size of the seed externality is driven by the model of Striga population dynamics, not the millet production functions. And, unlike the millet production functions, the M-S biological model appears to be sound. Accepting the changes in the seedbank predicted by the M-S biological model, one can hypothesize that the externality is likely to have a marginal effect on the value of production regardless of the millet production functions. ${ }^{62}$ This hypothesis could be tested in the field.

At low budget levels, the model chose millet in a pure stand to be planted at a hill density of $0.5 \mathrm{~m}^{-2}$ in Mourdiah, and $3.5 \mathrm{~m}^{-2}$ in Sirakorola. Urea is added to the optimal set of practices at high budget levels, although the exact application rate depends on the size of the seedbank and the zone. Hand-pulling with the UP's own labor is recommended for both zones, irrespective of the budget level. Table 7.1 describes a field trial consisting of six treatments and a control. The model suggests the following testable hypotheses associated with the trial. Using the treatment numbers as indices, inequalities $7.1 \mathrm{M}$ and 7.1S represent the relative size of the millet yield for each treatment in Mourdiah and Sirakorola, respectively.

\footnotetext{
${ }^{62}$ The yield predictions of the model appear to be too low. This may be due to over-estimation of the effect of Striga on millet yield (or other factors), but is unlikely due to an under-estimation of the deleterious effect of Striga. Therefore, if the number of seeds exchanged due to the seed externality is unchanged and the effect of a Striga seed on yield is diminished within a more accurate production function, the effect of the seed externality will be lower.
} 


$$
\begin{aligned}
& \mathrm{Y}_{1}<\mathrm{Y}_{5}=\mathrm{Y}_{6}<\mathrm{Y}_{2}=\mathrm{Y}_{3}<\mathrm{Y}_{4}<\mathrm{Y}_{7} \\
& \mathrm{Y}_{1}<\mathrm{Y}_{2}=\mathrm{Y}_{3}<\mathrm{Y}_{5}=\mathrm{Y}_{6}<\mathrm{Y}_{4}<\mathrm{Y}_{7} \\
& \text { where } \mathrm{Y}_{\mathrm{i}}=\mathrm{kg} \text { millet/ha in treatment i }
\end{aligned}
$$

If the trial were to be replicated with the same treatment in the same plot over consecutive seasons, the model suggests several more testable hypotheses. In each successive season, the seedbank in the treatment plots without weeding should be greater than in the season before. Therefore, millet yields should decline in each successive season. This hypothesis is represented by inequality 7.2.

$$
\mathrm{Y}_{\mathrm{i}, \mathrm{t}}>\mathrm{Y}_{\mathrm{i}, \mathrm{t}+1} \text { for } \mathrm{i} \in\{1,2,5\} \text {, and } \forall \mathrm{t}
$$

If all flowering Striga are pulled, the weeding treatments should prevent the introduction of new seed into the plot. As a result, the seedbank in these plots should decline in each successive season. Inequality 7.3 represents the hypotheses associated with a declining seedbank due to weeding. 
Table 7.1: Treatments for Striga Field Trials Suggested by the Model

\begin{tabular}{|c|c|c|c|c|}
\hline$\#$ & Treatment & $\begin{array}{c}\text { Millet Density } \\
\left(\text { hills } / \mathrm{m}^{2}\right)\end{array}$ & Urea (kg/ha) & Weeding \\
\hline 1 & Control & 1 & 0 & None \\
\hline 2 & Low Density & 0.5 & 0 & None \\
\hline 3 & Low Density + Weeding & 0.5 & 0 & All Flowering Striga \\
\hline 4 & Low Density + Urea + & 0.5 & 350 & All Flowering Striga \\
\hline 5 & Weeding & 3.5 & 0 & None \\
\hline 6 & High Density & 3.5 & 0 & All Flowering Striga \\
\hline 7 & High Density + Weeding & 3.5 & 350 & All Flowering Striga \\
\hline
\end{tabular}




$$
\mathrm{Y}_{\mathrm{i}, \mathrm{t}}<\mathrm{Y}_{\mathrm{i}, \mathrm{t}+1} \text { for } \mathrm{i} \in\{3,4,6,7\} \text {, and } \forall \mathrm{t}
$$

Evidence supporting the hypotheses of inequalities 7.2 and 7.3 would help to validate the mechanics of the model. More importantly, conducting this trial would provide some of the data necessary to estimate a millet production function that accounts for both Striga damage and yield responses to Striga control practices. Quantification of this relationship would not only improve the performance of the dynamic programming model developed for this study, but would also help farmers around the world make better decisions regarding their investments in Striga control measures. 


\section{References}

Adu-Tutu, K. O., and S. H. Drennan, "Effect of Sulfonylurea Herbicides on Striga," in J. K. Ransom, A. D. Worsham, and C. Parker (eds), Proceedings of the $5^{\text {th }}$ International Symposium of Parasitic Weeds, Nairobi: CIMMYT, pp. 361-371, 1991.

Agabawi, K. A. and A. E. Younis, "Effect of Nitrogen Application on Growth and Nitrogen Content of Striga hermonthica, Benth. and Sorghum Vulgare, Lur. Grown for Forage," Plant and Soil, vol. 23, no. 3, pp. 295-304, 1965.

Agbobli, C. A., "Effect of Nitrogen Rates on Striga Asiatica Emergence in Maize Culture in Togo," in J. K. Ransom, A. D. Worsham, and C. Parker (eds), Proceedings of the $5^{\text {th }}$ International Symposium of Parasitic Weeds, Nairobi: CIMMYT, pp. 28-30, 1991.

Alley, Mark, Department of Crop Soil Environmental Sciences, Virginia Polytechnic Institute and State University, Personal Communication, 1998.

Awad, A. E., A. D. Worsham, R. E. Eplee, and R. S. Norris, "Effects of Dicamba, Nitrogen and Presowing Hardening of Host Seed with Phenolic Acids on Witchweed (Striga Asiatica) Control in Grain Sorghum (Sorghum Bicolor)," in J. K. Ransom, A. D. Worsham, and C. Parker (eds), Proceedings of the $5^{\text {th }}$ International Symposium of Parasitic Weeds, Nairobi: CIMMYT, pp. 537-538, 1991.

Ayensu, S., H. Doggett, R. D. Keynes, J. Marton-Lefevre, L. J. Musselman, C. Parker, and A. Pickering, Introduction to Striga Biology and Control, E. S. Ayensu, H. Doggett, R. D. Keynes, J. Marton-Lefevre, L. J. Musselman, C. Parker, and A. Pickering (eds), ICSU Press and International Research Development Center, France, 1984.

Babiker, A. G. T., and A. M. Hamdoun, "Factors Affecting the Activity of GR-7 in Stimulating Striga hermonthica (Del) Benth.," Weed Research, vol. 22, pp. 111-115, 1982.

Babiker, A. G. T., A. M. Mohamed, and C. Parker, "Stimulation of Striga Seed Germination and Haustorium Initiation by Thidiazuron,” in J. K. Ransom, A. D. Worsham, and C. Parker (eds), Proceedings of the $5^{\text {th }}$ International Symposium of Parasitic Weeds, Nairobi: CIMMYT, pp. 537-538, 1991.

Babiker, A. G. T., and F. Reda, "Recent Advances in Striga Research in Sudan and Ethiopia," in J. K. Ransom, A. D. Worsham, and C. Parker (eds), Proceedings of the $5^{\text {th }}$ International Symposium of Parasitic Weeds, Nairobi: CIMMYT, pp. 180-189, 1991.

Bade, J., H. Hengsdijk, G. Kruseman, R. Ruben., nd P. Roebeling, "Farm Household Modeling in a Regional Setting: The Case of Cercle de Koutiala, Mali," DLV Report No. 6, Wageningen, The Netherlands, April 1997. 
Bebawi, F. F., "Cultural Practices in Witchweed Management," Chapter 11 in Parasitic Weeds in Agriculture, Volume I: Striga, L. J. Musselman (ed.), CRC Press, Boca Raton, FL, 1987.

Bebawi, F. F., R. E. Eplee, C. E. Harris, and R. S. Norris, "Longevity of witchweed (Striga asiatica) Seed," Weed Science, Vol. 32, pp. 494-497, 1984.

Bebawi, F. F., and A. F. Farah, "Effects of Nitrophoska and Atrazine on Relations between Sorghum Bicolor and Striga hermonthica," Experimental Agriculture, vol. 17, pp. 425-430, 1981.

Bebawi, F. F., S. A. Khalid and L. J. Musselman, "Effects of Urea Nitrogen on Stimulant Activity of Sorghum and Germination Capacity of Striga," in J. K. Ransom, A. D. Worsham, and C. Parker (eds), Proceedings of the $5^{\text {th }}$ International Symposium of Parasitic Weeds, Nairobi: CIMMYT, pp. 458-461, 1991.

Bengaly, M.P., T. Defoer, S. K. Debrah, and D. Dembele, "Quelles Perspectives pour la Lutte Chimique Contre le Striga dans la Conditions Paysans du Mali-Sud," in Proceedings of the $4^{\text {th }}$ General Workshop of Pan-African Striga Control Network (PASCON), Bamako, Mali, pp. 1-6, 1996.

Berner, D. K., K. F. Cardwell, B. O. Faturoti, F. O. Ikie, and O. A. Williams, "Relative Roles of Wind, Crop Seeds, and Cattle in Dispersal of Striga spp.," Plant Disease, Vol. 78, No. 4, pp. 402-406, 1994.

Boukar, I., D. E. Hess, and W. A. Payne, "Dynamics of Moisture, Nitrogen, and Striga Infestation on Pearl Millet Transpiration and Growth," Agronomy Journal, vol. 88, pp. 545-549, 1996.

Caldwell, John, Personal Communication, Department of Horticulture, Virginia Polytechnic Institute and State University, 1996.

Carson, A. G., "Development and Testing of a Control Package for Striga hermonthica on Small-Scale Holdings in the Gambia," Tropical Pest Management, vol. 34, no. 1, pp. 97-101, 1988.

Carson, A. G., and E. M. Kunjo, "Control of Striga in the Gambia,", ," in J. K. Ransom, A. D. Worsham, and C. Parker (eds), Proceedings of the $5^{\text {th }}$ International Symposium of Parasitic Weeds, Nairobi: CIMMYT, pp. 486-493, 1991.

Cechin, I., and M. C. Press, "Nitrogen Relations of the Sorghum-Striga hermonthica Host-Parasite Association: Germination, Attachment, and Early Growth," New Phytopathologist, vol. 124, pp. 681-687, 1993. 
Chancellor, R. J., C. Parker, and T. Teferedegn, "Stimulation of Dormant Weed Seed Germination by 2-chloroethyl-phosphonic Acid," Pesticide Science, vol. 2, pp. 35-37, 1971.

Cousens, R., "An Empirical Model Relating Crop Yield to Weed and Crop Density and a Statistical Comparison with Other Models," Journal of Agricultural Science, Cambridge, Vol. 105, pp. 513-521, 1985.

Davis, Douglas D. and Charles A. Holt, Experimental Economics, Princeton University Press, Princeton, NJ, 1993.

Dembele, B., A. Diarra, J. Caldwell, and B Gebrekidan, "Integrated Striga Management on Sorghum, Millet, and Cowpea in Mali," Paper presented at the IPM-CRSP Symposium, Guatemala, May 16-21, 1997.

Doggett, H., "Striga - It's Biology and Control: An Overview," in Striga Biology and Control, E. S. Ayensu, H. Doggett, R. D. Keynes, J. Marton-Lefevre, L. J. Musselman, C. Parker, and A. Pickering (eds), ICSU Press and International Research Development Center, France, 1984.

Egbers, W. S., A. H. Pieterse, and J. A. C. Verkleij, "Germination of Freshly Harvested Seed of Striga hermonthica After Storage Under Various Temperature and Relative Humidity Conditions," in J. K. Ransom, A. D. Worsham, and C. Parker (eds), Proceedings of the $5^{\text {th }}$ International Symposium of Parasitic Weeds, Nairobi: CIMMYT, pp. 407-414, 1991.

Egley, G. H., and J. E. Dale, "Ethylene, 2-chloroethylphosphonic acid, and Witchweed Germination," Weed Science, vol. 18, pp. 586-589, 1970.

Eplee, R. E., "Chemical Control of Striga," in Striga Biology and Control, E. S. Ayensu, H. Doggett, R. D. Keynes, J. Marton-Lefevre, L. J. Musselman, C. Parker, and A. Pickering (eds), ICSU Press and International Research Development Center, France, 1984.

Eplee, R. E., "The Effect of Animal Digestive Tract on Witchweed Seed Viability," 1966 Annual Report - Witchweed Lab, USDA, ARS, Plant Pest Control Division, Whiteville, NC, Unpublished data, 1966.

Eplee, R. E., "Ethylene: A Witchweed Seed Germination Stimulant," Weed Science, vol. 23, no. 5, pp. 433-436, 1975.

Eplee, R. E., R. C. Horne, and H. Williams, "Wild Bird Feces Analysis for Witchweed Seed," 1973 Annual Report - Witchweed Lab, USDA, APHIS, PPQ, Methods Division Lab, Whiteville, NC, Unpublished data, 1973. 
Eplee, R.E., and R. S. Norris, "Chemical Control of Striga," Chapter 12 in Parasitic Weeds in Agriculture, Volume I: Striga, L. J. Musselman (ed.), CRC Press, Boca Raton, FL, 1987a.

Eplee, R.E., and R. S. Norris, "Control of Striga asiatica (L.) Kuntze with Systemic Herbicides," in H. C. Weber and W. Forstreuter (eds), Proceedings of the $4^{\text {th }}$ International Symposium on Parasitic Flowering Plants, Marburg, F. R. G., pp. 183-186, 1987b.

Gworgwor, N. A., and H. C. Weber, "Effect of N-Application on Sorghum Growth, Striga Infestation and the Osmotic Pressure of the Parasite in Relation to the Host," Journal of Plant Physiology, vol. 139, pp. 194-198, 1991 a.

Gworgwor, N. A., and H. C. Weber, "Effect of Nitrogen Fertilization and Resistant Varieties on Striga hermonthica Infestation in Sorghum," in J. K. Ransom, A. D. Worsham, and C. Parker (eds), Proceedings of the $5^{\text {th }}$ International Symposium of Parasitic Weeds, Nairobi: CIMMYT, pp. 96-103, 1991b.

Hess, D. E., and G. Ejeta, "Effect of Cultural Treatments on Infestation of Striga hermonthica (Del.) Benth. (Scrophulariaceae) on Sorghum in Niger," in H. C. Weber and W. Forstreuter (eds), Proceedings of the $4^{\text {th }}$ International Symposium on Parasitic Flowering Plants, Marburg, F. R. G., pp. 367-375, 1987.

Hughes, D. W., D. Mansius, W. R. Butcher, and J. Day, "Use, Construction, and Documentation of the Whole-Farm Planning Model for West Africa (WFPMWA)," A. E. 90-6, Department of Agricultural Economics, Washington State University, Pullman, WA, October, 1990.

Ibrahim, N. E., A. G. T. Babiker, W. G. H. Edwards, and C. Parker, "Activity of extracts from Euphorbia Species on the Germination of Striga Species," Weed Research, vol. 25, pp. 135-140, 1985.

Kabambe, V. H., "The Development of Cultural Methods for Control of Striga in Maize in Malawi," in J. K. Ransom, A. D. Worsham, and C. Parker (eds), Proceedings of the $5^{\text {th }}$ International Symposium of Parasitic Weeds, Nairobi: CIMMYT, pp. 46-50, 1991.

Kasasian, L., and C. Parker, "The Effect of Numerous Herbicides on the Germination of Orobanche aegyptiaca and Striga hermontheca," PANS, vol. 17, pp. 471-481, 1971.

Konate, A., "Striga in Mali," in Proceedings of the FAO/OAU All-African Government Consultation on Striga Control, Maroua, Cameroon, Oct. 1988.

Kremer, A. R., and C. Lock, "Where Food is Capital: Labour Allocation in Cereals Production, N. W. Mali,” Agricutlural Systems, Vol. 41, pp. 197-213, 1993. 
Kroschel, J., "Der Einflu $\beta$ von Stickstoff auf phanerograme Wurzelparasiten und ihre Wirtspflanzen unter besonderer Berücksichtigung von Striga hermonthica (Del.) Benth. (Scrophulariaceae)," PLITS 7 (3), 1989.

Kunisch, M., K.-H. Linke, O. Richter, and W. Koch, "Inclusion of Conceptual Modeling in Studies on the Population Dynamics of the Genus Striga," Angew. Botanik, Vol. 65, pp. 45-57, 1991.

Kust, C. A., "Dormancy and Viability of Witchweed Seeds as Affected by Temperature and Relative Humidity during Storage," Weed Science, Vol. 11, pp. 247-250, 1963.

Lagoke, S. T. O., V. Parkinson, and R. M. Aguinbiade, "Parasitic Weeds and Control Methods in Africa," in Combating Striga in Africa, Proceedings, International Workshop organized by IITA, ICRISAT and IDRC, 22-24 August 1988, published by IITA, Ibadan, Nigeria, S. K. Kim (ed.), 1991.

Langston, M. A., and T. J. English, "Vegetative Control of Witchweed and Herbicide Evaluation of Techniques," Chapter 13 in Witchweed Research and Control in the United States, P. F. Sand, R. E. Eplee, and R. G. Westbrooks (eds), Weeds Science Society of America, Champaign, IL, 1990.

Last, F. T., "Effect of Cultural Treatments on the Incidence of Striga hermonthica (Del.) Benth. and Yields of Sorghum in the Sudan: Field Experiments 1957/8," Annals of Applied Biology, vol. 48, no. 2, pp. 207-229, 1960.

Liang, E., "Striga hermonthica: It's Adaptations and Distributions in Ghana," in Striga, Biology and Control, Ayensu et al, (eds.), pp.63-69, ICSU Press, 1984.

Mangnus, E. M., and B. Zwanenburg, "Tentative Molecular Mechanisms for Germination Stimulation of Striga and Orobanche Seeds by Strigol and its Synthetic Analogues," Journal of Agricultural and Food Chemistry, vol. 40, pp. 1066-1070, 1992.

Mboob, S. S., “A Regional Programme for Striga Control in West and Central Africa,” in Proceedings of the FAO/OAU All-African Government Consultation on Striga Control, Maroua, Cameroon, Oct. 1988.

Mengel, D. B., and S. A. Barber, "Development and Distribution of the Corn Root System under Field Conditions,” Agronomy Journal, Vol. 66, pp. 341-344, 1974.

Mussa, H., Weitere Untersuchungen zum Eisatz der Solarisation im Pflanzenschutz unter besonderer Berücksichtigung von Striga und Orobanche, Diploma Thesis, University of Hohenheim (unpubl.), 1987.

Myers, R. J. K., “The Root System of a Grain Sorghum Crop," Field Crops Research, Vol. 3, 1980. 
Ogborn, J. E. A, "Striga Control Under Peasant Farming Conditions," Chapter 10 in Parasitic Weeds in Agriculture, Volume I: Striga, L. J. Musselman (ed.), CRC Press, Boca Raton, FL, 1987.

Parker, C. and C. R. Riches, Parasitic Weeds of the World, CAB International, Wallingford Oxon, UK, 1993.

Patterson, D. T., "Effects of Environment on Growth and Reproduction of Witchweed and the Ecological Range of Witchweed," in Withcweed Research and Control in the United States, P. F. Sand, R. E. Eplee, and R. G. Westbrooks (eds), Weed Science Society of America, Champaign, pp. 68-80, 1990.

Pearce, David W. and R. Kerry Turner, Economics of Natural Resources and the Environment, The Johns Hopkins University Press, Baltimore, MD, 1990.

Pesch, C. and A. H. Pieterse, "Inhibition of Germination of Striga by Means of Urea," Experimentia, vol. 38, pp. 559-560, 1982.

Press, M. C., and J. D. Graves, "Carbon Relations of Angiosperm Parasites and their Hosts," in Progress in Orobanche Research, Proceedings, International Workshop on Orobanche Research, Obermarchtal, Germany, 1989, K. Wegmann and L. J. Musselman (eds), Eberhard-Karls-Universität, Tübingen, pp. 55-65, 1991.

Raju, P. S., M. A. Osman, P. Soman, and J. M. Peacock, "Effects of N, P, and K on Striga asiatica (L.) Kuntze Seed Germination and Infestation of Sorghum," Weed Research, vol. 30, pp. 139-144, 1990.

Ramaiah, K. V., "Breeding Cereal Grains for Resistance to Witchweed," Chapter 15 in Parasitic Weeds in Agriculture, Volume I: Striga, L. J. Musselman (ed.), CRC Press, Boca Raton, FL, 1987.

Reid, D. C., and C. Parker, "Germination Requirements of Striga Spp.," in L. J. Musselman, A. D. Worsham, and R. E. Eplee (eds), Proceedings of the Second International Symposium on Parasitic Weeds, North Carolina State University, Raleigh, NC, pp. 202-210, 1979.

Salle, G., B. Dembele, A. Raynal-Roques, M. F. Hallais, and C. Tuquet, "Biological Aspects of Striga Species, Pest of Food Crops", in H. C. Weber and W. Forstreuter (eds), Proceedings of the $4^{\text {th }}$ International Symposium on Parasitic Flowering Plants, Marburg, F. R. G., pp. 719-731, 1987.

Sand, P. F., and J. D. Manley, "The Witchweed Eradication Program Survey, Regulatory and Control," Chapter 17 in Witchweed Research and Control in the United States, P. F. Sand, R. E. Eplee, and R. G. Westbrooks (eds), Weeds Science Society of America, Champaign, IL, 1990. 
Saunders, A. R., "Studies in Phanerogamic Parasitism, with Particular Reference to Striga lutea Lour.," South Africa Department of Agriculture, Science Bulletin 128, 1933.

Setty, T. K. Prabhakara, and M. M. Hosmani, "Studies on Control of Striga in Sorghum through Herbicides," in H. C. Weber and W. Forstreuter (eds), Proceedings of the $4^{\text {th }}$ International Symposium on Parasitic Flowering Plants, Marburg, F. R. G., pp. 833-839, 1987.

Singh, L., R. Ndikawa, and M. R. Rao, "Integrated Approach to Striga Management on Sorghum in North Cameroon," in J. K. Ransom, A. D. Worsham, and C. Parker (eds), Proceedings of the $5^{\text {th }}$ International Symposium of Parasitic Weeds, Nairobi: CIMMYT, pp. 223-231, 1991.

Smith, M. C., J. Holt, and M. Webb, "Population Model of the Parasitic Weed Striga hermonthica (Scrophulariaceae) to Investigate the Potential of Smicronyx umbrinus (Coleoptera: Curculionidae) for Biological Control in Mali," Crop Protection, Vol. 12, No. 6, pp.470-476, 1993.

Smith, M. C., and M. Webb, "Estimation of the Seedbank of Striga spp.

(Scrophulariaceae) in Malian Fields and the Implications for a Model of Biocontrol of Striga hermonthica," Weed Research, Vol. 36, pp. 85-92, 1996.

Vail, S. L., R. E. Eplee, and R. S. Norris, "Synthesis and Testing of Strigol and Strigol Analogues," Chapter 6 in Witchweed Research and Control in the United States, P. F. Sand, R. E. Eplee, and R. G. Westbrooks (eds), Weeds Science Society of America, Champaign, IL, 1990.

Vallance, K. B., "Studies on the Germination of the Seeds of Striga hermonthica. I. The Influence of Moisture-Treatment, Stimulant-Dilution, and Afterripening on Germination," Annals of Botany, vol. 14, pp. 347-363, 1950.

Webb, M., and M. C. Smith, "Biology of Striga hermonthica (Scrophulariaceae) in Sahelian Mali: Effects on Pearl Millet Yield and Prospects of Control," Weed Research, Vol. 36, pp. 203-211, 1996.

Wylde, A., "Qualitative and Quantitative Studies on the Effect of Striga hermonthica upon the Quality and Quantity of Grain Yield from Millet (Pennisetum typhoides), in Progress in Orobanche Research, Proceedings, International Workshop on Orobanche Research, Obermarchtal, Germany, 1989, K. Wegmann and L. J. Musselman (eds), Eberhard-Karls-Universität, Tübingen, pp. 322-328, 1991.

World Bank, The, World Development Report 1994: Infrastructure for Development, published by Oxford University Press, Inc., New York, 1994.

Yeboah, Anthony K., and Richard L. Guthrie, Farming Systems Research and Extension in Mali - 1986-1994, L'Institute d'Economie Rurale, Bamako, Mali, 1995. 
Yaduraju, N. T., and M. M. Hosmani, "Striga asiatica Control in Sorghum," PANS, vol. 25, no. 2, pp. 163-167, 1979. 
APPENDIX 
Table A4.1: Results of Statistical Test of Equal Distribution of Individual Land Between Men and Women

\begin{tabular}{|c|}
\hline $\mathrm{H}_{0}$ : Area of Men's Individual Land - Area of Women's Individual Land $=0$ \\
\hline $\mathrm{N}=28$ \\
Sample Mean $=0.396$ \\
Sample St. Dev. $=2.482$ \\
T-Stat $=0.845$ \\
\hline Result: Fail to Reject $\mathrm{H}_{0}$ \\
\hline
\end{tabular}


Table A4.2: Daily Nutritional Requirements by Age and Gender ${ }^{63}$

\begin{tabular}{|c|c|c|c|c|c|c|c|c|}
\hline & \multicolumn{8}{|c|}{ Age (years) / Gender } \\
\hline & $0-2$ & $3-6$ & $\begin{array}{r}\text { Male } \\
7-14 \\
\end{array}$ & $\begin{array}{c}\text { Female } \\
7-14 \\
\end{array}$ & $\begin{array}{l}\text { Male } \\
14-60 \\
\end{array}$ & $\begin{array}{c}\text { Female } \\
14-60 \\
\end{array}$ & $\begin{array}{l}\text { Male } \\
>60 \\
\end{array}$ & $\begin{array}{c}\text { Female } \\
>60 \\
\end{array}$ \\
\hline Energy (kcal) & 1250 & 1710 & 2360 & 2040 & 2944 & 2640 & 2060 & 1830 \\
\hline $\operatorname{Protein}^{64}(\mathrm{~g})$ & 23 & 30 & 64 & 62 & 57 & 68 & 57 & 48 \\
\hline Fat $(\mathrm{g})$ & 35 & 48 & 66 & 57 & 83 & 73 & 56 & 51 \\
\hline $\operatorname{Iron}^{65}(\mathrm{mg})$ & 21 & 19 & 36 & 40 & 36 & $76^{66}$ & 23 & 19 \\
\hline Iodine $(\mu \mathrm{g})$ & 70 & 90 & 150 & 150 & 150 & 200 & 150 & 150 \\
\hline Vitamin A (RE) & 400 & 400 & 600 & 600 & 600 & 850 & 600 & 500 \\
\hline Thiamine (mg) & 0.5 & 0.8 & 1.2 & 1.0 & 1.2 & 1.1 & 1.2 & 0.9 \\
\hline $\begin{array}{l}\text { Riboflavin } \\
\text { (mg) }\end{array}$ & 0.8 & 1.1 & 1.7 & 1.5 & 1.8 & 1.7 & 1.8 & 1.3 \\
\hline Niacin (mg) & 9.0 & 12.1 & 19.1 & 16.4 & 19.8 & 18.2 & 19.8 & 14.5 \\
\hline Folate $(\mu \mathrm{g})$ & 40 & 65 & 140 & 150 & 200 & 400 & 200 & 170 \\
\hline Vitamin C (mg) & 20 & 20 & 30 & 30 & 30 & 50 & 30 & 30 \\
\hline
\end{tabular}

\footnotetext{
${ }^{63}$ The age ranges in Savage, King, and Burgess are not identical to those used in the IPMCRSP/Mali Baseline Survey. As a result, requirements reported in this table are based on the highest need for the age/gender category. For example, the requirements for the age range 7-14 are based on the requirements for the 12-14 age range reported in Savage, King, and Burgess. ${ }^{64}$ The Protein requirement represents diet B in Savage, King, and Burgess - "a diet containing a lot of cereals, starchy roots, and pulses... and little complete (animal) protein" (p. 427).

${ }^{65}$ The iron requirement is based on a low iron availability diet.

${ }^{66}$ This number is for pregnant women. Says will likely need supplements to attain this level of iron intake.
} 
Table A4.3: Daily Nutrient Requirements of $\mathrm{UP}_{\mathrm{I}, \mathrm{Z}}$

\begin{tabular}{|l|c|c|c|c|c|c|c|c|c|c|c|}
\hline \multicolumn{1}{|c|}{ UP } & $\begin{array}{c}\text { Energy } \\
(\mathrm{kcal})\end{array}$ & $\begin{array}{c}\text { Protein } \\
(\mathrm{g})\end{array}$ & Fat $(\mathrm{g})$ & $\begin{array}{c}\text { Iron } \\
(\mathrm{mg})\end{array}$ & $\begin{array}{c}\text { Iodine } \\
(\mathrm{mg})\end{array}$ & $\begin{array}{c}\text { Vitamin A } \\
(\mathrm{RE})\end{array}$ & $\begin{array}{c}\text { Thiamine } \\
(\mathrm{mg})\end{array}$ & $\begin{array}{c}\text { Riboflavin } \\
(\mathrm{mg})\end{array}$ & $\begin{array}{c}\text { Niacin } \\
(\mathrm{mg})\end{array}$ & $\begin{array}{c}\text { Folate } \\
(\mathrm{\mu g})\end{array}$ & $\begin{array}{c}\text { Vitamin C } \\
(\mathrm{mg})\end{array}$ \\
\hline Sirakorola, XS & 10,568 & 244 & 296 & 162 & 650 & 2,650 & 4.5 & 6.8 & 74 & 950 & 140 \\
\hline Mourdiah, XS & 10,358 & 230 & 290 & 167 & 650 & 2,550 & 4.4 & 6.6 & 72 & 970 & 140 \\
\hline Sirakorola, S & 17,978 & 432 & 503 & 285 & 1,190 & 4,650 & 8.1 & 12 & 132 & 1,505 & 250 \\
\hline Mourdiah, S & 18,528 & 429 & 518 & 340 & 1,160 & 4,900 & 8.1 & 12.1 & 133 & 1,595 & 260 \\
\hline Sirakorola, M & 37,956 & 868 & 1,062 & 642 & 2,360 & 9,850 & 16.8 & 24.9 & 274 & 3,025 & 520 \\
\hline Mourdiah, M & 44,930 & 1,038 & 1,256 & 809 & 2,840 & 11,750 & 19.7 & 29.3 & 321 & 3,985 & 630 \\
\hline Sirakorola, L & 69,996 & 1,612 & 1,958 & 1,151 & 4,350 & 17,850 & 31.1 & 46.2 & 507 & 5,700 & 940 \\
\hline Mourdiah, L & 63,334 & 1,481 & 1,770 & 1,147 & 4,020 & 16,650 & 28.1 & 41.6 & 456 & 5,545 & 890 \\
\hline Sirakorola, XL & NA & & & & & & & & & \\
\hline Mourdiah, XL & 116,246 & 2,691 & 3,252 & 2,051 & 7,240 & 30,050 & 51.1 & 76 & 833 & 9,835 \\
\hline Sirakorola, XXL & $\mathrm{NA}$ & & & & & & & & & \\
\hline Mourdiah, XXL & 201,512 & 4,772 & 5,627 & 3,675 & 12,920 & 53,150 & 89.1 & 133.1 & 1,458 & 18,520 \\
\hline
\end{tabular}


Table A4.4: Nutritional Content of Crops (100g edible) Grown on Communal Plots in Sirakorola and Mourdiah

\begin{tabular}{|c|c|c|c|c|c|c|c|c|c|c|}
\hline Crop & $\begin{array}{c}\text { Energy } \\
(\text { Kcal })\end{array}$ & $\begin{array}{c}\text { Protein } \\
(\mathrm{g})\end{array}$ & Fat (g) & $\begin{array}{c}\text { Iron } \\
(\mathrm{mg})\end{array}$ & $\begin{array}{c}\text { Vitamin A } \\
(\mathrm{RE})\end{array}$ & $\begin{array}{c}\text { Vitamin C } \\
(\mathrm{mg})\end{array}$ & $\begin{array}{c}\text { Niacin } \\
(\mathrm{mg})\end{array}$ & $\begin{array}{c}\text { Folate }(\mu \mathrm{gg}) \\
\begin{array}{c}\text { Thiamin } \\
(\mathrm{mg})\end{array}\end{array} \begin{array}{c}\text { Riboflavin } \\
(\mathrm{mg})\end{array}$ \\
\hline Pearl Millet $^{\mathrm{a}}$ & 363 & 11.8 & 4.8 & 11 & $4^{\mathrm{b}}$ & $0^{\mathrm{b}}$ & 2.8 & NA & 0.38 & 0.21 \\
\hline Sorghum $^{\mathrm{a}}$ & 329 & 10.4 & 3.1 & 5.4 & $3^{\mathrm{b}}$ & $0^{\mathrm{b}}$ & 4.3 & NA & 0.38 & 0.15 \\
\hline Cowpea $^{\mathrm{b}}$ & 320 & 23 & 1.4 & 5 & 3 & 0 & $\mathrm{NA}$ & 439 & NA & NA \\
\hline Groundnut $^{\mathrm{b}}$ & 570 & 25 & 45 & 3.8 & 3 & 0 & $\mathrm{NA}$ & 110 & NA & NA \\
\hline
\end{tabular}

a: Food and Agriculture Organization of the United Nations, Sorghum and Millet in Human Nutrition, FAO Food Nutrition Series, No. 27, FAO, Rome, Italy, 1995.

b: King, Felicity Savage, and Ann Burgess, Nutrition for Developing Countries, Second Edition, Oxford University Press, 1993. 
Table A5.1: Data Used to Estimate Equation 5.1

\begin{tabular}{|c|c|}
\hline Urea (kg/ha) & Proportion of Seeds Stimulated \\
\hline 0 & 0.753 \\
\hline 0 & 1 \\
\hline 150 & 0.607 \\
\hline 155 & 0.667 \\
\hline 300 & 0.213 \\
\hline 310 & 0.35 \\
\hline 600 & 0.16 \\
\hline 620 & 0.283 \\
\hline 1,200 & 0.087 \\
\hline 1,240 & 0.077 \\
\hline 2,400 & 0.027 \\
\hline 2,480 & 0.033 \\
\hline 4,800 & 0 \\
\hline 4,960 & 0 \\
\hline 9,600 & 0 \\
\hline 9,920 & 0 \\
\hline 19,200 & 0 \\
\hline 19,840 & 0 \\
\hline 30,000 & 0 \\
\hline 31,000 & 0 \\
\hline
\end{tabular}


Table A5.2 Estimation of Equation (5.1), Proportion of Germinated Striga versus Kg. Urea/Ha

\begin{tabular}{|c|c|c|c|}
\hline Descriptive Statistics: & $\mathrm{R}^{2}=.9207$ & \multicolumn{2}{|c|}{ Adjusted $\mathrm{R}^{2}=.9128$} \\
\hline Independent Variable & Estimate & $\begin{array}{c}\text { Approximate }^{67} \\
\text { Std. Err. }\end{array}$ & $\begin{array}{c}\text { Approximate } \\
\text { P-value }\end{array}$ \\
\hline$\beta_{0}$ & 0.878 & 0.063 & 0.0001 \\
\hline$\beta_{1}$ & -0.003 & 0.0004 & 0.0001 \\
\hline
\end{tabular}

\footnotetext{
${ }^{67}$ Because the model is nonlinear, standard errors of the estimates, T-ratios, and p-values are only approximate (SAS Institute, Inc., 1993).
} 
Table A5.3: Data Used to Estimate Equation 5.7

\begin{tabular}{|c|c|}
\hline Nitrogen $(\mathrm{kg} / \mathrm{ha})$ & Proportion of Seeds Stimulated \\
\hline 0 & 1 \\
\hline 0 & 1 \\
\hline 0 & 1 \\
\hline 0 & 1 \\
\hline 0 & 1 \\
\hline 0 & 1 \\
\hline 0 & 1 \\
\hline 0 & 1 \\
\hline 26.4 & 1 \\
\hline 51.7 & 1.778 \\
\hline 60 & 8.677 \\
\hline 60 & 10.923 \\
\hline 90 & 0.700 \\
\hline 90 & 0.702 \\
\hline 103.3 & 1 \\
\hline 1,121 & 0.181 \\
\hline 1,121 & 0.191 \\
\hline 1,121 & 0.382 \\
\hline 2,243 & 0.052 \\
\hline 2,243 & 0.087 \\
\hline 2,243 & 0.182 \\
\hline 3,364 & 0.242 \\
\hline 3,364 & 0.249 \\
\hline 3,364 & 0.352 \\
\hline 4,486 & 0.104 \\
\hline 4,486 & 0.046 \\
\hline 4,486 & 0.030 \\
\hline
\end{tabular}


Table A5.4 Estimation of Equation (5.7), Proportion of Emerged Striga without Nitrogen versus $\mathrm{Kg}$. N/Ha

\begin{tabular}{|cccc|}
\hline $\begin{array}{l}\text { Descriptive } \\
\text { Statistics: }\end{array}$ & $\mathrm{R}^{2}=.5941$ & & Adjusted $\mathrm{R}^{2}=.5784$ \\
\hline \hline $\begin{array}{l}\text { Independent } \\
\text { Variable }\end{array}$ & Estimate & $\begin{array}{c}\text { Approximate } \\
\text { Std. Err. }\end{array}$ & $\begin{array}{c}\text { Approximate } \\
\text { P-value }\end{array}$ \\
\hline$\beta_{1}$ & 0.07111 & 0.00951 & 0.0001 \\
$\beta_{2}$ & -0.00068 & 0.00014 & 0.0001 \\
\hline
\end{tabular}


Table A6.1: Estimates of Nutritional and Financial Gains from Striga Eradication Under Status Quo Millet Production in Mourdiah

\begin{tabular}{|c|c|c|c|c|c|c|}
\hline \multirow{2}{*}{ UP Size } & \multirow{2}{*}{ Year } & \multirow{2}{*}{$\begin{array}{c}\text { Change in } \\
\text { Millet Yield } \\
(\mathrm{kg})\end{array}$} & \multicolumn{3}{|c|}{$\begin{array}{c}\text { Change in \% UP Nutrient } \\
\text { Requirement }\end{array}$} & \multirow[t]{2}{*}{$\begin{array}{c}\text { Change in Present Value } \\
\text { of Net Revenue (CFA) }\end{array}$} \\
\hline & & & Energy & Protein & Iron & \\
\hline \multirow[t]{3}{*}{ Extra Small } & 1 & 361 & 34.7 & 50.7 & 65.2 & 18,050 \\
\hline & 2 & 388 & 37.3 & 54.5 & 70 & 17,465 \\
\hline & 3 & 402 & 38.6 & 56.5 & 72.6 & 16,285 \\
\hline \multirow[t]{3}{*}{ Small } & 1 & 591 & 31.7 & 44.5 & 52.4 & 29,550 \\
\hline & 2 & 631 & 33.9 & 47.5 & 56 & 28,395 \\
\hline & 3 & 656 & 35.2 & 49.4 & 58.2 & 26,565 \\
\hline \multirow[t]{3}{*}{ Medium } & 1 & 1261 & 27.9 & 39.3 & 47 & 63,045 \\
\hline & 2 & 1351 & 29.9 & 42.1 & 50.4 & 60,795 \\
\hline & 3 & 1401 & 31 & 43.7 & 52.2 & 56740 \\
\hline \multirow[t]{3}{*}{ Large } & 1 & 1693 & 26.5 & 36.9 & 44.5 & 84,645 \\
\hline & 2 & 1818 & 28.5 & 39.7 & 47.8 & 81,810 \\
\hline & 3 & 1878 & 29.4 & 41 & 49.4 & 76,055 \\
\hline \multirow[t]{3}{*}{ Extra Large } & 1 & 3763 & 32.2 & 45.2 & 55.3 & 188,145 \\
\hline & 2 & 4038 & 34.5 & 48.5 & 59.3 & 181,705 \\
\hline & 3 & 4178 & 35.7 & 50.2 & 61.4 & 169,205 \\
\hline \multirow{3}{*}{$\begin{array}{l}\text { Extra Extra } \\
\text { Large }\end{array}$} & 1 & 3783 & 18.7 & 25.6 & 31.1 & 189,150 \\
\hline & 2 & 4053 & 20 & 27.5 & 33.3 & 182,385 \\
\hline & 3 & 4198 & 20.7 & 28.4 & 34.5 & 170,060 \\
\hline
\end{tabular}


Table A6.2: Estimates of Nutritional and Financial Gains from Striga Eradication Under Status Quo Millet Production in Sirakorola

\begin{tabular}{|c|c|c|c|c|c|c|}
\hline \multirow{2}{*}{ UP Size } & \multirow{2}{*}{ Year } & \multirow{2}{*}{$\begin{array}{l}\text { Change in } \\
\text { Millet Yield } \\
(\mathrm{kg})\end{array}$} & \multicolumn{3}{|c|}{$\begin{array}{c}\text { Change in \% UP Nutrient } \\
\text { Requirement }\end{array}$} & \multirow[t]{2}{*}{$\begin{array}{l}\text { Change in Present Value } \\
\text { of Net Revenue (CFA) }\end{array}$} \\
\hline & & & Energy & Protein & Iron & \\
\hline \multirow[t]{4}{*}{ Extra Small } & 1 & 163 & 15.3 & 21.6 & 30.4 & 8,150 \\
\hline & 2 & 175 & 16.4 & 23.2 & 32.6 & 7,875 \\
\hline & 3 & 182 & 17.1 & 24.2 & 33.9 & 7,370 \\
\hline & 4 & 185 & 17.4 & 24.6 & 34.5 & 6,745 \\
\hline \multirow[t]{4}{*}{ Small } & 1 & 157 & 8.7 & 11.4 & 16.6 & 7,850 \\
\hline & 2 & 169 & 9.3 & 12.6 & 17.8 & 7,605 \\
\hline & 3 & 175 & 9.7 & 13.1 & 18.5 & 7,085 \\
\hline & 4 & 178 & 9.8 & 13.3 & 18.8 & 6,490 \\
\hline \multirow[t]{4}{*}{ Medium } & 1 & 343 & 9 & 12.8 & 16.1 & 17,150 \\
\hline & 2 & 368 & 9.6 & 13.7 & 17.2 & 16,555 \\
\hline & 3 & 381 & 10 & 14.2 & 17.8 & 15,430 \\
\hline & 4 & 388 & 10.1 & 14.4 & 18.2 & 14,135 \\
\hline \multirow[t]{4}{*}{ Large } & 1 & 665 & 9.5 & 13.3 & 17.4 & 33,355 \\
\hline & 2 & 714 & 10.2 & 14.3 & 18.7 & 32,220 \\
\hline & 3 & 739 & 10.5 & 14.8 & 19.3 & 30,010 \\
\hline & 4 & 753 & 10.7 & 15.2 & 19.7 & 27,520 \\
\hline
\end{tabular}


Table A6.3: Optimal Input Levels and Net Returns for $\mathrm{UP}_{\mathrm{XS} \text {, Sirakorola }}$ in the Absence of Striga

\begin{tabular}{|l|c|c|c|c|c|c|}
\hline $\begin{array}{l}\text { CFA } \\
\text { Spent / year }\end{array}$ & Association & $\begin{array}{c}\text { Hectares } \\
\text { Cultivated }\end{array}$ & $\begin{array}{c}\text { Millet } \\
\text { Density/m² }\end{array}$ & $\begin{array}{c}\text { Urea } \\
\text { (kg/ha) }\end{array}$ & $\begin{array}{c}\text { Person- } \\
\text { Days Hired } \\
\text { by Task }\end{array}$ & $\begin{array}{c}\text { Net } \\
\text { Returns } \\
(1,000 \text { CFA })\end{array}$ \\
\hline 1,000 & Pure Millet & 1.6 & 3.2 & 0 & 0 & 79.9 \\
\hline 2,000 & Pure Millet & 1.6 & 3.5 & 3.2 & 0 & 87.6 \\
\hline 10,000 & Pure Millet & 1.6 & 3.5 & 31.7 & 0 & 117.2 \\
\hline 25,000 & Pure Millet & 1.6 & 3.5 & 85.2 & 0 & 172.6 \\
\hline 50,000 & Pure Millet & 1.6 & 3.5 & 174.3 & 0 & 265 \\
\hline 100,000 & Pure Millet & 1.6 & 3.5 & 352.6 & 0 & 449.7 \\
\hline
\end{tabular}

${ }^{68}$ Total net present value over all four years of the planning horizon. 
Table A6.4: Optimal Input Levels and Net Returns for $\mathrm{UP}_{\mathrm{S} \text {, Sirakorola }}$ in the Absence of Striga

\begin{tabular}{|l|c|c|c|c|c|c|}
\hline $\begin{array}{l}\text { CFA } \\
\text { Spent / year }\end{array}$ & Association & $\begin{array}{c}\text { Hectares } \\
\text { Cultivated }\end{array}$ & $\begin{array}{c}\text { Millet } \\
\text { Density/m² }\end{array}$ & $\begin{array}{c}\text { Urea } \\
\text { (kg/ha) }\end{array}$ & $\begin{array}{c}\text { Person- } \\
\text { Days Hired } \\
\text { by Task }\end{array}$ & $\begin{array}{c}\text { Net } \\
\text { Returns } \\
(1,000 \text { CFA })\end{array}$ \\
\hline 1,000 & Pure Millet & 1.5 & 3.3 & 0 & 0 & 78.6 \\
\hline 2,000 & Pure Millet & 1.5 & 3.5 & 3.5 & 0 & 84.7 \\
\hline 10,000 & Pure Millet & 1.5 & 3.5 & 33.1 & 0 & 114.2 \\
\hline 25,000 & Pure Millet & 1.5 & 3.5 & 88.6 & 0 & 169.7 \\
\hline 50,000 & Pure Millet & 1.5 & 3.5 & 181 & 0 & 262 \\
\hline 100,000 & Pure Millet & 1.5 & 3.5 & 366 & 0 & 446.8 \\
\hline
\end{tabular}

${ }^{69}$ Total net present value over all four years of the planning horizon. 
Table A6.5: Optimal Input Levels and Net Returns for $\mathrm{UP}_{\mathrm{M} \text {, Sirakorola }}$ in the Absence of Striga

\begin{tabular}{|l|c|c|c|c|c|c|}
\hline $\begin{array}{l}\text { CFA } \\
\text { Spent / year }\end{array}$ & Association & $\begin{array}{c}\text { Hectares } \\
\text { Cultivated }\end{array}$ & $\begin{array}{c}\text { Millet } \\
\text { Density/m² }\end{array}$ & $\begin{array}{c}\text { Urea } \\
\text { (kg/ha) }\end{array}$ & $\begin{array}{c}\text { Person- } \\
\text { Days Hired } \\
\text { by Task }\end{array}$ & $\begin{array}{c}\text { Net } \\
\text { Returns } \\
(1,000 \text { CFA })\end{array}$ \\
\hline 1,000 & Pure Millet & 3.3 & 1.5 & 0 & 0 & 112 \\
\hline 2,000 & Pure Millet & 3.3 & 3 & 0 & 0 & 152.6 \\
\hline 10,000 & Pure Millet & 3.3 & 3.5 & 13.1 & 0 & 190 \\
\hline 25,000 & Pure Millet & 3.3 & 3.5 & 38.6 & 0 & 238.7 \\
\hline 50,000 & Pure Millet & 3.3 & 3.5 & 81.1 & 0 & 319.8 \\
\hline 100,000 & Pure Millet & 3.3 & 3.5 & 166.1 & 0 & 482.1 \\
\hline
\end{tabular}

${ }^{70}$ Total net present value over all four years of the planning horizon. 
Table A6.6: Optimal Input Levels and Net Returns for $\mathrm{UP}_{\mathrm{L}, \text { Sirakorola }}$ in the Absence of Striga

\begin{tabular}{|l|c|c|c|c|c|c|}
\hline $\begin{array}{l}\text { CFA } \\
\text { Spent / year }\end{array}$ & Association & $\begin{array}{c}\text { Hectares } \\
\text { Cultivated }\end{array}$ & $\begin{array}{c}\text { Millet } \\
\text { Density/m² }\end{array}$ & $\begin{array}{c}\text { Urea } \\
\text { (kg/ha) }\end{array}$ & $\begin{array}{c}\text { Person- } \\
\text { Days Hired } \\
\text { by Task }\end{array}$ & $\begin{array}{c}\text { Net } \\
\text { Returns } \\
(1,000 \text { CFA })\end{array}$ \\
\hline 2,000 & Pure Millet & 6.4 & 1.7 & 0 & 0 & 235.2 \\
\hline 10,000 & Pure Millet & 6.4 & 3.5 & 4.8 & 0 & 364.7 \\
\hline 25,000 & Pure Millet & 6.4 & 3.5 & 18 & 0 & 422.4 \\
\hline 50,000 & Pure Millet & 6.4 & 3.5 & 39.9 & 0 & 518.7 \\
\hline 100,000 & Pure Millet & 6.4 & 3.5 & 83.7 & 0 & 711.3 \\
\hline
\end{tabular}

\footnotetext{
${ }^{71}$ Total net present value over all four years of the planning horizon.
} 
Table A6.7: Optimal Input Levels and Net Returns for $\mathrm{UP}_{\mathrm{XS} \text {, Mourdiah }}$ in the Absence of Striga

\begin{tabular}{|c|c|c|c|c|c|c|}
\hline $\begin{array}{l}\text { CFA } \\
\text { Spent / year }\end{array}$ & Association & $\begin{array}{l}\text { Hectares } \\
\text { Cultivated }\end{array}$ & $\begin{array}{c}\text { Millet } \\
\text { Density/m² }\end{array}$ & $\begin{array}{l}\text { Urea } \\
(\mathrm{kg} / \mathrm{ha})\end{array}$ & $\begin{array}{c}\text { Person-Days } \\
\text { Hired by } \\
\text { Task } \\
\end{array}$ & $\begin{array}{c}\text { Net } \\
\text { Returns }^{72} \\
(1,000 \text { CFA }) \\
\end{array}$ \\
\hline 250 & Pure Millet & 1.3 & 0.9 & 0 & 0 & 67.8 \\
\hline 500 & Pure Millet & 1.3 & 1.9 & 0 & 0 & 72.3 \\
\hline 750 & Pure Millet & 1.3 & 2.8 & 0 & 0 & 76.9 \\
\hline 1,000 & Pure Millet & 1.3 & 3.5 & 0 & Weed $1=0.1$ & 80.3 \\
\hline 2,000 & Pure Millet & 1.4 & 3.5 & 0 & Weed $1=1.0$ & 81.4 \\
\hline 4,000 & Pure Millet & 1.5 & 3.5 & 0 & Weed $1=2.6$ & 83.5 \\
\hline 6,000 & Pure Millet & 1.6 & 3.5 & 0 & Weed $1=3.9$ & 85.6 \\
\hline 8,000 & Pure Millet & 1.8 & 3.5 & 0 & Weed $1=5.1$ & 87.7 \\
\hline 10,000 & Pure Millet & 1.9 & 3.5 & 0 & Weed $1=6.1$ & 89.8 \\
\hline 16,000 & Pure Millet & 2 & 3.5 & 11 & Weed $1=7.1$ & 95.7 \\
\hline 20,000 & Pure Millet & 2 & 3.5 & 22.1 & Weed $1=7.1$ & 99.6 \\
\hline 25,000 & Pure Millet & 2 & 3.5 & 36 & Weed $1=7.1$ & 104.4 \\
\hline 50,000 & Pure Millet & 2 & 3.5 & 105.5 & Weed $1=7.1$ & 128.3 \\
\hline 100,000 & Pure Millet & 2 & 3.5 & 245.6 & Weed $1=7.1$ & 176.1 \\
\hline
\end{tabular}

\footnotetext{
${ }^{72}$ Total net present value over all three years of the planning horizon.
} 
Table A6.8: Optimal Input Levels and Net Returns for $\mathrm{UP}_{\mathrm{S} \text {, Mourdiah }}$ in the Absence of Striga

\begin{tabular}{|c|c|c|c|c|c|c|}
\hline $\begin{array}{l}\text { CFA } \\
\text { Spent / year }\end{array}$ & Association & $\begin{array}{c}\text { Hectares } \\
\text { Cultivated }\end{array}$ & $\begin{array}{c}\text { Millet } \\
\text { Density/m² }\end{array}$ & $\begin{array}{c}\text { Urea } \\
(\mathrm{kg} / \mathrm{ha})\end{array}$ & $\begin{array}{c}\text { Person- } \\
\text { Days Hired } \\
\text { by Task } \\
\end{array}$ & $\begin{array}{c}\text { Net } \\
\text { Returns }^{73} \\
(1,000 \mathrm{CFA})\end{array}$ \\
\hline 250 & Pure Millet & 2.2 & 0.6 & 0 & 0 & 108 \\
\hline 500 & Pure Millet & 2.2 & 1.1 & 0 & 0 & 112.6 \\
\hline 750 & Pure Millet & 2.2 & 1.7 & 0 & 0 & 117.1 \\
\hline 1,000 & Pure Millet & 2.2 & 2.3 & 0 & 0 & 121.7 \\
\hline 2,000 & Pure Millet & 2.2 & 3.5 & 0 & Weed $1=0.3$ & 131.9 \\
\hline 4,000 & Pure Millet & 2.3 & 3.5 & 0 & Weed $1=1.3$ & 134 \\
\hline 6,000 & Pure Millet & 2.4 & 3.5 & 0 & Weed $1=2$ & 136.1 \\
\hline 8,000 & Pure Millet & 2.6 & 3.5 & 0 & Weed $1=3.2$ & 138.2 \\
\hline 10,000 & Pure Millet & 2.7 & 3.5 & 0 & Weed $1=4.0$ & 140.3 \\
\hline 16,000 & Pure Millet & 3.1 & 3.5 & 0 & Weed $1=6.0$ & 146.6 \\
\hline 20,000 & Pure Millet & 3.3 & 3.5 & 0.8 & Weed $1=7$ & 150.8 \\
\hline 25,000 & Pure Millet & 3.3 & 3.5 & 9.3 & Weed $1=7$ & 155.6 \\
\hline 50,000 & Pure Millet & 3.3 & 3.5 & 51.9 & Weed $1=7$ & 179.5 \\
\hline 100,000 & Pure Millet & 3.3 & 3.5 & 137.2 & Weed $1=7$ & 227.3 \\
\hline
\end{tabular}

\footnotetext{
${ }^{73}$ Total net present value over all three years of the planning horizon.
} 
Table A6.9: Optimal Input Levels and Net Returns for $\mathrm{UP}_{\mathrm{M}, \text { Mourdiah }}$ in the Absence of Striga

\begin{tabular}{|c|c|c|c|c|c|c|}
\hline $\begin{array}{l}\text { CFA } \\
\text { Spent / year }\end{array}$ & Association & $\begin{array}{l}\text { Hectares } \\
\text { Cultivated }\end{array}$ & $\begin{array}{c}\text { Millet } \\
\text { Density/m² }\end{array}$ & $\begin{array}{c}\text { Urea } \\
\text { (kg/ha) }\end{array}$ & $\begin{array}{c}\text { Person- } \\
\text { Days Hired } \\
\text { by Task }\end{array}$ & $\begin{array}{c}\text { Net } \\
\text { Returns }^{74} \\
(1,000 \text { CFA })\end{array}$ \\
\hline 1,000 & Pure Millet & 4.7 & 1.1 & 0 & 0 & 238.7 \\
\hline 2,000 & Pure Millet & 4.7 & 2.1 & 0 & 0 & 256.9 \\
\hline 4,000 & Pure Millet & 4.7 & 3.5 & 0 & Weed $1=0.2$ & 280.7 \\
\hline 6,000 & Pure Millet & 4.8 & 3.5 & 0 & Weed $1=0.7$ & 282.8 \\
\hline 8,000 & Pure Millet & 5 & 3.5 & 0 & Weed $1=1.2$ & 284.9 \\
\hline 10,000 & Pure Millet & 5.1 & 3.5 & 0 & Weed $1=1.7$ & 287 \\
\hline 16,000 & Pure Millet & 5.4 & 3.5 & 0 & Weed $1=3.0$ & 293.4 \\
\hline 20,000 & Pure Millet & 5.7 & 3.5 & 0 & Weed $1=3.8$ & 297.6 \\
\hline 25,000 & Pure Millet & 6 & 3.5 & 0 & Weed $1=4.6$ & 302.8 \\
\hline 40,000 & Pure Millet & 6.9 & 3.5 & 0 & Weed $1=6.8$ & 318.6 \\
\hline 50,000 & Pure Millet & 7 & 3.5 & 6.7 & Weed $1=7$ & 328.3 \\
\hline 100,000 & Pure Millet & 7 & 3.5 & 46.7 & Weed $1=7$ & 376.2 \\
\hline
\end{tabular}

\footnotetext{
${ }^{74}$ Total net present value over all three years of the planning horizon.
} 
Table A6.10: Optimal Input Levels and Net Returns for $\mathrm{UP}_{\mathrm{L}, \text { Mourdiah }}$ in the Absence of Striga

\begin{tabular}{|c|c|c|c|c|c|c|}
\hline $\begin{array}{l}\text { CFA } \\
\text { Spent / year }\end{array}$ & Association & $\begin{array}{l}\text { Hectares } \\
\text { Cultivated }\end{array}$ & $\begin{array}{c}\text { Millet } \\
\text { Density/m² }\end{array}$ & $\begin{array}{c}\text { Urea } \\
\text { (kg/ha) }\end{array}$ & $\begin{array}{c}\text { Person- } \\
\text { Days Hired } \\
\text { by Task }\end{array}$ & $\begin{array}{c}\text { Net } \\
\text { Returns }^{75} \\
(1,000 \text { CFA })\end{array}$ \\
\hline 2,000 & Pure Millet & 6.3 & 1.6 & 0 & 0 & 332.5 \\
\hline 4,000 & Pure Millet & 6.3 & 3.2 & 0 & 0 & 368.9 \\
\hline 6,000 & Pure Millet & 6.4 & 3.5 & 0 & Weed $1=0.3$ & 377.7 \\
\hline 8,000 & Pure Millet & 6.5 & 3.5 & 0 & Weed $1=0.7$ & 379.8 \\
\hline 10,000 & Pure Millet & 6.6 & 3.5 & 0 & Weed $1=1.1$ & 381.9 \\
\hline 16,000 & Pure Millet & 7 & 3.5 & 0 & Weed $1=2.1$ & 388.2 \\
\hline 20,000 & Pure Millet & 7.2 & 3.5 & 0 & Weed $1=2.8$ & 392.4 \\
\hline 25,000 & Pure Millet & 7.5 & 3.5 & 0 & Weed $1=3.5$ & 397.6 \\
\hline 40,000 & Pure Millet & 8.4 & 3.5 & 0 & Weed $1=5.4$ & 413.4 \\
\hline 50,000 & Pure Millet & 8.8 & 3.5 & 2.5 & Weed $1=6$ & 423.6 \\
\hline 100,000 & Pure Millet & 8.8 & 3.5 & 34.3 & Weed $1=6$ & 471.4 \\
\hline
\end{tabular}

\footnotetext{
${ }^{75}$ Total net present value over all three years of the planning horizon.
} 
Table A6.11: Optimal Input Levels and Net Returns for $\mathrm{UP}_{\mathrm{XL}, \text { Mourdiah }}$ in the Absence of Striga

\begin{tabular}{|l|l|c|c|c|c|c|}
\hline $\begin{array}{l}\text { CFA } \\
\text { Spent / year }\end{array}$ & Association & $\begin{array}{c}\text { Hectares } \\
\text { Cultivated }\end{array}$ & $\begin{array}{c}\text { Millet } \\
\text { Density/m² }\end{array}$ & $\begin{array}{c}\text { Urea } \\
\text { (kg/ha) }\end{array}$ & $\begin{array}{c}\text { Person- } \\
\text { Days Hired } \\
\text { by Task }\end{array}$ & $\begin{array}{c}\text { Net } \\
\text { Returns } \\
(1,000 \text { CFA })\end{array}$ \\
\hline 1,000 & Pure Millet & 10 & 0.5 & 0 & 0 & 490.6 \\
\hline 2,000 & Pure Millet & 13.9 & 0.7 & 0 & 0 & 694.6 \\
\hline 6,000 & Pure Millet & 13.9 & 2.2 & 0 & 0 & 767.5 \\
\hline 10,000 & Pure Millet & 13.9 & 3.5 & 0 & 0 & 836.2 \\
\hline 16,000 & Pure Millet & 14.3 & 3.5 & 0 & Weed1 =0.6 & 842.5 \\
\hline 20,000 & Pure Millet & 14.6 & 3.5 & 0 & Weed1 =0.9 & 846.7 \\
\hline 25,000 & Pure Millet & 14.9 & 3.5 & 0 & Weed1 = 1.3 & 851.9 \\
\hline 50,000 & Pure Millet & 16.4 & 3.5 & 0 & Weed1 $=3.1$ & 878.2 \\
\hline 100,000 & Pure Millet & 19.4 & 3.5 & 0 & Weed1 = 5.9 & 930.9 \\
\hline 125,000 & Pure Millet & 20.3 & 3.5 & 2.9 & Weed1 =6.6 & 956.2 \\
\hline 200,000 & Pure Millet & 20.3 & 3.5 & 23.6 & Weed1 =6.6 & 1027.9 \\
\hline
\end{tabular}

\footnotetext{
${ }^{76}$ Total net present value over all three years of the planning horizon.
} 
Table A6.12: Optimal Input Levels and Net Returns for $\mathrm{UP}_{\mathrm{XXL}}$, Mourdiah in the Absence of Striga

\begin{tabular}{|l|l|c|c|c|c|c|}
\hline $\begin{array}{l}\text { CFA } \\
\text { Spent / year }\end{array}$ & Association & $\begin{array}{c}\text { Hectares } \\
\text { Cultivated }\end{array}$ & $\begin{array}{c}\text { Millet } \\
\text { Density/m² }\end{array}$ & $\begin{array}{c}\text { Urea } \\
(\mathrm{kg} / \mathrm{ha})\end{array}$ & $\begin{array}{c}\text { Person- } \\
\text { Days Hired } \\
\text { by Task }\end{array}$ & $\begin{array}{c}\text { Net } \\
\text { Returns } \\
(1,000 \text { CFA })\end{array}$ \\
\hline 1,000 & Pure Millet & 10 & 0.5 & 0 & 0 & 490.6 \\
\hline 2,000 & Pure Millet & 14 & 0.7 & 0 & 0 & 697.7 \\
\hline 6,000 & Pure Millet & 14 & 2.1 & 0 & 0 & 770.6 \\
\hline 10,000 & Pure Millet & 14 & 3.5 & 0.1 & 0 & 840.1 \\
\hline 20,000 & Pure Millet & 14 & 3.5 & 4.1 & 0 & 849.7 \\
\hline 25,000 & Pure Millet & 14 & 3.5 & 6.1 & 0 & 854.4 \\
\hline 50,000 & Pure Millet & 14 & 3.5 & 16.1 & 0 & 878.3 \\
\hline 100,000 & Pure Millet & 14 & 3.5 & 36.1 & 0 & 926.2 \\
\hline 125,000 & Pure Millet & 14 & 3.5 & 46.1 & 0 & 950.1 \\
\hline 200,00 & Pure Millet & 14 & 3.5 & 76.1 & 0 & 1021.8 \\
\hline
\end{tabular}

\footnotetext{
${ }^{77}$ Total net present value over all three years of the planning horizon.
} 
Table A6.13: Estimated Financial and Nutritional Returns, Millet Yield, Seedbank Growth, and Expenditures in Mourdiah Under Optimal Practices with a Very High Budget, Average Striga Infestation and Seed Externality

\begin{tabular}{|c|c|c|c|c|c|c|c|c|}
\hline \multirow[b]{2}{*}{ UP Size } & \multirow[b]{2}{*}{ Year } & \multirow{2}{*}{$\begin{array}{c}\text { Seedbank } \\
\left(10^{3} \text { seeds } \mathrm{m}^{-2}\right) \\
\end{array}$} & \multirow{2}{*}{$\begin{array}{c}\begin{array}{c}\text { Millet Yield } \\
(\mathrm{kg})\end{array} \\
\end{array}$} & \multicolumn{3}{|c|}{$\%$ Nutrient Requirement } & \multirow{2}{*}{$\begin{array}{c}\text { Expenditures } \\
(\mathrm{CFA})\end{array}$} & \multirow{2}{*}{$\begin{array}{c}\text { Present Value of } \\
\text { Net Returns } \\
\text { (CFA) }\end{array}$} \\
\hline & & & & Energy & Protein & Iron & & \\
\hline \multirow[t]{3}{*}{ Extra Small } & 1 & 40 & 3294 & 316 & 463 & 594 & 100,000 & 64,600 \\
\hline & 2 & 21.4 & 3294 & 316 & 463 & 594 & 100,000 & 58,140 \\
\hline & 3 & 11.7 & 3294 & 316 & 463 & 594 & 100,000 & 52,960 \\
\hline \multirow[t]{3}{*}{ Small } & 1 & 40 & 3368 & 180 & 254 & 299 & 100,000 & 68,415 \\
\hline & 2 & 22.2 & 3383 & 181 & 254 & 299 & 100,000 & 62,255 \\
\hline & 3 & 12.4 & 3400 & 182 & 256 & 301 & 100,000 & 56,715 \\
\hline \multirow[t]{3}{*}{ Medium } & 1 & 40 & 3368 & 74.6 & 104 & 125 & 100,000 & 68,415 \\
\hline & 2 & 22.2 & 3383 & 74.9 & 105 & 126 & 100,000 & 62,255 \\
\hline & 3 & 12.4 & 3400 & 75.3 & 105 & 126 & 100,000 & 56,715 \\
\hline \multirow[t]{3}{*}{ Large } & 1 & 40 & 3368 & 52.9 & 73.5 & 88.5 & 100,000 & 68,415 \\
\hline & 2 & 22.2 & 3383 & 53.1 & 73.8 & 88.9 & 100,000 & 62,255 \\
\hline & 3 & 12.4 & 3400 & 53.4 & 74.2 & 89.3 & 100,000 & 56,715 \\
\hline \multirow[t]{3}{*}{ Extra Large } & 1 & & & & & & & \\
\hline & 2 & Same & As & Low & And & Very & Low & \\
\hline & 3 & & & & & & & \\
\hline \multirow{3}{*}{$\begin{array}{l}\text { Extra Extra } \\
\text { Large }\end{array}$} & 1 & & & & & & & \\
\hline & 2 & Same & As & Low & And & Very & Low & \\
\hline & 3 & & & & & & & \\
\hline
\end{tabular}


Table A6.14: Estimated Financial and Nutritional Returns, Millet Yield, Seedbank Growth, and Expenditures in Sirakorola Under Optimal Practices with a Very High Budget and Average Striga Infestation

\begin{tabular}{|c|c|c|c|c|c|c|c|c|}
\hline \multirow[b]{2}{*}{ UP Size } & \multirow[b]{2}{*}{ Year } & \multirow{2}{*}{$\begin{array}{c}\text { Seedbank } \\
\left(10^{3} \text { seeds } \mathrm{m}^{-2}\right) \\
\end{array}$} & \multirow{2}{*}{$\begin{array}{c}\text { Millet Yield } \\
(\mathrm{kg})\end{array}$} & \multicolumn{3}{|c|}{$\%$ Nutrient Requirement } & \multirow{2}{*}{$\begin{array}{c}\text { Expenditures } \\
\text { (CFA) }\end{array}$} & \multirow{2}{*}{$\begin{array}{l}\text { Present Value of } \\
\text { Net Returns } \\
\text { (CFA) }\end{array}$} \\
\hline & & & & Energy & Protein & Iron & & \\
\hline \multirow[t]{4}{*}{ Extra Small } & 1 & 40 & 4586 & 432 & 608 & 853 & 100,000 & 129,300 \\
\hline & 2 & 22.2 & 4595 & 432 & 609 & 855 & 100,000 & 116,775 \\
\hline & 3 & 12.4 & 4601 & 433 & 610 & 856 & 100,000 & 105,340 \\
\hline & 4 & 7.3 & 4605 & 433 & 610 & 857 & 100,000 & 94,950 \\
\hline \multirow[t]{4}{*}{ Small } & 1 & 40 & 4584 & 254 & 343 & 485 & 100,000 & 129,200 \\
\hline & 2 & 22.2 & 4589 & 254 & 343 & 485 & 100,000 & 116,505 \\
\hline & 3 & 12.4 & 4590 & 254 & 343 & 485 & 100,000 & 104,895 \\
\hline & 4 & 7.3 & 4592 & 254 & 344 & 486 & 100,000 & 94,480 \\
\hline \multirow[t]{4}{*}{ Medium } & 1 & 40 & 4586 & 120 & 171 & 215 & 100,000 & 129,300 \\
\hline & 2 & 22.2 & 4595 & 120 & 171 & 216 & 100,000 & 116,790 \\
\hline & 3 & 12.4 & 4606 & 121 & 172 & 216 & 100,000 & 105,530 \\
\hline & 4 & 7.3 & 4616 & 121 & 172 & 217 & 100,000 & 95,365 \\
\hline \multirow[t]{4}{*}{ Large } & 1 & 40 & 4586 & 65.2 & 92.0 & 120.1 & 100,000 & 129,300 \\
\hline & 2 & 22.2 & 4595 & 65.3 & 92.2 & 120.3 & 100,000 & 116,790 \\
\hline & 3 & 12.4 & 4606 & 65.4 & 92.4 & 120.6 & 100,000 & 105,530 \\
\hline & 4 & 7.3 & 4616 & 65.6 & 92.6 & 120.9 & 100,000 & 95,365 \\
\hline
\end{tabular}


* This program is for Scenario I, Status Quo Production

* for a M UP in Mourdiah over 3 years,

* with 40,000 starting seedbank, and no externality

* The seedbank is scaled down to 1/1000th its size

* Net Revenues are scaled down by a factor of 10,000

* To begin GAMS program, declare set of crops one can produce

SET

$\mathrm{T}$ set of time periods

$/ \mathrm{T} 1$

$\mathrm{T} 2$

T3/

CROP set of available crops

/MIL Millet

NIEBE Cowpea

ARACHIDE Groundnut/

ASSOC Set of available crop associations

/MILLET Sole Millet harvested on time

COWMIL Millet and Cowpea Association harvested on time

NUTMIL Millet and Groundnut Association harvested on time/

* declare index of inputs one can use

INPUT Set of available inputs

/SOWOWN UP person days used to sow and prepare

SOWPAY person days hired to sow and prepare

WEEDOWN1 UP person days used in first weeding

WEEDOWN2 UP person days used in second weeding

WEEDPAY1 person days hired for first weeding

WEEDPAY2 person days hired for second weeding

HARVOWN UP person days used in harvest

HARVPAY person days hired for harvest

POSTOWN UP person days used for post harvest

POSTPAY person days hired for post harvest

SIOWN UP person days used in pre harvest striga weeding

S1PAY person days hired for pre harvest striga weeding

S2OWN UP person days used in post harvest striga weeding

S2PAY person days hired for post harvest striga weeding

UREA kg urea applied per hectare

DENSITY planting density of crops/

* declare index for distribution of UP gender \& age groups

PEOPLE Set of gender and age groups 
/BABY Infants 0 to 2 years of either gender

CHILD Children 3 to 6 years of either gender

GIRLTEEN Girl 7 to 14 years

BOYTEEN BOY 7 to 14 years

WOMAN Woman 15 to 60 years

MAN Man 15 to 60 years

OLDWOMAN Woman over 60 years

OLDMAN Man over 60 years/;

* declare age and gender distribution of UP

PARAMETER NUMBER (PEOPLE)

/BABY 0

CHILD 1

GIRLTEEN 2

BOYTEEN 0

WOMAN 1

MAN 2

OLDWOMAN 2

OLDMAN $0 /$;

* declare person days per ha required to prepare and sow fields

PARAMETER PDSOW (ASSOC)

/MILLET 10

COWMIL 12.7

NUTMIL $16.5 /$;

* declare person days per hectare required for first weeding

PARAMETER PDWEED1 (ASSOC)

/MILLET 21

COWMIL 24.2

NUTMIL $38.4 /$;

* declare person days per hectare required for second weeding

PARAMETER PDWEED2 (ASSOC)

/MILLET 14

COWMIL 16.2

NUTMIL $25.6 /$;

* declare person days per hectare required to harvest

PARAMETER PDHARV (ASSOC)

/MILLET 4 
COWMIL 9.6

NUTMIL $29.3 /$;

* declare person days per hectare required for post harvest

PARAMETER PDTHRESH (ASSOC)

/MILLET 6

COWMIL 14.5

NUTMIL 44 ;

* declare prices associated with each input

PARAMETER WAGE (INPUT)

/ SOWOWN 0

SOWPAY 500

WEEDOWN1 0

WEEDPAY1 750

WEEDOWN2 0

WEEDPAY2 750

HARVOWN 0

HARVPAY 500

POSTOWN 0

POSTPAY 500

SIOWN 0

SIPAY 750

S2OWN 0

S2PAY 750

UREA 178.5

DENSITY $200 /$;

* declare percent nitrogen of each input

PARAMETER PERCENTN (INPUT)

/ SOWOWN 0

SOWPAY 0

WEEDOWN1 0

WEEDPAY 10

WEEDOWN2 0

WEEDPAY2 0

HARVOWN 0

HARVPAY 0

POSTOWN 0

POSTPAY 0

SIOWN 0

SIPAY 0

S2OWN 0

S2PAY 0

UREA 0.46

DENSITY $0 /$; 


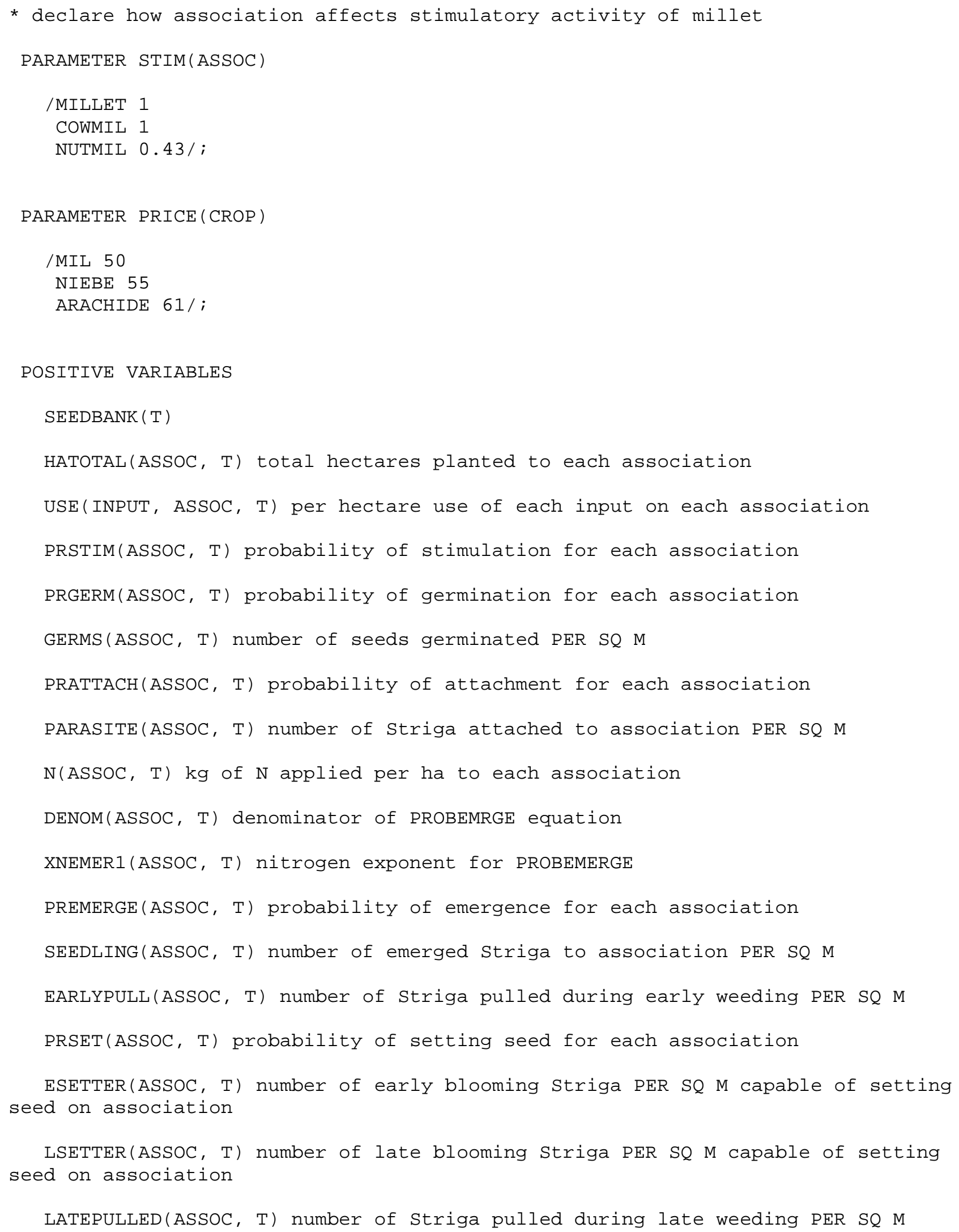




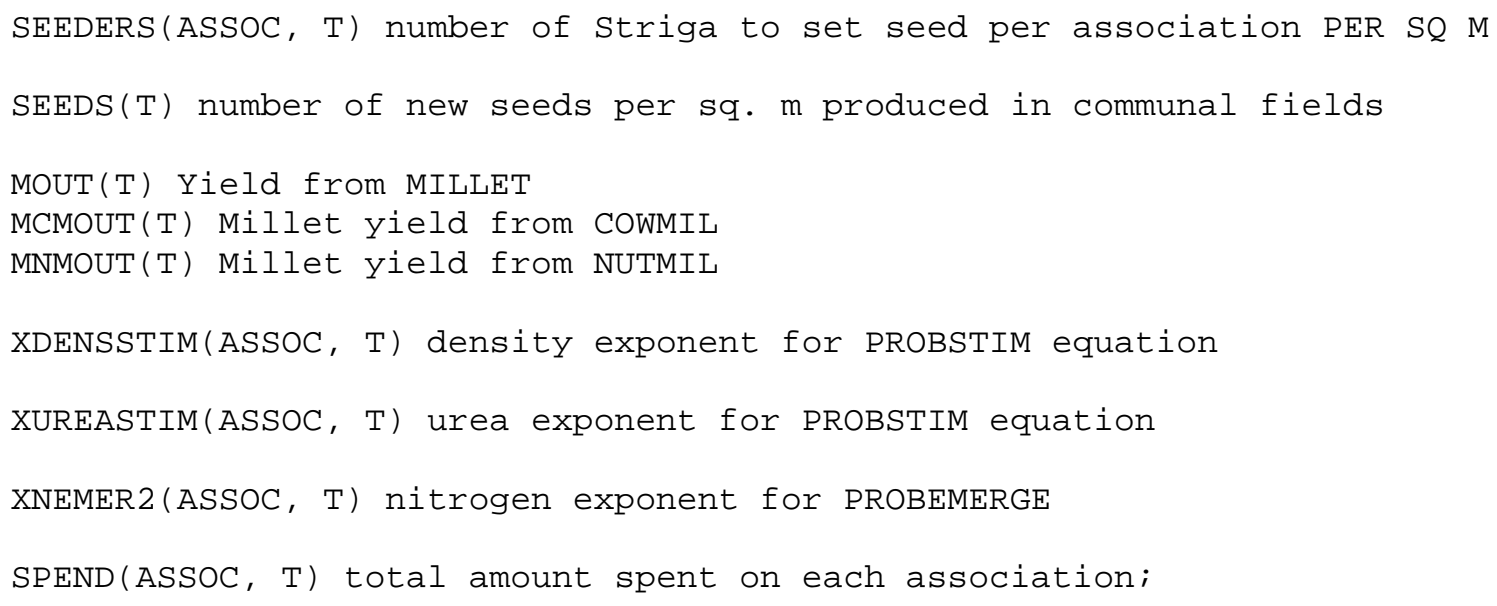




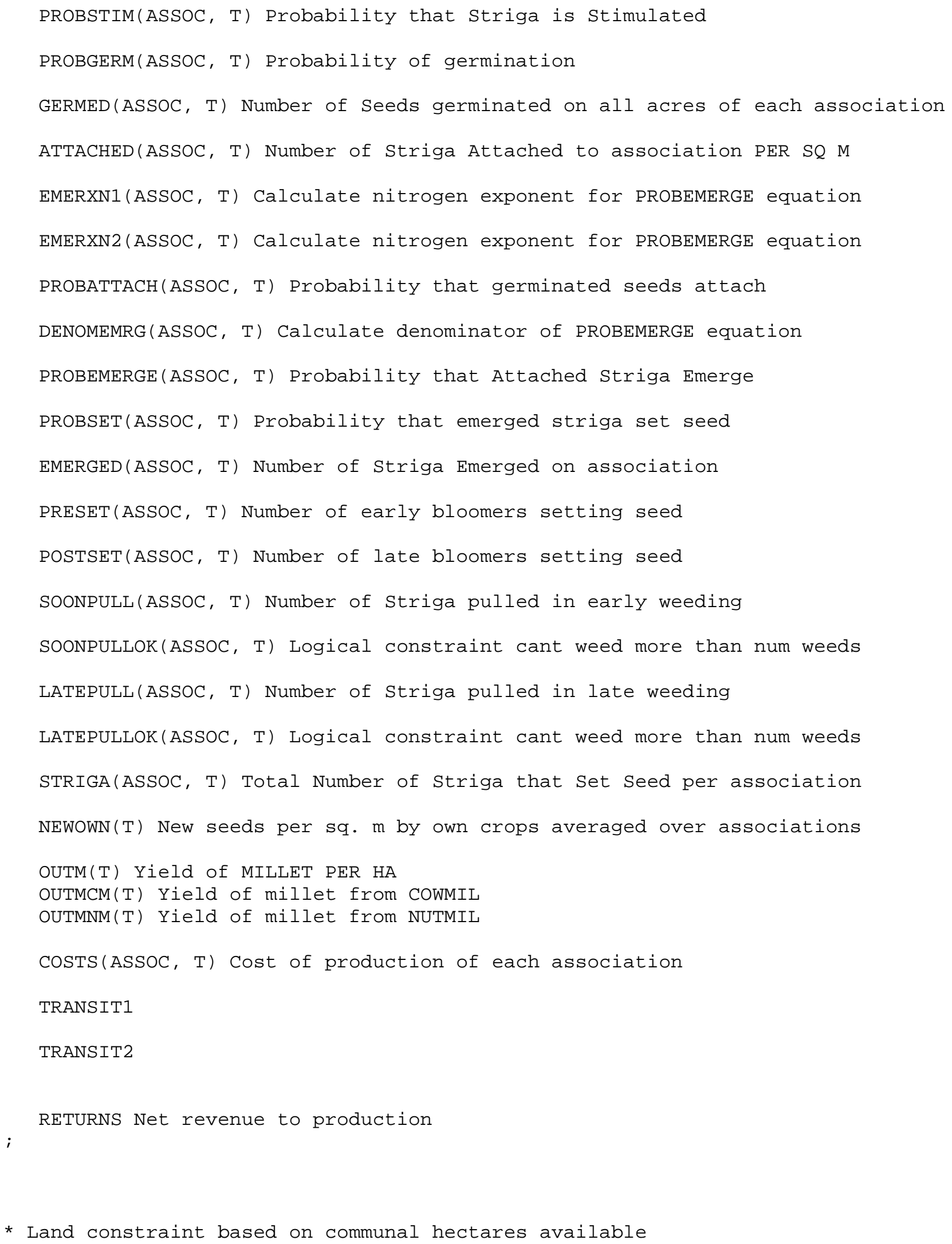




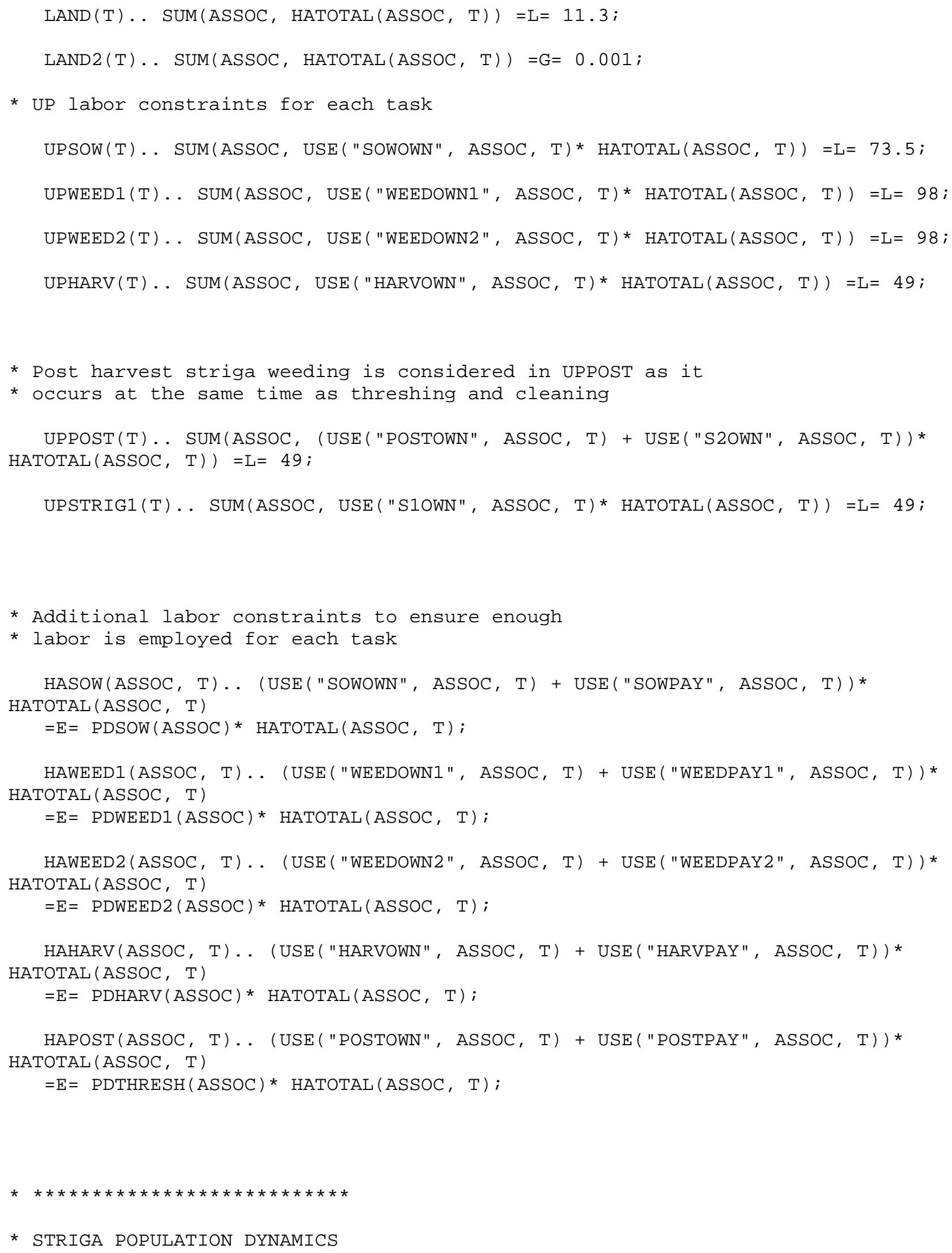




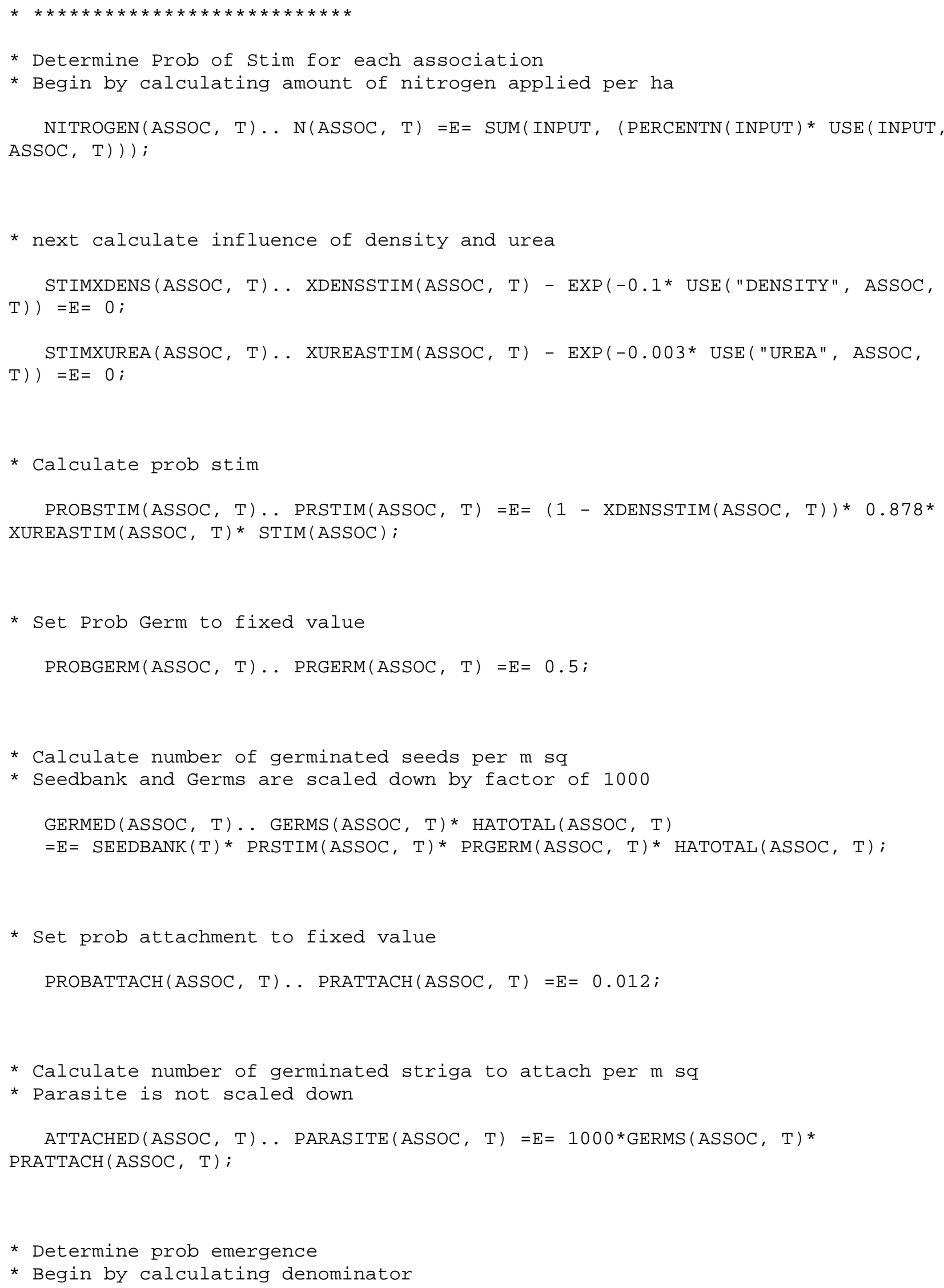


DENOMEMRG (ASSOC, T) . DENOM (ASSOC, T) * (50* USE ("DENSITY", ASSOC, T) + PARASITE (ASSOC, T)) $=\mathrm{E}=1$;

* next calculate influence of nitrogen

EMERXN1 (ASSOC, T) . XNEMER1 (ASSOC, T) $=\mathrm{E}=\operatorname{EXP}(0.07111$ * $\mathrm{N}(\mathrm{ASSOC}, \mathrm{T}))$;

EMERXN2 (ASSOC, T) . XNEMER2 (ASSOC, T) $=\mathrm{E}=\mathrm{EXP}(-0.00068 *(\mathrm{~N}(\mathrm{ASSOC}, \mathrm{T}) * \star 2))$;

* Combine to get prob emergence

PROBEMERGE (ASSOC, T) . PREMERGE (ASSOC, T) =E= 50* USE ("DENSITY", ASSOC, T) * DENOM (ASSOC, T) * XNEMER1 (ASSOC, T) * XNEMER2 (ASSOC, T) ;

* Calculate total number of emerged striga per m sq in each association

EMERGED (ASSOC, T) . SEEDLING (ASSOC, T) =E= PARASITE (ASSOC, T) * PREMERGE (ASSOC, T) ;

* Set prob set to fixed value

PROBSET (ASSOC, T) . PRSET (ASSOC, T) $=\mathrm{E}=0.34$;

* Determine number of early blooming striga to weed per $\mathrm{m}$ sq SOONPULL (ASSOC, T) . E EARLYPULL (ASSOC, T) =E=0.25* (USE ("S1OWN", ASSOC, T) + USE ("SIPAY", ASSOC, T)) * HATOTAL (ASSOC, T);

* Ensure do not weed more than have emerged SOONPULLOK (ASSOC, T) . SEEDLING (ASSOC, T) /2 - EARLYPULL (ASSOC, T) =G=0;

* Calculate number of early bloomers per m sq $\operatorname{PRESET}(\mathrm{ASSOC}, \mathrm{T}) \ldots \operatorname{ESETTER}(\mathrm{ASSOC}, \mathrm{T})=\mathrm{E}=(((\operatorname{SEEDLING}(\mathrm{ASSOC}, \mathrm{T})) / 2)-$ (EARLYPULL (ASSOC, T))) * PRSET (ASSOC, T) ;

* Do same for late bloomers as for early bloomers 
LATEPULL (ASSOC, T) .. LATEPULLED (ASSOC, T) =E=0.25* (USE ("S2OWN", ASSOC, T) + USE ("S2PAY", ASSOC, T)) * HATOTAL (ASSOC, T) ;

POSTSET (ASSOC, T) . L LSETTER (ASSOC, T) $=\mathrm{E}=((\operatorname{SEEDLING}(\mathrm{ASSOC}, \mathrm{T})) / 2-$

(LATEPULLED (ASSOC, T))) * PRSET (ASSOC, T) ;

LATEPULLOK (ASSOC, T) . SEEDLING (ASSOC, T) $/ 2-\operatorname{LATEPULLED}(\operatorname{ASSOC}, \mathrm{T})=\mathrm{G}=0$;

* Calculate number of striga to set seed per $m$ sq in each association STRIGA (ASSOC, T) . SEEDERS (ASSOC, T) $=\mathrm{E}=\operatorname{ESETTER}(\operatorname{ASSOC}, \mathrm{T})+\operatorname{LSETTER}(\operatorname{ASSOC}$, T) ;

* Calculate number of seeds per m sq produced across all associations NEWOWN $(\mathrm{T}) \ldots \operatorname{SEEDS}(\mathrm{T})=\mathrm{E}=11$ *SUM (ASSOC, SEEDERS (ASSOC, T) * HATOTAL (ASSOC, T)) / SUM (ASSOC, HATOTAL (ASSOC, T)) ;

* Determine number of new seeds per $\mathrm{m}$ sq introduced to

* communal fields at end of seasons t1 t2 and t3

* symmetric seed externality of $1 \%$ assumed

TRANSIT1.. SEEDBANK ("T2") $=\mathrm{E}=0.545 *(\operatorname{SEEDBANK}(" \mathrm{~T} 1 ")$

- SUM(ASSOC, GERMS (ASSOC, "T1") * HATOTAL (ASSOC, "T1")/11.3))

$+0.9 * \operatorname{SEEDS}(" \mathrm{~T} 1 ")$;

TRANSIT2 . SEEDBANK ("T3") $=\mathrm{E}=0.545 *(\operatorname{SEEDBANK}(" \mathrm{~T} 2 ")$

- SUM(ASSOC, GERMS (ASSOC, "T2") * HATOTAL (ASSOC, "T2")/11.3))

$+0.9 * \operatorname{SEEDS}(" \mathrm{~T} 2 ")$;

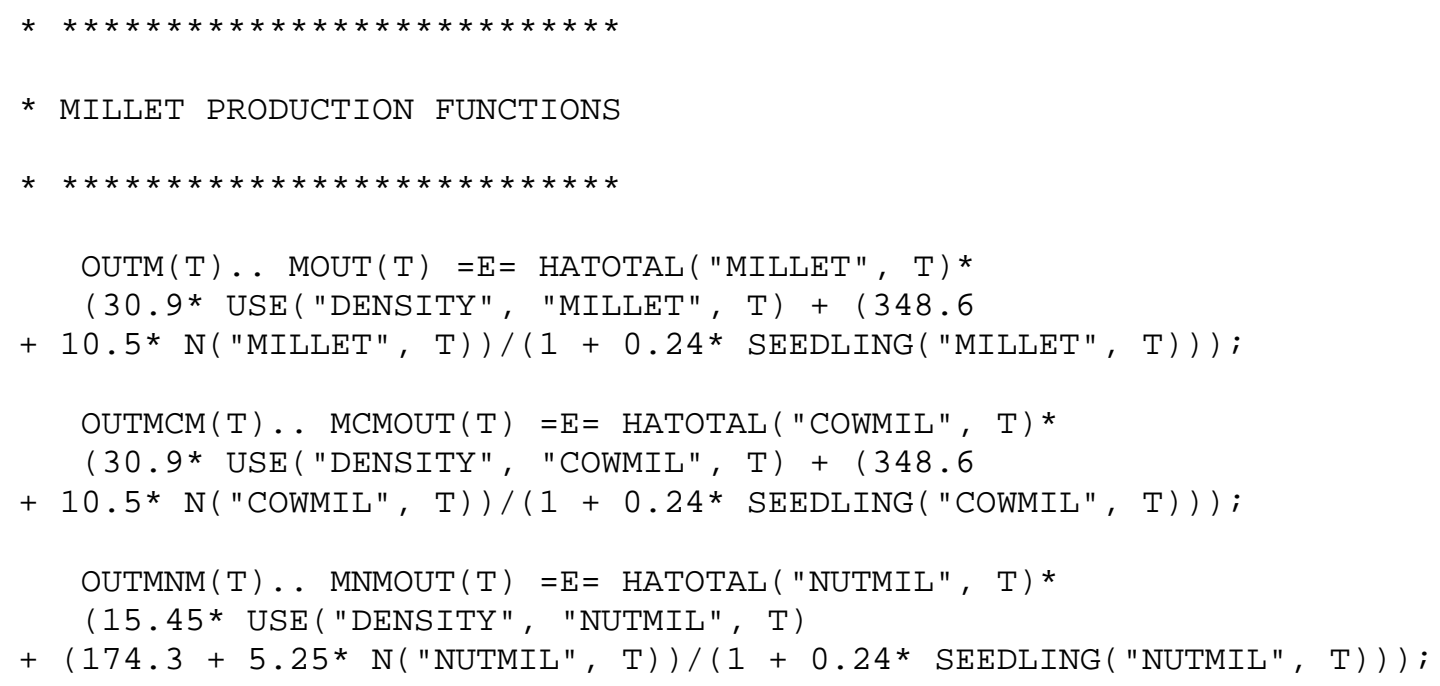




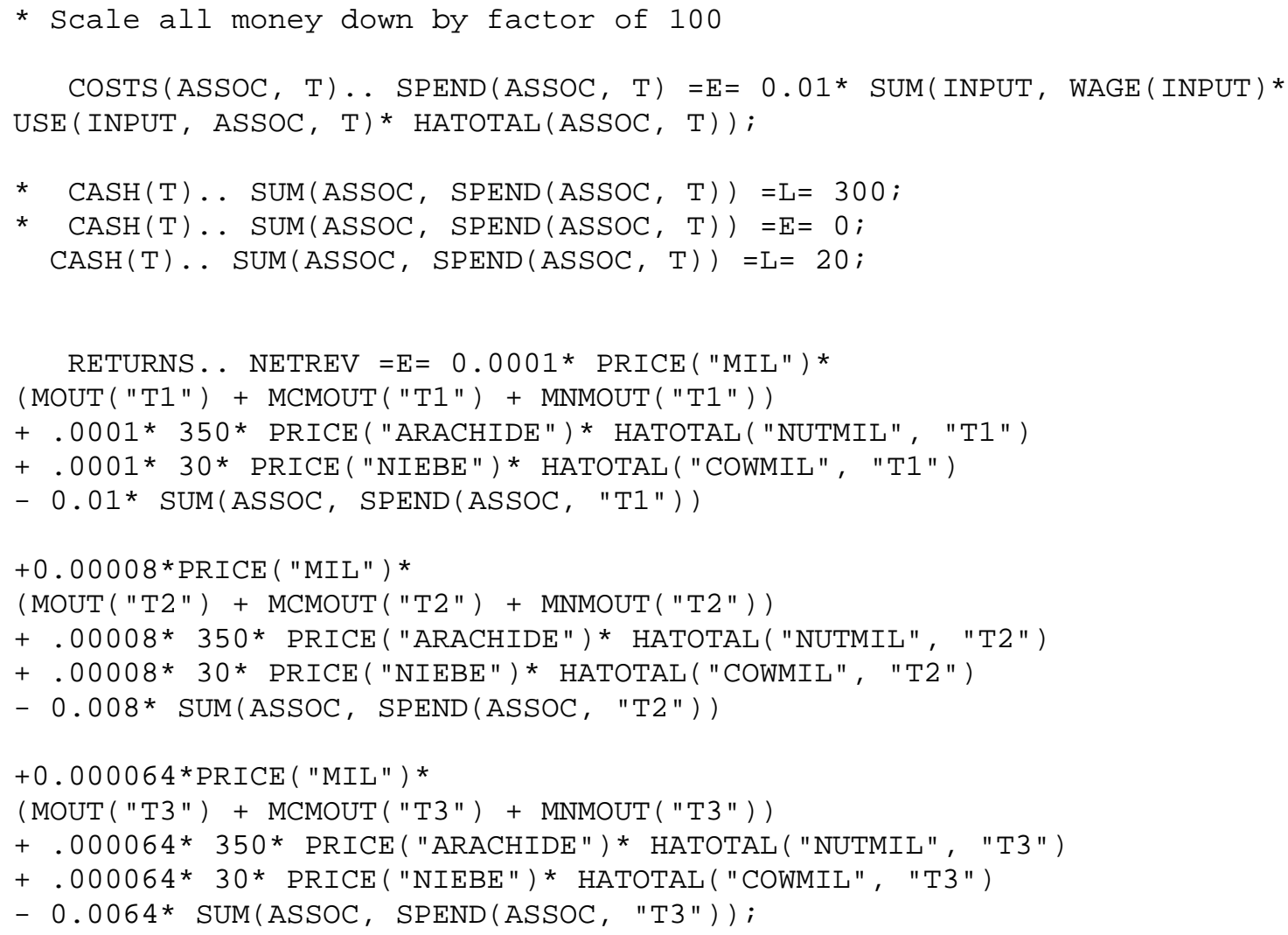

MODEL YEARS3 /ALL/;

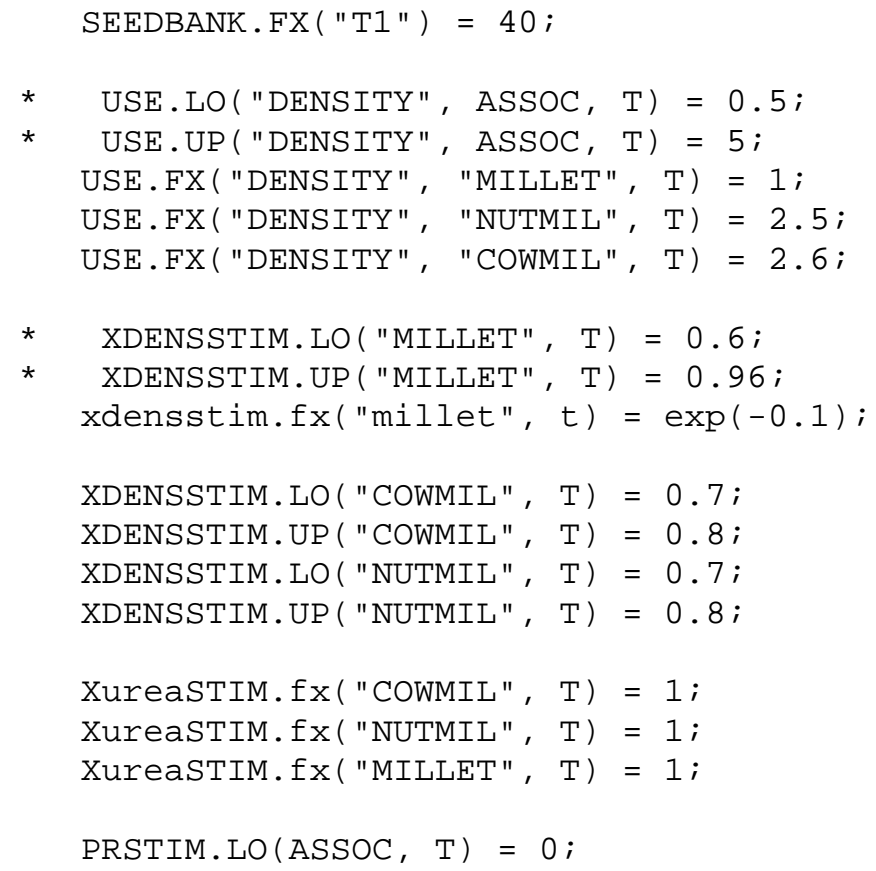




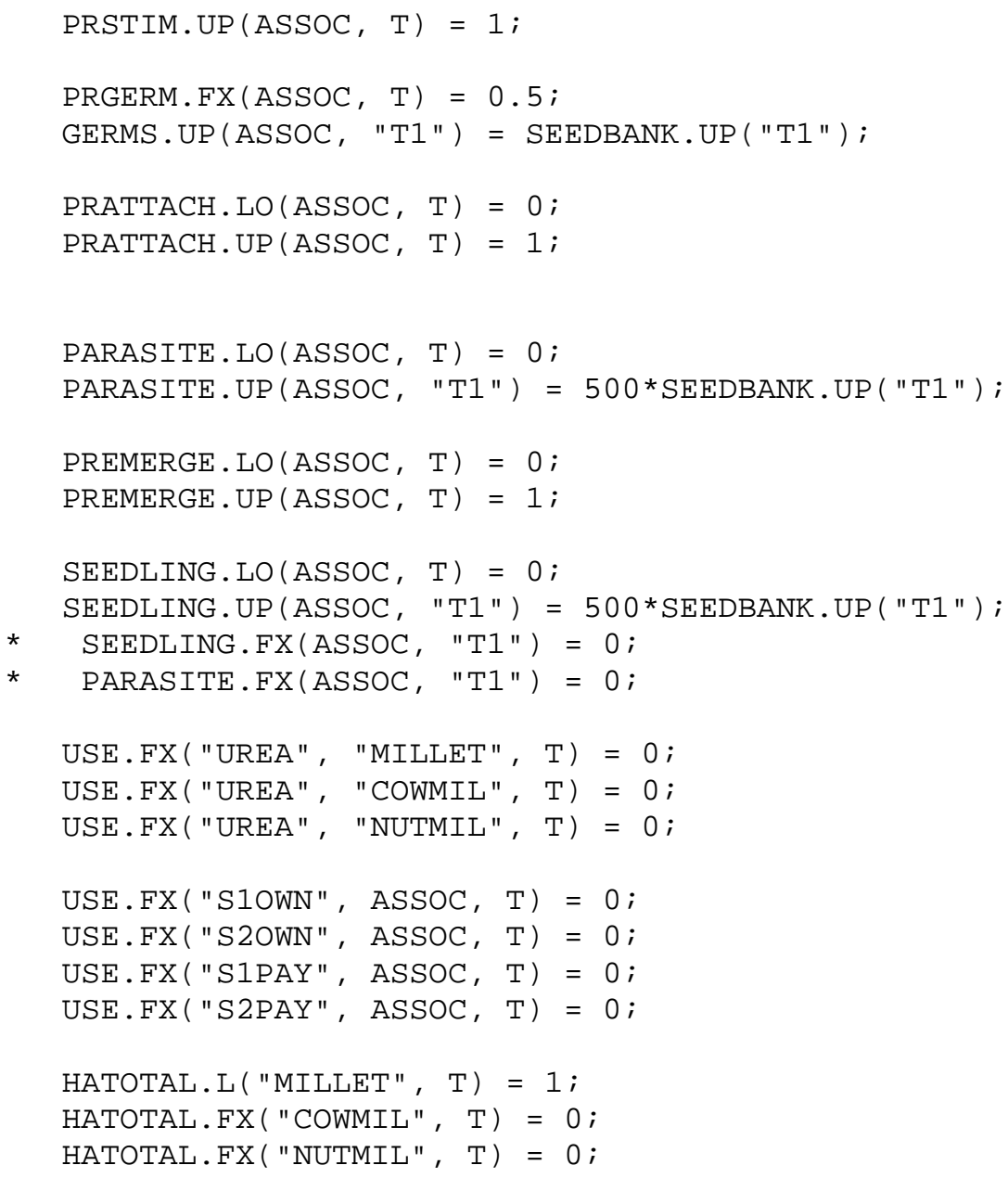

SOLVE YEARS3 MAXIMIZING NETREV USING NLP; 